1918

KI:TCRED

THE SKLI-I RF AN RURUS. 

Digitized by the Internet Archive in 2013 



\section{THE SKULL OF AMIURUS}

BY

JAMES ERNEST KINDRED

A. B. Tufts College, 1914

A. M. University of Illinois, 1915

THESIS

Submitted in Partial Fulfillment of the Requirements for the

Degree of

DOCTOR OF PHILOSOPHY

IN ZOOLOGY

IN

THE GRADUATE SCHOOL

OF THE

UNIVERSITY OF ILLINOIS

1918. 



\section{UNIVERSITY OF ILLINOIS}

\section{THE GRADUATE SCHOOL}

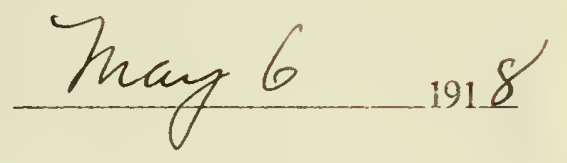

I HEREBY RECOMMEND 'THAT THE THESIS PREPARED UNDER MY SUPERVISION BY_James Frnest Iindred

ENTITLED The Skull of Amiurus

BE ACCEPTED AS FULFILLING THIS PART OF THE REQUIREMENTS FOR THE DEGREE OF Doctor of Thilosophy in Zoology

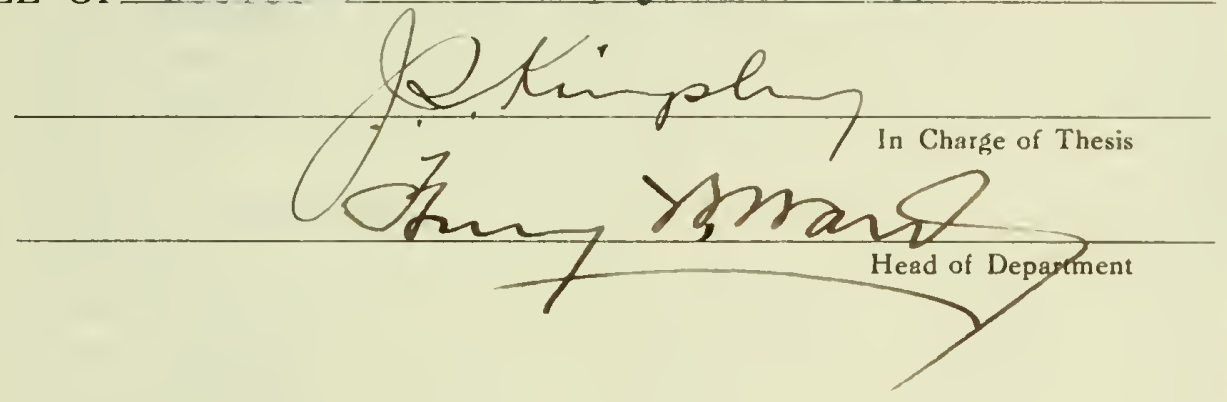

Recommendation concurred in*

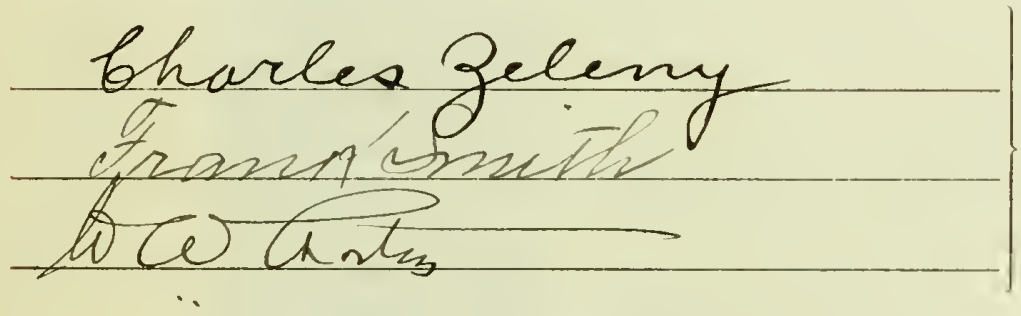

Committee

on

Final Examination* 



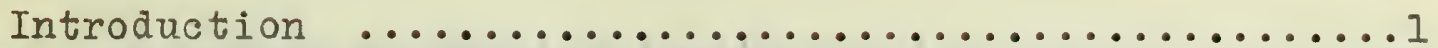

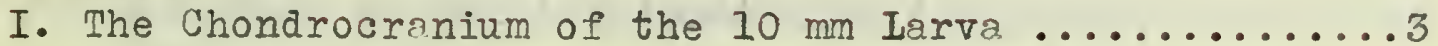

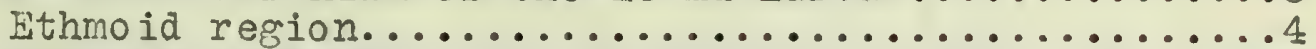

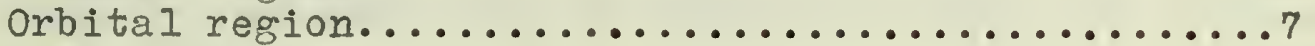

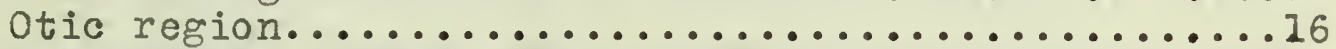

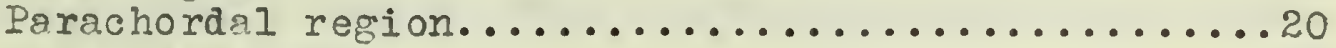

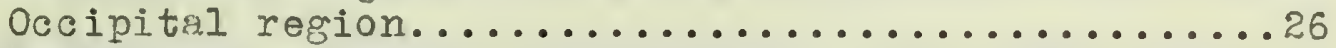

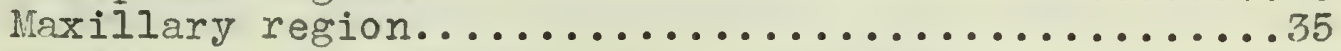

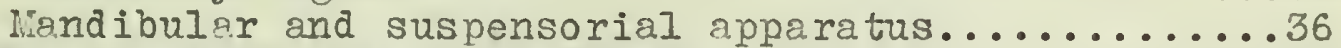

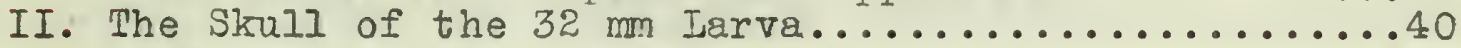

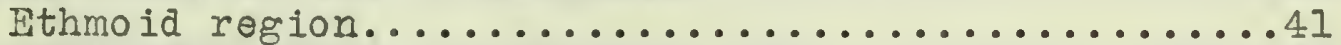

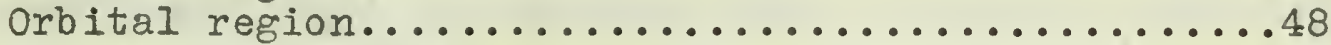

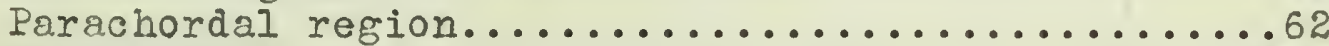

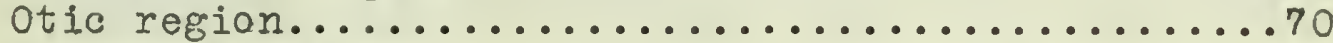

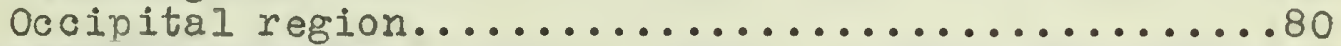

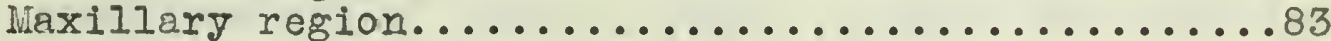

Mandibular and suspensorial apparatus...........83

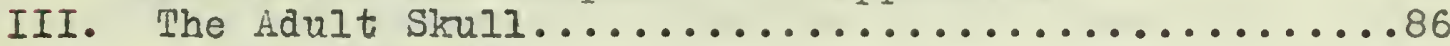

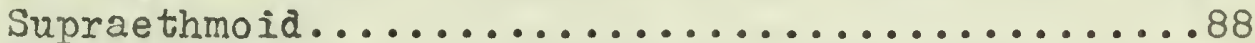

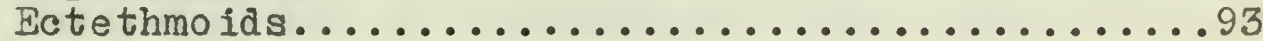

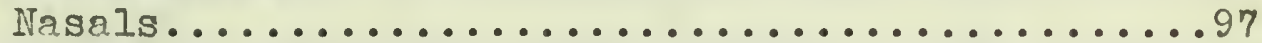

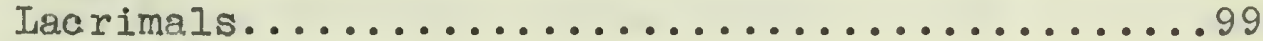

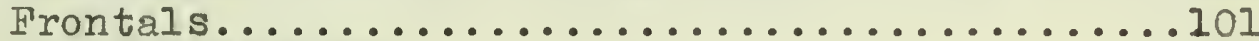

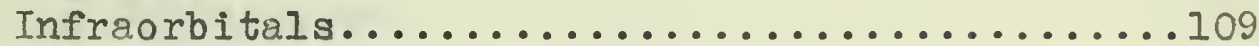

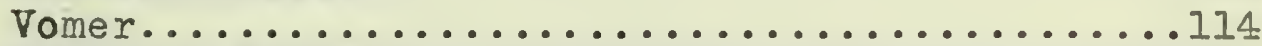

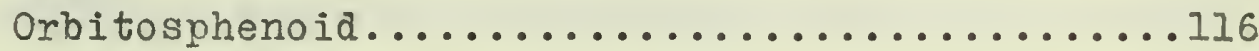

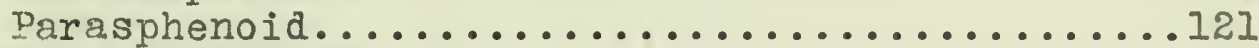

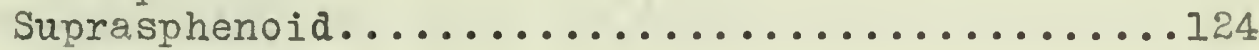

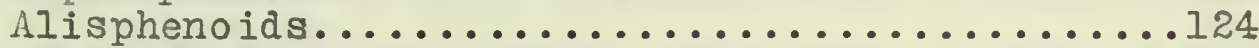

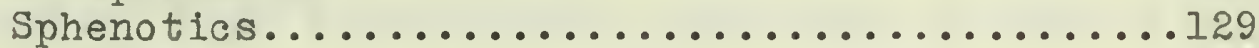

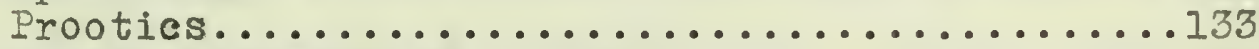

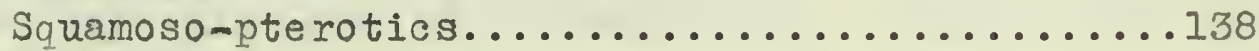

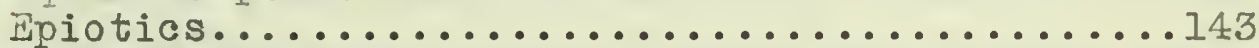

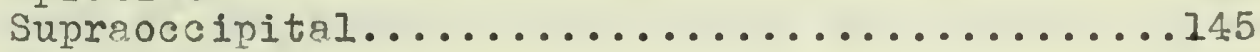

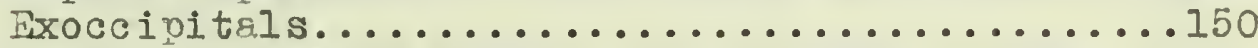

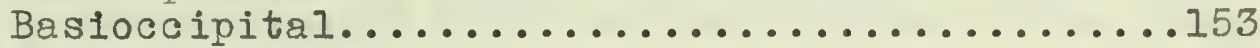

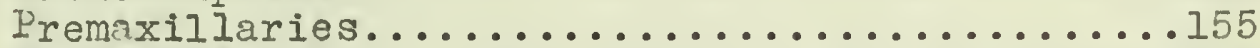

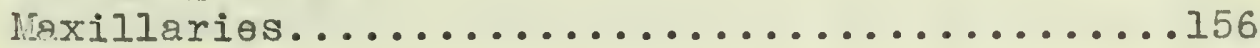

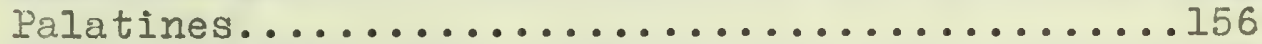

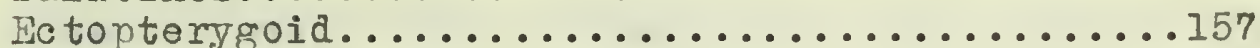

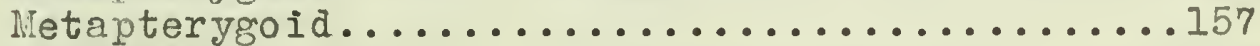

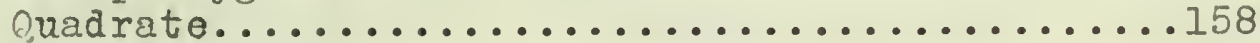

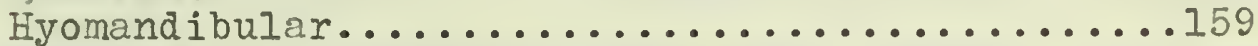

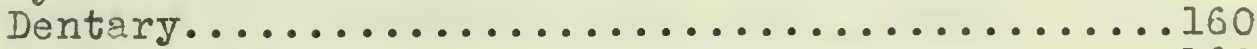

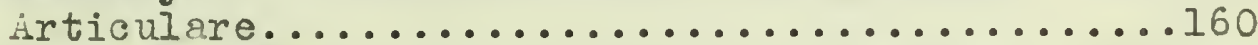

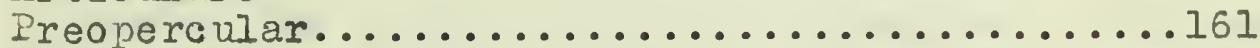

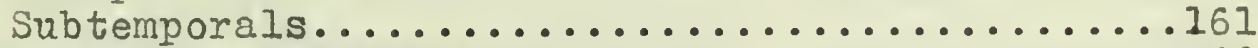

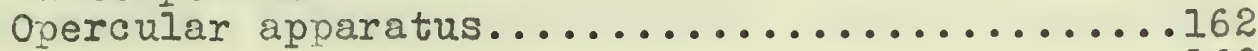

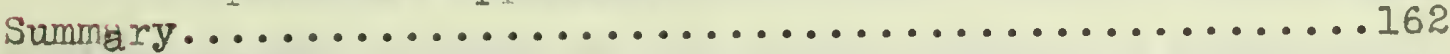

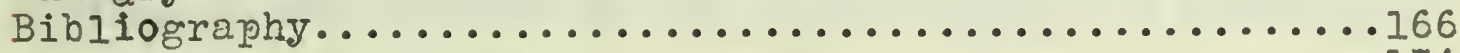

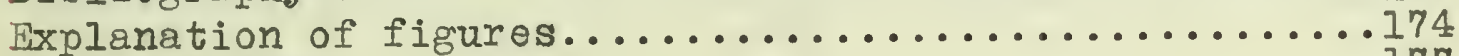

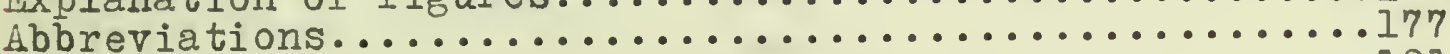

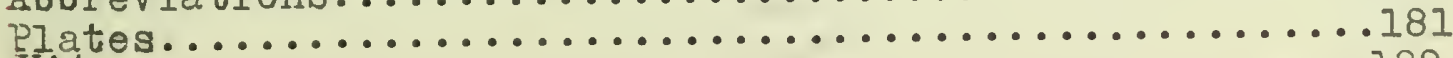

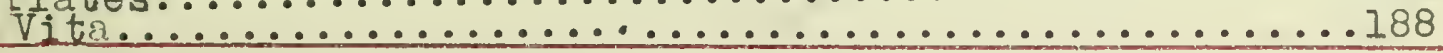



Introduction.

The study of the development of the teleost. skull has been confined for the most part to isolated stages and there have been very few papers dealing with the changes which trke place in any one species. Parker's (172) work on the development of the cranium of Salmo has remained the standard and has been supplemented by Gaupp ('02) and Schleip ('03). Winslow ('97) describes the chondrocranium of the trout, Ryder (186) and PolIard ('95) the chondrocranie of some of the Siluroids, but none of these attempted to trace the formation of the bones and their relation to the cartilage, in the same way that Parker did.

Swinnerton (102) has described several stages in the development of the skull of Gasterosteus.

The skull of the adult teleost has been widely studied in a topographical way, but very few authors have analyzed the bones in terms of their developmental relations, so that a wide field is open for this line of investigation. Gouan (1770) gives a simple account of the bones of the cranium and naively states that although there are many bones in the cranium of the young f1sh, these fuse into severgl large bones in the adult, as in man. liang of the nomes in use in the terminology of the present time have come directly from Cuvier, but others have been introduced into the litersture principally by Owen ('48), Huxley ('64), and Parker (172). Lixcept for a few scattered references to the crania of Silurus glanis, claris, Auchensspis, and the incomolete description of the cranium of the adult smiurus by ifliurrich ('84) 

the skull of the Siluroids has been neglected.

This study of Amiurus has been undertaken becruse of the low organization of the Siluroids and the primitive relation of certain parts of the skull. Wany points of relationship with the ganoids have been found and a sounder basis for grouping the Siluroids with the Charecinidae and the Cyprinidee, has been developed. Very early stages of the skull were not procurable, so that the following account is based upon the $8,10,20,32$, and $60 \mathrm{~mm}$ stages, though earlier stages than the earliest of these may be described in a later paper. liost of the material was obtained from Wisconsin, though the $32 \mathrm{~mm}$ stage was surplied by Professor J.S.Kingsley under whose direction the work was completed, and whom I take this opportunity to thank for the many helpful suggestions and facilities placed at my disposal. The adult specimens were obtained through the generosity of the Illinois Natural History Survey, and originally came from the Illinois River. 

I. The Chondrocranium of the $10 \mathrm{~mm}$ Larva

The description of the early chondrocranium of Amiurus is based upon the study of a group of specimens from 8 to $10 \mathrm{~mm}$ in length. Earlier stages than the $8 \mathrm{~mm}$ larva vere not procurable. From one series of transverse sections of a $10 \mathrm{~mm}$. larva of $\mathrm{A}$. nebulosus (catus), a wax model of the entire cranium and the visceral arches was made by Born's method of reconstruction. The description of this is supplemented by a careful microscopical examination of several other specimens.

The cranium is elongate and not as depressed as it is in the adult animal. There is no roof of cartilage or of bone above the brain at this stage, although a transverse bar between the alisphenold cartilages of the two sides divides the large space into an anterior and a posterior fontanelle (fig. 2). The anterlor of these is the smaller and is limited to the region above the forebrain and the olfactory region. The posterior fontanelle is very large and extends posteriorly between the dorsal margins of the otic capsules, its posterior margin is formed by the occipital arch.

The floor of the cranium is fenestrated by the large oval fenestra hypophyseos (f.h.), which extends from the anterior end of the parachordal plate $(p c h)$ to the posterior end of the ethmoid plate (eth), the trabeculae cranii (tr) forming its lateral margins. The parachordal plate is solid posteriorly and is grooved for the reception of the sacculi of the inner ears. On either side and above the parachordal plate the otic capsules are situated and the only foramina in the wall of the cranium in this region are those for the passage to the exterior 

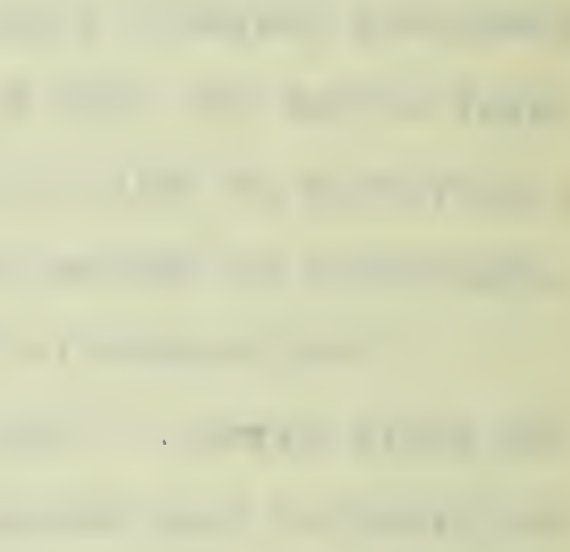

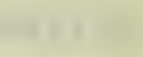

\section{.}
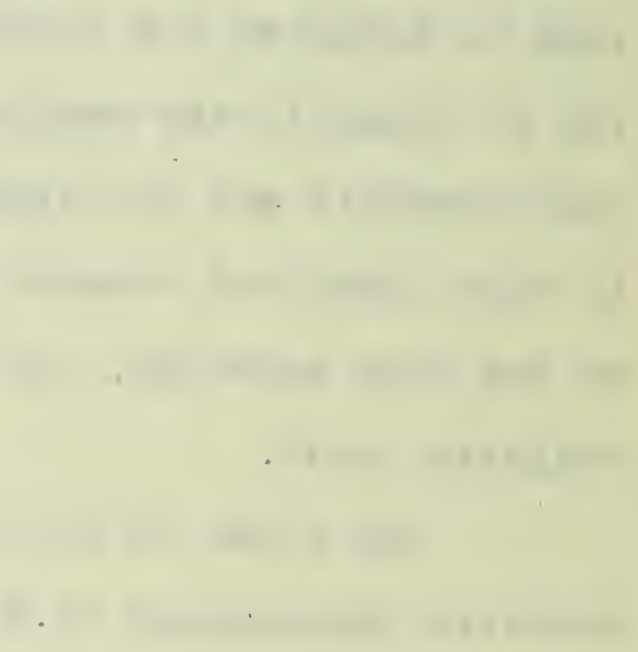

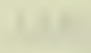


of the glossopharyngeal (fig.l, $I X)$ and vagus nerves $(X)$, nothing comparable to the posterior basicranial fenestra and the basicapsular fenestrae of Salmo (Parker, '72;Gaupp,'06) being observed. The cavum of the labyrinth opens widely into the cavum cranil. The alisphenoid cartilage, extending dorsally and anteriorly from the anterior end of the otic capsule, forms the dorsal margin of a large foramen in the cranial wall, through which the optic,oculomotor,abducens, trigeminal and facialis nerves issue (figs. 1,2). The nerres penetrate the connective tissue membrane which extends across the fenestra from the alisphenoid cartilage to the trabecula cranii (fig. 14). The detailed descriptions of the various regions of the cranium and the comparisons with the chondrocranial parts of other forms follows below.

The ethmoid region. At the $10 \mathrm{~mm}$ stage in the development of the ethmoid region, the dorsal surface of the cartilage forms a trough, the sides of which are formed by dorsal projections near the lateral edges of the plate: the floor is formed by the ethmoid plate itself (fig. 2). The olfactory lobes lie in this trough and are roofed by membrane which extends between the two lateral projections and is attached dorsally to the epidermis. The olfactory foramen, which is very large at this stage, occupies the anterior half of the lateral wall of this region and the olffactory lobe protrudes through this foramen (fig. I). A short olfactory tract extends from the lateral part of the lobe to the olfactory bulbus which lies just lateral to it. The ethmoid plate extends laterally beyond these walls (fig. 30 ) and forms the floor, called by Gaupp ('06) the solum nasi in Salmo, of the nasal fossa of each side (fig. 2). The anterior end of the 
plate projects as two massive cartilapinous processes, the ethmoid cornue (fig. 2). Just behind these a transverse ridge in the middle of the plate forms the anterior end of the carum cranii and marks the anterior extent of the olfactory lobes. The ventral surface of the ethmoid plate is slightly concave (fig. 30). At the posterior end of the ethmoid region, the anterior ends of the fused trabeculae and alisphenoid cartilages fuse with the side walls and floor of the trough and the floor forms the anterior margin of the fenestra hypophyseos (fig. 2). Each lateral wall of the ethmoid region is produced laterally into an ectethmoid process: which projects abruptly from the external face of the cranial wall and the ventral face of which forms the articular surface for the palatine cartilage (fig. 1). The anterior face of the process is concave near its ventral margin: the ophthalmic superficialis ramus of the trigeminus passes obliquely through the dorsal margin. The posterior face of the process is fused medially to the anterior dorsal margin of the alisphenoid cartilage. The ventral part of this fused region is separated from the trabecula by a small foramen, behind the ectethmoid process the orbital foramen (fig. 1 ). This foramen is the posterior limit of the ethmoid region or wall. As jet there is no internasal septum between the olfactory lobes of the two sides. The oblique eye muscles have no relation to the ventral surface of the ethmoid plate as thay have in Salmo (gaupo '06), but are attached to the ventral margin of the orbital foramen posterior to the ectethmoid process.

Sagemehl ('85) discussed the morphology and development of the olfactory region in the different families of teleosts. He recognized three different degrees of relationship between the 


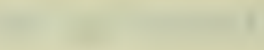

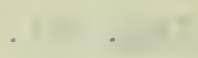

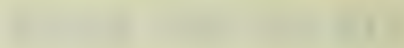
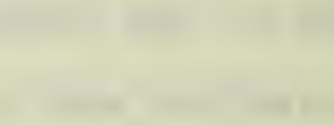

\section{$\left(\frac{10}{2}\right.$}

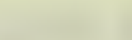

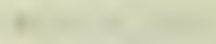

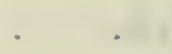

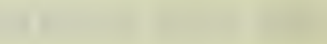
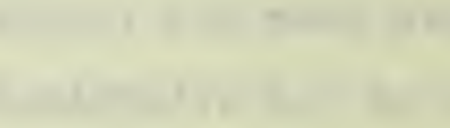

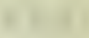

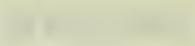


olfactory organ, the bulbus olfactorius, and the brain. In the first and most primitive relation which he described as the cyclostome type, the bulbus lies between the brain and the organ within the cavum cranil, closely fused to each. With subsequent development a long tractus olfactorius is spun out between them, and the bulbus remains applied to the olfactory organ. He called this the Selachian type, as it is most common in this group. It is also found in the Cyprinoids, Siluroids, Mormyrids, and Gadids among the teleosts. In these families the tractus always lies within a canal directly continuous with the carum cranii.

In the other teleosts families, as represented by Salmo. a membranous interorbital septum is developed between the orbits, on the dorsal surface of the trabecula communis. This septum, by growth backward and dorsally. limits the anterior extent of the cavum cranii. The bulbus olfactorius, which in the larva of one of these forms, has the primitive cyclostome relation, is carried posteriorly by the interorbital septum, so that it becomes enclosed within the cavum cranii. The bulbus retains its connexion with the olfactory organ by a long slender olfactory nerve which passes unenclosed across the orbit between the anterior end of the cavum wall and the ectethmoid process. Sagemehl recognizes this condition as the teleosts type of olfactory development. It is also interesting to note that in the Characinidae (Sagemehl, '85). Citharinus is very close to the selachian type and lacrodon has the teleostean relation of parts. Other members of this family present greater or lesser degrees of relationship to the two types. The olfactory region at this stage of development in Amiurus, according to this view has just reached the cyclostome stage. 

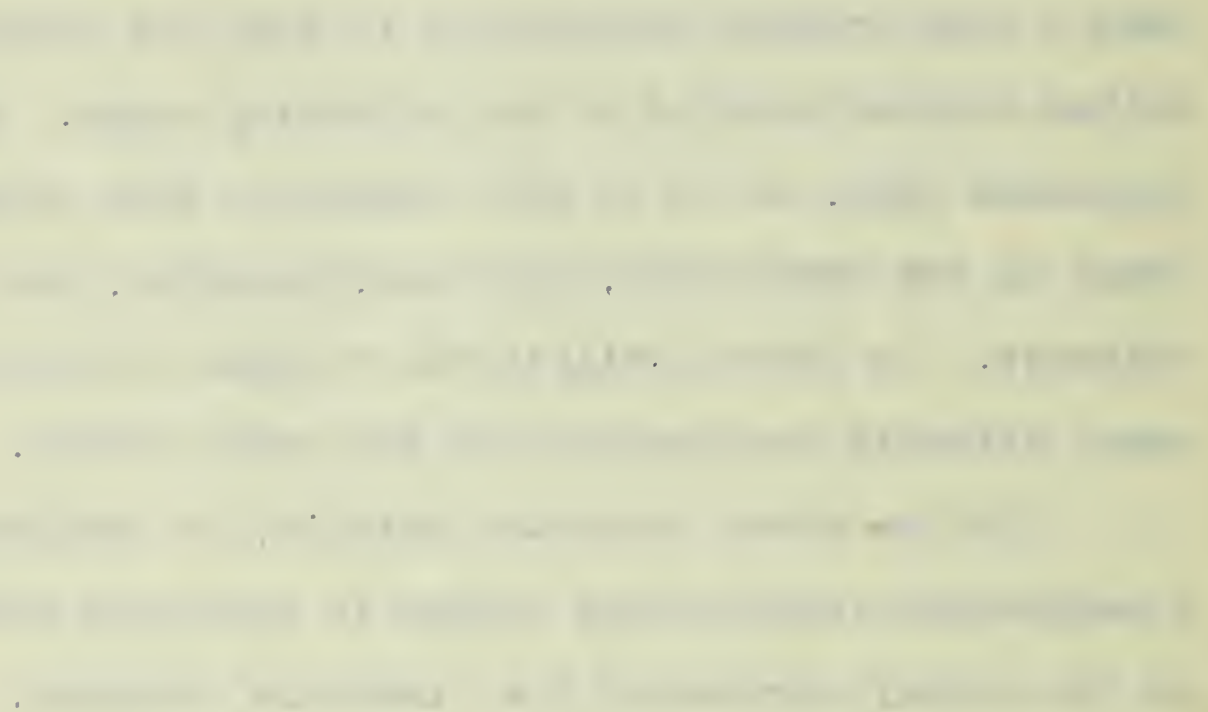

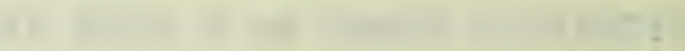
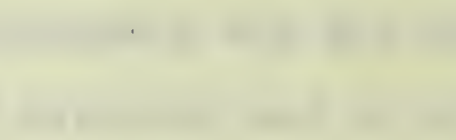
The orbital region. Each lateral wall in the orbital region of the $10 \mathrm{~mm}$ Amiurus is formed by a ventral trabecular and a dorsal alisphenoid cartilage, between which, the optic, oculomotf or, most of the trigeminal, the abducens and the facialis nerves pass outward (figs. 1,2). In front of the opticus these two cartilages meet and form a solid wall for a short distance, its continuity being broken by the orbital foramen, dorsal to which, the alisphenoid is fused to the posterior face of the ectethmoid process. Posteriorly the alisphenoid cartilage is fused to the anterior face of the otic capsule. A connective tissue membranous wall connects the ventral margin of the alisphenoid cartilage with that of the trabecula and it is through this membrane that the above mentioned nerres pass ( 1 ig. 30 ).

The ramus oticus of the facialis nerve passes ventro-dorsally through the alisphenoid cartilage, just anterior to its union with the otic capsule. At about the midale of the cartilage are two small foramina, the more ventral for the ramus ophthalmicus superficialis of the trigeminus and the more dorsal for the ophthalmicus superficialis of the facialis (figs. 1,2). After its exit from the cranium and its passage through the orbit, the ophthalmic branch of the trigeminus passes through the orbitonasal foramen of the ectethmoid process, mentioned above, while the ophthalmic branch of the facialis passes around the lateral margin of the process.

A cartilage bar, the epiphysial bar, described by Sagemehl in the adult Characinidae and Cyprinidae, and by Pollard ('95) in the Siluridae, extends across the dorsal surface of the forebrain just posterior to the ectethmoid 

processes and is fused at each end to the anterior dorsal ends of the alisphenold cartilages. There is no other trace of a cranial roof in this region at this atage.

The alisphenoid cartilage was described by sewertzoff ('97) In the larval Acanthias as a large cartilage lying lateral to the fore- and mid-brains and connected secondarily with the anterior paracordalia. Later it fuses behimd with the anterior margin of the otic capsule and below with the posterior end of the trabecula cranil enclosing the optic, oculomotor, trigeminus anf facialis nerves. It grows anteriorly to the ectethmold process, and independent cartilage and fuses with 1t. Dorso-medianly 1 t grows toward the middle line and unites with its fellow of the opposite side to form the solid cranial roof. Except for it ventro-posterior relations the alisphenoid of Acanthias can be compared to that of Amiarus. In both, these cartilages form the anterior and dorsal margins of the foramina for the nerves, mentioned above, and extend across the dorsal part of the orbit. There is no cartilaginoas roof in the chondrocranium of Amiurus with the exception of the epiphysial bar, which may be a remnant of such a condition. The notch at the anterior margin of the optic fenestra of Acanthias is auggestive of the orbital foramen of Amiurus.

Parker ('82) recognized three cartilaginous parts in the lateral wall of the orbital region of the chondrocranium of Acipenser ruthenus. A posterior allsphenoidal part, lateral to the paracordal plate; and anterior orbitospbanoldal part; and a dorsal supraorbital part, which fuses with its fellow of the opposite side to form the cranial roof. The orbitosphenoidal 

the Teleosts in Gasterosteous (Swinnerton, '02), the Characinidae (Sagemehl, '85), the Cyprnidae (Sagemehl, '91) and other sluridae (Pollard,95), is the striking feature of a comparison between these two forms, as Polypterus is specialized in so many other features, that it differs from ven the majority of the Ganoids and has been mentioned as representing the ancestral stage of the Stegocephali.

In Gymnarchus niloticus (Assheton;00) the early chondrocranium of which has been very briefly degcribed from Budgett's collections and notes, there is a long slit-like foramen in the wall of the orbit just anterior to the otic capsule and a smaller anterior foramen separated from this for the passage of the opticus. There is also a transverse bar similar to the epiphysial bar of Amiurus and Polypterus, connected however with the anterior etbmoidal roof by a medien longitudinal bar of cartilage, which divides the anterior fontanelle into tro parts. this may be the representative of a group in which the reduction from the solid cartilaginous roof of the lower ganolds is taking place, a continuation of which would produces the condition found in Polypterus and Amiurus.

In salmo salar (Parker '73; Gaupp 196) a cartilaginous bar extends on each side of the cranium above the orbit, from the anterior end of the otic capsule to the posterior margin of the tegmen cranil, which extends bck as far as the middle of the orbit. Posterforly, between this bar and the otic capsule, the branches of the facialis and the jugular vein pass through separate foramina in the cartilage. The bar itself, called by Gaupp the taenia marginalis extends anteriorly above the trigem- 

part is pierced by the optic nerve and the alisphenoidal part by the trigeminus and the facialis. This more like the adult Acanthlas cranium than it is like the cranium of the developing Amiurus. In the chondrocranium of Lepidosteous osseous (Parker,'8z), the allsphenold cartilage curves anteriorly above the nerves, from the anterior edge of the otic capsules. It is a thin flat bar and forms the lateral margin of the almost circular fontanelle in the cranial roof. Ventro-anteriorly it unites with the anterfor end of the trabecula at the anterior end of the orbit, as in Amiurus. Medially and anteriorly it fuses with its fellow, above the fore-brain forming a solid cartilaginous tegmen cranil, the remnant of which as above, may be represented by the epiphysial bar of Amiurus.

Concerning this region in Polypterus chondrocranium, Budgett (100) says:

"The lateral walls of the cranium extend forward from the auditory region on either side of the alisphenold region as continuous vertical plates of cartilage, somewhat dumb-belled shaped in section and perforated by foramina for the III,V, and VII nerves in the thinner middle portion. In the sphenethmold region there is a large lateral fontanelle closed only by membrane through which passes the optic nerve, while above and below this membranous portion there pass the thickened upper and lower cartilaginous borders of the cranial wall, connecting on either side the ethmold region with the posterior region of the cranium."

Dorsally the alisphenold cartilages of the two sides in Polypterus, are connected with each other by a transverse cartilagnous bridge, which is placed further back in the roof than the eplphysial bar in the cranium of Amiurus. The general relations of the alisphenoid cartilage to the crandil nerves in this region are much the same as in the devloping Acanthias, and are closer to that condition than to the condition found in the chondrocranIum of Amiurus. The epiphysial bar, which is found again among 
inus and does not enclose any of its branches. Here, as in Amiurus, the large fenestra left in the wall between this cartilage and the trabeculae cranil is closed by membrane, through which the nerves issuing from the cranium pass. In Amiurus as we have seen, both the fifth and seventh nerves issue through this membrane and with them the external carotid. In salmo, as in Acanthias these two nerves are separated from each other by a bar of cartilage, thus showing a nearer degree of relationship selachian than to the siluroid condition. The closer resemblance of Salmo to Acanthias is again evidenced by the presence of a well-developed tegmen cranil, not found in Amiurus.

In Ceratodus and the Urodeles, the alisphenoid cartilage is fused ventrally wihh the trabecula during the first stages of development and later unites with the ethmold and otic regions. As in the Ganoids and Teleosts, its anterior end and the trabecula anclose the optic nerve. Since the posterior ends of these cartilages enclose the trigeminus and the facialis, there is no question as to their homology with the alisphenoid and trabecular cartilages of these groups. Gaupp ('06) calls the former, the crista trabeculae, thus adding to the confusion of names.

This same author claims that the cartilaginous bar, following the sewertzoff, called the allsphenoid cartilage is not homologous with the alisphenold cartilage of the Mammalia and therefore cannot be named such. He says that the ala temporalis in the mammalian cranium is a new formation homologous with the process basipterygoideus of the Lacertalian cranium, which arises from the procartilage cells around the anterior end of the palatopterygoid cartilage. 


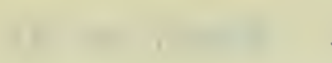

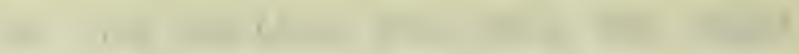
t (5)

(1)

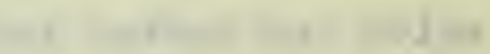
4.

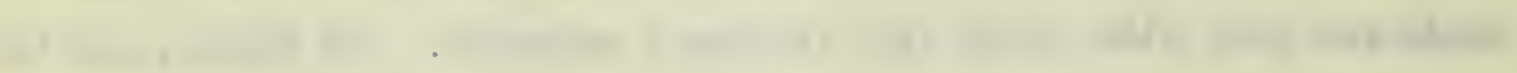
(1)

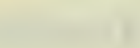
. 10

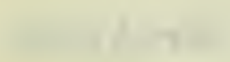

$1+1+1+1+10$

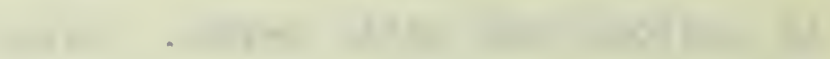

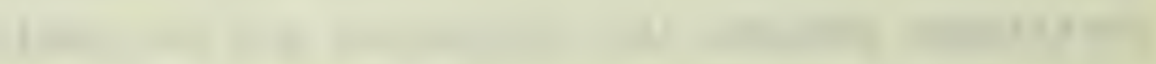

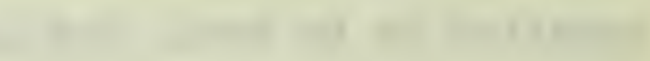

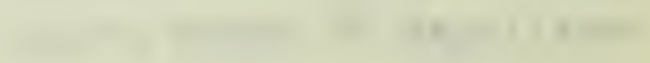
i i

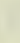


On comparison with the alisphenoid of mammals this homolo. gy falls to the ground if the relations of nerve and cartilage are used as the criteria for homologies of the chondrocranial parts. Throughout all of the lower Gnathostome groups the posterlor end of this cartilage is connected with the development of the foramina for the passage of the branches of the trigeminus, but when such a cartilage appears in the mammals, the above associations are discounted and the cartilage is compared to an outside formation. In denying the homology, Gaupp takes this question into cpnsideration, but maintains that the nerve relation are secondary and that nerves go through the ala temporalis because it replaces the original wall of this region. Assuming this to be the case, he states that anybody who relles upon the passage of nerves for their criterla of homology of cartilaginous parts is sure to err. ('J2) It is a settled fact however that nerves are constant throughout the vertebrate series and that they precede the cartilage in both. ontogeny and phylogeny. Therefore, any homology which is made with these as a basis is sure to have a landmark which varies less than the parts of any other organis system, such as the blood vessels or muscles.

The trabeculae cranil are flat and acute on both inner and outer edges, becoming narrower anteriorly before uniting with the alisphenoid cartilages. Their posterior ends are fused with the anterior paracordalia and with them form the lateral margins of the fenestra hypophyseos and the fenestra basicranil anterior (18 fig.2.14). The anterior ends are fused to each other median to their union with the alisphenoid cartilages and form the posterior margin of the ethmold plate which has been discussed. 


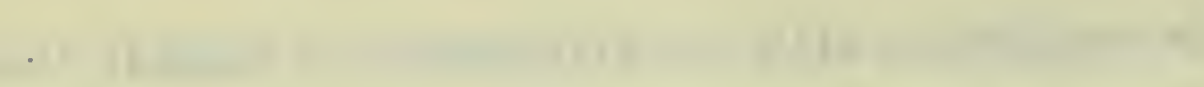

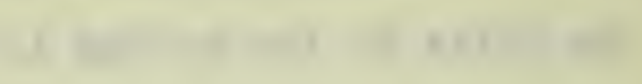

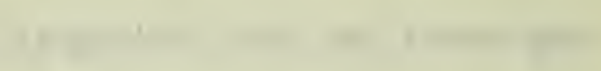

$-\frac{1}{2} \cdot$

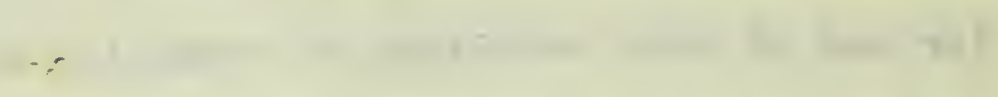

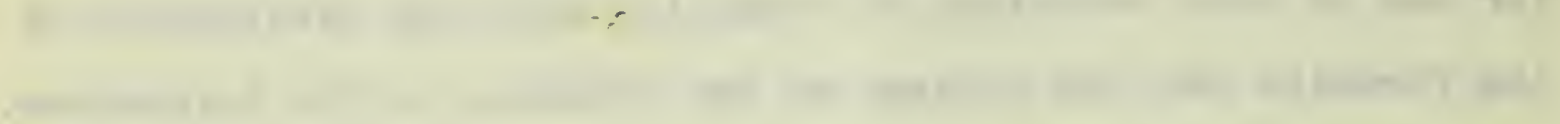

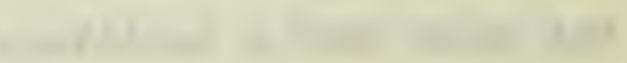

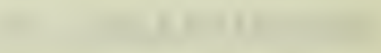

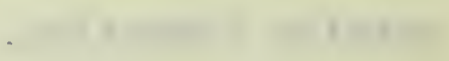

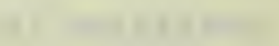
is ans

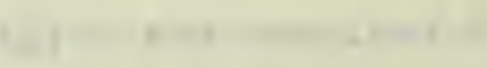

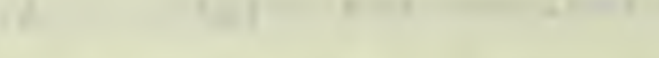

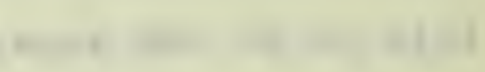

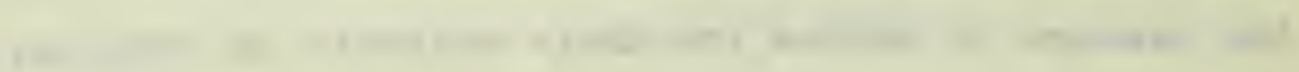

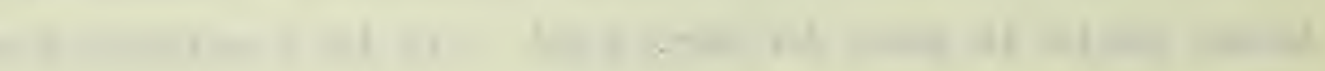

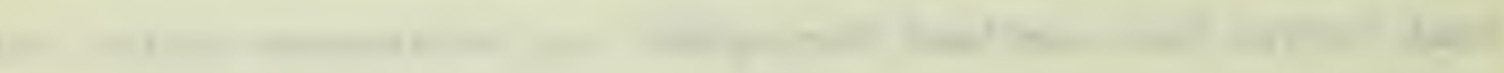

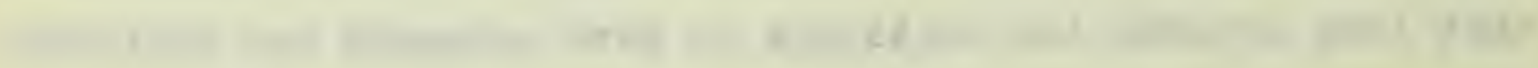
that

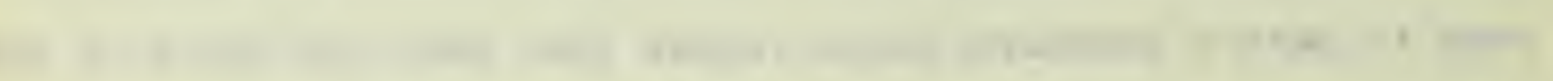

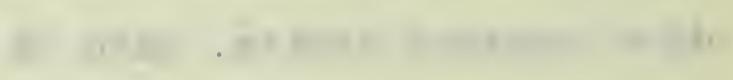

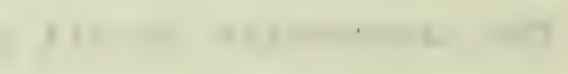

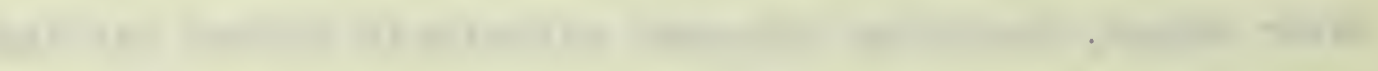

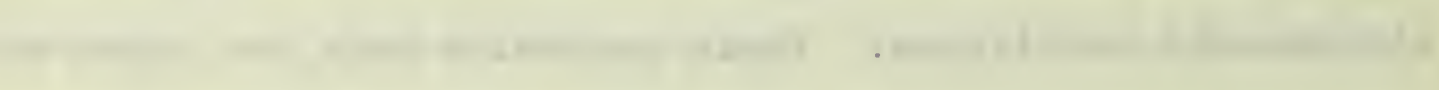

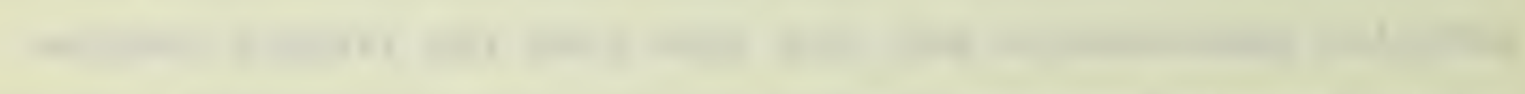

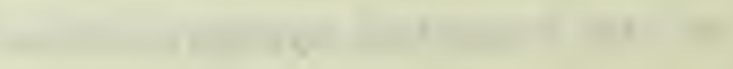
1

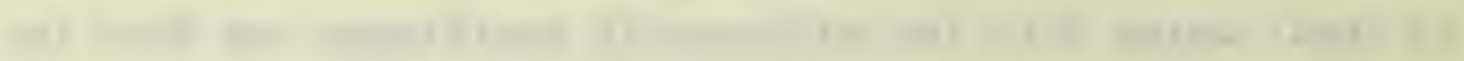


There is no trabecula communis such as occurs in salmo, the cranium being distincily platybasic. An internal carotid artery approaches the trabecula of its side ventrally, and enters the cranial cavity through the inner edge in about the middle region of the orbit (fig. 2 ), and proceeds'anteriorly in the membranous wall of the orbit. Each artery sends a branch along the dorsal surface of the optic nerve and then unites lateral to the cerebral hemispheres with an internal branch from the external carotid.

The rectus eye muscles and a ligament to the pterygoid cartilage are attached to the lateral surface of each trabecula in the posterior part of the orbit. There is no trace of a myodome in this or the later stages. The oblique eye muscles are inserted on the trabecula below the orbital foramen.

The fenestra hypophyseos and the fenestra basicranil anterior are closed by a sheet of fibrous connective tissue which stretches between the trabeculae (fig. If) and extends anteriorly below the ethmoid plate and posteriorly below the paracordal plate. It is not intimately connected with the cartilage of any of these parts.

In a $19 \mathrm{~mm}$ larva of Amia, the rectus eye muscles are inserted in a ppace between the brain and the trabeculae, including some connective tissue with them. In the adult Amia in this region there is a canal separated from the cavum cranil by the prootic ossification. The trabeculae are wider in Amia than they are in Amiurus and forms a trabecula communis plate before fusilng with the ethmoid plate. In Amia each internal carotid artery passes through the trabecula on its medial side. 
1

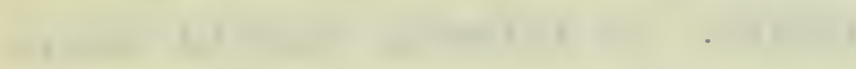

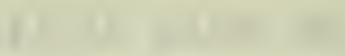

10

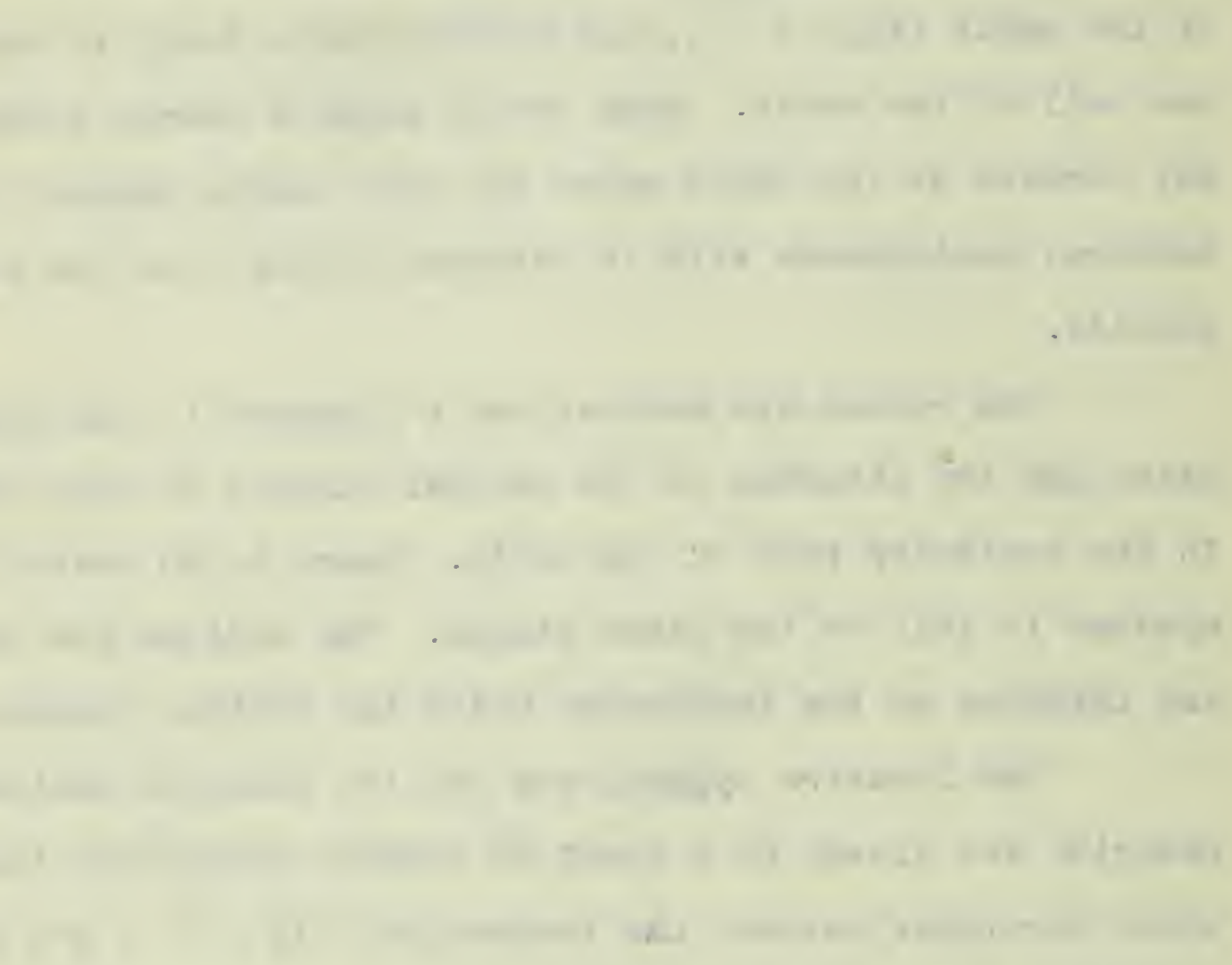

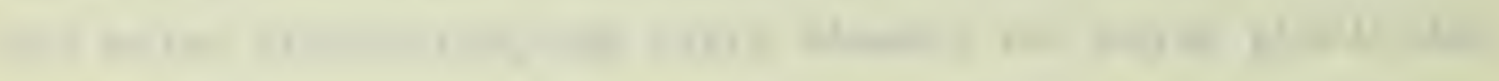

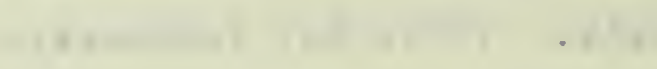

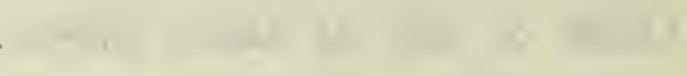

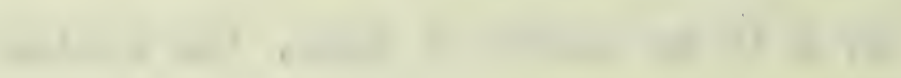

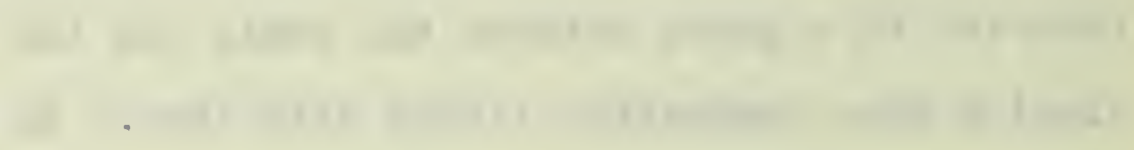

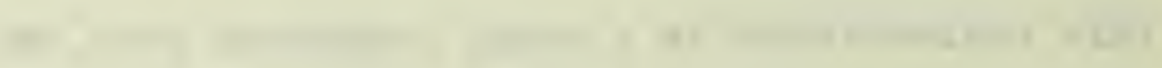
.

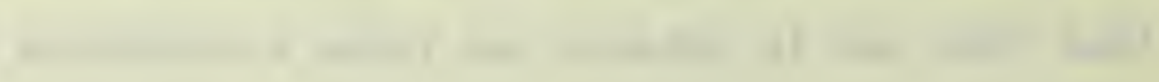

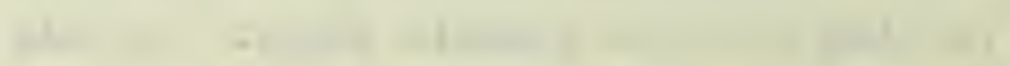


The artery gives off a branch above the optic nerve in amia as it does in Amiurus. The fenestra hypophyseas is even smaller than in the known higher teleosts, in the former. In the cranial wall anderior to the otic capsule, the fifth and seventh nerves are separated by a bar of cartilage between the trabecula and the otic capsule, as in the Selachians and the Salmonidae, differing in this respect from Amiurus.

The oblique eye muscles in a $19 \mathrm{~mm}$ Amia are inserted in a foramen in the wall of the cranium between the ectethmoid process and the optic foramen, comparable to the orbital foramen of Amiurus. In Amia this foramen continues anteriorly with a groove on the dorso-lateral surface of the ethmoid plate. Beyond the eye muscle insertion, the olfactory tractus continues along the anterior part of the same groove. In Amiurus this groove is lacking and the eye muscles do not enter the foramen. There is, hovever, a concavity on the anterior face of the ectethmoid process which if continued through to the posterior would at the anterior margin of the orbital foramen and may have some significance in comparisons with the anterior continuation of the foramen in Amin. The cartilage of the ethmoid floor in this region between the anterior parts of the orbits, is thiscker in Amin than it is in Amiurus.

In the Acanthias larve (Sewertzoff,'97), the trabeculae develop as paired independent cartilages at right angles and ventral to the anterior ends of the parachordals, eventually becoming fused with its ventral face. They grow forward on either side of the hypophysial region of the brain and fuse anteriorly as a trabecula communis plate. As the flexure of the 

neural parts disappear, the trabecula become horizontal in position, except in that immediate region where thay are attached to the parachordal plate. Unlike the trabeculae in Amiurus, the Selachian trabeculae later form a solid floor in the cranium. The cartilaginous connexion between the alisphenoid and trabecular cartilages is far more extensive in the later Acanthias than it ever is in Amiurus. The condition of the cranial floor of Acipenser (Parker,' 82 ), is the same as that of Acanthias, although the fenestra hypophyseos may persist for a longer time. In the early Ienidosteus cranium (Parker,'82b) there is a large fenestra hypophyseos which later becomes closed by the growth medially of the trabeculae. There is a large fenestra hypophyseos in the chondrocranium of the larvel Polypterus (Budgett, 'or), which, from its ellipsoidal shape is comparable to that of Amiurus. In none of these, however, have the relstion of the internal carotid and trabecula been brought out. In all cases the nerves of the cranial series from the second to the seventh issue from the cranium above the trabeculae.

In Salmo (Parker, '72; Gaupp, '06) the trabeculae unite immediately anterior to the hypophysial region to form an elongated anteriorly extending trabecula communis on the dorsal surface of which the membranous interorbital septum arises. The relation of the trabecule to the nerves is typical, but the trabeculae do not meet the alisphenoid cartilages in the medial wall of the orbit as in the Selachians, Ganoids, and Amiurus. Further comparisons of the relations of the trabeculae in other groups then the fishes are made by Parker and Bettany ('77), and Gaupp $(106)$ 

The otic region. The otic cansules at this stage are two large cartilaginous masses forming the sides of the posterior region of the cavum cranii (figs. 1,2). Ventrally, they are fused with the basal plate of the posterior cranial floor, from the posterior ends of the trabeculae to the occipital arch, and there is no gap ( basicapsular fenestra; Parker, in Salmo) beween each capsule and the basal plate. Posteriorly there is no line of division between the occipit 1 arch and the posterior boundary of the otic capsules. Anteriorly the cartilage surrounding each auditory mass is confluent with the posterior end of the alisphenoid cartilage. The dorsal medial margins, at this stage, do not meet above the hind-brain to form a cartilaginous synotic tectum as is found in other teleosts (fig. 2).

The vagus nerve passes obliquely between the otic capsule and the ventral end of the occipital arch, latero-dorsal to the parachordal plate. The glossopharyngeal nerve has a smaller and more anterior foramen in the floor of the otic capsule and is separated from the foramen of the vagus by a small bar of cartilage.

The cavum of the otic capsule is fully open to the cavum cranii, except at the exteme anterior end where there is a small medial wall, bounding the anterior part of the anterior semicircular canal. The cavum within the capsule is divided by three septa semicircularia into the cartilaginous labyrinth containing the membranous semicircular canals. The septum semicircularis anterius as in the adult (fig. 7 ) is a short bar of cartilage extending from the anterior wall of the capsule posteriorly to the midventral surface of the roof, parallel to the 

long axis of the body. From its dorsal connexion with the utriculus, the anterior membranous samicircular canal passes above this soptum into the anterior part of the capsule. The septum semiciraularis laterale is situated at right angles to the anterior septum between the roof and the floor of the capsule, but nearer to the pasterior than to the anterior septum. The anterior end of the membranous lateral semicircular canal and the ventral end of the anterior enter the cavum cranii anterior to this septum laterale. The posterior end of the membranous lateral semicircular canal and the ventral end of the posterior, enter posterior to it. The septum semicircularis posterius lies in about the same horizontal plane as the anterius and makes an angle of about 120 degrees with the ventral surface of the roof of the capsule. The posterior end of this septum is continued as a medial wall between the cavum of the posterior membranous semicircular canal and the cavum cranii. The dorsal end of this canal passes posteriorly above this septum. The fenestrae above both the anterior and posterior septa are much smaller than the fenestrae anterior and posterior to the lateral septum.

After leaving the ganglionic mass of the facialis, the ramus lateralis accessorius of this nerve proceeds dorsally and curves around the anterior end of the capsule roof and thence along the dorsal surface of the cartilage, above the occipital arch to the body musculature. In all this distance the nerve is unenclosed by cartilage, nor is there any indication of ossification around it. It is accompanied by a branch of the internal jugular which descends and fuses with the 

postcardinal vein in the region of the second vertebral arch.

The hyomandibular cartilage articulates with the extern-

al surface of the ventro-lateral wall of the anterlor and

lateral semi-circular canals ( $f$ igs.1,2.). This articulation extends from the ventroanterior edge of the capsule just above the posterior margin of the foramen for the facialis nerve, posteriorly in an obliquely dorsal direction toward the lateral edge of the roof of the capsule. The articular surface is very small in comparison with the longitudinal extent of the capsule and at this stage there is no projecting shelf for this articulation. In a nine day Ictalurus albidus chondrocranium (Ryder, '86), the hyomandibula articulation differs from that in Amiurus, the anterior end being more dorsal than the posterior and in addition the surface is smaller and overlapped by a process from the anterior margin of the capsule, suggestive of the pterotic ridge of Polypterus (Budgett) in the same region. The hyomandibular articulation of other Teleosts and some of the Ganoids in in neraly the same plane and region as in Amiurus, this scheme of articulation appearing to be typical for these groups.

The ot1c capsule of the Amiurus type is apparently derived fram a primitive condition represented by the Cyclostomes (Parker and sewertzoff) and found in the larval Acanth1as as well. In these forms the otic capsules are fused ventrally to the basal plate and the cavum of each communicates with the cavum cranli by a large foramen through which the seventh and eithth cranial nerves enter the capsule. The ninth and tenth nerves leave the cranium posterior to the capsule 
-

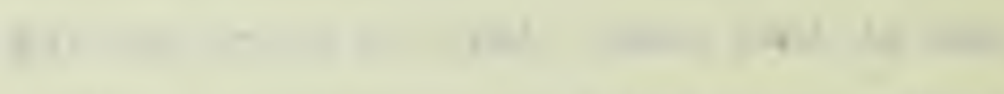
-
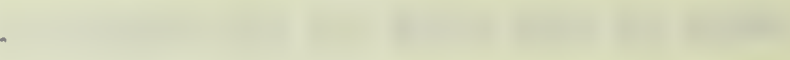
$\sqrt{2}+2$
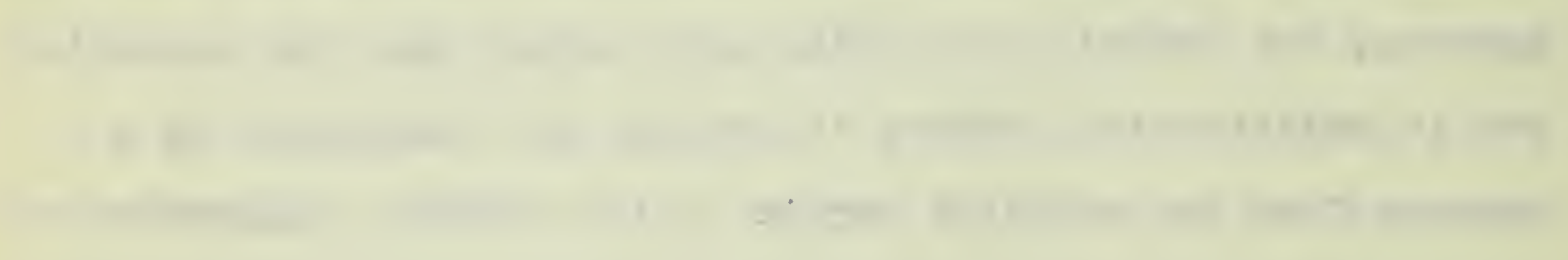

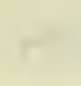

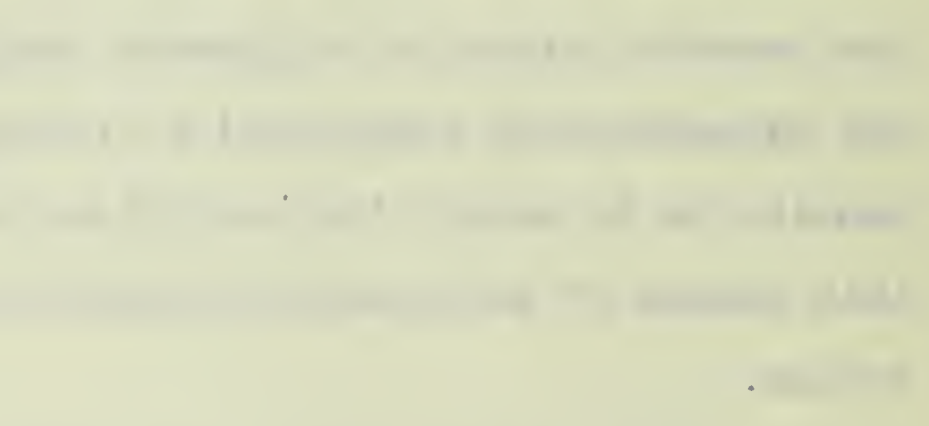

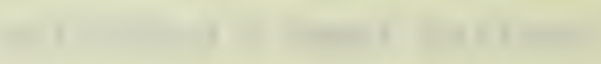

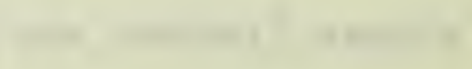
$\cdot$

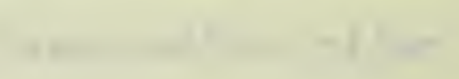

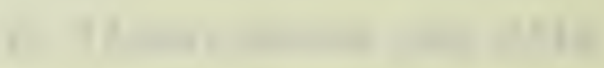

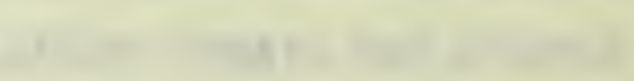


cranium posterior to the capsule in the cyclostomes, but are in the same relative position in the larval Acanthias as in Amiurus. In Amiurus (p 13) these leave by separate foramina, the tenth between the otic capsule and the occipital arch, the ninth a little anterior. A description of the septa semi-circlilaria of the cyclostomes is lacking so that a comparison with the inner surface of the capsules cannot be made. However the structure of the ears in these forms is so different from that of the Gnathostomes, that detalled comparisons would have little v\&lue here.

In the larval Acanthias the fenestra of communication between the cavum cranil and the cavum labyrinthil is as wide as it is in Amiurus, but a wall is beginning to grow from the line between otic capsule and basal plate, which will eventually separate the two cavi. Sagemehl, from his comparative morphological study of the crania of the Teleost, says that their condition in this region is derived from the constant fenestration of the foramen for the auditory nerve, rather than from the cyclostome condition. The evidence given above of the presence of a wide fenestra in the larval Acanthias is against his view and in favor of the derivation of the condition in the Teleosts from an ancestor with a wide fenestra.

The ninth and tenth nerves leave the cranium by separate foramina in Acanthias just as they do in Amiurus as stated above. The synotic tectum in Acanthias is formed very early by the growth of the median margins of the otic capsules, a condition not reached by Amiurus until very late in the larval period and then only for a short distance anteriorly. 


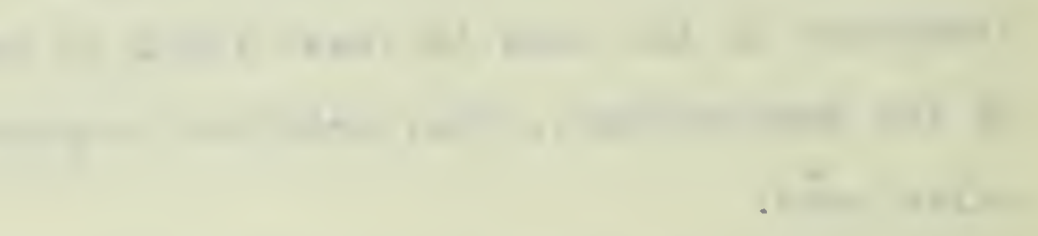


The relation of the capsules to the basal plate and to the cavum cranil of Lepidosteous osseous (Parker,'82), is much the same as in Amiurus except for the large fenestra in the ventral floor of each capsule. There is no wall between the cavum cranil and that part of the capsule containing the inner ear. A detalled description of the septal relations is lacking. Part for part, the otic capsule of the larval salmo as described by Gaupp ('06) is nearer to the condition of Amiurus than any other that has as yet been described. Except for the precocity in growth of Amiurus they can be said to be identical in all their relations, if the presence of the basicapsular fenestra in the floor of the capsule be left out of consideration. There is the same relation of cavum of the labyrinth to cavum cranil and the same number of septa semi-circularia are present and have the same relation to the membranous labyrinth in both forms. The relations of the ninth and tenth nerves are homologous in both cases. Externally the hyomandibular articulation surface is about in the same region in both. The synotic tectum of Salmo is very well developed as compared to that region of Amiurus. Except for the inclusion of the branches of the facialis between it and the alisphenold cartilage in Salmo, the anterior margins of the capsules are homologous, although theprocessus postorbitalis is more pronounced in Salmo than in Amiurus. From these comparisons it may be observed that Amlurus has an otic capsule which, except for several minor differences, is typical of the Teleostean condition. The parachordal Region. Authors describing the origin of the chondrocranium in the Teleosts have remarked that the 


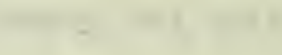

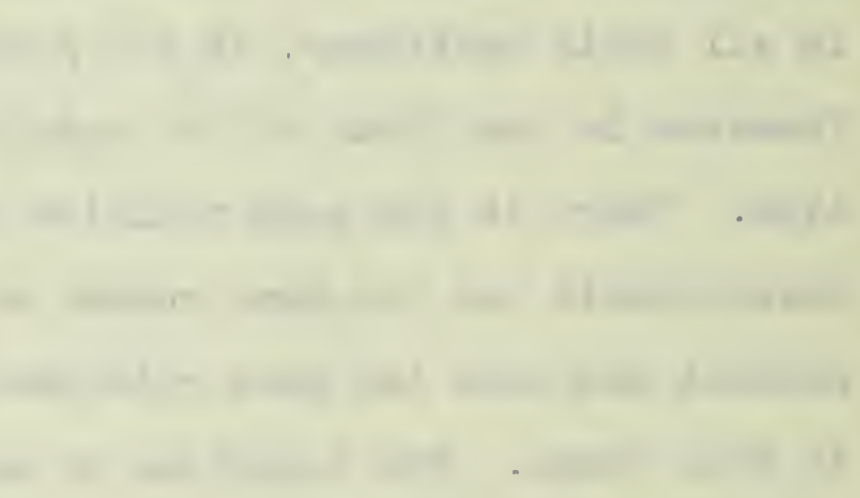

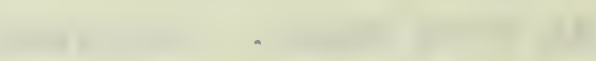

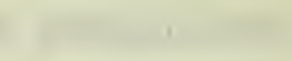
.

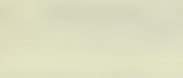

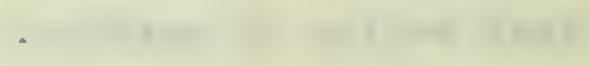

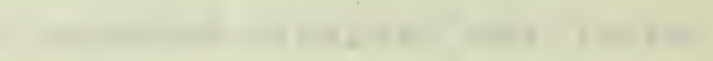

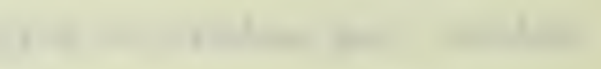

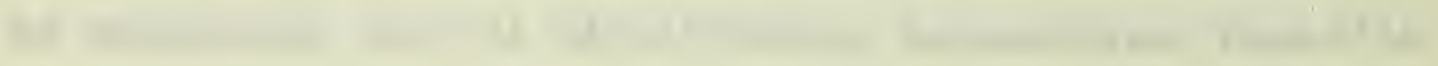

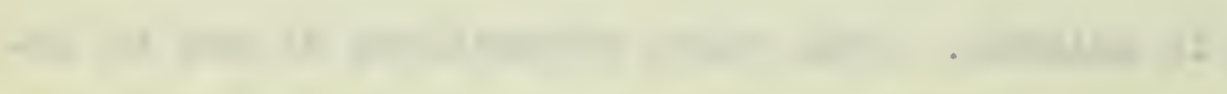

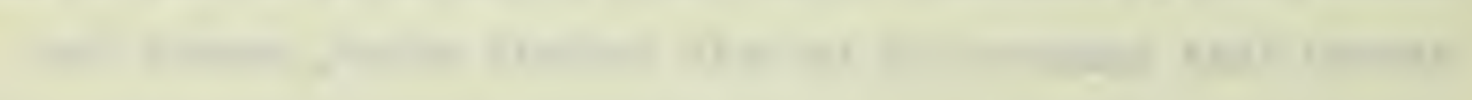

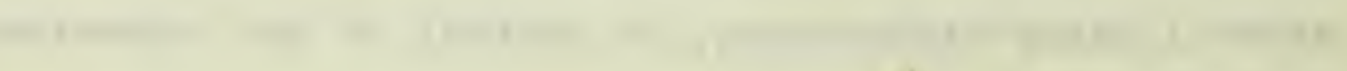

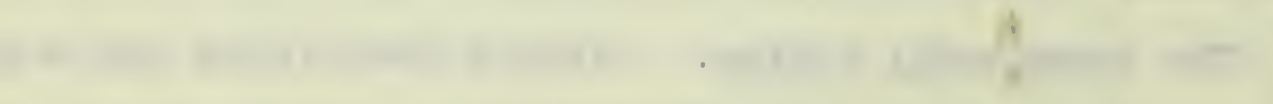


basal plate of the older larva arises from paired cartilaginous masses lying lateral to the notochord. Stohr('82) differentiated each of these masses into an anterior and a posterior part, the anterior lying medial to the otic capsules, and the posterior behind the exit of the vagus nerve from the cranium. The parachordal masses, as these cartilages are called, eventually fuse, partially at least, with each other around the notochord, anterior1.y with the posterior ends of the trabeculae, laterally with the otic capsules, and posteriorly form the base of the oocipital region. Concerning the parachordals in a general way, Parker and Bettany ('77:p.311) say:

"When the parachordals unite in the region where the notochord still persists, it is by growth of the cartilage over and under it. The bridge beneath the notochord is very marked and becomes thick; the cartilage is thinner above, and oftem nonexistent for a long time, so that the notochord lies in a groove on the basilar plate constituted by the union of the parachordalia In many cases where a basicranial fontanelle exists, the cartilage do not approach one another again, and the fontanelie is only closed by a bony gowth...... The whole of the cranial notochord is gradually aborted in most instances, and its place is occupied by cartilage; but in various forms a remnant is left as a slender string, embedded in the basiocoipital bone or cartilage."

In the chondrocranium of the $10 \mathrm{~mm}$ Amiurus, the parachordalia have already passed through the early stages of development and are partially fused with each other, with the trabeculae, and the otic capsules, forming the base of the occipital region (fig.2f Terry ('17) has recently worked over the literature on the parachordal region of the mammals and concludes that the parachordals may arise in three ways; from a hypochordal center of chondrification: from a pair of bilaterally placed masses: and by growth and fusion of the apposed ends of the lateral occipital arches. In the $10 \mathrm{~mm}$ cat, the notochord enters the occipital 


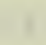

+

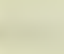

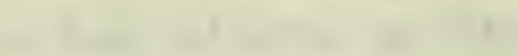

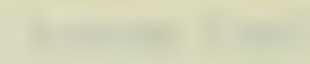

\section{$\left(\frac{10}{2}\right.$}

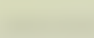

.

.

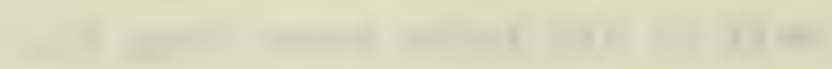

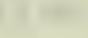

$-$
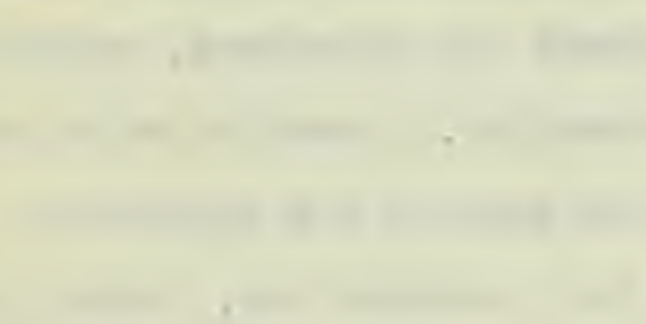

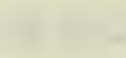

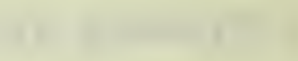

(n)

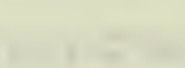

\section{-}

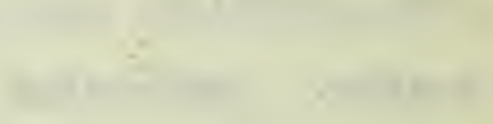

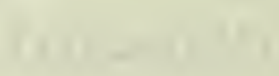

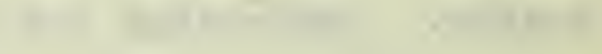

$\sqrt{3}$
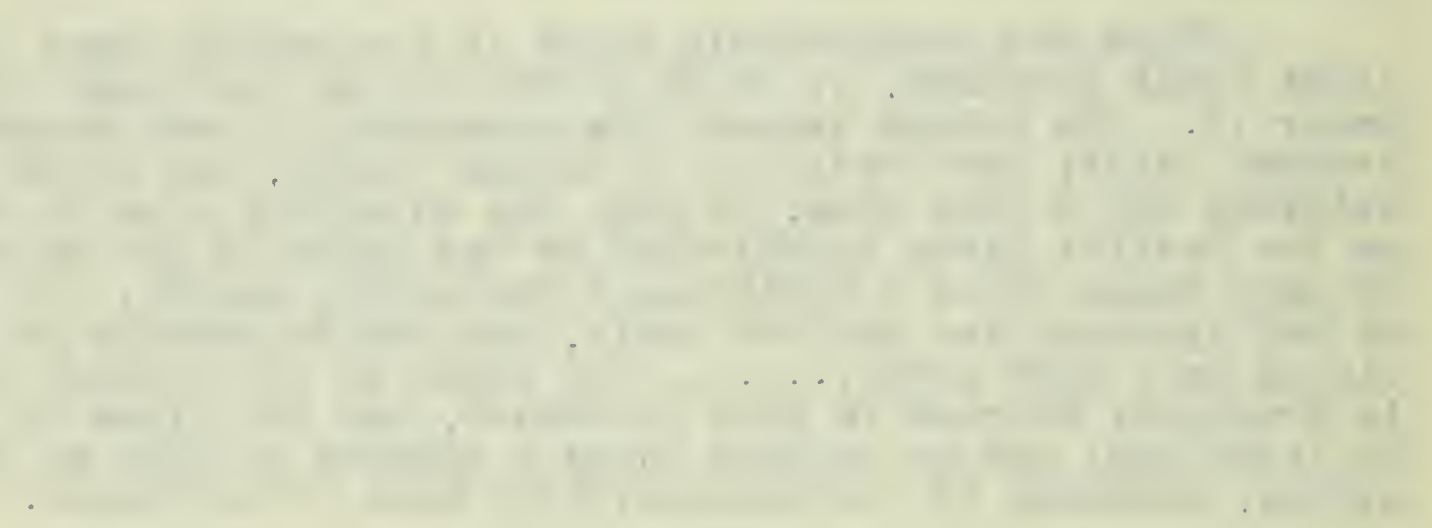
region between two laterally lying parachordal cartilages, dorsal to a mesenchymal sheet which connects them. This sheet later becomes chondrified in connexion with the parachordals, forming thus an hypochordal bridge of cartilage. This agrees. with the statement quoted from Parizer and Bettany, but cannot be applied as a rule for the development of the basal plate of the teleost chondrocranium, as the condition in Amiurus shows.

The concavity marking the anterior extent of the notochord on the ventral surface of the plate is continued anteriorly beyond the tip of the notochord as far as tho margin of the fenestra basicranii anterior. The anterior end of the notochord does not project into a fenestra basicranii posterior, for such is absent in Amiurus. There is no fenestra between the parachordal and the otic capsule corresponding to the basicapsular fenestra of Salmo. The sacculi of the inner ears have invaded the cartilage of the basal plate to such an extent that they have replaced most of it (fig. 8). The grooves on the dorsal surface of the plate containing them, extend from below the base of the lateral septa semicircularis to the posterior end of the cranium, lateral to the notochord. The sacculi communicate with each other across the anterior ends of these grooves, above the tip of the notochord by a transverse canal sinus imparis (ductus endolymphaticus, Wright, '84), from the posterior wall of which the sinus impar of the Weberian apparatus projects. This sinus impar lies along the mid-dorsal surface of the cavum floor and is separated from the laterally situated acculi by a membranous V-shaped wall, the apex of which is attached to the dorsal surface of the notochord (figs. 17,21). It is separated from the cavam cranii by a mem- 


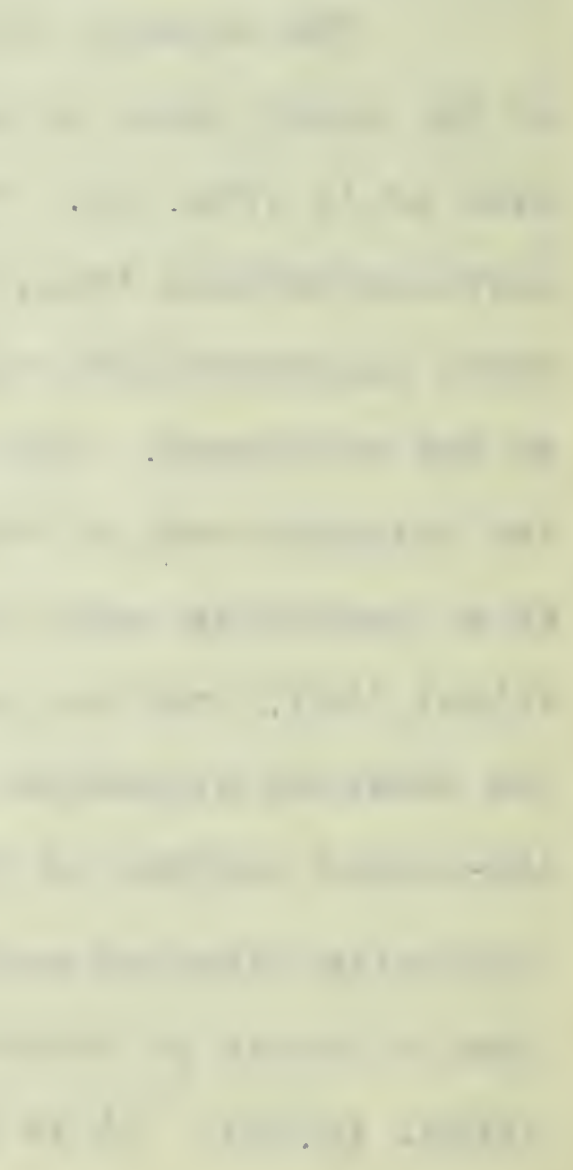


branous roof which continues laterally as the roof of the saccular recesses and is attached to the cranial wall at the junction of otic capsule and parachordal cartilages. Posteriorly, the membranous roof over the saccular cavities is replaced by cartilag which is continuous medially with the ventral walls of the caram sinus imparis and laterally adjoins the otic capsule. The ventral floor of each recessus saccull is very thin (fig. 8), but the posterior wall which marks the posterior extent of the parachordal plate is thick dorso-ventrally (fig. 2l). The dorso-lateral surface of this posterior part of the parachordal plate is separated from the ventral end of the occipital arch posterior to the otic capsule (fig.17), and through this space the sinus impar communicates with the Weberian ossicles contained in the saccus paravertebralis. The first post-vagal nerve or hypoglossus passes out through this space, but does not touch the cartilage of the posterior end of the parachordal plate which has narrowed considerably in this region.

The relation of the inner ear to the cranial floor has been described by several investigators in those forms having a Weberian apparatus, but the descriptions have been confined to adult conditions. In a later paper, I hope to follow the developmental relations of the inner ear to the parachordals, if I am fortunate enough to obtain the proper stages.

There is no evidence of segmentation of the basal plate at this stage, such as is found at the posterior end of the parachordal plate of Acanthias (Sewertzoff,'97). The distinct ridge of cartilage called the"Sattellehne" is lacking in Amiurus 


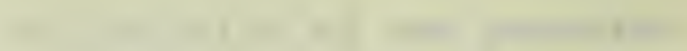

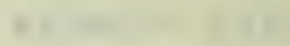

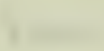

4 - 915
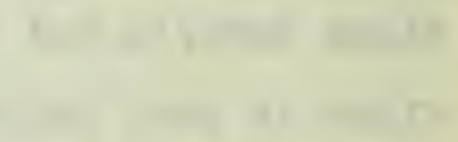

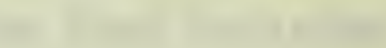

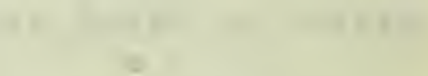

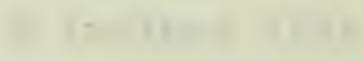

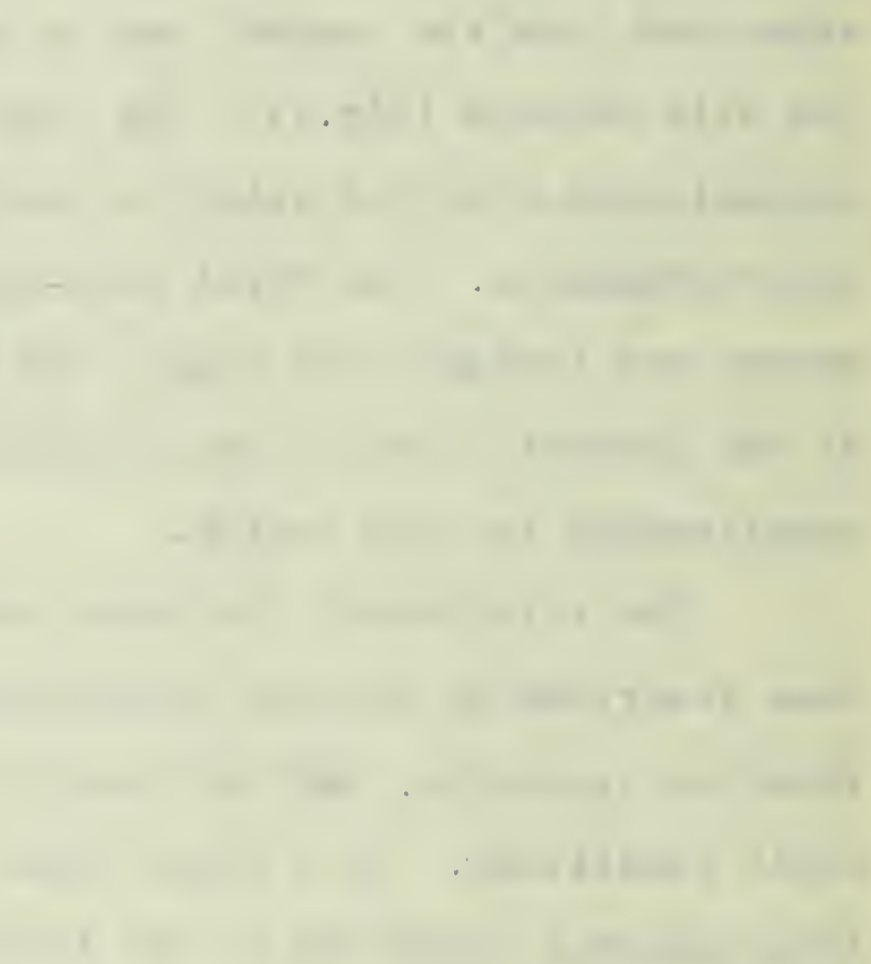


because the trabeculae do not become attached to the ventral surface of the parachordalia, but lie in the same plane with them. Iike the intereapsular floor of Acanthias, this region of Amiurus is solid, and, although in the early stages of Acanthias the notochord projects into the basicranial fenestra it is laterenf closed by cartilage as in Amiurus. The inner ear relations have nothing in common as regards the parachordal plate, because in the older Acanthias the cavam of the ear is shut off from the carum cranii by a wall of cartilage.

As I was unable to find any statement concerning the later larval history of the parachordalia of Amia. I found it necessary to study 2 series of transverse sections through the head of a specimen $19 \mathrm{~mm}$ long. I have referred to the condition in the anterior region of the head of this same specimen earlier in this description.

The parachordalia do not extend beyond the anterior end of the notochord, but lie lateral to it and are separated from it by a space filled with a stroma of procartilage cells. This space is comparable to the posterior basicranial fenestra which Gaupp has described for the $25 \mathrm{~mm}$ Salmo, but which is lacking in the $10 \mathrm{~mm}$ Amiurus. The parachordalia are triangular in crosssection and fused latero-dorsally with the floor of the saccular cavity of the otic capsule. A sharp crest marks the line of division between the two, and from the dorsal edge of this crest a membrane extends to the roof of the cranium, soparating the cavum cranii from the cavum labyrinthii. The sacculus lies on the capsular side of this membrane within the otic capsule, on 


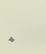

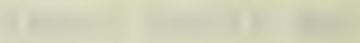

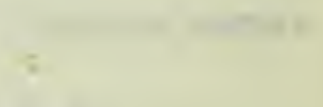


a higher plane than the medial ends of the parachordals. As the parachordals extend posteriorly, they gradually come in contact with the lateral surfaces of the notochord, at first by a sharp edge which gradually becomes blunt and finally concave, as it comes into closer contact with the notochord. The parachordals of the two sides remain distinct from each other however, and I was unable to observe a surface of fusion either above or below the notochord. The glossopharyngeal nerve passes to the exterior through the cavum labyrinthii between the sacculus and the posterior semicircular canal. The passage of this nerve in Amiurus follows the same route between the sacculus and the semicircular canal, but the foramen lies between the dorso-lateral edge of the parachordal plate and the ventral margin of the capsule, rather than in the wall of the capsule proper as it does in Amia. The vagus nerve issues higher up in the wall than it does in Amiurus and instead of being ventral, is posterior to the otic capsule. The cartilage of the parachordals has a greater posterior extent in Amia than they have in Amiurus.

In a $25 \mathrm{~mm}$ Salmo, as described by Gaupp, the parachordalia lie lateral to and close around the notochord except at its anterior tip which projects freely into the posterior basicranial fenestra. This fenestra is cut off from the more anterior fenestra by a transverse bar of cartilage between the anterior ends of the parachordalia. The rectus eye muscles are inserted between the anterior ends of the parachordalia which form the lateral walls of an eye muscle canal in this region, the cavum of which is cut off from the carum cranii by a membranous floor 
(See Gaupp,'06:fig. 342). Commenting upon the parachordal relation Gaupp ('06) says:

" Die Balkenënden verschmelzen mit den vorderen Parachordalia; die ursprüngliche Grenze liegt angangs etwa in der Hohe der vordere Chordaspitze und entspricht dem (in dem Folge sich mehr verengernden) Uebergang der vorderen une hinteren basikranialen Fontanelle. Schliesslich tritt auch eine vordere und eine hintere Vereinigung $\mathrm{zwischen}$ dem Parachordale und dem inzwischen vergrossten periotische Knorpel ein."

As noted in the discussion of the otic region there is a fenestra between the parachordal cartilage and the otic capsule in Salmo which is not prsent in Amiurus and the ninth nerve issues through its posterior end. Whether the foramen for the passage of the ninth nerve in Amia and Amiurus is a remnant of this or not, it is hard to say without knowing the earlier history. The saccular relations are probably the same in Salmo as they are in Amia, as the siluridae have a specialization not found in all of the teleosts, just as the eye muscle relations are peculiar in a certain large group with well developed eyes.

The relations of the anterior end of the parachordals of Amiurus and of Salmo are homologous in that they lie between the otic capsules on either side of the notochord and are connected enteriorly with the trabeculae. Primitively they are alike, but specialization in one form in connexion with the ear and in the other with the eye have made detailed comparisons difficult.

The occipital region. As remarked above, the dorsal part of the occipital arch forms the posterior margin of the posterior fontanelle (fig. 2). The occipital-otic capsule fusion takes place above the foramen for the vagus nerve and behind it the ventral ends of the occipital arch are fused for a short distance to the parachordals (fig.2I). Behind this 

region of fusion the anterior ends of the scaphoid processes project between the occipital arch and the parachordals. At this stage, the scaphoid process is a membranous plate connected posteriorly with the perichondrium of the cartilaginous scaphium (fig. 13).

The first post-vagal nerve (figs. 17,35) leaves the vertebral canal between the anterior end of the scaphoid process and the ventral end of the occipital arch. This part of the arch is enclosed in a perichondrial ossification eren at this stage. The anterior margin of the foramen for the passage of the nerve is formed by the occipital arch-parachordal fusion. The cartilage of the parachordals does not extend posterior to this immediate region, and the dianeter of the notochord is much larger than it was intercranially (compare figs. 8 and 17). The elastica interma and externa are very distinct from each other in this part of the notochord.

On the median dorsal surface of the notochord there is a thickened mass of connective tissue, the endorhachis which forms a floor for the support of the spinal cord (fig. 13). This floor is supported laterally by connexion with the ventral en ends of the occipital arch. In this manner the space between the occipital arch and the notochord is divided into three chambers, a dorsal unpaired one containing the spinal cord, and two lateroventral chambers, the lateral walls of which are formed by the scaphoid processes. The saccus paravertebralis lies external to each scaphoid process and contains the ossicles of the Weberian apparatus. The lateral chambers within the scaphoid 
.

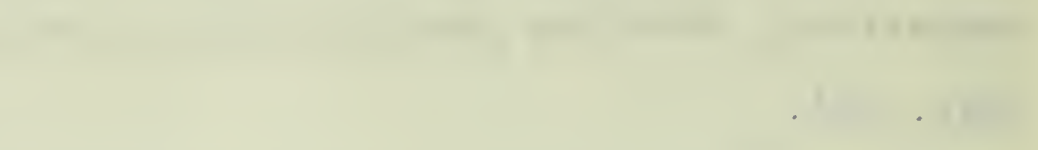

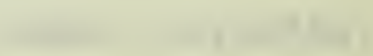
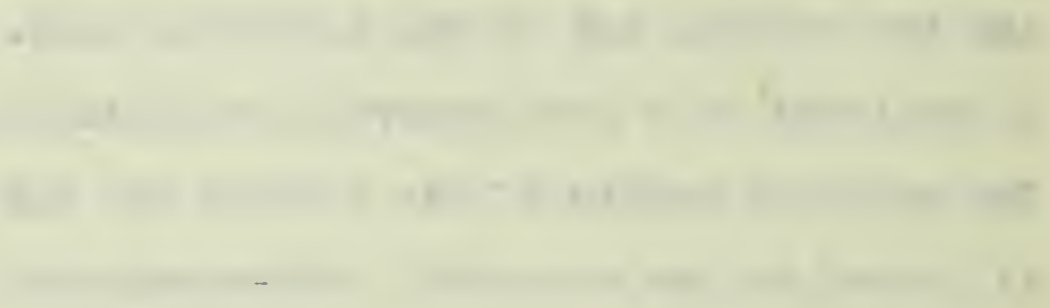

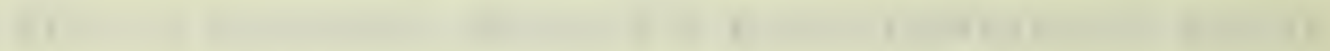
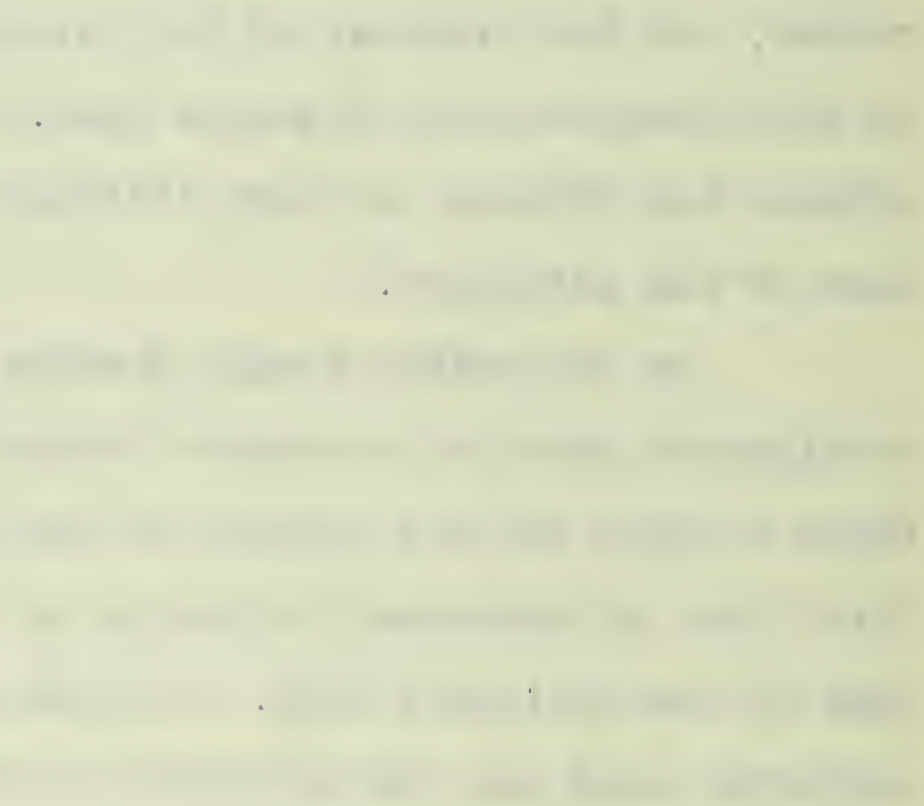
processes are called the atria sinus imparis and are the posterior continuation of the sinus impar.

The scaphium (fig.13) at this stage is a small piece of cartilage which articulates with the dorso-lateral surface of the notochord by a rounded end. It has all the appearances of a modified neurapophysis. Between its dorsal end and the occipital arch there is a small triangular piece of cartilage, the claustrum of the Weberian apparatus. Sagemehl ('85) regarded this in the Characinidae as the first true nourapophysis, and maintained that the nerve which originally passed between the claustrum and the scaphium has been suppressed in those groups having a Weberian apparatus. The scaphium vas homologized to the second neurapophysis.

The second pair of neura pophyses lie a short distance posterior to the scaphia and are separated from them by a pair of rather wide foramina through which the second poir of postvagal nerves issue (figs.12,35). The ventral ends of these neurapophyses are concave and closely applied to the notochord in contradistinction to the rounded ends of the scaphia. Above the dorsal ends of this second pair of neurapophyses and the claustrum, the posterior end of the occipital arch has narrowed down to a small process which is inserted into the anterior face of the third neural arch (fig. 12). The posterior end ventral ends of this neural arch descend behind the second pair of neurapophyses leaving a wide foramen in the wall on each side. The third post-vagal nerve (fig 35) 

nerve passes out through this foramen nearer to the second nourapophysis than to the third.

Briefly, the skeletal and nerve elements alternate with each other in this region, just as they do farther back in the body (fig. 35). None of the post-vagal nerves are actually included within the cranium at this stage, as the dorsal and ventral parts of the occipital region have not as yet united posterior to the first pair. The dorsal surface of the occinital arch does not show any segmentation and ventrally is continuous with the parachordalia posterior to the passage of the vagus nerve and the otic capsule (fig. 2l). The parkchordal cartilages do not extend posteriorly beyond the passage of the first postvagal nerve and there is no cartilage lateral to the notochord until the ventral ends of the third neural arch are reached. There are four distinct muscle segments between the posterior end of the otic capsule and the ventral end of the third neural arch on each side (fig. 35). The more anterior are dorsal and oblique to the posterior, which extend in under their ventral ends (figs. 12,13). The first rnyotome is very short and projects into the shallow temporal fossa, lateral to the dorsal helf of the occipital arch (fig. 12). The second starts ventral to the first, and lateral to the passage of the first postvrgal nerve. It is separated from the cartilage of the occipital arch by a wide space filled with loose connective tissue. The third myotome comes in below the second, lateral to and above the second postvagal nerve, and the fourth is lateral to the anterior projection of the neural arch of the third bortebra. Distinct myosepta are present between all of 


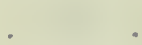


these segÆments.

All the post-vagal nerves have both dorsal and ventral roots, but the first one is the only one in which the ganglion of the dorsal root lies within the cavum spinalis. The ganglia of the others all lie external and lateral to the side walls of the neural arches. All except the first have very well developed dorsalis and lateralis rami and usually an additionally dorsally sensory ramus which proceeds dorsally to the epidermis (f1g. 12.). The ramus lateralis of the flrst post-vagal nerve (fig. 17. )descends obliquely to the muscles in the ventral wall of the body between the anlagen of the shoulder girdle and in this way is comparable to the somatic hypoglossal nerbe of the higher groups. The first two muscle segments have no visible innervation. The third and fourth muscle segments are innervated by the distinct rami dorsales of the second and third nerves. The laterales rami of these two nerves descend as did the ramua lateralis of the first nerve, to the musculature between and around the developing shoulder girdle.

The work of Gegenbaur ('87), Sagemehl ('84,'85,'91), Froriep ('01), Styhr ('82), Dohrn('01), Sewertzoff ('95), Van W1jhe ('82), Furbringer ('97), and others on the relation of the trunk and head in the occipital region has been reviewed by Gaupp ('06). He emphasizes the work of Furbringer as a step in the right direction for the understanding of this question and I refer briefly to some of the points of interest in the researches of Fllrbringer (' 97 ).

According to this author, the crania of the Teleosts may be divided into two parts, an anterior Paleocranium, ending 

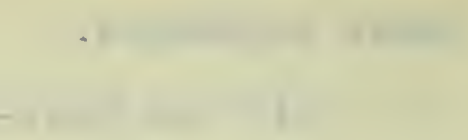

1
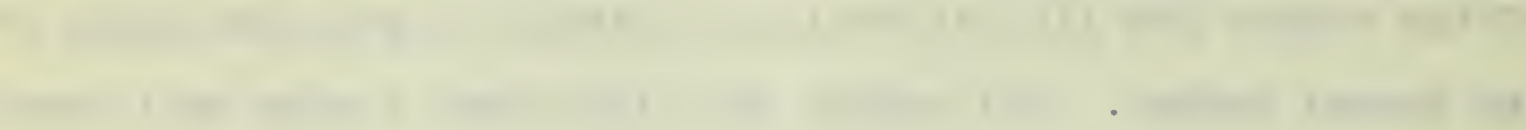

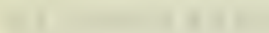

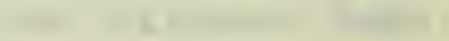

(1)

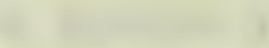

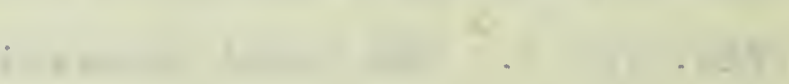

- no

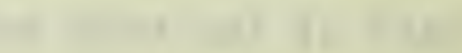

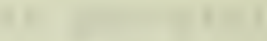

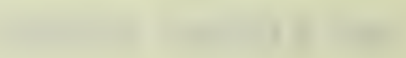

-

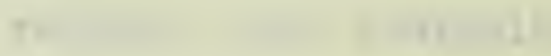

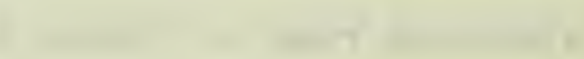

(2)
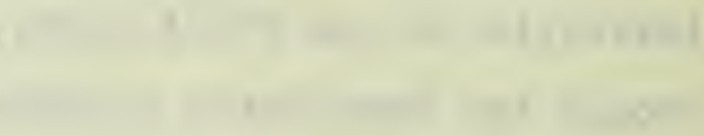

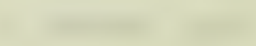

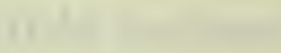

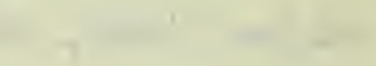

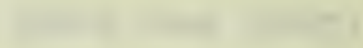

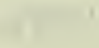

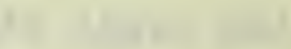

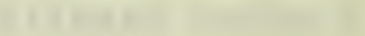


with the vagus, and a part posterior to this, the neocranium. The neocranial condition arose from the assimliation of body segments and is represented in the occipital part of the cranium by skeletal segments and nerves. The primitive type of neocranium is termed the protometameric and is represented in the prsent day forms in the crania of the selachians and the Amphibia. When more elements are assimilated the auximetameric condition is reached. This type of neocranium is found in the higher fishes and in the Amniotes. The distribution and occurence of nerves posterior to the vagus are used by the author in his analysis of the types of neocrania in the different groups. The paleocranial nerves end with the vagus and the neocranial are those, which, before becoming included within the cranlum, were of a free spinal type. These nerves so included are called the'spino-occipital" nerves and are further divided into two categories; those enclosed in the protometameric neocranium are known as the "occipitale" nerves and those in the auximetameric neocranium as the "occlpito-spinale" nerves. He explains the difference in number and appearance of these nerves in the different animal groups as the result of more or less assimilation of vertebrae and atrophy of somites. In his diagramatic representations of the condition in the Selachians, the last "occipitale" nerve is represented by the letter " $z$ " and the first of the"occipito-spinale" nerves of the higher fishes and the Amniotes as " $a$ ", the homologue of the first free spinal nerve of the Selachians. Holocephala, Ganoids, Dipnoi, Teleosts, and Amniotes possess an occipital region of the auximetameric type. According to Furbringer, the different numbers of vertebra 


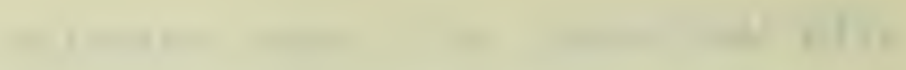

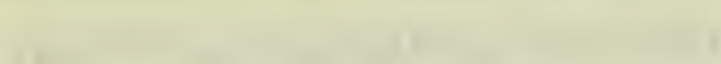

(1)

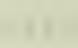

1

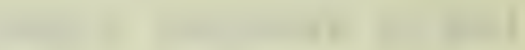
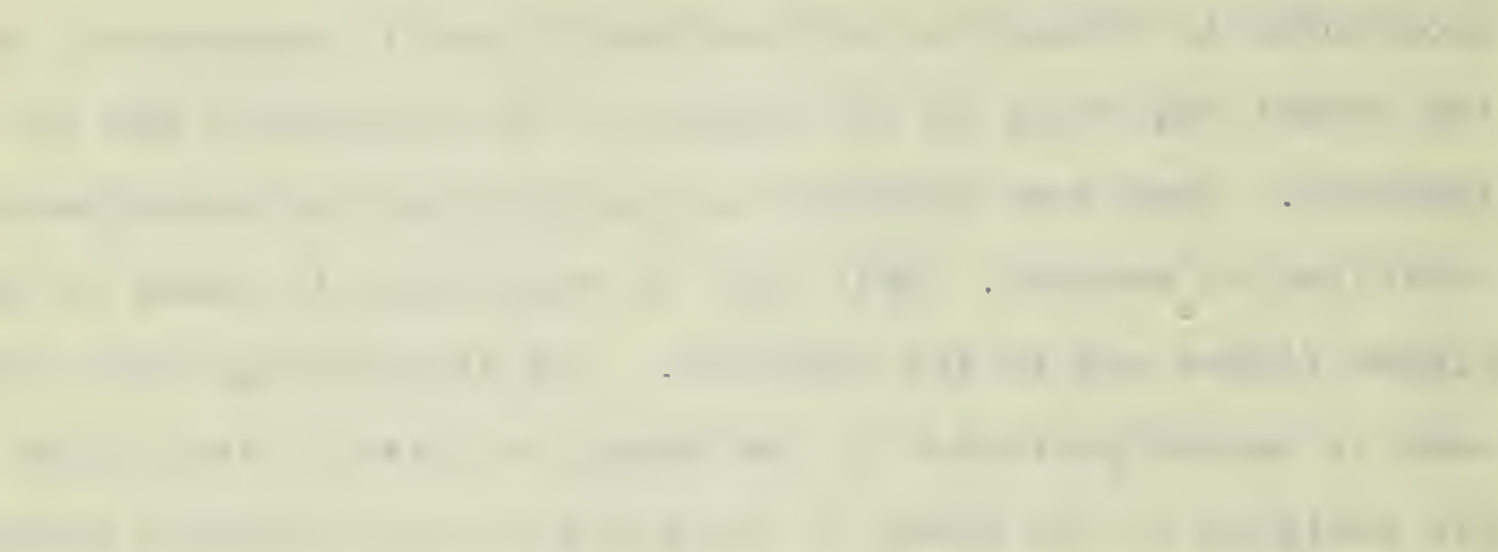

1

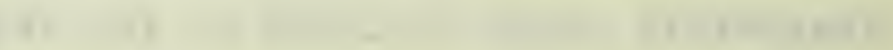

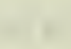

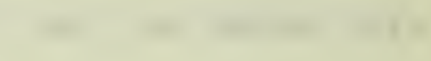

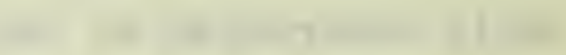
$1+1$

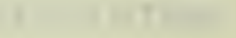

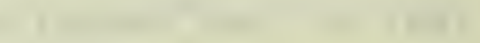

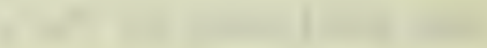


and segments take part in the formation of this region, so that the cranium does not end in the same place in all these groups. The cranial-vertebral complex of the Amniotes includes tiree vertebrae and the hypoglossus nerve of this group is the result of the fusion of the three nerves corresponding to these tinee vertebrae. He says, that in a general way the auximetameric neocranium of the Teleost agrees with the Amniotic condition. The nerve formula for the occipital region of the Siluroids is $b-0-4$. According to this view, the first postvagal nerve of Amiurus is an "occipito-spinale" nerve and corresponds to the second free spinal nerve of the selachians, which the Arabic numeral represents. Thus, there is one segment missing between the paleocranium of Amiurus and the auximetamerid neocranium, and another between this and the first free spinal nerve. This method of reasoning is based on Sagemehl"s hypothesis that in the characinidae and the silurbidae, where the Weberian apparatus is developed, the claustrum represents the neurapophysis of a rudimentary vertebra, and that the nerve which originally came in between the claustrum and the scaphium is lost together with the muscle segment. I do not regard the claustrum as a rudimentary vertebra, but as an intercalated cartilage, developed in connexion with the specialized weberian ossicles. The scaphium may be the first true neurapophysis and a modified representative of this part of the first vertebra. I hope to get further evidence later, for the exect somitic relations of these parts in younger larva than have yet been accessible. For the present I accept the hypothesis suggested by Kingsley ('I0) concerning the relations of the occipital 


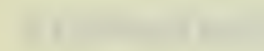

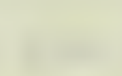

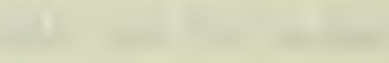

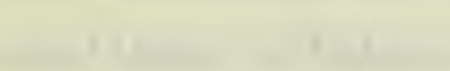

.

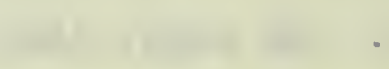

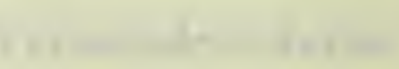

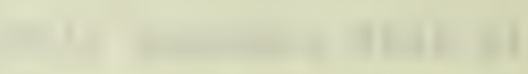

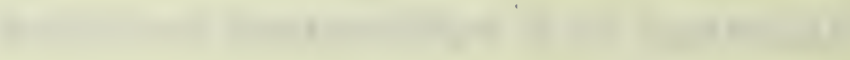

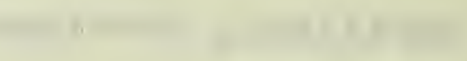

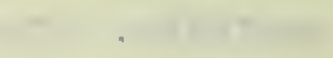
- 
region in vertebrates, where he says:

"In the vertebrates there is a continuous addition of new somites at the posterior end of the body as in the arthropods and annelids, implying the existence of the equivalent teloblasts at the posterior end. The assumption of budding zones at other points will explain other features noted. Such a zone in the occipital region will allow us to explain the difference in the number of cranial nerves in the Mammals and the Ichthyopsida and yet allow us to accept the homology of the occipital bone throughout the series. The additional nerves are thus to be regarded not as transferred from the neck, but as new or intercalated structures."

Reasoning on this basis, the first post-vagal nerve of Amiurus is a new intercalated formation, possibly associated with the second somite. What part the first somite plays in the development of the occipital region I have not been able to ascertain, if we assume that the first dorsal muscle segment is th that of the first metotic somite. In the larval salmo, Miss Willcox found that there were five segments between the posterior end of the otic capsule and the first neurapophysis. Two of these disappear very early in development and have no trace of nerve connexions. The third has a rudimentary nerve which atrophies early. The next two nerves innervate the next two somites and issue from the cranium between the parachordals and the neurapophysis of the first vertebra. These are later enclosed in bone and leave the exoccipltal through the same foramen as the hypoglossus. Furbringer's formula for this family is $b-c-4$, thus having one more element in the occipital region than is found in Amiurus and adding another vertebra to the cranium. The myotomes which disappeared in this case were those which took part in the formation of the protometameric neocranium, most traces of which have entirely disappeared in the Teleosts (Furbringer). But here in the larval condition, there 


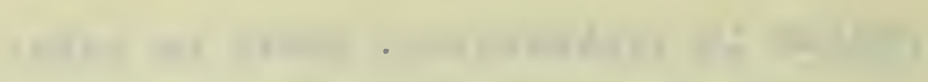

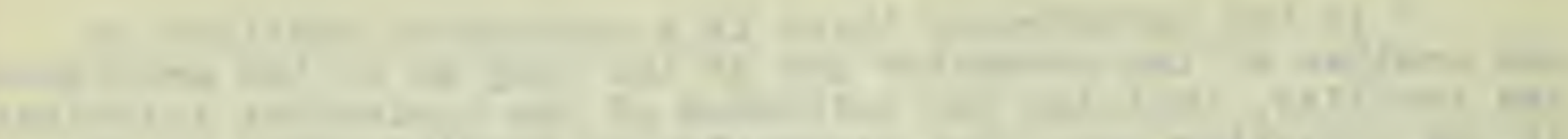
7.

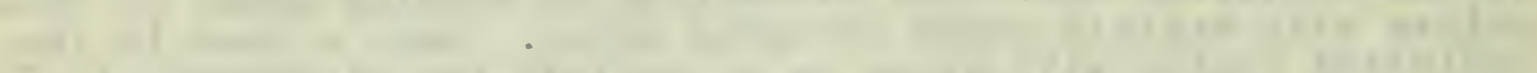

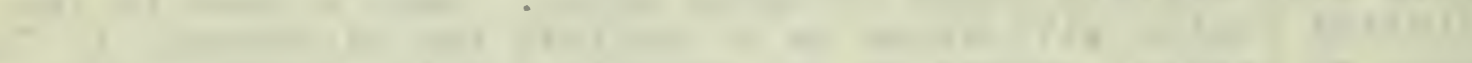

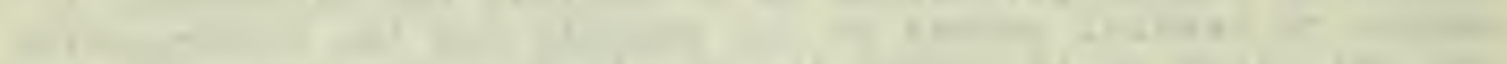

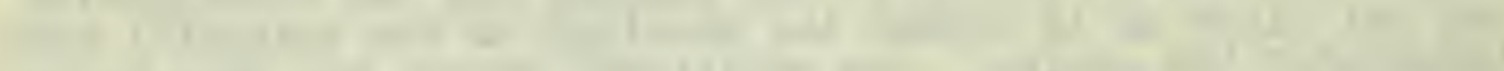
$-\quad+$

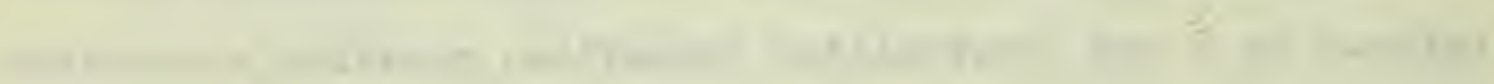

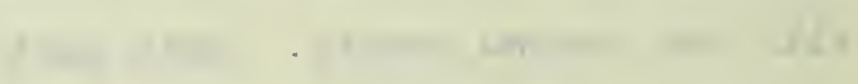

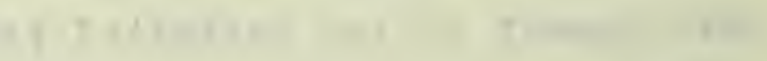

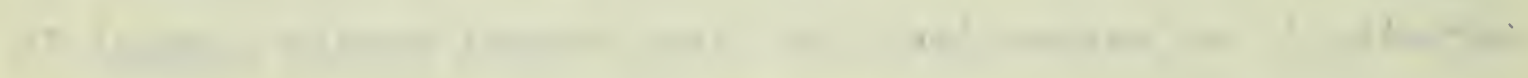

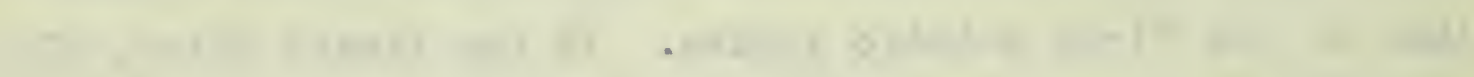

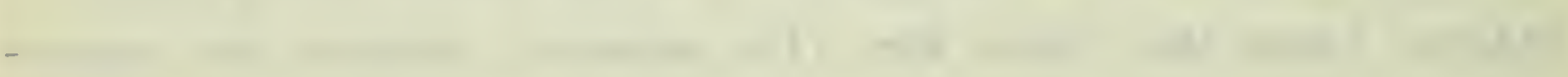
- 10

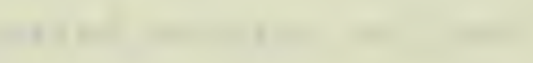


are more somites related to the occipital region than in Amiurus and yet the ultimate development is the occipital bones. If we assume with Furbringer that there are more vertebrae in one case than in tho other, our homologies are no longer such, but are analogies of structure without any natural relationship. Even within one family it would be possible to have an exoccipital vertebral articulation which was not constant, allowing for the attachment and detachment of vertebrae. If we assume that the first vertebra, however modified by specialization remains constant throughout the series, and that the changes in the occipital region are brought about by intercalation of parts, th then our homologies and our basis for natural relationshio are maintained throughout all the groups.

Jordan ('93) in his work on the relation of the number of vertebrae and the distribution of fishes has shown conclusively that homologies cannot be based upon numerical sequence. He counted the number of vertebrae in closely related species of Teleosts from northern and troplcal aters and found that the tropical forms usually had the smaller number. The cranial nerves and bones were constant and yet there were cases of intercalation and excalation of the vertebrae.

Schauinsland ('06) has also shown that vertebrae can be intercalated and that myotomes, nerves and blood vessels of the body cannot be serially homologized. There are various degrees of intercalation from the or prsence of both arches, nerves and myotomes, to the absence of one or two of tinese elements. These facts give conclusive evidence that the nerves leaving the cranium posterior to the vagus cannot be serially homolo- 


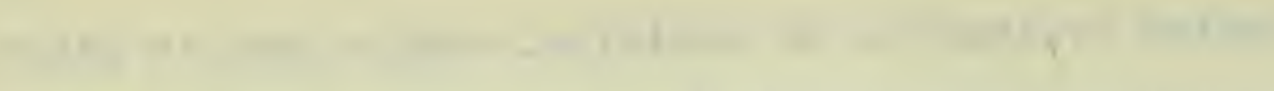

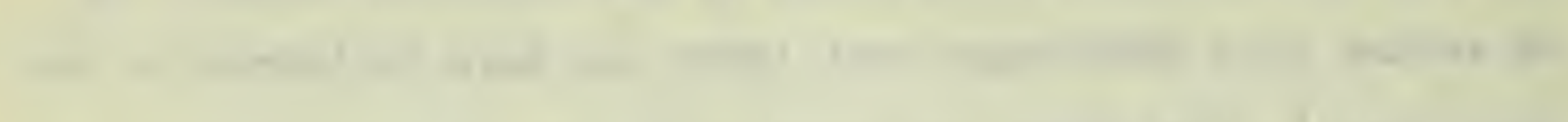

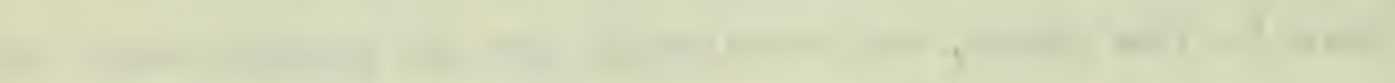

.

(1)

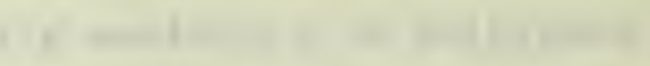
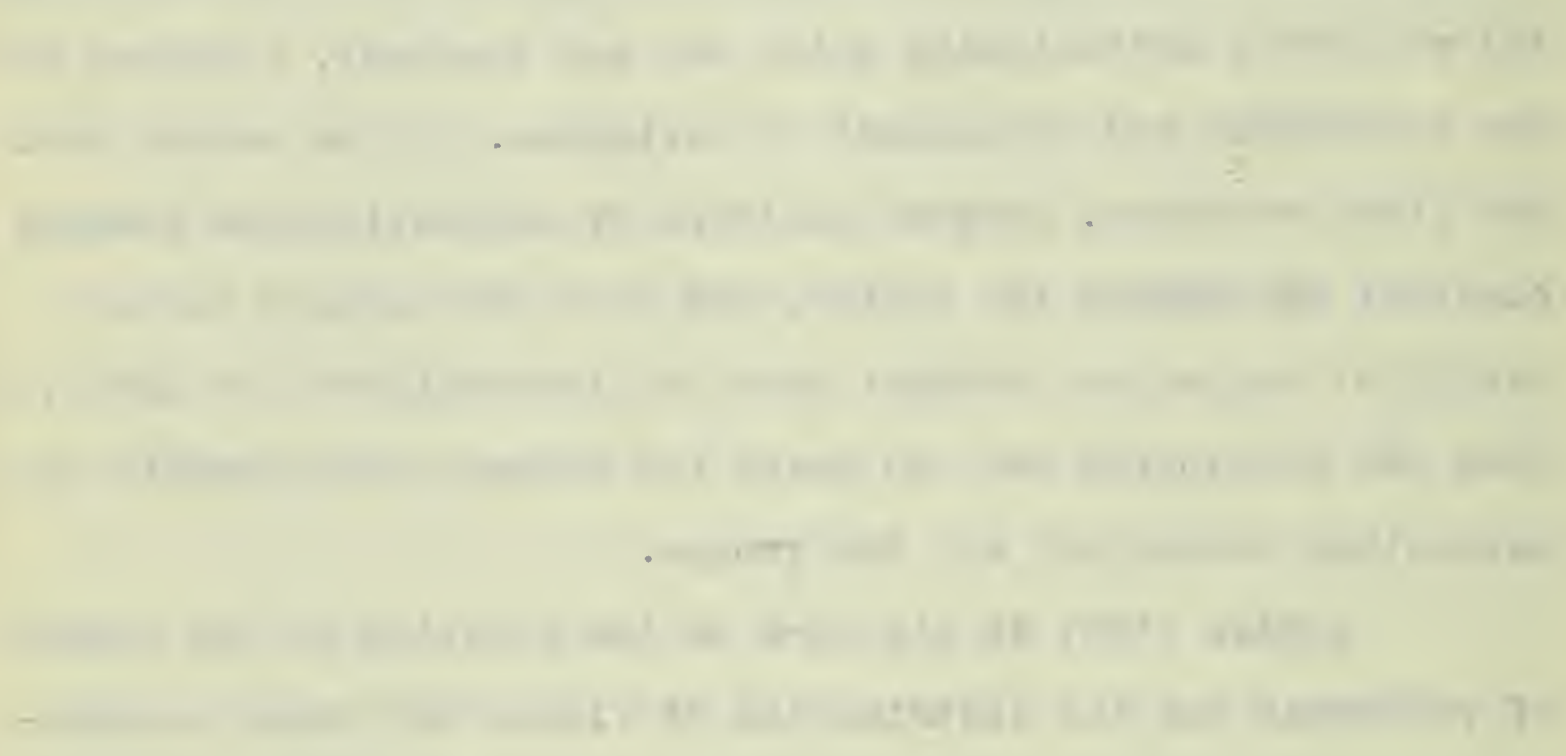

-

(20)

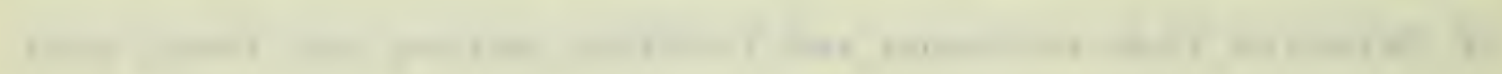

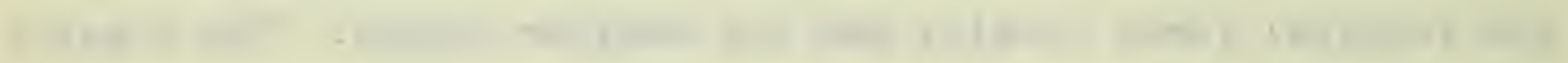

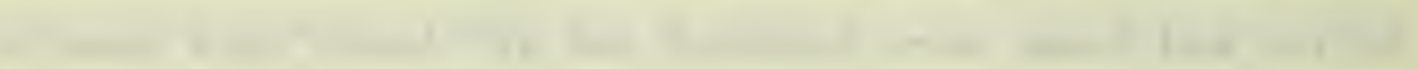

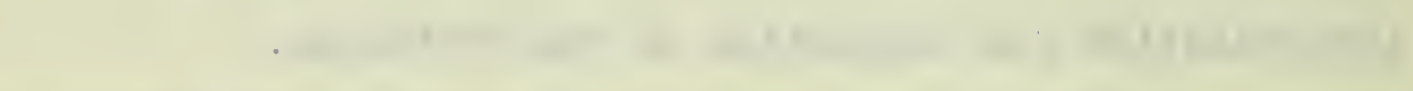
(1)

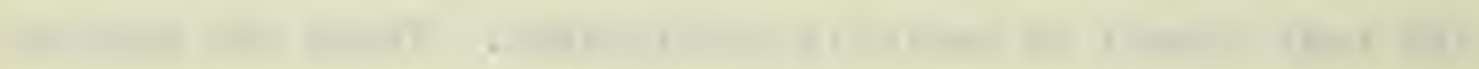

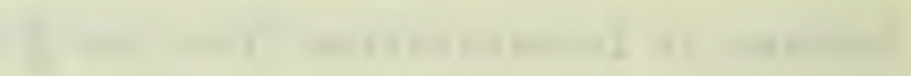

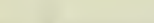
(n) 
gized with free spinal nerves.

Nidillary region. The premaxillary ossification, th one of the few centers of ossification appearing in the cranium at this stage, is a thin horizontal osseous plate lying beneath the anterior end of the ethmoid cornu and extending posteriorly below the nasal organ forming the anlage of the nasal fossa floor (fig.18). It is connected with the ethmoid cartilage by a few strands of fibrous connective tissue, with its fellow of the opposite side, but otherwise lies free in the mass of embryonic connective tissue in this region. Five or six developing teeth are attached to the ventral surface of the ossification.

Schleip ('03) says that the bone and the teeth arise separately in Salmo and fuse later. In the youngest Amiurus I have studied, the earlier stages have already been passed through, but some tooth germs lie below, unconnected with the posterior part of the ossification, and lend support to the view that Amiurus resembles Salmo in this respect. The ascending part of the ossification in Salmo, is lacking in Amiurus, but that which extends medianly beneath the cranium corresponds in the two forms. I find no trace of a labial cartilage in Amiurus. In Salmo this lies between the cartilage of the ethmoid plate and the premaxillary ossification.

In the $10 \mathrm{~mm}$ Amiurus the maxillary bone is represented by a small ossification lateral to the anterior end of the palatine cartilage (fig.30). The medial surface of this plate curves half way around the palatine cartilage and a small process projects laterally from its external surface above the proximal end of the maxillary barbel. There are no teeth connected with the ossifica- 
tion. In Salmo, (Schleip,'03) the maxillary ossification abuts against the palatal cartilage in the same region as in Amiurus, but teeth arising below it fuse with it later.

The palatine cartilage is a slender cylindrical bar lying lateral to and parallel with the ethmoid plate (fig. 1,2). It is not uniform in diameter, but tapers posteriorly. Its anterior end lies lateral to the nasal organ (fig.30) and posterior to it the medial surface is flattened for articulation with the lateral surface of the ectethmoid process. The posterior end of the palatine cartilage is connected with the anterior end of the pterygoid cartilage by a thin stroma of connective tissue cells, among which I was unable to find any cartilage cells. Muscle fibres extend to the dorsal and ventral surfaces of the posterior end of the cartilage from the margin of the ethmoid plate ventral to the orbital foramen.

The pterygoquadrate cartilage consists of an anterior slender, flat pterygoid bar and a posterior thickened quadrate cartilage (fig. I). The pterygoid part extends anteriorly beneath the eye, parallel with the trabecula cranii and connected to it by a sheet of muscle fibres. It ends there and is connected with the posterior end of the palatine cartilage by the stroma of cells, mentioned above. Its posterior end descends obliquely toward the lower jaw and passes into the quadrate cartilage just dorsal to its articulation with leckel's cartilage. The ventral anterior surface of the thickened quadrate cartilage is concave where it articulates with the dorsal surface of liechelis cartilage postero-dorsally the quadrate is indistinguishably fused with the hyomandibular cartilage. 

The anterior end of the dorsal margin of the hyomandibular cartilage abuts against the latero-ventral surface of the posterior end of the alisphenoid cartilage (fig.l). From this point the articular surface for the hyomandibula extends obliquely dorso-posteriorly along the lateral wall of tho otic capsule to a point external to the lateral semicircular canal. From this articulation the hyomandibular descends as a thin vertical plate of cartilage from the wall of the otic capsule behind the quadrate and is connected at its ventro-posterior end with the hyoid cartilage by the interhyal. Its anterior ventral margin encloses the hyomandibularis branch of the facialis. A cartilaginous process for the support of the operculum projects from the posterior margin just below its articulation with the otic capsule.

The opercular bones are present at this stage as thin curved sheets of fibrous connective tissue posterior to and below the hyomandibular cartilage.

Meckel's cartilage has fused in front with its fellow of thd opposite side forming a continuous lower jaw. The anterior part of the cartilage is slender and cylindrical, but posteriorly just before articulation with the quadrate there is a sharp process on the dorsal surface and the dorso-ventral diameter is greatly increased. A small piece of the cartilage extends posteriorly beyond the quadrate articular surface.

In Elasmobranchs (Holocephali excepted) the palatine cartilage is continuous with the pterygo-quadrate bar and abuts against the lateral surface of the trabecula by the palatal process. Its anterior extent is not as great as in Amiurus and it never comes in contact with the ectethmoid process, but fuses with the pars 

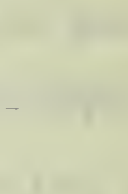

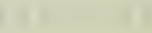

\section{f}
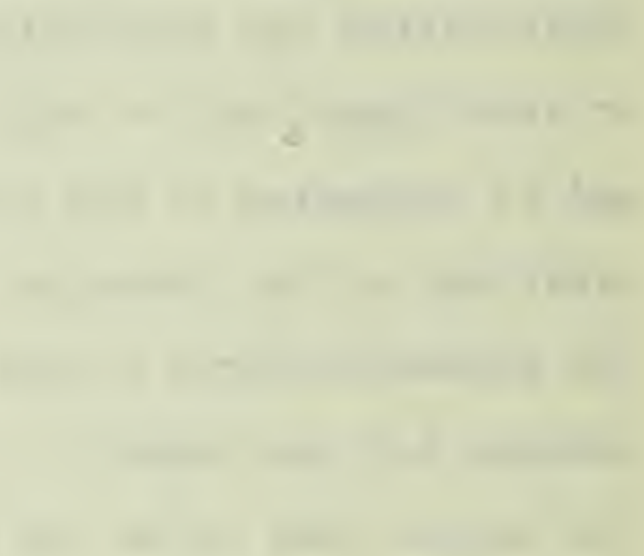

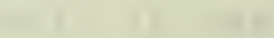
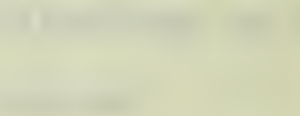

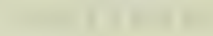

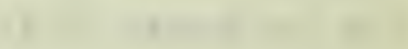


palatina of the opposite side forming a complete upper jaw. Since it is supported by the hyomandibular posteriorly and touches the cranium anteriorly, this type of jaw has been termed amphistylic. By dismemberment of the primitive upper jaw of the Elasmobranchs, the condition of Amiurus is brought about and the palatine part of the arch is separated from the pterygoquadrate part. Steps in this process occur in the ganoids (Polypterus) and in the teleosts (BaImo). In Polypterus (Budgett,'00) the palatine is continuous with the pterygoquadrate part as in the Elasmobranch but has an extent much greater anteriorly.. There is no palatal process as in the latter group and the anterior end is attached to the ventral surface of the nasal capsule. In salmo (Parker, '72; Gaupp, '06) the palatine cartilage is at first independent and secondarily fuses with the pterygoquadrate. It articulates with the ventral surface of the ectethmoid process and at a point anterior to this with the ventral surface of the solum nasi. The part of the palatine which articulates with the ectethmoid process is club-shaped and larger than the more posterior part. Thus ther are important differences in the shape of the cartilage and the manner of articulation when compared with Amiurus. The wider separation of the palatine cartilages and their articulation with the lateral surface of the ectethmoid process may be the result of the depression of the cranium. In Gymnarchus (Assheton, (00) the palatine part of the palatopterygoid cartilage is fused with the ventral surface of the cranium, thus differing radically from the condition of Salmo and Amiurus.

In all of the forms referred to above with the exception of Amiurus, the quadrate is a thickened is a thickened mass 

of cartilage connected anteriorly with the pars palatina by the pterygoid cartilage and bearing on its ventral posterior part a surface for the articulation of Meckel's cartilage. The quadrate cartilage of Amiurus corresponds in its relations to those of the other forms, but is fused dorso-posteriorly with the hyomandibular (fig. 1). In Polypterus the hyomandibular cartilage is aumbbelled shaped, one of its clubbed ends articulating dorsally with the wall of the otic capsule and the other descending posterior to, but separate from, the quadrate cartilage. Unlike Amia. Amiurus and Salmo it does not enclose the ramus hyomandibularis facialis. In Amis (Van Wijhe,'82) the palatine and pterygoid cartilages are fused and have an articulation with the ventral surface of the ectethmoid process. In the latter forms the hyomandibular has a greater extent of articulation than in Polynterus, but the foramen for the hyomandibularis nerve is nearer the anterior edge of the cartilage in Amiurus than it is in Salmo. In the latter the quadrate lies much farther anterior to the bulk of the hyomandibula than it does in Amiurus, and a slender cartilaginous process descends below it from the anterior end of the hyomandibula. This is the symnlectic element which is not found independent in smiurus, but is fused with the quadrate hyomandibular mass of cartilage and may be the part which descends behind the quadrate and connects with the interhyal.

In all of these forms Meckel's cartilage has the same general shape and relations. The articular surface may be convex as in Amiurus or concave as in Acanthias. Usually a small bit of the posterior end projects beyand the quadrate. The coronoid process found on the dorsal surface of the cartilage 


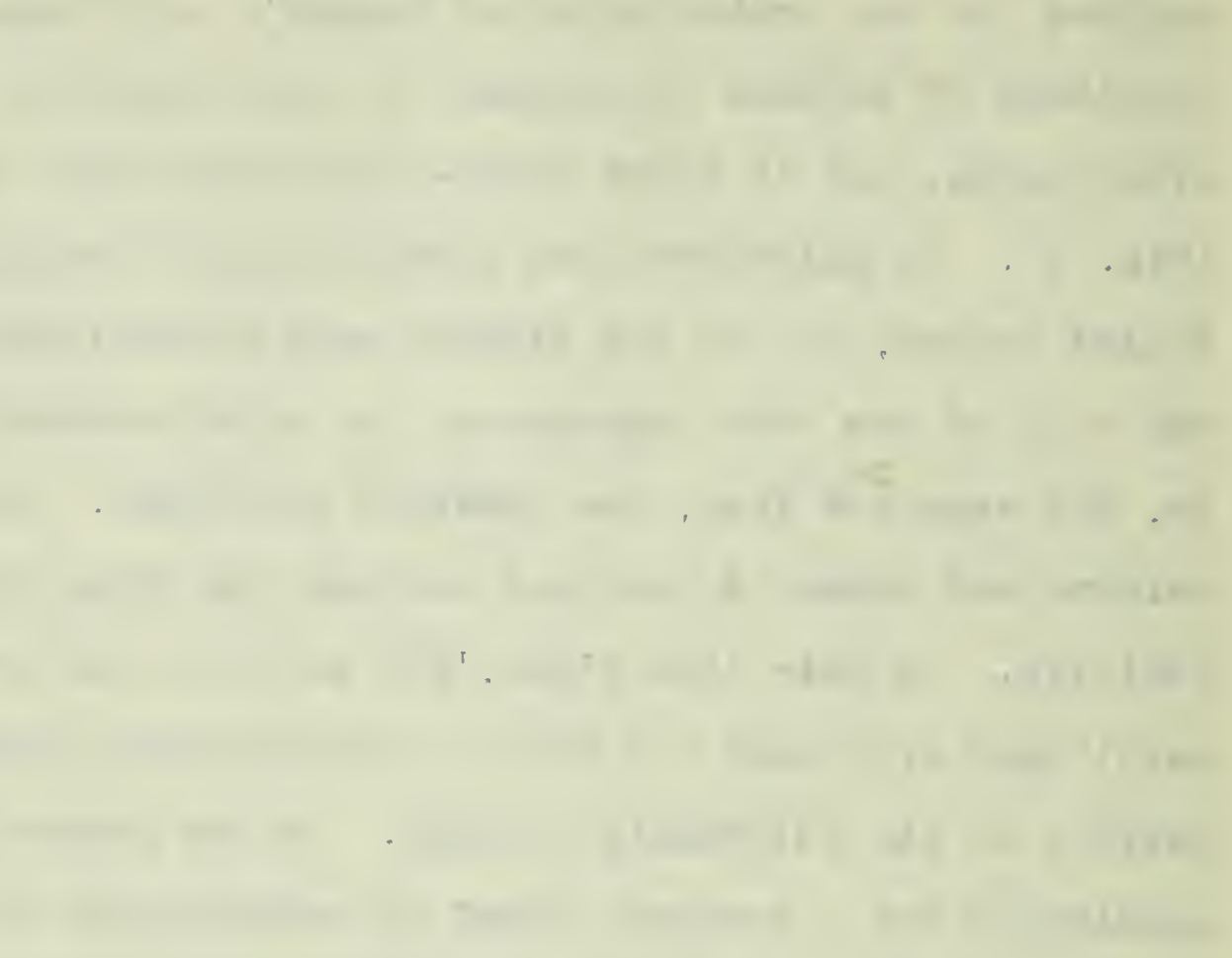


is well marked in Polypterus, but does not project as abruptly as in Amiurus. In Salmo the cartilage has practically the same size from anterior to posterior ends.

\section{The Shull of the $32 \mathrm{~mm}$ Larva.}

The description given in the following section is based upon the study of the head region of $20 \mathrm{~mm}, 32 \mathrm{~mm}$, and $60 \mathrm{~mm}$ larvae. The first two stages were specimens of Amiurus nebulosus (catus), and the third of A. melas. A wax model of the cranium of the $32 \mathrm{~mm}$ stage was made, as it gave all of the typical perichondrial and dermal ossifications at an intermediate stage in their development. One side of the model was left without osseous parts, to facilitate comparisons, as is commonly done in modelling of this kind. The 20 and $60 \mathrm{~mm}$ stages were used to supplement this. Nearly the whole roof of the cranium at this stage is covered by either perichondrial or dermal ossification (fig. 3). The former are derived from the ossification of the perichondrium of the chondrocranium and the latter from the ossification of connective tissue membrane external to it. Sometimes the two elements are intimately fused. Another type of bone development may be mentioned here, the ossification around a lateral line canal. The development of this type of bone has been worked out in detail by Platt ('93) and Klaatsch ('95).

The roof is no longer widely open as in the younger stage, but the fontanelies are limited to narrow slits, anteriorly between the frontals and posteriorly between the parietal part of the supraoccipital ossification (fig. 3). The nasal region has an internasal septum which has grown up from the floor of the ethmoid plate, separating the olfactory lobes (fig. 22). 


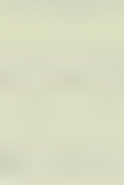

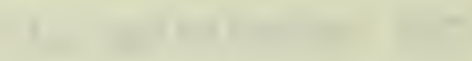


In all parts of the cranium the cartilage is more massive and there are very few places where ossification has proceeded far enough to replace it entirely. The fenestra hypophyseos (fig. 3) is narrower and closed ventrally by the elongate parasphenoid ossification (fig. 4). The cranium has grown $6 \mathrm{~mm}$ in length since the $10 \mathrm{~mm}$ stage, and is relatively much flatter. Detailed descriptions of the various cranial regions follow. The ethmoid region. This part of the cranium differs considerably from the younger stage. The olfactory lobes are no longer in the very anterior region of the ethmoid plate, lateral and internal to the olfactory foramina (fig. 30), but lie farther posteriorly, and a massive internasal septum has grown up between them (fig.22). The foramina instead of lying in an anteroposterior plane parallel to the long axis of the body as in the $10 \mathrm{~mm}$ stage, now lie almost at right angles to it (fig. 3 ).

The ethmoid cornua formerly wide blunt processes separated by a slight indentation, are now narrow and pointed, with a d deep notch between them (fig. 3). The floor of the nasal fossa (fig. 22), the solum nasi of Gaupp, is wider and thicker than in the $10 \mathrm{~mm}$ stage, although even now it does not extend as far laterally as the palatine cartilage. The ectethmoid process (figs.3.4) described earlier as projecting from the cranial wall at the junction of the ethmoid and alisphenoid cartilages, forms an oblique ridge in the cranial wall above the orital foramen (fig.39) and the anterior part of the orbit. The foramen orbitonasale is more posterior, evidence that the cranial parts anterior to it have elongated. The cartilage internal to the ectethmoid 

process in the dorsal part of the cranial wall has grown medially and fused with the internasal septum to form a rudimantary tegmen cranii (fig. 3 ).

The anterior margin of the fenostra hypophyseos formed by the fusion of the anterior ends of the trabeculae lies midventral to the optic foramina (fig. 4), and farther posterior than in the younger stage. The orbital foramen is in approximateIy the same position as in the younger stage, bu the posterior dorsal margin of the ectethmoid process now lies above it (fig. 39). The foramen is limited by a perichondrial ossification between its ventral and dorsal margins, so that a small aperture is all that remains of the larger foramen of the $10 \mathrm{~mm}$ stage. These ossifications are continuous anteriorly with the perichondrial ossifications on the posterior wall of the ectethmoid process.

A perichondrial ossification on the dorsal margin of the olfactory foramen encloses a branch of the internal carotid artery, as it passes from the cranium to the nasal sac. The olfactory tract is entirely enclosed within the cranium from lobus to the olfactory foramen. The development from the condition in the younger stage, has kept the lobus close to the brain, while the anterior end of the cranium grew forward and pulled the olfactory organ with it, resulting in an elongate tractus olfactorius. This stage of the development of the olfactory relations is comparable to that of the Selachian type as has been pointed out in the Cyprinidae by sagemehl ('91). 

The dorsal surface of the roof of the internasal septum is surmaounted by a pair of dermal ossifications (figs. 3,22) which lie on each side of the median line of the head. Near the anterior end of the cranium they fuse to form a single median plate. The anterior ventral surface of this plate is fused to the underlying perichondrial ossification by trabeculae; posteriorly there is a layer of connective tissue between these two ossifications. The paired posterior pieces of the dermal ossification interdigitates with the anterior ends of the paired frontal ossifications above the posterior end of the internasal septum. The dermal element is the anlage of the dermosupraethmoid part of the adult bone, and the perichondrial, the autosupraethmoid part.

In the $60 \mathrm{~mm}$ stage these ossifications have covered the ethmoid cornua and extend laterally above the anterior end of the nasal fossa. There is also a perichondrial and a dermal ossification on the ventral surface of tho ethmoid cartilage, which, though not apparentin the $32 \mathrm{~mm}$ stage are well developed and fused with each other in the $60 \mathrm{~mm}$ stage. Both dorsal and ventral dermal elements extend anderiorly beyond the cartilaginous cornua and fuse with each other forming a sharp anterior cranial edge, notched medially. A small pocket is left in the wall of the nasal fossa between the lateral edges of these ossifications which persists in the adult. The anlage of the premaxillary bone is fused to the ventral surface of the ventral dermal ossification.

A thin flat plate of osseous tissue derived from the ossification of a membrane lies along the lateral margin of the 


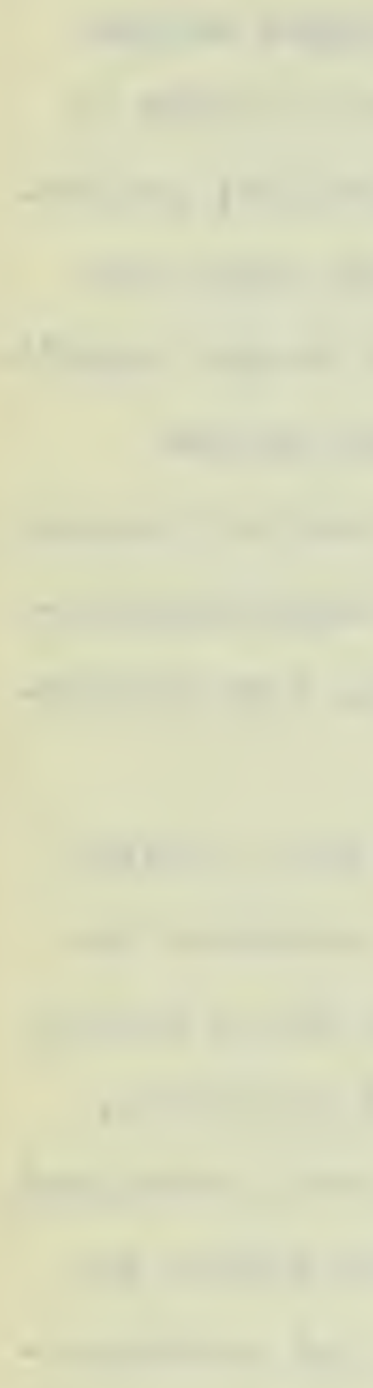

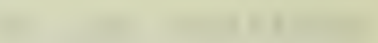

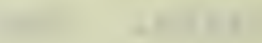
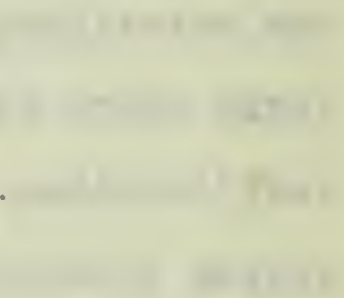

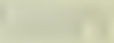
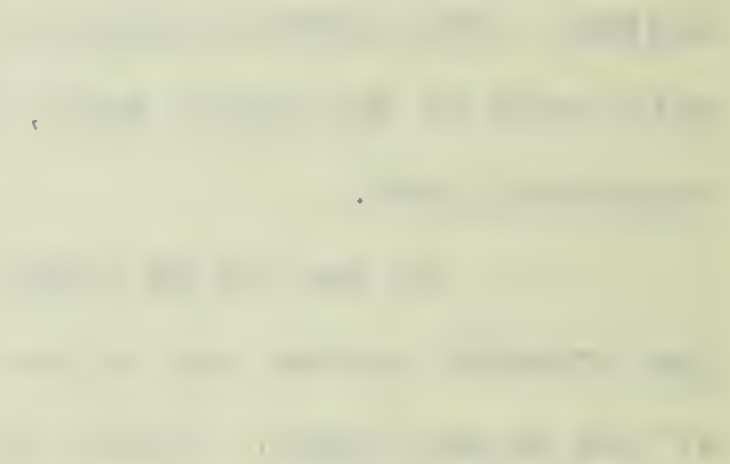
of the dorsal part of the ectethmoid process. (fig. $3,4$. ). It projects laterally above the anterior end of the orbit and the orbital foramen, and is the dermal postion of the ectethmoid ossification. The rest of the ectethmoid process has hardly begun to show signs of ossification and yet this dermal part extends from the anterior end of the orbit to the palatal articular surface (fig. 3.). Perichondrial ossification has taken olace on the ectethroid process ar jund this articular surface, (fig. 4. I, but the surface itself remains unossified. Thus the anlagen of the ectethmoid bone has both auto and dermal parts. Two lateral line bones, the nasal and the lacrimal (fig. 3.22. I, form a part of the roof of the nasal fossa on each side. The nasal (no.) is a long straight ossified tube extending parallel to the supraethmoid and separated from it by a narrow space. It contains the anterior end and opening of the supraorbital latero-sensory canal. The process of the formation of such a bone as this has been described by Platt ('93) and Klatsch ('95), so that it is unnecessary here.

The lacrimal lies near the ventro-lateral margin of the roof of the nasal fossa and contains the anterior end of the suborbital latero-sensory canal. Its triangular outline is due to the division of the canal into two tubes for cummunication with the exterior. Ventro-posteriorly it artioulates with the anterior ossicle of the infraorbital series (fig. $3 . \quad$ ) and anteriorly is fastened by connective tissue to the dorsal surface of the palatine ossification ( nal) . Between the posterior portions of this bone and the more medianly lying nasal, the roof of the nasal fossa is formed by the cartilage which supports 
the nasal barbel (fig. 22. ). This has no connexion with the chondrocranial cartilage and has been named, the "Nasenfltgelnknorpel", in the Characinidae, by Sagemehl ('85), who regarded it as the phylogenetic remnant of the nasal-flap cartilage of the Selachians.

The anlage of the vomer (figs. 4,22) appears as an unpaired dermal ossification ventral to the perichondrial ossification on the inferior surface of the ethmoid cartilage. These two ossifications are distinct and have no connexion as did the two types of ossification on the superior surface. There are no teeth on the vomer anlage which interdigitates posteriorIy with the anterior projections of the parasphenoid ossification by two pointed processes. This interdigitation takes place below the posterior margin of the ethmoid cartilage. The ethmoidal region of the developing Ganoids is, as far as is known, entirely cartilage at a stage comparable to the $32 \mathrm{~mm}$ stage of Amiurus. The only place where perichondrial ossification has appeared is around the ectethmoid process. The supraethmoid ossification is a distinctly dermal bone, comparable to the dermosupraethmoid of Amiurus, but has a transverse lateral-sensory canal ossification on its dorsal surface connecting the supraorbital canals of the two sides. There is always a space usually filled with connective tissue between this ossification in the Ganoids and the underlying cartilage. The nasals of Amia are very much larger and flatter than the corresponding bone in Amiurus and lie on the ethmoid cartilage. These bones are developed in connexion with the latero-sensory canal system and enclose the anterior ends of the supraorbital 


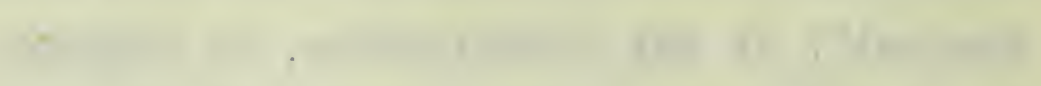

$$
12
$$

$\left(\frac{10}{2}\right.$

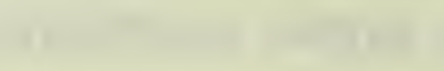

\section{$+1$}


canals. The large nasals limit the supraethmoid, so that it remains as a small triangular ossification at the anterior tip of the cranium. The massive internasal septum of the adult Amia is comparable to the same element of the $32 \mathrm{~mm}$ Amiurus. The prefrontal ossification (my ectethmoid) of Amia, is limited even in the adult, to a small area around the dorso-lateral margin of the ectethmoid process; whether or not it develops perichondrially is not known. The vomer in Amia is paired and toothed on its ventral surface, and limited, as in the vomer of Amiurus, to the medial part of the ventral surface of the cranium. As in Amiurus the palatine articular surface remains as cartilage. The ethmoidal region of the $32 \mathrm{~mm}$ Amiurus, in its cartilaginous parts is somerhat like that of a $25 \mathrm{~mm}$ Salmo, as described by Gaupp. There is the same massive cartilaginous internasal septum flanked by the nasal fossae, but the anterior end of the ethmoid cartilage is rounded off in Salmo and no ethmoid cornua are present. The postero-dorsal extent of the ectethmoid process is approximately the same in both cases, relative to the anterior end of the orbit, but the foramen orbito-nasale is much higher in the cranial wall and farther posterior in Amiurus than in salmo. The large tectum cranii is not present in Amiurus.

The oblique eye muscles of Amiurus have no relation to the ventral surface of the ethmoid cartilage as in Salmo. Because of the development of an interorbital septum, the trabecular wall of the orbit has disappeared and the olfactory nerve crosses the orbit and penetrates the ectethmoid process to reach the olfactory organ. Gaupp ('06) probably selected the 


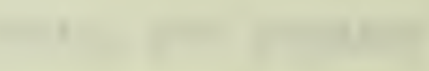


Salmon as his type of Teleost âevelopment because of the ease of obtaining material, although it is more highly specialized in many parts in which the siluroids are almost schematic: The othmoid region is an example of this and I think the general development of the ethmoidal region in the Siluroids is more primitive than is the same region of Salmo.

$$
\text { Gaupp says (06; p676): }
$$

" Die Ersatzknochen occupieren das Chondrocranium bei den Teleostiern in sehr verschiedenem Umgange; meist bliebt ein sehr betrachlicher Teil von ihm in knorpeligen Zustande erhalten. Die Zahl der einzelnen Ersatzknochen ist dabei ziemlich gross, aber ihre Ausdehnung ist beschrankt. Und zwar k8nnen, wie bei den Ganoiden, nicht zur zwischen den einzeInen Stllcken grobsere Knorpelzonen bestehen blieben, sondern bei manchen Formen dringen die Knochen auch nur wenig in die Tiefe des Knorpels ein, so dass die Zerlegung des Knorpelschldels in knocherne Territorien sehr unvollstandig sein kann ( Alepocephalus rostratus, Gegenbaur). Die Ithmoidalgegend bleibt häufig in grossten Ausdehnung knorpelig."

The ectethmoids of Salmo (Pleurethmoidale, Gaupp) are formed by perichondrial ossifications around the ectethmoid process and a ligamentous connexion with the palatine ossifies with them. A large laterally lying dermal ossification which is found in Amiurus is not mentioned.

When ossification first appears in Gasterosteus (Swinnerton;'02), the ethmoid region of the cranium is greatly elongated in a manner somewhat comparable to the condition in Amiurus. The preethmoid cornua are very elongate and have a separate ossification not found in Amiurus, but which Swinnerton compares to the septo-maxillary bones of Amia. Concerning the mesethmoid ( supraethmoid, Author), he sags:

"In the anterior portions of the skull the expanded plate-like portions of the parethmoid cornua have given rise to the parethmoia bones (figs. $4,9, e, p, b$.$) , whilst a center of$ ossification, the mesethmoid, has appeared on the dorsal surface of the corresponding cartilage. The edges of the latter 

ossification extend freely into the surrounding tissue, and give the impression of a membrane bone whose central portion has united with the cartilage ; leaving the edges quite free."

Evidently Swinnerton did not study the histological relations of this dermal plate to the underlying cartilage or he would probably have observed a condition similar to that in Amiurus and what Allis ('10) found in the young Scorpaena. The latter author says:

"The mesethroid of scorpaena, although undoubtedly a so-called primary bone, consists of two distinctly different portions. One of these portions is a thin dense layer of superficial bone. The other portion is a deeper one, of quite different appearance, which underlies the central portion only of the superficial portion, and there replaces portions of the cartilage of the skull...... The superficial portion of the bone is represented by a thin plate that lies closely upon the cartilage of the skull, without intervening membrane, and must primarily be wholly of perichondrial origin; But this perichondrial plate receives at certain places, accretions or additions to its outer surface, and these accretions, although they present in scetions exactly the same appearance as the perichondrizl plate, seem to be of purely perichondrial origin. This is perticularly: noticeable, in my specimens, along the lines of articulation of the mesethmoid with the frontals, and in the mesethmoid process."

This identical with the condition in Amiurus. The ectethmoidal relations are practically identical in the two forms. They are both of perichondrial origin with a dermal ossification in the form of a large wing of bone added to them. The other relations of the ethmoidal bones are best discussed in connexion with the adult cranium.

The orbital region. The orbital wall of the cranium at this stage is formed by the persisting and enlarged alisphenoid cartilage (figs.3,4.), together with the ossifications above and below it. It extends from the posterior face of the ectethmold process as far poteriorly as the anterior end of the otic capsule. The cartilage in this region has grown 

considerably since the ten mm stage, but it has approximately the same topographical relation to the otic capsule and to the optic, trigeminal and facial nerves. The dorsal margins for the foramina of these nerves is as yet formed by the unossified cartilage.

Below the ectethmoid process the cartilage of each wall fuses with the anterior end of the trabecula cranii of that side and, as in the younger stage, forms the posterior margin of the orbital foramen, separating it from the optic foramen (fig. 4.$)$. The posterior margin of the latter foramen has developed from the ossification of the membrane which in the $10 \mathrm{~mm}$ larva extended from the alisphenoid cartilage to the trabecula. This ossification (fig.32.) is not a continuum, but is divided into a dorsal and ventral part. The dorsal part is continuous with the perichondriun of the alisphenoid cartilage as was the membrane of the young animal, but the relations of the ventral part are not so simple and will be taken up in the discussion of the trabecular region. This ossified wall is continued as far posteriorly as the trigeminal nerve ( fig. 4. ) and forms the anterior margin of its foramen; the dorsal margin has been described above as formed by the alisphenoid cartilage proper ( ). The posterior margin of this foramen, through which the main branches of the facial nerve also issue, is formed by a perichondrial ossification (fig. 4. ) between the ventral wall of the otic capsule and the posterior end of the trabeculae.

The foramen for the passage of the ophthalmicus superficialis trigemini (fig. 4,oph. Iy of cartilage, has now ossified on its ventral external side, so that the nerve is enclosed in an osseous canal posterior to 

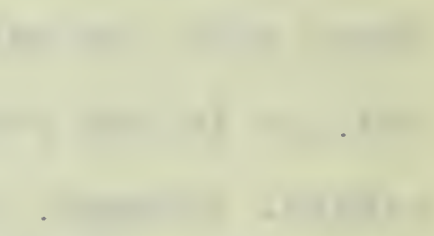

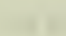

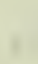


and above the optic foramon. The ophthalmicus superficialis

facialis (fig. 4) issues through a foramen in the cartilage just above the opening of the osseous canal of the opthalmicus superficialis trigemini and innervates the lateral line canal organs of the anterior part of the supraorbital canal which lie in the frontal and nasal bones, (fig. 11).

The roof of the cranium posterior to the internasal septum is formed by the frontal ossifications (fig. 3) and the very thin cartilaginous epiphysial bar. The latter is now relatively much farther posterior to the ethmoid region than it was previously and lies in about the same transverse plane as the optic foramina. dorsally it is covered by the broad frontals, which are separated from each other in the mid-dorsal line by a very narrow fontanelle except in the region immediately above the epiphysial bar where they interdigitate. These frontal ossifications are the largest in the roof of the cranium at this stage and project laterally above the orbit in continuation with the dermoectethmoid (fig. 4) The ventral surface of the frontal sits on the dorsal surface of the alisphenoid and tegmen cranii cartilages (figs. 32, 39) and extends down the outside face of the former without being at all intimately connected with the perichondrium of the cartilage. Behind the eye each frontal is grooved for the reception of the suborbital lateral line canal and articulates with the posterior ossicle of the infraorbital series (fig. 3 ). The suborbital canal enters the frontal at this point and unites With the posterior end of the supraorbital canal to form a canal which extends posteriorly on to the dorsal surface of the (fig. II) sphenotic, this condition persists in the adult. The ossification 

surrounding the supraorbital canal (fig.32.) is indistinguishably fused with the membranous frontal ossification. This canal runs anteriorly within the frontal to a point just posterior to the union of the supraethmoid and frontal, and from here passes into the connective tissue surounding the posterior end of the nasal bone and thence into the latter (fig. 11.). From the junction of the supraorbital and suborbutal canals, a tubule, enclosed in and osseous canal, runs obliquely posterior toward the midale line of the frontal and opens through a small pore on its dorsal surface (fig. 3,11.). Another dermal tubule leaves the frontal through a pore in its dorsal surface just posterior to the entrance of the supraorbital canal into the frontal from the nasal (fig.3, $t \cdot p \cdot)$

The infraorbitalia (fig. 3.) are a series of slender, cylindrical, pipe-like bones, beneath and behind the eye, including within them the suborbital lateral line canal. They are six in number, each separated from its successor by the passage of a tubule from the enolosed canal to the external surface of the head, a so-called dermal tubule (fig.11.). The most anterior bone od this series conneats with the ventro-lateral margin of the lacrimal bone into which the suborbital lateral line canal passes. These bones are typical of the teleosts.

The anterior part of the alisphenoid cartilage, as we have noted, is unossified at this stage (figs.3,4,), and is probably converted into the orbitosphenoid bone of the adult which appears in this region (figs. 16,20). The perichondrial ossification between the optic and trigeminal foramina (fig. 4) 

is the beginning of part of the alisphenoid bone of the adult (fig. 20).

In the younger stage the internal carotid artery enters the cranium internal to the trabecula (fig.2,ca..), but now it has a different relation. This blood vessel enters a rete mirabile, lateral and posterior to the optic foramen, and a branch to the internal part of the cranium enters through the posterior part of the optic foramen. The external carotid enters the cranium as before, between the branches of the trigeminal nerve. The ramus oticus of the facial nerve (fig. 3, r.otVII) issues through the dorsal posterior margin of the alisphenoid cartilage just anterior to the otic capsule, and proceeds posteriorly within the latero-sensory canal ossification on the sphenotic bone to innervate a canal sense organ.

Speaking in a general way about the orbitosphenoid development throughout the whole vertebrate series, Parker and Bettany say that it is the result of the ossification of the anterior part of the lateral cranial wall and may be either anterior to or penetrated by the optic nerve. It also arises from paired centers, although in the adult it may be unpaired. It is described by these authors in Salmo as an"ectosteal" ( comparable to my term perichondrial) lamina in the anterior part of each side wall of the cranium. Concerning the development of the same bone in Salmo, Gaupp (06) says that it is developed in the dorseanterior part of the interorbital septum and the ventral surface of the tegmen cranii of this region and, further, the olfactory nerve issues through it before entering the orbit. Since an interorbital septum is absent from Amiurus, comparisons with 


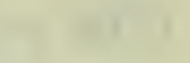

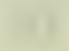

$$
\cdot
$$

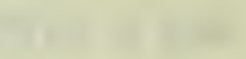
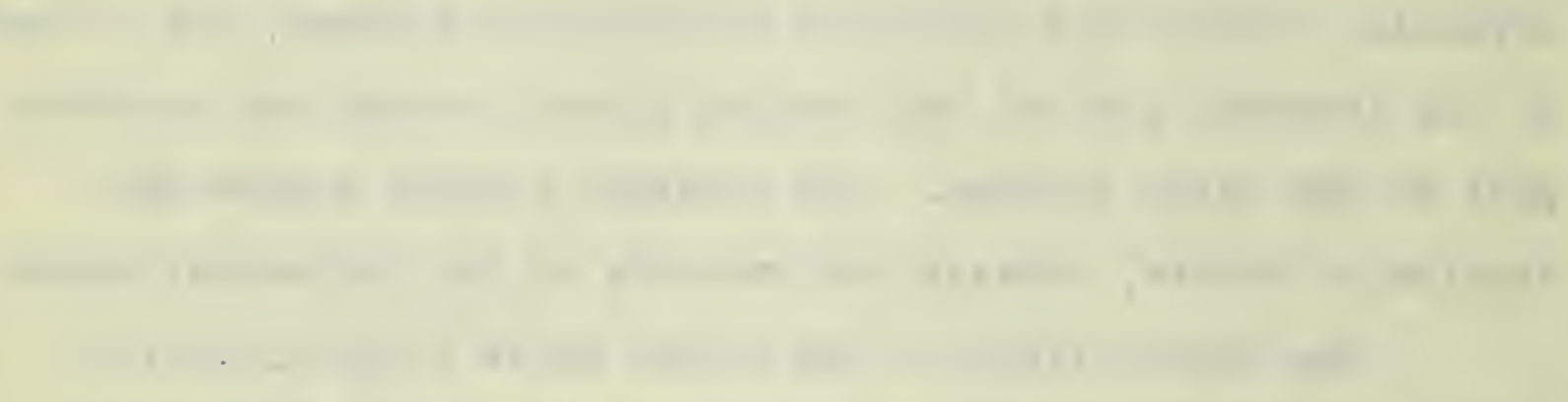

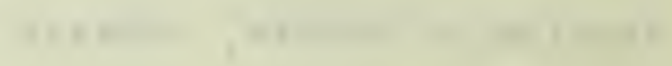

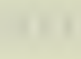

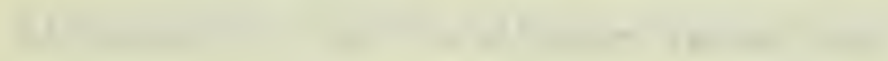
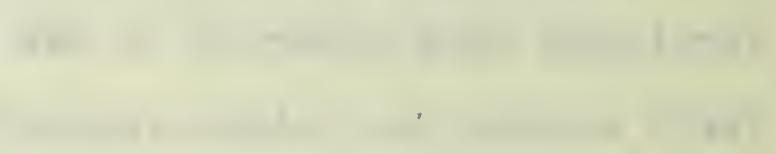
10
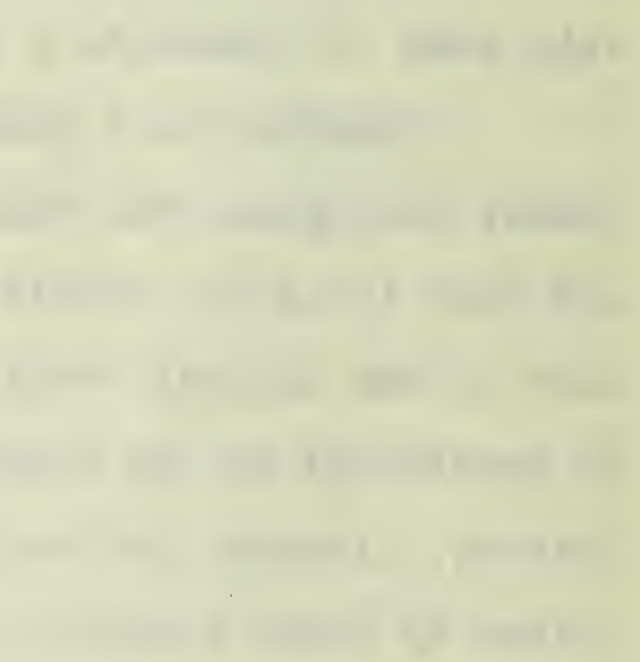

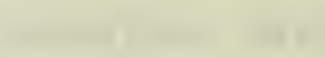

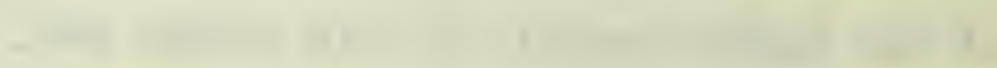


the Salmonoid condition is not very easy and clear to the casual observer. But if we can conceive of the cranium of Amiurus being compressed instead of depressed, then the anterior ends of the alisphenoid cartilages where they unite with the ectethmoid process, would be pushed together, and the surface where they met would be comparable to the interorbital septum. At this stage of Amiurus there is no ossification on the dorsal part of the anterior end of the alisphenoid cartilage in the region of the anterior part of the optic formen, although the perichondrium shows signs of the beginning of a perichondrial ossifioation both on the outer and inner surfaces which extends down to the trabecula. The first traces of the orbitospehnoid occurs in the Salmon at the $35 \mathrm{~mm}$ stage.

The alisphenoid of the Salmon is a later ossification, after the orbitosphenoid, whereas in Amiurus it is quite well developed before any great development of the orbitospehnoid. Speaking of the alisphenoid in Salmo, Gaupp ('06) says:

" Entsteht sehr spat (Salmo fario von $40 \mathrm{~mm}$ ) in Form von zwei perichondrálen inochenlamellen, einer inneren und einer Husseren, auf der knorpeligen Schädelseitenwand vor der Ohrkapsul. Im Anschiuss an den perichondrale entstanden Abschnitt ossifiziert auch ein Teil der hatig gebliebenen seitenwand der Orbitotemporal region. Das Alisphenoid schliesst in selbstandige Foramina den N.Trochlearis und den ersten Ast des Trigeminus ein und begrenzt von oben her das opticum."

The posterior alisphenoid ossification between the optic and trigeminal nerves of Amiurus, has most of these characters given by Gaupp for the alisphenoid of Salmo. He says little about the nature of the "Hautig" wall and its relation to the trabecula. As I interpret it, this wall is developed at a very early age from the perichondrium of the alisphenoid cartilage, since they are intimately connected in the $10 \mathrm{~mm}$ stage. The 

relations of the ventral part of this region will be taken up later in the aiscussion of the trabecular region. In Salmo, the ophthalmicus superficialis trigemini has a different course through the alisphenoid cartilage and is closer to the otic capsule than it is in Amiurus. Gaupp does not dicuss the relations of the ophthalmicus superficialis facialis of Salmo.

Both alisphenoid and orbitospehnoid ossifications occur very late in the development of the ganoids in approximately the same place in regard to the passage of nerves as in the teleosts. In the Amphibia the orbitosphenoid (sphenethmoid; Parker,'72) is developed on the anterior end of the alisphenoid-trabecular cartlage and the posterior margin of the ethmoid cartilage, in approximately the same position that it has in Amiurus. The alisphenoid ossification does not form.

As mentioned above, Gaupp ('02) claims that the alisphenoid of the mammalian cranium is developed from a newly added cartilaginous part the "ala temporalis", but I have adopted an entirely different view and believe that the cartilage is the same in both Mammals and Iohthyopsida, because of its relation to the trigeminal nerve. Gaupp, himself admits that nerves are good landmarks in the establishment of homologies and yet denies this homology.

The frontal bones first appear developmentally in the Acipenseridae (Parker;'82) and the lower Siluriaae (Hertwig;'76). as demal plates, slightly separated from the corium and heving their origin in this layer. Theynever form a pair of distinct frontalia as in Polypterus, Amia and Lepidosteus, but remain as groups of plates. They do not touch the cartilage of the tegmen 


$$
\text { 1 }
$$
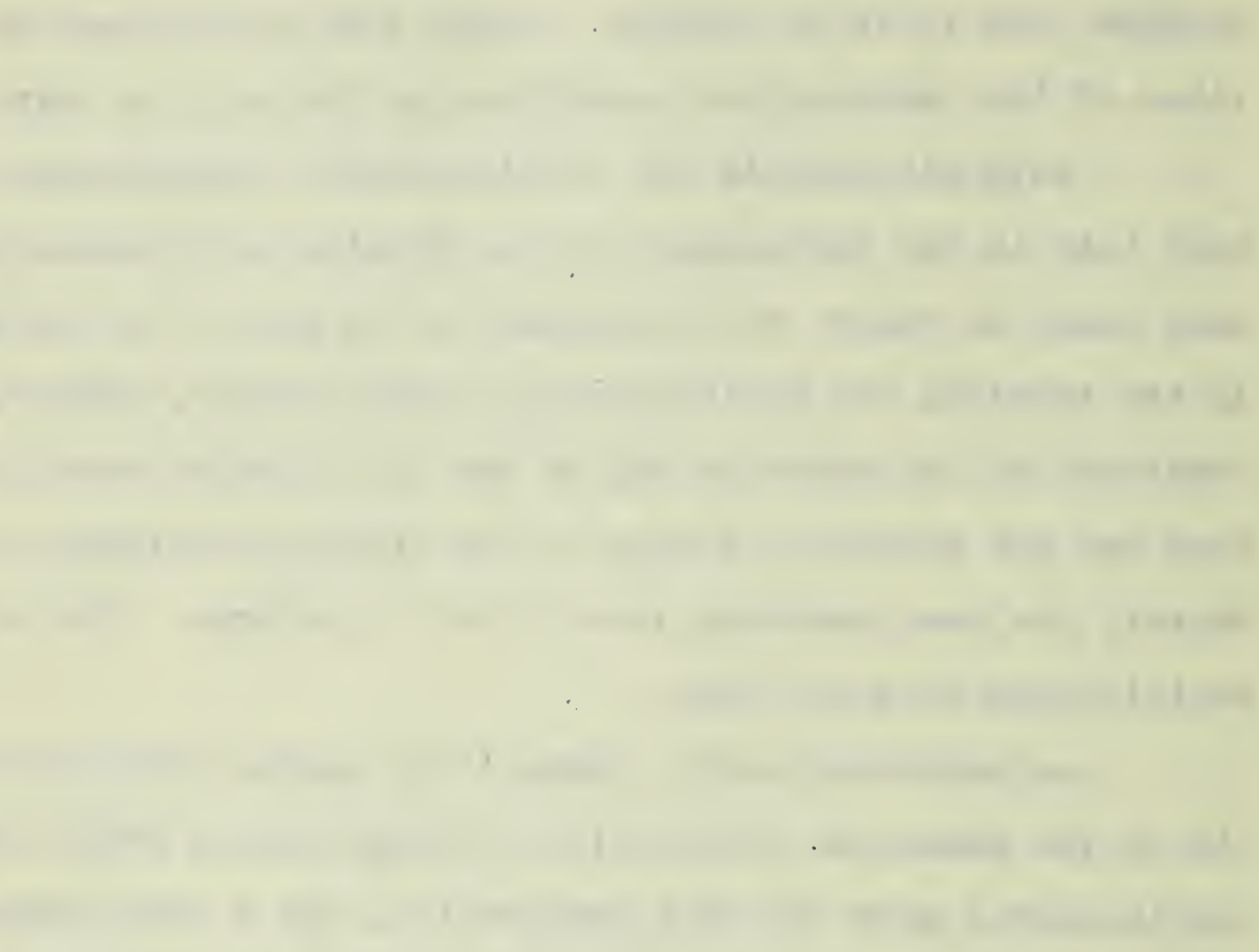

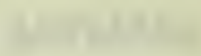
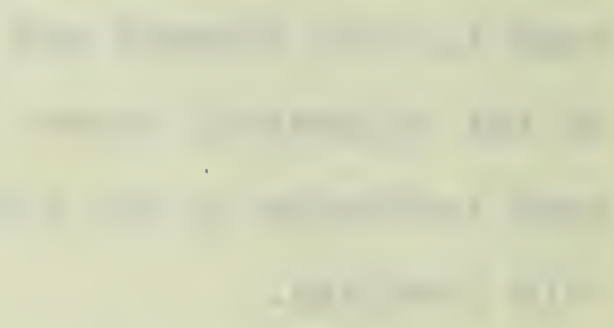

\section{.}

+ atrats .

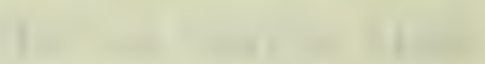


cranii, but are separated from it by connective tissue.

Walther ('82) found that the frontalia in Esox develop in the same way, but were nearer the cartilage and had less relation to the corium. Hertwig ('76), Williamson ('51), and Heincke ('67), came to the conclusion that the frontals of the teleosts and ganoids were descended from dermal acales, a view universally accepted for all osseous vertebrates.

Vrolik ('73), in his discussion of the development of the frontals in the teleosts, remarked that they were formed for the protection of the lateral line canal which in the adult of most toleosts runs along the dorsal surface of the bone. Walther ('82) in his work on Esox denies that such a condition exists, because the anlagen of the frontals apnear before there is any trace of the lateral osseous canals, and that in some forms, the osseous canals are entirely separate from the frontals throughout life, but in the majority of forms they fuse with the underlying independent frontal. The frontal of Amiurus bear out this latter statement as the anlagen appears as paired membranous sheets roofing the large fontanelles. The lateral line canal ossification arises independently of this membrane and only secondarily becomes connected with it. This independence of ossifications shows especially well in the relation of the ossification surrounding that canal extending toward the middle line of the head from the junction of the suborbital and supraorbital canals; here the canal ossification is very distinct from the underlying frontal. At this stage in Amiurus the frontals have practically the same relations to the syrrounding bones that they have in the adult cranium. 


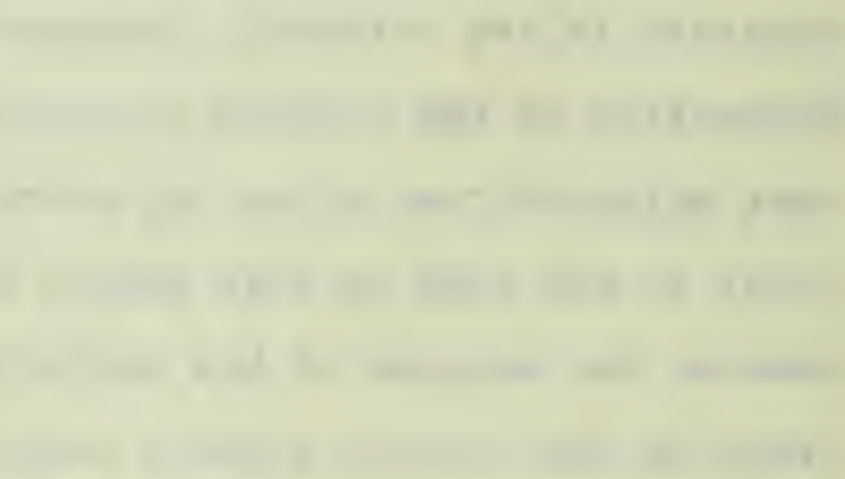

$=0$

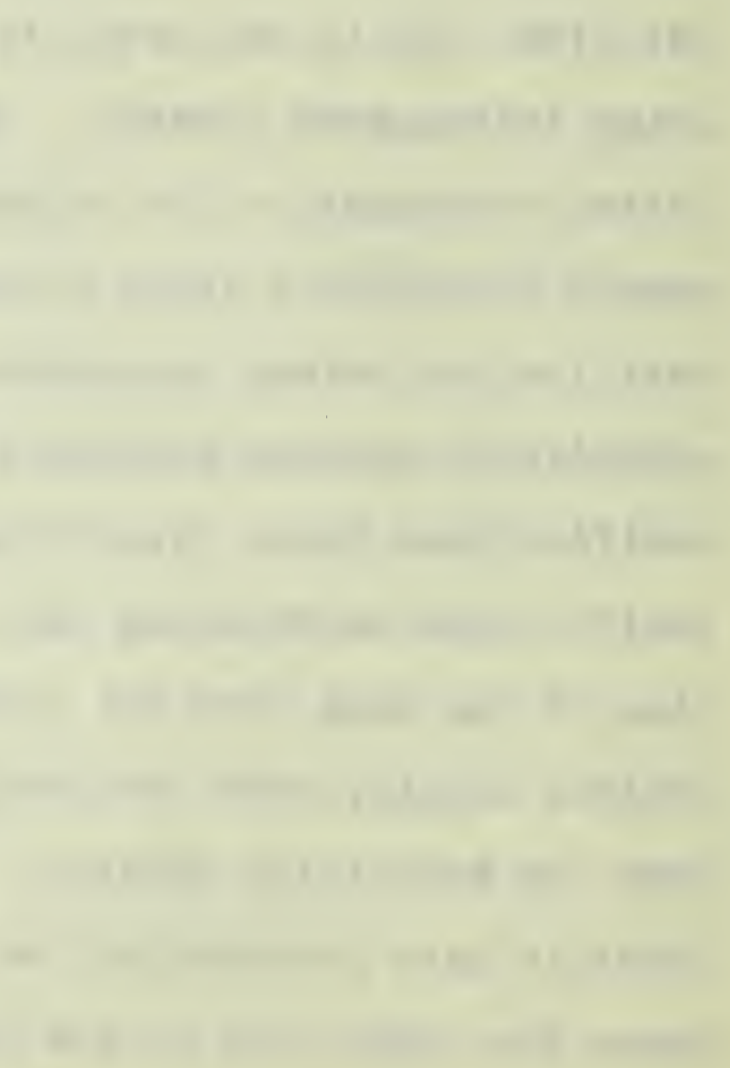


The infraorbital chain of bones whenever developed is related to the suborbital lateral line canal and in most cases the component bones of the chain are larger and flatter than in Amiurus, a condition usually correlated with the development of the eye.

The anterior ends of the trabeculae are as yet continuous with the posterior end of the ethmoid plate, although the fenestra hypophyseos is more posterior than it was in the younger stage (fig. 3). They are no longer continuous bars from the ethmoid plate to the parachordal plate, but half way between these regions a part of each has been resorbed and parasphenoid and suprasphenoi ossifications have replaced it by growth dorsally into this region forming the posterior margin of the optic foramen and part of the margin of the trigemino-facial foramen (fig. 4).

The trabeculae of the two sides are connected across the anterior end of the fenestra hypophyseos by a perichondrial ossification separated by a wide space from the more ventrally situated parasphenoid ossification (fig. 4). This ossification lies in the floor of the cranium between the optic foramina. Anterior to these foramina the trabeculae are united to the anterior ends of the alisphenoid cartilages to form the cranial wall between the orbital and optic foramina as in the $10 \mathrm{~mm}$ stage. Toward the posterior end of the optic foramina, the perichondrial connexion between the trabeculae disappears, and osseous trabeculae, the anlage of the suprasphenoid bone extend dorsally from the parasphenoid ossification which now forms the medial cavum floor (fig.32). Farther posteriorly, the suprasphenoid ossification extends above the 


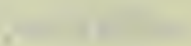
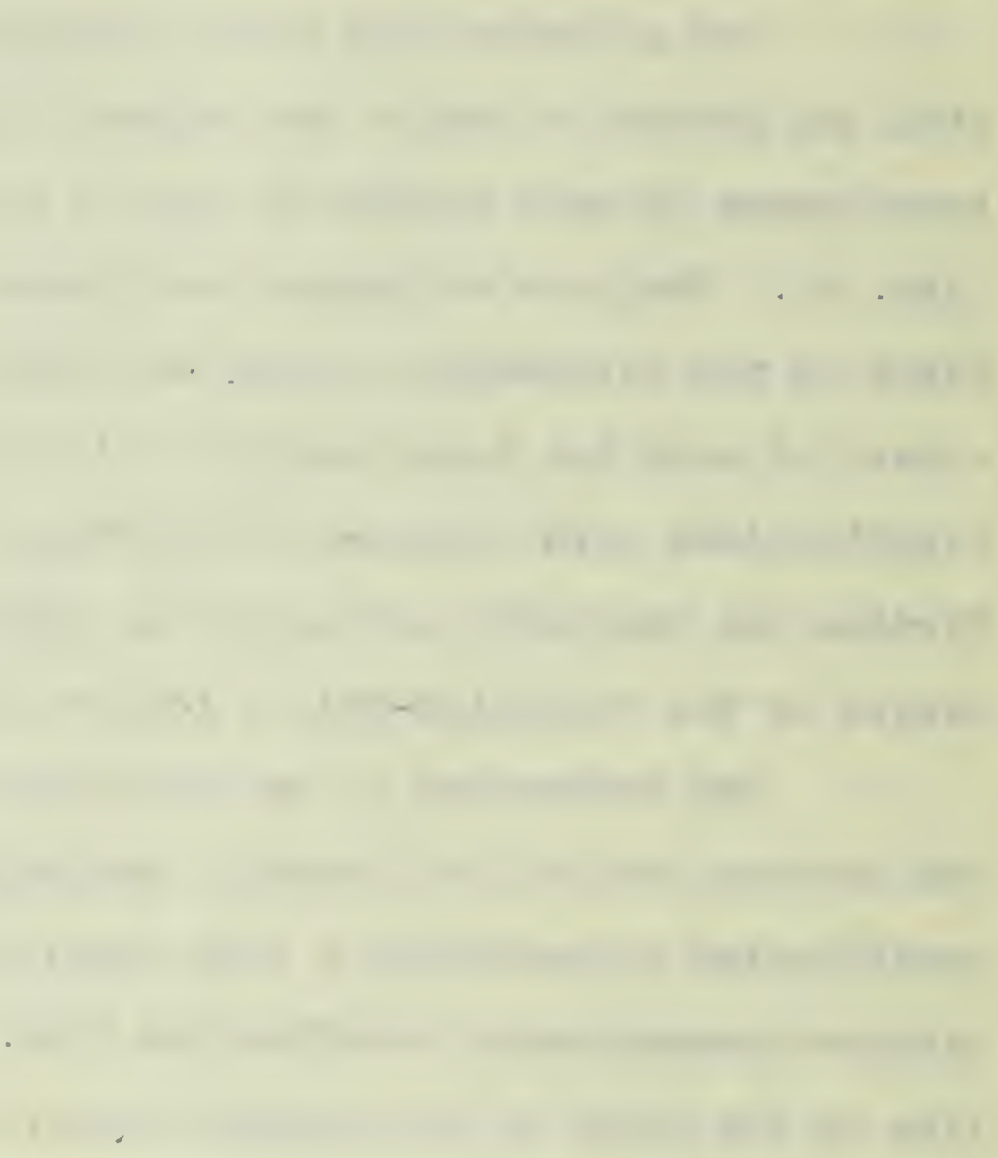
trabeculae and meet the lateral margins of the parasphenoid external to them, thus encasing the cartilage in an osseous sheath unconnected with the perichondrium. In this immediate region, just back of the preceeding part, between the optic and trigeminal nerves the cartilage of the trabecula disappears (fig. 3 ), and the suprasphenoid ossification is connected with the parasphenoid by osseous trabecula across the space formerly occupied by the cartilage. The ossification extends dorsal Iy in the cranial wall and with a ventral ossified spur from the alisphenoid cartilage (fig. 4. ) forms the wall between the optic and trigeminal nerves.

Ventral to the trigeminal nerve, the cartilage reappears within the ossification, but unconnected with it as before. This cartilage becomes larger posteriorly, until, posterior to the passage of the facialis nerve, ossification has again become limited to the median ventral surface and has only a couple of splints protruding into the cavum cranii (fig. 3 ) through the anterior fenestra basicranii.

The question now arises as to the proper designation for this part of the basal fenestra, which lies behind the hypophysis in the Salmon (Parker, '72;Gaupp, '06) it is termed the fenestra basicranii anterius, in contradistinction to a more posteriorly lying parachordal fenestra. The cartilaginous plates on either side of the cranial floor in this region of Amiurus have grovn onteriorly in concert with the otic capsules, since their lateral ends are confluent with the perichondrial ossification of the ventral side of the otic capsules (fig. 4 ). The small medial space between them is a fenestra between the anterior parachordals 


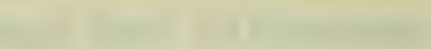

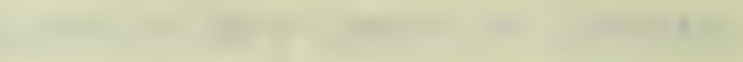

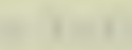

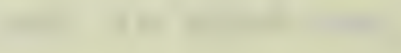

(n)

(1)

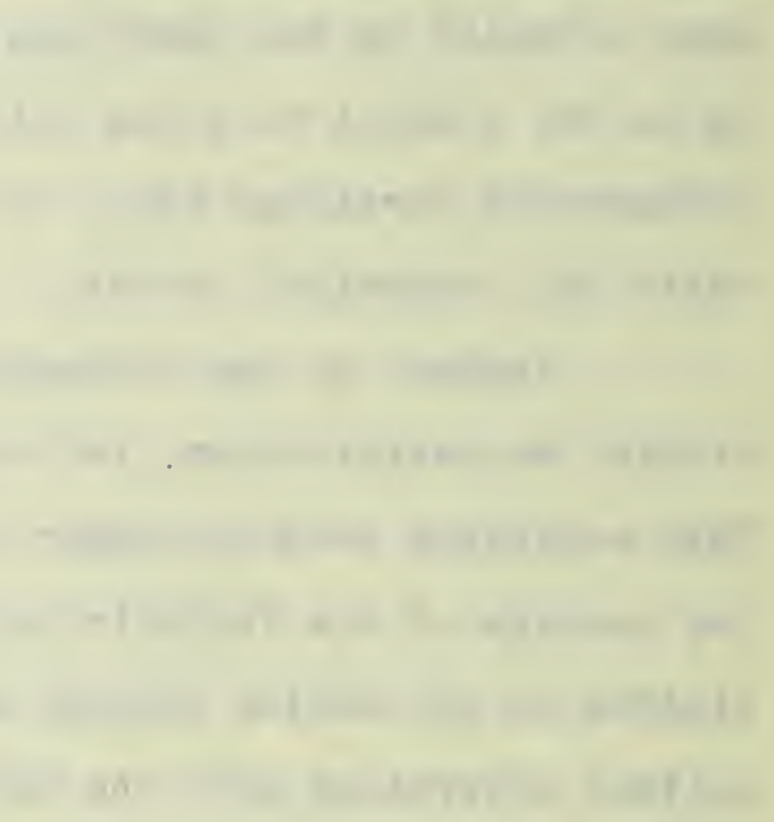

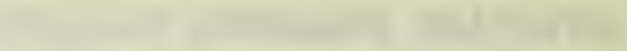

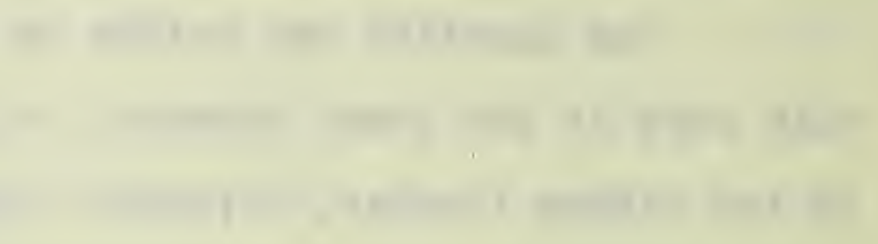

(1) 
and is therefore comparable to the corresponding fenestra in is

Salmo and mey be so designated. It evident therefore, that the connexion between trabeculae and parachordals has disappeared by resorption of cartilage. The dorsal ossification on the parasohenoid, the suprasphenoid, has taken its place.

In Gasterosteus (Swinnerton, '02) the trabecular cartilage has disoppeared in this region as in Amiurus, but the floor of the cranium is formed by the parasphenoid except in the region of the eye-muscle canal, here there is an ossification corresponding to the suprasphenoid of Amiurus. Unfortunatelythe detail of the development of this region has not been described. The modifications of the basal part of the cranium in forms having an interorbital septum, where the parts are all compressed, are not easily homologized with the depressed condition of the same region. in Amiurus, and in making comparisons, this fact always has to be borne in mind. Also the absemce of an eye-muscle canal in Amiurus makes for differences in the development of the basal parts between the orbiti.

In Salmo there is an elongate trabecula communis (Parker, 173; Winslow,'97; Gaupp, '06)) which is concave below and bears the membranous interorbital septum on its crested dorsal surface. I have found no mention of a perichondrial ossification around this trabecula communis such as is found at the anterior ends of the trabeaulae in Amiurus between the orbits, and which is the anlage of the orbitasphenoid of the adult. The parasphenoid has the typical relation to the floor of the cranium that it usually has in the Ichthyorsida.

Mclurrich ('84b) has described a basisphenoid in this 

region of the adult Amiurus, as an "indistinct ossification comoletely fused with the parasphenoid". I have remarked above, that there is an ossification on the dorsal surface of the parasphenoid between the trabeculae and have named the suprasphenoid. In the piscine nomenclature commonly used at the present tim, this is ossification is regarded as the basisphenoid, although it has been known for a long time that it is not the homologre of the basisphenoid center of ossification of man, from which the terminology is derived. In all fishes where it appears as a distinct bone, it lies anterior to the hypophysis and is developed from connective tissue nembrane. Cuvier called it the 'sphenoide anterieur', but Hallmann (' 37 ) pointed out that Cuvier's diagnosis of this bone as the homologue of the presphenoid region of man was incorrect. Conceming this bone, Hallman says:

" Ein vorderer Keilbeinkorper ware wie bei die SHugethieren und wie als der Name sagt, vor dem hintern zu suchen. Aber mit Cuvier (der die Ynochen Fig. 24 g and Fig. $25 u \cdot 26$ beide vordern Keilbeinkörper nennt) einen auf den vordern Theil des Keilbeins oder auf die litte desselben sich herabsenkenden Knochen Keilbeinkorper nennen, heisse aller Ahalaogie."

Reasoning upon this basis and continuing to regard the parasphenoid as the homologue of the basisphenoid of mammalian cranium, he named the bone under question, the 'sphenoide superior and maintained that it was found only in fishes and that it had varying developments in these.

Huxley ('64) stidied the development of the parasphenoid in Isox and concluded that it was a dermal derivative and hence not the homologue of the basisphenoid ossification center of man, a purely cartilage development posterior to and below the hypophysis. He named Hallmann's 'sphenoide superior', the 
. 
basisphenoid, but remarked that it was only comparable to the anterior part of the basisphenoid and that the rest of the bone persisted as cartilage. His reasons for regarding this bone as the homologue of the basisphenoid are, that in the foetal human skull the basisphenoid contributes nothing toward the posterior boundary of the pituitary fossa, which is formed by the long cartilaginous synchondrosis which connects the rudimantary basisphenoid with the basioccipital. Thus he regarded the bone as a rudimentary basisphenoid. Owen, following st.Hilaire, called it the entosphenal, and regarded the parasphenoid as divided into a presphenoid and basisphenoid part regardless of the work of Huxley. Allis ('97) regarded it as the homologue of the presphenoid bone of man and yet called it the basisphenoid.

The development of this bone is the keystone in making the homologies and all who have studied its development have found that it develops from connective tissue membrane anterior to the hypophysis, and hence cannot be the homologue of the basisphenoid bone of man, a cartilage bone developed from the basis cranii. The cartilage which is enclosed within the parasphenoid and this ossification in Amiurus may be the homologue of the basisphenoid which never ossifies. This is an ossification peculiar to fishes and together with the parasphenoid it becomes gradually replaced in the higher vertebrates by the ossification of the basis cranii. Since it is neither the homologue of the basisphenoid nor of the presphenoid, it must be regarded as a distinct bone and hence the name proposed a priori by Hallman ('37), the suprasphenoid, may be applied to it, although it is to be understood that his criterie for distinguishing it are 


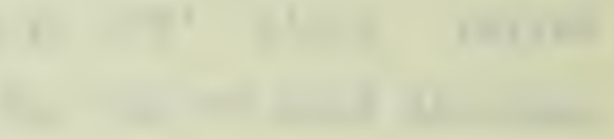

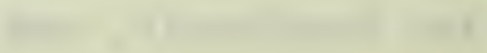

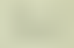

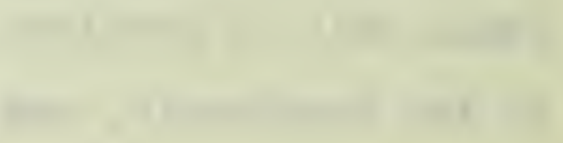

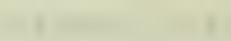

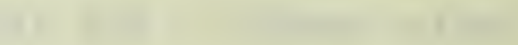

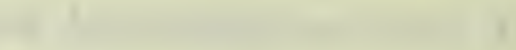


not used as the basis of the terminology, but rather its independence as a connective tissue ossification above the parasphenoid and between the ventral ends of the alisphenoids.

Schleip ('03) says that in Salmo the bone arises from a direct ossification of the membranous wall at the anterior end of the eye-muscle canal, and that it is indirectly connected to the parasphenoid and the alisphenoids by membrane which later ossifies. He recognizes it as part of the anlagen of the primordial cranium wich has no cartilage stage and says:

" Das Bindegewebe, aus dessen Ossifikation sie vorgehen, geht in Teile des Knorpelschddel aufweist, und ist daher wohl nicht zu weit gegangen, wenn man als einen Teil desselben, der nicht zur Verknorpelung kommt."

Even assuming this view to be true the morphological relations of the bone must be considered before it can be called the basi- or presphenoid.

The parasphenoid of Amiurus in its development, is like the large parasphenoid of the Urodeles which develops between the trabeculae and forms the floor of the cranium in this group. Its lateral edges form the ventral margin of the lateral wall of the orbital region as in Amiurus. It is related to the orbitosphenoid in the anterior region, just as the parasphenoid of Amiurus is related to the ossification around the anterior ends of the trabeculae. In the $10 \mathrm{~mm}$ stage of Amiurus, the place occupied by the parasphenoid of the $32 \mathrm{~mm}$ stage, is closed by a membrane which is separated from the trabeculae and already shows signs of extending above and below them. In Amia, the median floor of the cranium is continuous cartilage, a condition arising from 

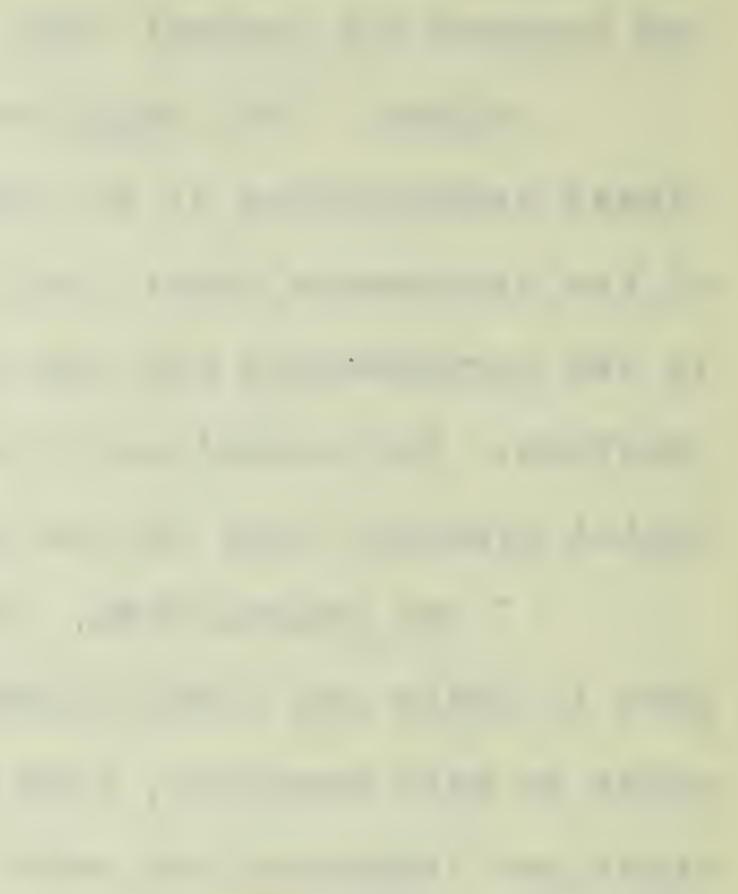

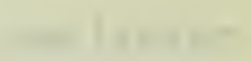
$\sqrt{2}-x^{2}$

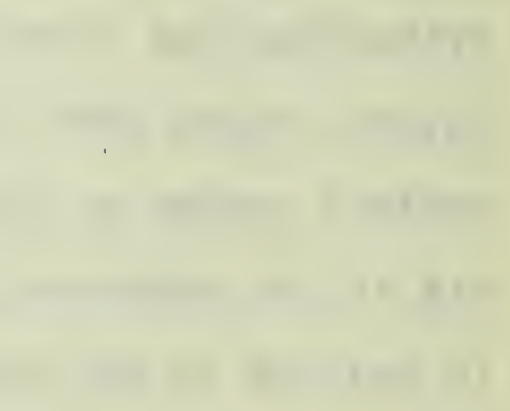

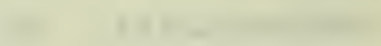

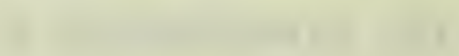

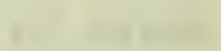

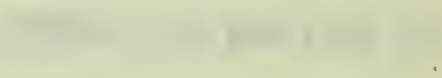


growth medially of the trabeculae and the whole hypophysial fenestra is closed except for a small fenestea just below the hypophysis which is closed by the parasphenoid. The parasphenoid here has the same superficial extent on the ventral surface that it has in Amiurus, but its growth dorsally is restricted by the cartilaginous cranial base. The orbitosphenoids of Amia, one on either side of the cranium,are situated around the anterior margin of the optic foramina, but do not have the same ventral extent as in the ossification around the anterior ends of the trabeculae of Amiurus.

The Parachordals. In the $10 \mathrm{~mm}$ larva of Amiurus, the parachordal plates posterior to the hypophysis, were rather widely separated from each other (fig. 2 ). Laterally they were continuous with the cartilage of the anterior end of the otic capsules, this cartilaginous connexion forming the posterior margin of the trigemino-facial foramen, ( fig. 2 ). In the 32 $\mathrm{mm}$ lurva this is replaced by a thin lamella of perichondrial bone (fig. 4 ). It appears as if this condition arose from the earlier one by a growth of the otic capsule and the parachordal away from each other, without a corresponding growth of the immediate connecting region.

Posterior to the hypophysis, the parachordals gradually approach each other and the fenestra between them narrows to a mere slit as compared with the wide fenestra in this region of the younger cranium. The parasphenoid ossification forms the floor of this fenestra and a couple of processes from its dorsal surface project into the cavum cranii,(fig. 4, Ps.). With fusion of the parachordals with each other farther back, the parasphenoid 


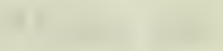

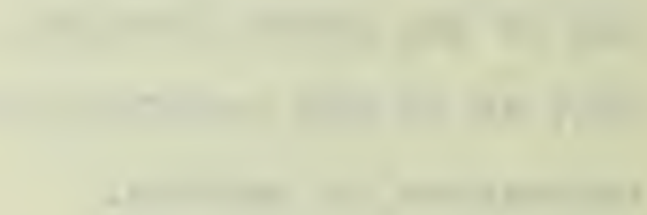

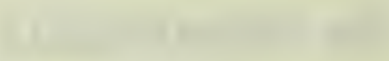

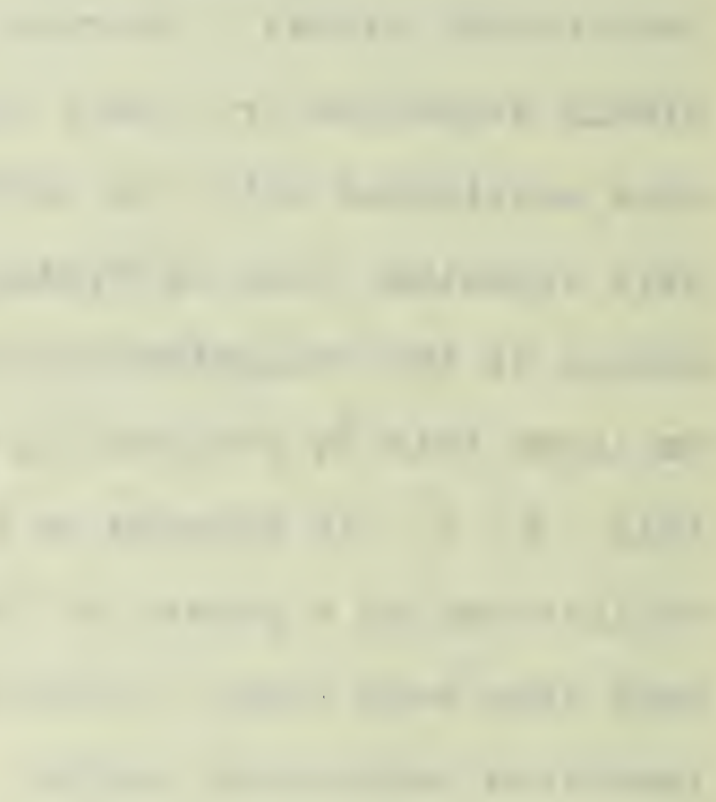

10. 
is excluded from the floor of the cavum cranii and lies ventral to the cartilage thus formed (fig. 27 ). In the layer of osteoblasts ( ) between the periosteum of the parasphenoid and the cartilage the anterior projection of the perichondrial ossification on the ventral surface of the posterior part of the basal plate, appears as a couple of spicules.

At the line where the parachordals (fig. 4 ) fuse with each other they also form a cartilaginous continum with the otic capsules, the perichondrium of which is ossified. Iaterally and above the parachordal-otic capsule fusion the cartilage of the capsular wall, which was thick in the younger stage is reduced to an osseous plate continuous with the perichondrium of the cartilage above, and below it (fig. 4 ). The edges of this thin region are abrupt and the macula utriculi abut against the wall. giving evidence that the thinness of the wall was caused by the lateral growth of the utriculus.

There is 8 small recess in the floor of the cranium on either side in the region where otic capsule and parachordal fuse. Each recess is covered with a dorsal thin lamella of bone and osseous trabeculae (fig. 27 ) extend across its lumen. Proceeding posteriorly, these recesses converge and the anterior ends of the sacculi appear within them (fig. 27 ). These recesses were not present in the younger stage, but have been caused by the anterior growth of the sacculi beyond the canal sinus imparis, and subsequent growth of the cartilage of the floor around them. The osseous roof above these recesses is apparently formed by the ossification of perichondrial strands from this cartilage, (fig.

27 ). These recess ${ }_{1}$ contain the anterior ends of the sacculi 


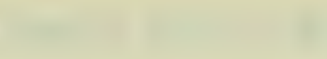


("processes of Comparetti", Wright;'84) and are said to lie within the prootic bones of the adult. For a short distance posteriorly the "processes of Comparetti" are separated from each other by a median crest of cartilage (fig. 28 ), the dorsal surface of which is grooved and filled with osseous trabeculae of perichondrial origin. The sacculi grow larger as they approach the canal sinus imparis (fig. 28 ), the median cartilage diminishes in amount and the recessi come closer together. The osseous roof of each recessus disappears in the region where the ramus sacoularis of the auditory nerve descends to innervate the macula sacculi (fig. 28 ). Just posterior to this innervation the sacculi of the two sides are connected with each other by the canal sinus imparis.

In the other teloosts whose developmental history has been followed, the ossifications which arise in this region around the anterior parachordals and the ventral ends of the otic capsules, have been described as the anlagen of the prootics. Schleip ('03) says:

" Die ersten Spuren von Verkndcherung treten bei einem Iachs von $24 \mathrm{~mm}$ Illnge auf: das Prooticum besteht hier aus einer ineren un einer alusseren, den Inorpel in der Umgebung des Facialisloches einfassenden perichondrialen Knochenlamelle; ein Zusammenhang beider an der Randern des Foramen ist aber nirgends vorhanden, vielmehr entbehrt di Wand des Facialiskanals selbst den Knochentborzug noch vollstünig (Siehe Fig.5). Die genannten Lamellen sind wie therhaupt alle perichondralen Veriknocherungen auf diesem Entwickelungsstadium homogen, scharf vom Knorpel wie rom Bindegewebe abgesetzt und haben kein anderes Reliefe, als es durch die Anlagerung an die Knorpeloberfldche bedingt ist; wenige schmal, spindelige Zellen bilden das Periost."

In the Salmon, however, the ye-muscle canal is formed by tha inwerd growth of the rectus eye muscles between the parachordalia and the cavum cranii, a membranous bridge roofing the canal so formed, and supporting the brain. The homology between the 

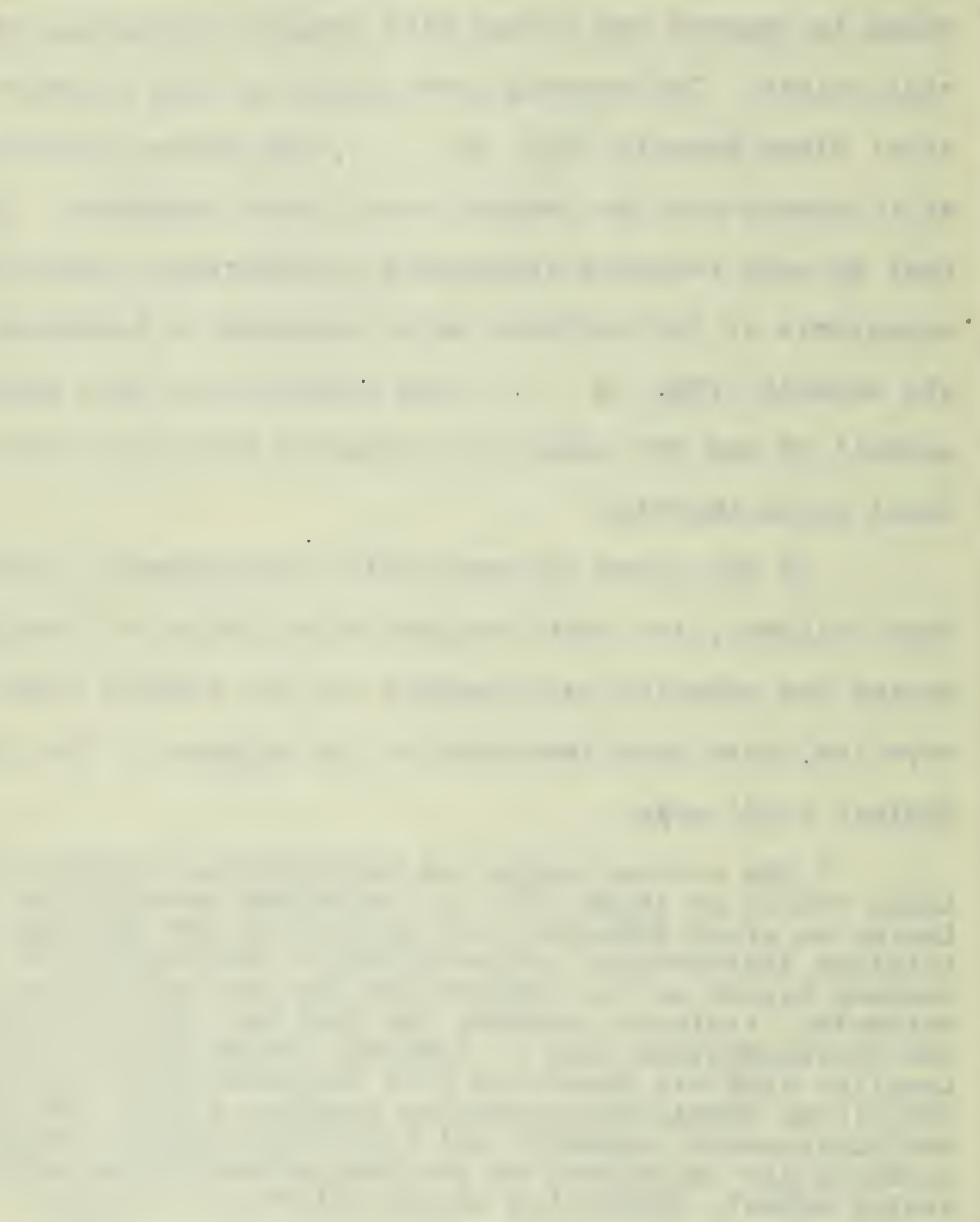

$+2$ 
Amiurus and Salmo in this region is easily seen despite tho specialization in the latter. In both, the parachordalia are continuous with the otic capsules posterior to the hypophysis and there is the narrow fenestra basicranii anterius between them, the floor of which is formed by the parasphenoid ossification. There are the same inner and outer perichondrial lamellae as described by Schleip ('03), but in Amiurus at this stage these lamellae have united. The "process of Comparetti" do not occur in Salmo, but are Iimited to the Ostariophysi. The relations of these processes to the cartilage of the floor of the carum and to the caram itself are very similar to the oye muscle relations and have arisen by an invasion of the cranial floor. The thin osseous wall of the otic capsule, describod above, is formed in the same way as in Salmo (Schleip), by the disappearanoe of the inner lamella and resorption of the underlying cartilage, so that the wall is formed by the outer lamella alone. In Amiurus, tho cartilaginous wall (fig. 4 ) lateral to the utriculotsaccular connexion ( ) is very thick and is continuous dorsally with the septum semicircularis laterale ). That part of the parachordal which contains the sacculus (fig.28) forms an angle of about 120 degrees with the otic capsule proper ( ). The glossopharyngeal nerve issues from the cranium dorso-lateral to the sacculus and between it and the utriculus (fig. 4 ). The anterior margin of its foramen is formed entirely of cartilage, (fig. 4 ). Posterior to the passage of this nerve the sacculi are again enclosed in recesses as were their anterior ends. The ossification which forms the roof extends transversely from botween tho two jugu- 
10

10.

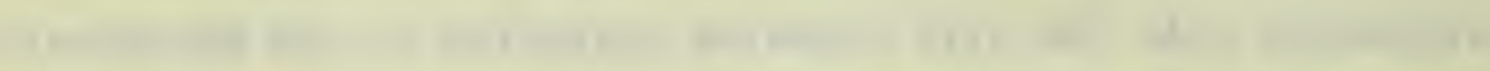
10 10

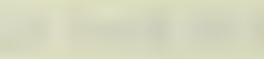
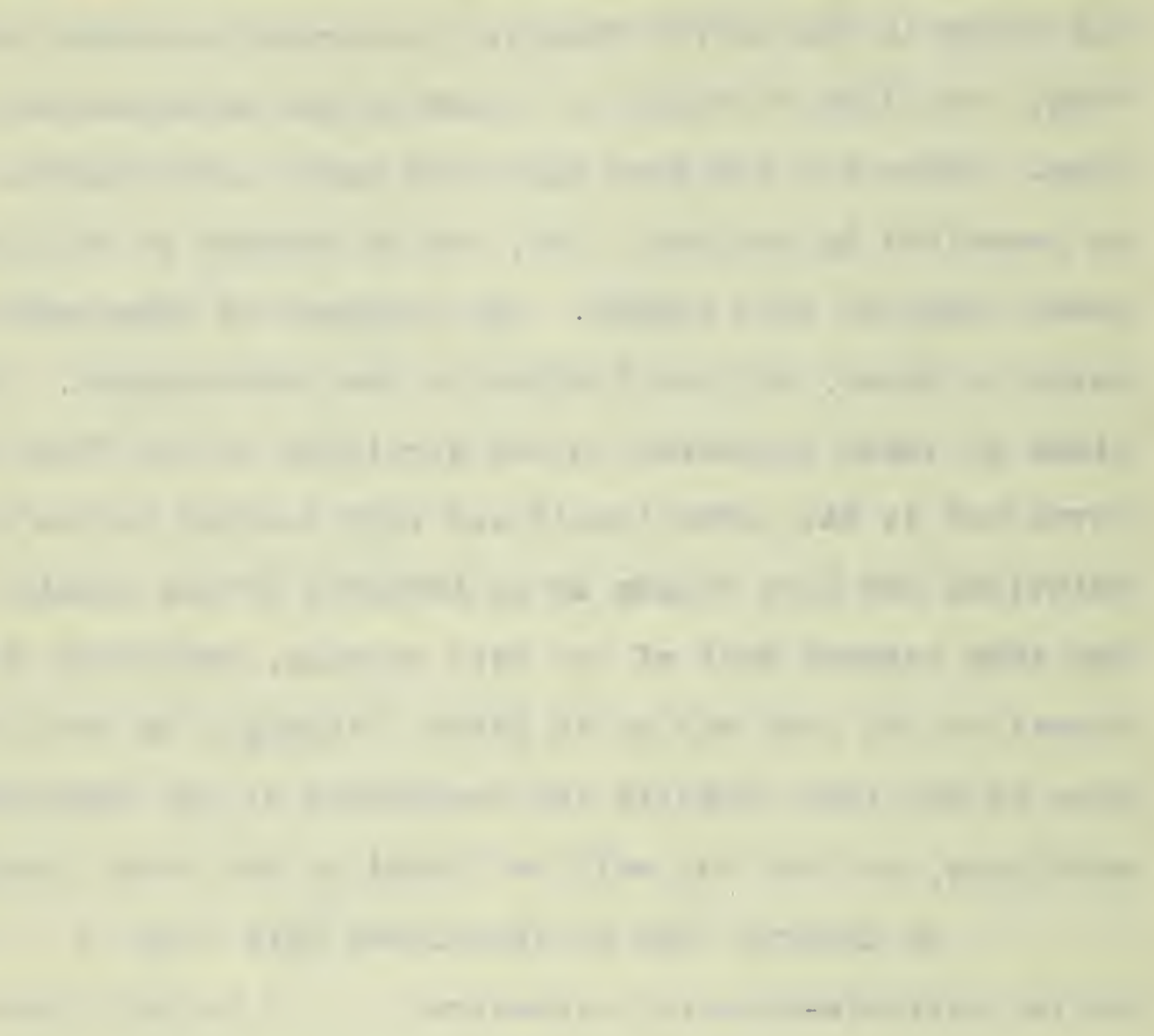

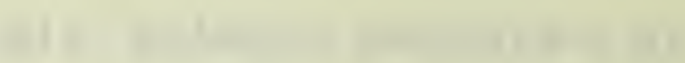

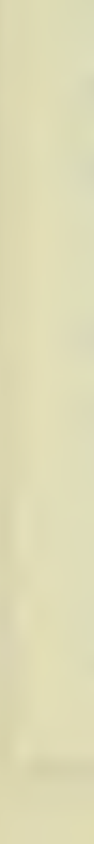


lar foramina ( $f i g .26$ ) and meet by suture medially below the brain. From the ventral surface of each of these ossifications, an ossified bar extends obliquely toward the midventral surface of the basal plate. This basal plate is triangular in crosssection and forms a cartilaginous crest between the recessus sacculorum. It is surmounted by a perichondrial ossification which has two diverging processes connected by suture to the descending processes of the roof plates of the recessus sacculorum. Thus there are formed three chambers. The two lateral contain the sacculi and the lagenae, while the medial unnaired chamber contains the sinus impar of the Weberian apparatus, and is called the cavum sinus imparis. The floor of each recessus sacculi is formed by a thin osseous lamella, as the cartilage which was originally in this region has been resorbed and the Derichondrial ossification alone remains. The ventral surface of the median basal plate is covered by a thick perichondrial ossification which extends lateral beneath the recessus sacculorum and with which the parasphenoid ossification interdigitates. In cross-section, the notochord appears as a very small circular area within the median basal plate, the tip lying fust beneath the region of the canal sinus imparis. In the younger stage it extended anterior to this connexion and in this immediate region was very large in comparison with the amount of the surrounding cartilage. The plate at that stage $(10 \mathrm{~mm}$ ) was divided into halbes (fig. 8), but now forms a continum above and below the notochordal tip (fig. 27)

The amount of cartilage around the notochord gradually 
- 100

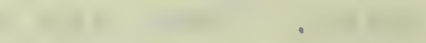

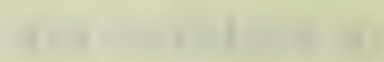

-

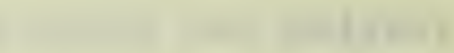

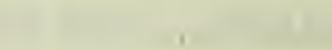

10

$\left(\frac{10}{2}\right.$

(10)

-

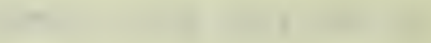

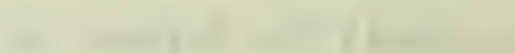

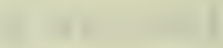

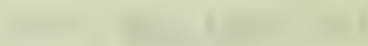

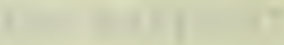

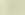


diminishes toward the posterior end of the cranium, while the diameter of the notochord increases, (fig. 26 ). The whole floor of this region has become deeper and narrower than it is anteriorly and the ossification in the floor of the recessi sacculorum has replaced the cartilage entirely (bo) ). The former cartilage between the glossopharyngeal and vagus nerves, has been resorbed and the lamella formed by the ossification of its outer perichondrium alone is left, separating the two nerves (fig. 4 ). The vagus nerve issues posterior to this lamella through a very elongate foramen ( $X$ ) between the otic capsule and the dorso-lateral edge of the recessus sacculi of that side. Posterior to this foramen the perichondrial ossification ( ) at the ventral end of the occipital arch is continuous with that on the roof and side walls of the recessus saccull. This lamella is, however, only an anterior projection of the perichonarial lamella around the anterior surface of that part of the occipital arch which joins the cartilage of the roof of the recessus more posteriorly (fig. 23 ). This cartilage is not very great in extent (fig. 2.3 ) and osseous trabeculae again appear between the saccular recesses and the posterior ventral and of the occipital arch. The hypoglossus nerve which in the younger stage, issued from the cranium through a rather large space is now enclosed within this osseous mass $(e x)$.

Solid cartilaginous masses on each side of the notochord mark the posterior ends of the recessi sacculorum just posterior to the passage of the hypoglossus, ( pch ). These cartilaginous masses extend farther posterior than in the younger stage and rise higher on the sides of the notochord (compare figs. 17.23 


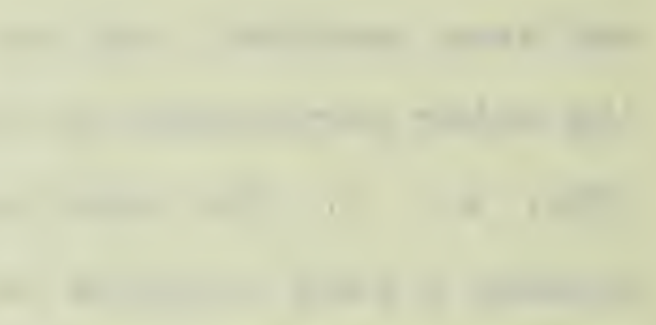


so that there is a groove between them filled with osseous tissue (fig. 37). The whole notochord is surrounded with osseous tissue and there is an hypochordal cartilage present on its ventral medial surface. This piece of cartilage was not developed in the $10 \mathrm{~mm}$ stage. Anterior to the hypochordal cartilage the anlage of the basioccipital on the ventral surface of the parachordal plate is thick and spongy, and continuous with the ossification surrounding the notochord. The transcapular processes of the shoulder girdle are fused with the perichondrial ossifications on the lateral surface of the posterior end of the parachordals. Mclurrich ('84b), from a study of young Amiurus, 20 to $38 \mathrm{~mm}$ long, concluded that there never was a preformation of cartilage in the floor of the sacculi in this region. Cartilage occurred here in the $38 \mathrm{~mm}$ stage, but he stated that it was due to the growth anteriorly of the cartilage at the very posterior end of the cranium. I have observed cartilage in this region in the $10 \mathrm{~mm}$ stage, and the ossification at the 3 ? $\mathrm{mm}$ stage which forms the floor of the recessus sacculorum is the result of the verichondrial ossification of the original cartilage, the cartilage itself having been resorbed.

The anterior processee of the scaphia, which, in the 10 $\mathrm{mm}$ larva, lie immediately dorso-lateral to the notochord (fig. I2) are now separated from it by paired cartilaginous masses (fig. 37) the posterior continuation of the posterior parachordalia. These are covered ventrally with the perichondrial anlage of the basioccipital and latero-dorsally with that of the exoccipital. Posten ior to this region the notochord is relatively much larger than it is intercranially. The endorhachis which supports the spinal 


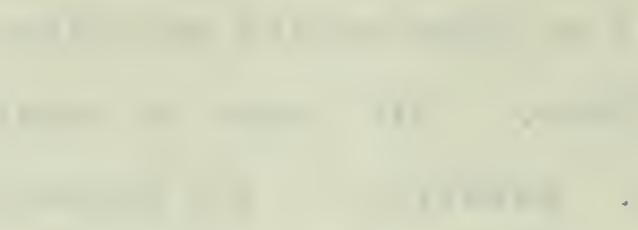


cord and divides the sinus impar into the atria sinus imparis is more compressed than in the younger stage. It widens posteriorly in the region where the anterior processes of the scaphia fuse with the scaphia proper (fig. 29), which are as yet of cartilage and articulate by rounded surfaces with the notochord. The claustra are better defined than in the younger stage; they lie between the scaphia an the anterior end of the third neural arch, forming the wall of the vertebral canal in this region. The second post-vagal nerve issues poaterior to the scaphium (fig.35). The most striking morphological feature of this region is the post erior growth of the parachordalia and the subsequent separation of the anterior processes of the scaphia from the notochord (fig.37). The enlcosure of the hypoglossus nerve within the cranium by ossification(fig. 23) is comparable with the history of the same nerve in Gasterosteous (Bwinnerton,'02) and the first two post-vagal nerves of Salmo (Harrison,'95; Willcox,'99). Schleip(03) has described the formation of the ossifications around the parachordal cartilages and the ventral parts of the otic capsules in Salmo. He describes the basioccipital ossification as arising frorn paired inner and outer lamellae on the parachordals in the region of the fenestra basicranif poaterius, into which the notochord projects. Anterior to the notochord the inner and outer lamellae meet across thia fenestra, but in the region of the notochordal tip they are separated from each other by an osseous mass around the notochordal sheath, which he calls the "ausfillende Knockenmasse". In Amiurus there is no fenestra around the anterior tip of the notochord and the 


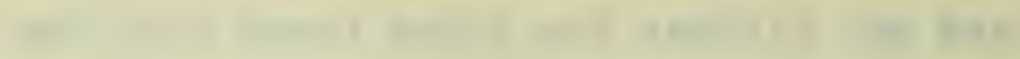

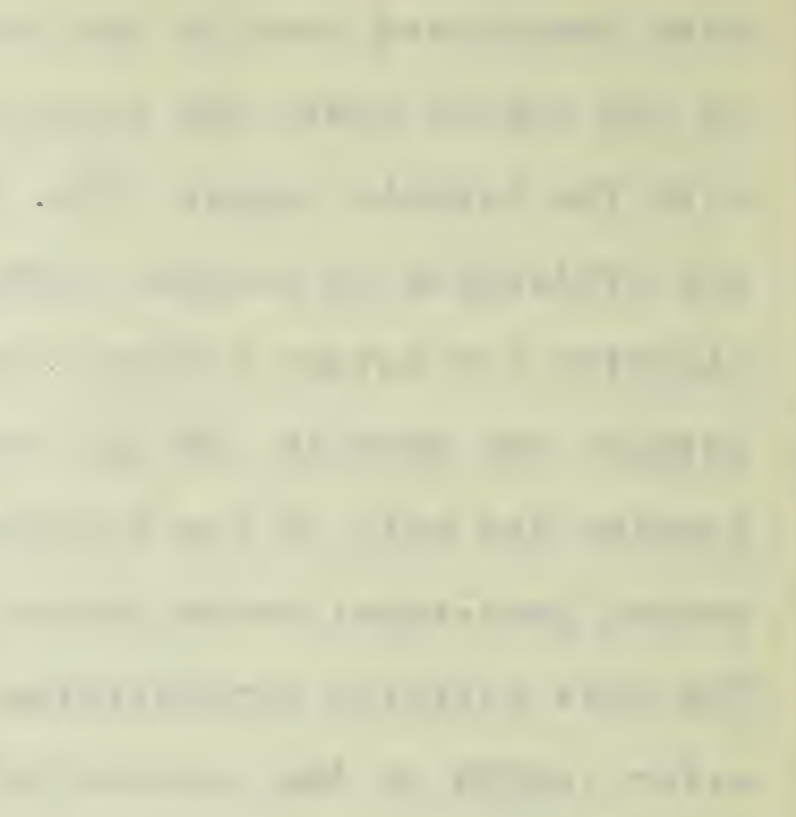

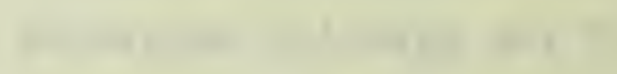

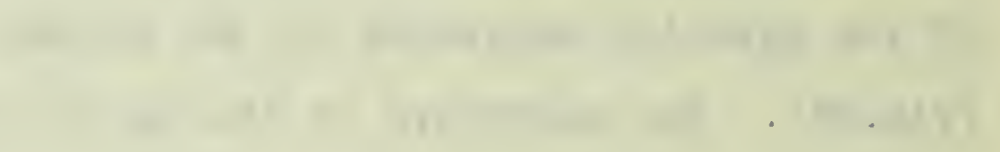


ossification on the inner perichondrium forms the walls of the cavum sinus imparis. The outer lamella is unpaired and is thicker in the midale line than on the sides, a contrast to the paired outer lamellae of Salmo. The paired rectus externus muscles are located in this region in salmo. Further posterior in Salmo, the outer lamella has a spongy appearance. comparable to the appearance of the osseous lamella in the same region of Amiurus and which Schleip says arises from the ossification of fibrous connective tissue in that immediate region in connexion with the perichondrial ossification of the basal plate. From this comparison. I have condluded that the ossifications in this region are homologous and that they are the anlagen of the basioccipital of Amiurus as of Salmo.

The osseous lamella which I have described around the glossopharyngeal and vagus foramina and the ventral ends of the posterior semicircular canal and above the recessi sacculorum and cavum sinus imparis, have been described by Schleip and Gaupp as the anlagen of the exoccipitals. In Amiurus, the part above the sinus impar is preformed in membrane and only secondarily connects with the perichondrial ossification and hence cannot be exoccipital, though fused with it. The hypoglossus in both Salmo and Amiurus was not included within the cranium at an earlier stage, but is not enveloped in an osseous sheath between parachord al plate and the occipital arch.

The Otic Capsules. The cartilage enclosingeach membranous labyrinth has grown considerably since the $10 \mathrm{~mm}$ stage, but the relations of the septa sernioiroulares (fig. 7 ) have remained the same. The detailed description of these, given for the 
younger stage, will also fit the $32 \mathrm{~mm}$ stage and the adult, except for a change in size. The parts which merit description at this $32 \mathrm{~mm}$ stage are the anlagen of the otic bones, which in the teleosts include prootic, sphenotic,pterotic,epiotic, and opisthotic. All except the latter are present in Amiurus, according to McMurrich ('84), and the problem now in hand is to locate and describe them in their earliest form. These bones were first grouped as the otica by Huxley ('64), who called attention to the fact that they were developed around the otic capsule, which, as cartilage, had an independent origin and only secondarily became connected with the parachordalia and the occipital arch. Hence these bones formed a natural group in comparison to the other bones of the cranium. Vrolik('73) objected to the grouping of these bones as otics, and, because of the relation of the occipital bones to the labyrinth, maintained that these also could be included with the otica. As Van wijhe ('82), later pointed out, this was due to a misunderstanding of the original statement of Huxley, because it is a well-known fact that the membranous labyrinth invades other bones than those which are developed around the capsule. Vrolik also claimed that the otic bones took no part in the formation of the cranial wall because he found the opisthotic to be a variable bone, sometimes developed in the cartilage of the capsule wall, again not related: to the cartilage, and sometimes entirely wanting. We have no reason to believe that at some stage in the phylogenetic history of the vertebrates there was another ossification forning the wall of the cranium in place of the otic capsules of today. Could we prove that the otic capsule superseded an osseous or cartilaginous brain case 


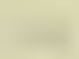

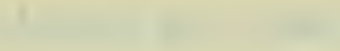

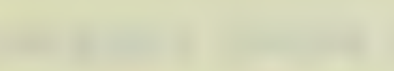
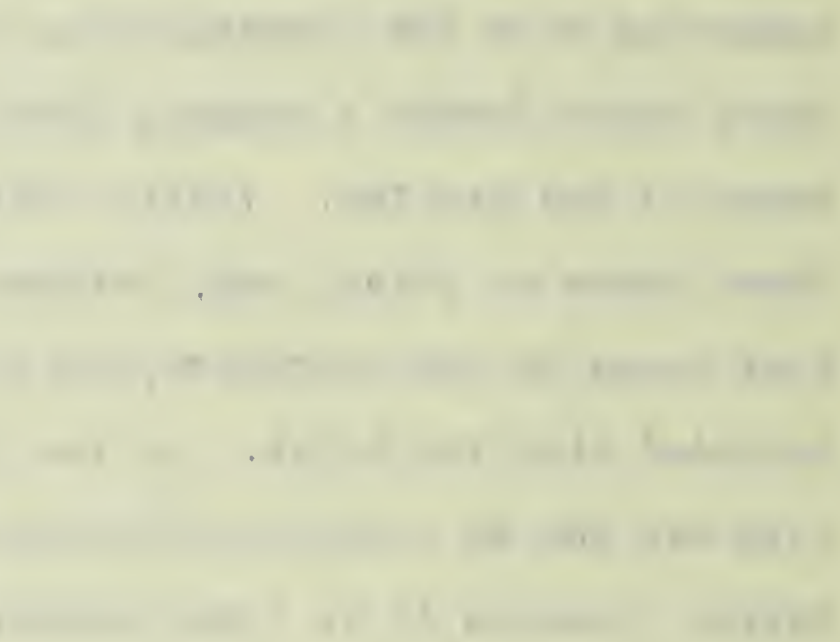
wall, only then could we say that the otic bones were not parts of the brain case.

The sphenotic is the most anterior dorsal of the otic bones and according to authors who have studied its development in the teleosts, it appears as an ossification around the dorsal anterior end of the cartilage of the anterior semicircular canal recess, and of a part of the posterior end of the alisphenoid cartilage. In the $30 \mathrm{~mm}$ Salmo, (Schleip;'03), the first sign of this ossification is an osseous lamella in the perichondrium of the postorbital process, and forms a ledge of bone which projects laterally above the hyomanoibular articular surface and extends posteriorly along the roof of the anterior semicircular canal. The levator operculi muscle is attached to its outer surface. It spreads dorsally on the surface of the cartilage as far posteriorIy as the pterotic ossification which is developed on the roof of the lateral semicircular canal, and ventrally as far as the hyomandibula. At a later stage another perichondrial lamella is formed on the inner surface of the roof of the anterior semicircular canal. The fornation of the adult bone takes place by the resorption of the cartilage between these two layers and by endochondrial ossification. Schleip makes no mention of the development of a latero-semsory canal ossification in connexion with the outer lamella. A fine nerve issues through the cartilage and bone in this region to innervate the sense organ of the laterosemsory canal contained in the pterotic ossification.

In the development of the sphenotic of Gasterosteus (Swinnerton;'02), the inner lamella and the cartilage disappear so that the wall is formed by the outer lamella alone. 


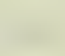

(1)
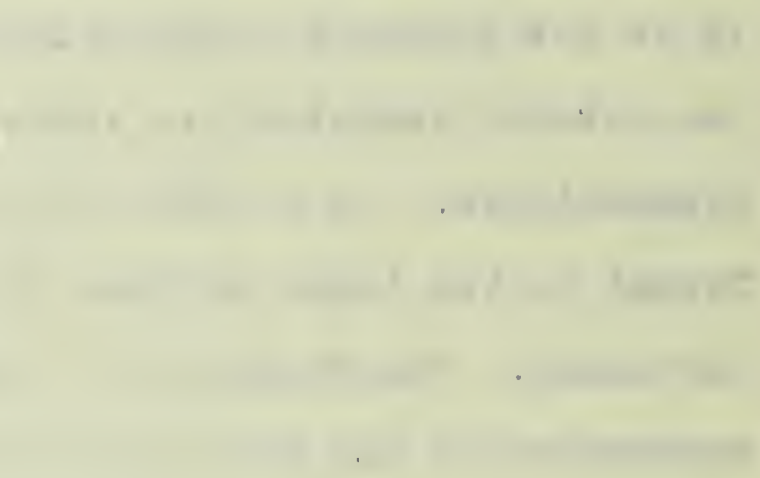

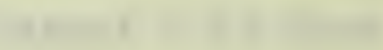

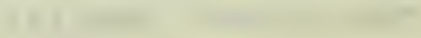

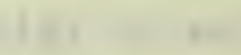

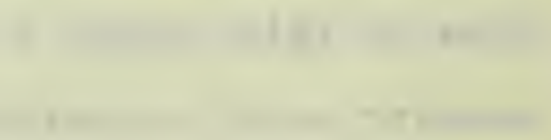


In the $32 \mathrm{~mm}$ larva of Amiurus, ossification is far along, but I didinot find any ossifications in this region of the $20 \mathrm{~mm}$ larve. The ossification enclosing the supraorbital lateral line canal is intimately connected with the perichondrial ossification on the outer surface of the cartilage forming the roof of the recess for the anterior semicircular cangl (fig. 19). Just anterior to the cavum of the anterior semicircular canal, the ramus oticus of the ifacial nerve ( the fine nerve of Salmo, Schleip, '03) issues through the cartilage (fig. 3) and divides into anterior and posterior branches; the posterior continues within the lateral osseous canal to innervate the next sense organ of the canal system. The perichondrial ossification and that of the lateral line canal cannot be distinguished from each other. Although there was no ossification in the $20 \mathrm{~mm}$ stage in this region, the anlage of the lateral line ossification was renresented by a heavy tract of osteoblasts surrounding the membranous canal. With subsequent ossification the bone thus formed fused immediately with the underlying perichondrial ossification of the alisphenoid cartilage and the otic capsule. The cavum of the anterior dorsal end of the skeletal anterior semicircular canal is filled with osseous trabeculae extending between the osseous lamellae in the perichondrium of its walls (fig. 36). The outer lamella extends down on the side wall of the capsule as far as the hyomandibular articulation, but does not enter into the formation of the articular surface, which is as yet of cartilage. The adductor hyomandibularis muscle and the lesator operculi are attached to the outer lamella, the former having broader 


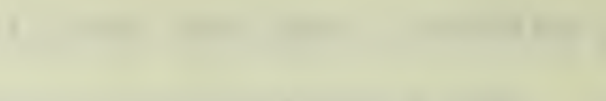
-

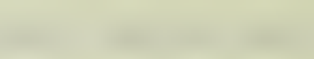


surface of attachment.

A part of the cartilage in the roof of the anterior semicircular canal recess has been resorbed together with the outer perichonarial lamella, so that the inner lamella forms the wall between the cavum of the recess and the Iumen of the lateral Iine osseous canal (fig. 19). This is just the reverse of the process that Schleip observed in Salmo, where the inner perichondrial lamella disanpeared first. Toward the posterior end of the hyomandibular articular strface, the outer perichondrial lamella disappears and the lateral line ossification alone remains; it is separated from the underlying cartilage by fibrous connective tissue. This is the posterior end of the sphenotic, and when the perichondrial lamella apears again it is on the dorsal surface of the lateral semicircular canal region of the otic capsule and is the anlage of the pterotic ossification.

In the $60 \mathrm{~mm}$ stage, cartilage resorption in the roof of the anterior semicircular canal recess has gone istill farther, and the outer and inner lamellae are indistinguishably fused with each other (fig. 33), and endochondrial ossification has occurred, so that the place originally occupied by cartilage is now filled with osseous trabeculae. The cartilage near the posterior end of the roof of the recess still persists, and a thicker and spongier osseous mass projects laterally above the hyomandibular facet.. Behind this, as in the $32 \mathrm{~mm}$ stage, the lateral line ossification of the surface of the sphenotic passes on to the surface of the squamosal part of the succeeding ossification. The ossification surrounding the lateral wall of the 

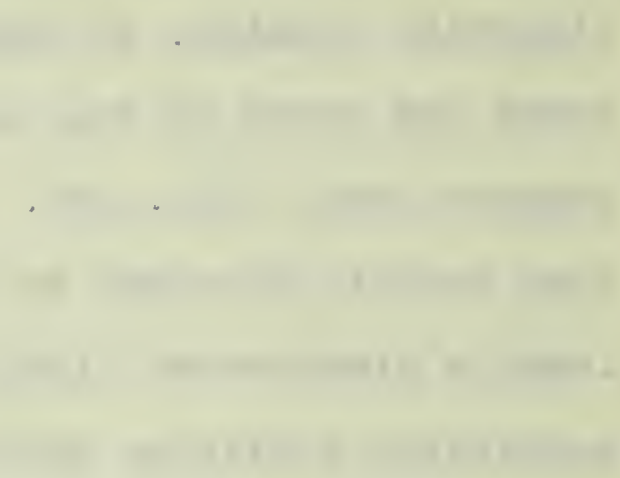
recess for the lateral semicircular canal, is the squamosal of most authors and the pterotic of Parker (173). As part of the bone is preformed in cartilage and part of it of membranous origin a combination of these two names is preferable as it implies relationships which neither term ased alone would signify. Hence I propose the name squamoso-pterotic for this mixed ossification. Allis ('99) made a detalled study of the descriptions of this bone in differcnt groups of fishes by the invstigators before him. He says in summarizing his review:

"We thus see that the squamosal of fishes is composed of a canal component and a deeper lying component which may be either a so-called membrane bone, or such a bone fused with a so-called primary ossification. The primary ossification may be wholly wanting, and perhaps the canal component also. Furthermore the canal component may be found entirely separated from the under lying bone, may be found fused simply with an underlying membrane component, or may be fused with such a component and with a socalled primary ossification, which latter ossification, alone is traversed by the semicircular canal. The canal component, apparently always united with the underlying membrane bone, may as a so-called dermal bone, be found fused with other, adjoining dermal bones; while the primarylosaification may befused with other adjoining primary ossifications (Ctenodus), or with such ossifications and the intercalar (Polypterus). It is the primary part of the bone, and not its 'Deckenknochenanteil' that gives articulation to the hyomandibular.

He does not throughout the discussion give any reason for calling this bone the squamosal. The term squamosal signifies a homolgy with the squamosal of the Tetrapoda which only a part of this compound bone of the fishes has. According to the researches of Thyng ('05), on the squamosal bone of the Tetrapoda, some of the criteria for the establishment of its identity throughout the series were as follows:

" The term squamosal, including its various forms, was first applied to an element in the human skull which later fuses with others to formsthe temporal bone. Hence in applying the term to the lower groups the laws of nomenclature demand that it be given to that element which is the homologue of the squamosal 


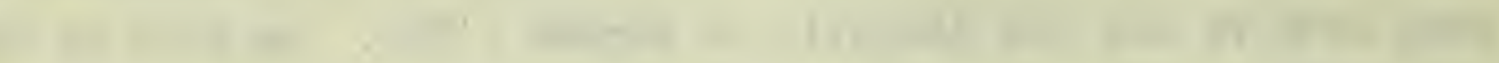
4

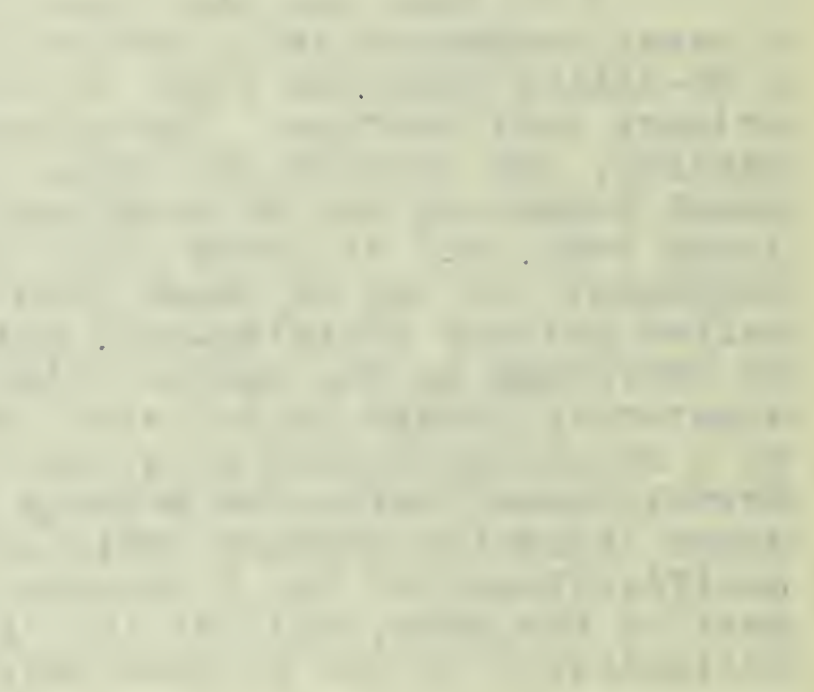


in man. It is also evident that all possible criteria should be utilized in settling these homologies, not alone those of adult relationships and articulations, but those of development as well.

The development of the mammalian squamosal shows it to be a membrane bone which overlies the otic capsule and is at first intimately connected with the incus (quadrate) by a dense and fibrous stroma. Hence it must be concluded that close association with the quadrate (incus) and the otic capsule is the primitive relation of the squamosal, and therefore, the most important criterion in ascertaining its homology in the non-mammalian vertebrates."

Comparing the above, with the statemwnts of.Allis, it is clear that the only bone in the fishes which may be compared to the mammalian squamosal is that dermal ossification which overlies the otic capsule above the lateral semicircular canal. The question of connexion with the underlying primary ossification is secondary, as is also that of the quadrate, for in the fishes the quadrate is separated from the cranium by the hyomandibular. The true squamosal would therfore, be the dermal ossification, dezcribed by Allis as lying above the cartilage of the wall of the lateral semicircular canal; it has nothing to do with the articulation of the hjomandibular and is in the fishes connected with the lateralline osseous canal. The primary ossification underlying it is the pterotic ossification of Parker ('73) and is just as much a center of ossification of the otic capsule as are the other periotic ossification centers of the mammalian petrosal portion of the temporal bone, although no center has been found corresponding in position to the pterotic center of the otic capsule of the fishes.

Schleip ('03) gives a detailed description of the ossifications in the region of the lateral semicircular canal wall in Salmo and follows Gaupp in his nomenclature, naming parts derived from membrane and the lateral Iine ossification, the dermosquamosal 

parts, and those derived from perichondrial ossification the autosquamosal parts. His figures are clear and very easy to understand. The outer perichondrial lamella, for there are two, one on the outer perichondrium of the wall and one on the inner, is strongest where it is unprotected by the dermosauamosal. In the younger stages the dermosquamosal was separate from the autosquamosal, but gradually the parts become intimately fused. He cannot say which of the two ossifications appeared first. Toward the posterior end of the roof of the lateral semicircular canal, the muscle fibres at the insertion of the levator operculi ossify and fuse with the perichondrial lamella. The articular surface for the hyomandibular ossifies later.

In the $32 \mathrm{~mm}$ Amiurus, the two elements described by schleip for Salmo, are present above the lateral semicircular canal. The dermal ossification contains the lateral line canal ossification and is partly fused with the perichondrial lamella (fig. 31 ). Toward the middle line of the cranium the inner end of the dermal ossification is separated from the cartilage of the otic capsule by fibrous connective tissue and connects by suture with another dermal ossification which forms the margin of the median posterior fontanelle (fig. 3). By fusion with the otic perichondrial ossification (fig. 31), the dermal ossification loses its identity) as a descrete ossification, as does the squamosal element of man when it fuses with the underlying periotic ossifications. Despite the fact that it is not related to an auditory ossicle, I think that this dermal ossification overlying the roof of the lateral semicircular canal of Amiurus is the homologue of the mammalian squamosal. This homology however, 

does not apply to any other part of the comoound bone. The perichondrial ossifications are formed around a center of ossification peculiar to fishes and called by Parker ('73), the pterotic ossification. As in Salmo, the fibres at the dorsal end of the levator operculi muscle have ossified and form a crest connected to the outer perichondrial lamella and extending posteriorly above the hyomandibular. At the posterior end of the roof of the lateral semicircular canal, the ventral arm of the post-temporal ossification projects in beneath this crest (fig. 3). The dorsal arm of the same ossification lies behind the crest of the epiotic ossification, above the perichondrial ossifiaation on the outer surface of the roof of the posterior semicircular canal.

Posterior to the hyomandibular articular surface on the dorso-lateral face of the lateral semicircular canal wall, the opercular-mandibular lateral line canal ends at this stage. The lateral Iine canal in the squamosal sends down a tubule which opens immediately above the aorsal end of the opercular-mandibular canal and eventually unites ith it as in the adult (fig.ll). The canal passes from the squamosal into the post-temporal, but before entering the latter the osseous canal enclosing the sensory canal is independent (fig. 3). There is also a short interval between the end of this canal ossification and the post-temporal, where the cancl lies unenclosed in connective tissue.

In certain regions of the roof of the lateral semicircular canal, the cartilage has been resorbed as the foramina left in the chondrocranial roof show (fig. 3), and the dermal ossification together with the lateral line ossification forms the 

protecting roof. The cavum of the inner ear and that of the lateral osseous canal are separated by the perichondrial ossification of the inner surface of the resorbed wall (fig. 31). In the $60 \mathrm{~mm}$ stage, endochondrial ossification has appeared in some regions between inner and outer lamellae, so that the space formerly occupied by cartilage is now filled with osseous trabeculae, just as in the more anterior sphenotic region (fig. 33). Toward the posterior end of the roof of the lateral semicircular canal, the perichondrial lamellae, both inner and outer are prsent in the $32 \mathrm{~mm}$ stage (fig. 31 ).

The ossification of this region of Amiurus agrees with the descriptions of Schieip. Gaupp. Allis and others for the teleosts, but the name squamosal employed by them should not alone be used in naming this compound bone. A squamosal element is prsent, but the name cannot be applied to the whole bone, as it consists of a pteroticossification with a squamosal element added (fig. 31), it is more like, but not completely in agreement with the mammalian temporal.

The epiotic ossification (figs. 3,38), or the ossification around the dorso-posterior wall of the posterior semicircular canal, has been described by various authors as a perichondrial ossification. In the teleosts it is connected to the post-tempporal ossification of the shoulder girdle by a ligament which ossifies in connexion with the outer perichondrial lamella. In places the cartilage is resorbed and the lamellae form the wall, It is homologous with one of the centers of ossification of the periotic cartilage of man.

This ossification is well developed in the $32 \mathrm{~mm}$ Amiurus. 

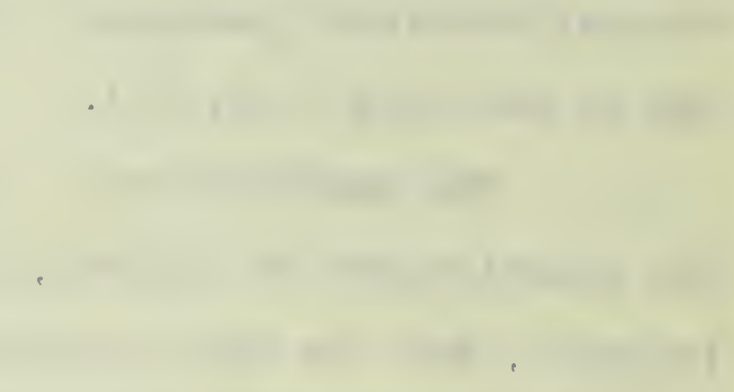

\section{.}


Inner and outer osseous lamellae appear in the perichondrium of the dorso-lateral and posterior walls of the posterior semicircular canal. The ligament which connects the outer lamella to the post-temporal is just beginning to ossify (fig. 38). The posterior dorsal part of the cavum for the posterior semicircular canol is filled with osseous trabeculae continuous with the inner lamella. Ther is no rescrption of cartilage at this stage. At the $60 \mathrm{~mm}$ stage, the perichondrial lamellae are much thicker and cover more surface. The outer lamella has extended ventrally on the wall of the semicircular canal so that it meets the ascending exoccipital ossification. Near the anterior end of the posterior semicircular cenal roof, the cartilage has diseppeared and the outer lamella alone forms the wall.

The occipital region. This part of the cranium has grown considerably since the condition described for the $10 \mathrm{~mm}$ larva. The cartilage forming the posterior margin of the posterior fontanelle has grown forward and together with the medial edges of the otic capsules forms the synotic tectum (fig. 3). There are ossifications on both the inner and outer perichondria of this tectum, which have been described in other teleosts os the anlage of the supraocipital bone. The morphology of this bone will be discussed under the adult description. Sagemehl ('9l) claims that the supraoccipital of the adult is a new formation in the teleosts and is not found in the ganoids nor in the dipnoi, and that it is the result of a fusion of one or more vertebra with the protometameric cranium. 


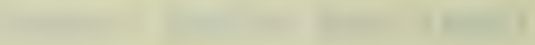
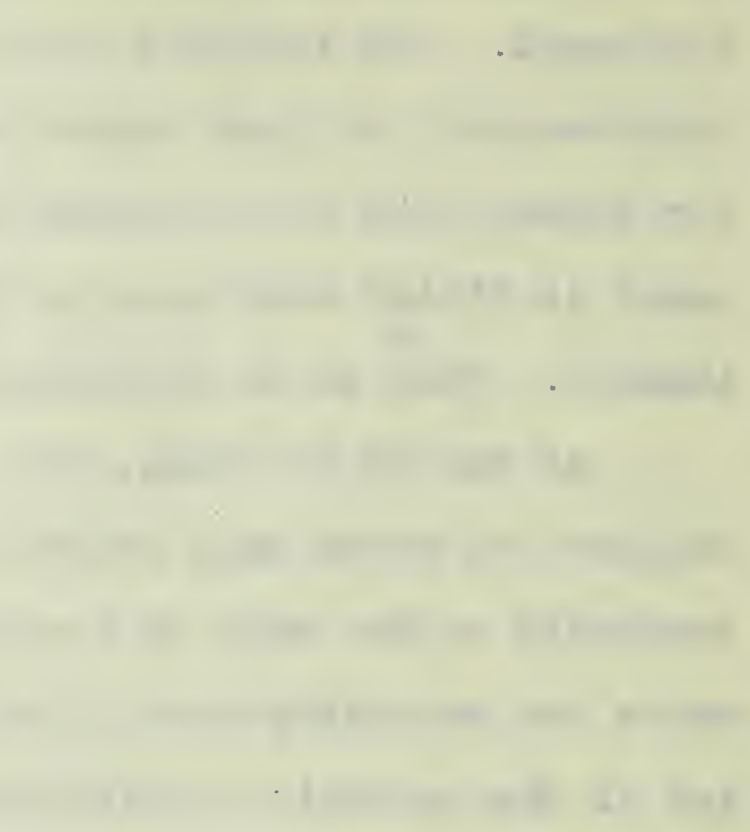

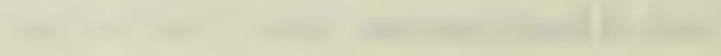

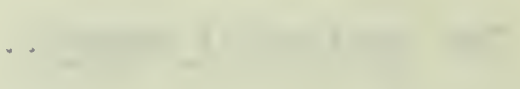

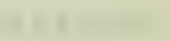

$+1$

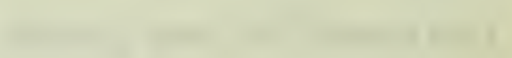

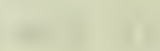

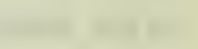

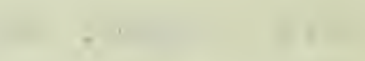

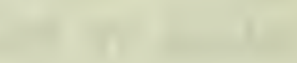

(2)

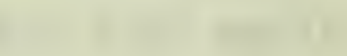

1

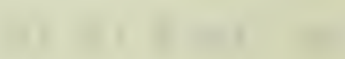

+1 ren 
In Salmo (Schleip), paired parietalia are present and

form descrete bones in the adilt. In the larva they develop as dermal sheets dorsal to the otic capsules, fused anteriorly to the frontals, laterally to the squamosal element of the squamoso-pterotic, and medianly to the anterior ends of the supraoccipital. They are separated fron the cartilage of the otic capsule by fibrous connective tissue.

In Amiurus there are a pair of such dermal ossifications in the same region and having the same histological relations. These ossifications are fused medianly with the perichondrial ossification on the margin of the posterior fontanelle (fig.34). Despite this fusion with the perichondrial ossification, these dermal ossifications are comparable to the anlagen of the parietalia in the developing Salmo. The adult cranium shows that these ossifications do not persist as descrete bones as they do in Salmo and other teloosts. Laterally they are connected with the sauamosal by a thin stroma of fibrous connective cells (fig. 31

) and anteriorly are continuous with the frontalia (fig 3 They have no lateral line relationships.

The details of the developing supraoccipital ossification have been deseribed by Schleip for the Salmon. The main part of this ossification, according to this author, develops as inner and outer lamellae in the perichondriam of the synotic tectum. The median dorsal fibrous septum between the dorso-lateral muscles of the two sides of the body ossifies as a vertical osseous plate above the outer lamella and connected with it. It supports at its dorsal end a horizontal osseous sheet developed from the fibrous connective tissue between the muscles and the 


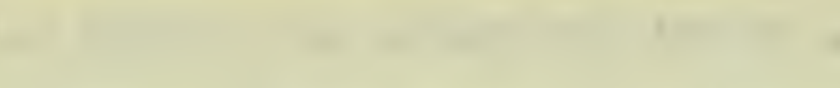

(1)

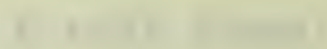

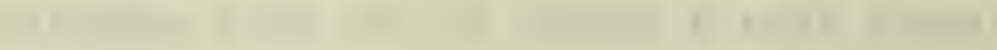

,
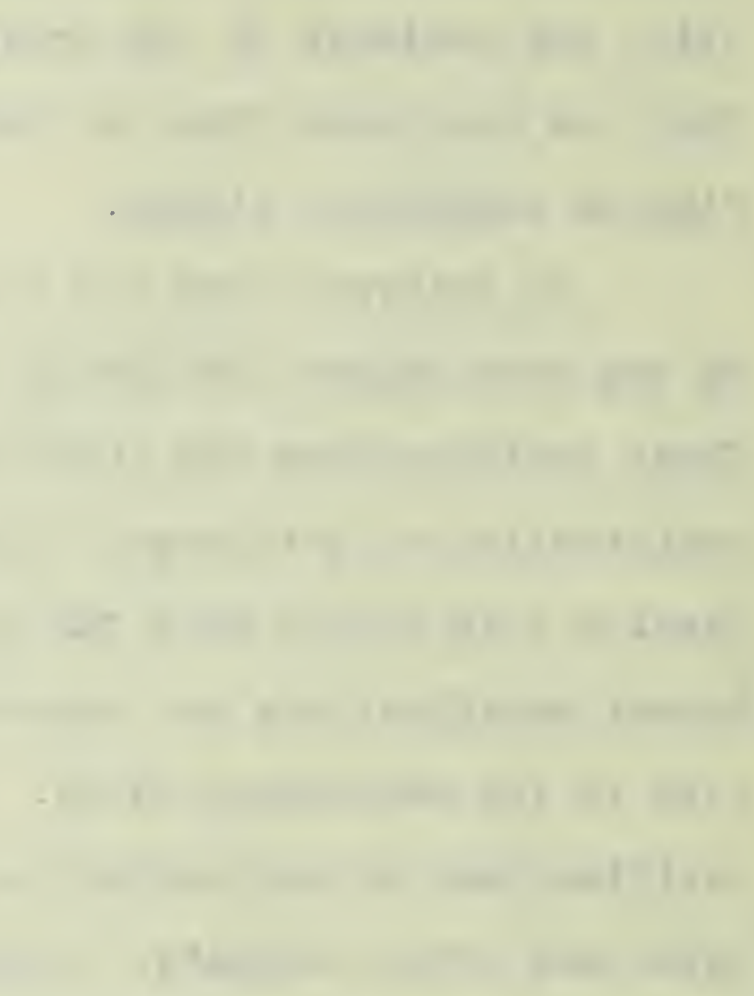

(1)

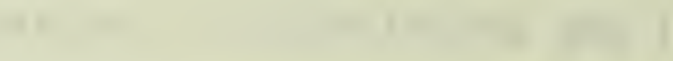

.

가

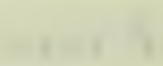

$x^{2}$ 
corium. He calls it the spina occipitis. Both inner and outer osseous lamellae extend forward on the margins of the fontanelle anterior to the synotic tectum and are connected with each other by a transverse fibrous sheet which later ossifies and forms the roof of the cranium in this region. Schleip maintains that this fibrous sheet was originally part of the chondrocranium whose ontogenetical history has become shortened.

In Amiurus at the $32 \mathrm{~mm}$ stage, the synotic tectum, as remarked above, is well developed. Inner and outer osseous lamellae are present in its perichondrium (fig. 34). The ramus lateralis accessorius facialis and the jugular vein of each side are enclosed in a canal formed by this perichondrial ossification along the posterior margin of the fontanelle. This canal has its anterior end at that point, where the nerve and vein extend dorsally from the brain, medial to tha anterior end of the posterior semicircular canal. In the $10 \mathrm{~mm}$ larva, this nerve and vein lie dorsal to the cartilage of the roof of the posterior semicircular canal. Since that stage, the cartilage below the nerve and vein has been resorbed and the perichondrial osseous lamella forms the floor of the canal in which they lie in the $32 \mathrm{~mm}$ stage. The outer perichondrial ossification together with the parietal ossification forms the roof of the canal, while the cartilage of the synotic tecturn forms its lateral walls.

Near the anterior end of the otic capsules, the perichondrial lamellae on the margins of the fontanelle interdigitate with the frontalia (fig. 3). There is no lateral line ossification anywhere near the vicinity of the developing sunraocipital. 

The spina occipitis element of the supraoccipital is developed from the ossification of the fibrous sheet between the dorsal anterior muscle segments and the connective tissue on the dorsal surface of these (fig. 29), as in Salmo. Near the anterior end of the spina occipitis the dorsal dermal sheet is very broad and extends laterally above the anterior ends of the body muscles (fig. 3). The connexion of this sheet with the outer perichondrial lamella is effected by numerous osseous trabeculae. The interval between the dermal sheet and the perichondrial ossification gradually becomes greater more posteriorly and the trabeculae become limited to the apex of the occipital arch, which is pointed in this region (fig. 29).

The dorso-lateral sides of the occipital arch are embraced by a pair of osseous plates, posterior to the otic capsules and separated from the cartilage of the arch by fibrous connective tissue (fig. 29). These plates enclose the neural arch of the third vertebra which ensheathes the posterior end of the occipital arch and are fused with the perichondrium of the former farther posteriorly. These may be the representatives of an ossification comparable to the proatlas of the reptiles.

The maxillary region. The premaxillary ossification lies in the same place as in the younger stage and differs only in its extent and in the greater number of teeth attached to the ventral surface (fig. 4). The maxillary ossification is larger and as before, forms a case for the proximal end of the maxillary barbel cartilage. It is attached to the lateral surface of the palatine cartilage, (fig. 4).

landibular and suspensorial apparatus. The palatine 

cartilage has persisted to a great extent, but there are regions anterior to its articulation with the ectethmoid where the perichondrium has ossified and small osseous processes of bone project from its periphery (fig. 22). The anterior end of the cartilage is large and spherical, tapering posteriorly as in the younger stage (fig. 4), and it is flattest at the place of contact with the ectethmoid process. A small knob of cartilage projects posteriorly from its anterior dorsal surface, to serve as a support for the anlage of the lacrimal (fig. 3 ). Posterior to the articular surface the palatine is held in position by a pair of muscles which extend from the ethmoid cartilage and are fastened to its ventral and dorsal surfaces respectively (fig.39). Schleip ('03) says that the palatine of the salmon and trout is a mixed bone and that it has both perichondrial and dermal elements entering into its composition. In the ganoids (Nan Wighe, '82) there is a dermopalatine below the perichondrial autopalatine which in spatulario is attached to the maxillary and in Polyoterus to the ectopterygoid. Such a bone or ossification is wanting in Amiurus.

The pterygoduadrate cartilage is larger than in the younger stage and the pterygoid part forms the midale of an osseous sheet, which extends ventrally beneath the cranium and posteriorly below medial to Meckel's cartilage (fig. 5). This is the anlage of the metapterygoid bone of the adult. The quadrate is ossified along its ventral margin and is continuous dorsaly with the ossification around the ventral and anterior edges of the hyomandibular cartilage. The posterior edge of this ossification is raised slightly above the surrounding parts and 

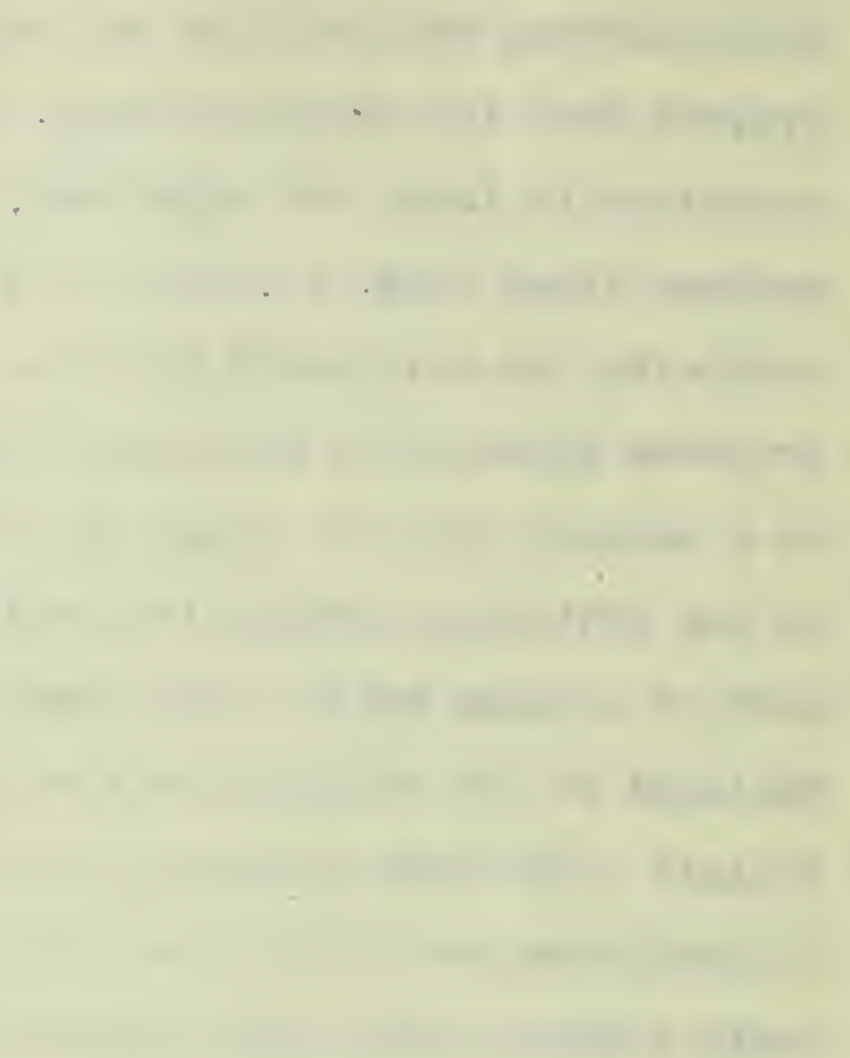
and encloses the superior part of the operculo-mandibular canal of the lateral line; it is the anlage of the preopercular bone Which has these relations in tho adult. The hyomandibular branch of the facialis issues through this ossification immediately below the anterior edge of the hyomandibular cartilage. This whole region, except for the preopercular part, was preformed in cartilage in the younger stage, the latter part having become secondarily attached to the perichondrial ossification of the hyomandibular. The dorsal part of the hyomandibular cartilage persists and abuts the lateral surface of the otic capsule in the same region as in the younger stage. The opercular knob on its posterior face is larger and furniches articulation for the thin plate-like operculum (fig. 5). The interoperculum lies at the ventral end of the of the latter between it and the mandible. The anlage of the dentry bone appears on the lateral surface of lieckel's cartilage and is at this stage distinct from the cartilage (fig.25). Teeth are attached to the dorsal anterior surface of this ossification (fig. 5). A lateral line ossification which has arisen independently around the mandibular lateral line canal is attached to its ventral surface and perforated for passage of dermal tubules of the canal. Neckel's cartilage lies in a groove on the medial surface of this ossification. In the $60 \mathrm{~mm}$ stage perichondrial ossification has appeared on the surface of the cartilage and is connected by osseous trabeculae with the dermodentary (fig. 24). The cartilage at the anterior and of the jaw has been resorbed where the symphysis takes place and the ossifioation here although usually fused with the dentary has been compared by Van Wi ghe to the mento-lieckelian bone 
-

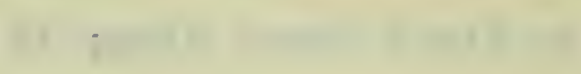
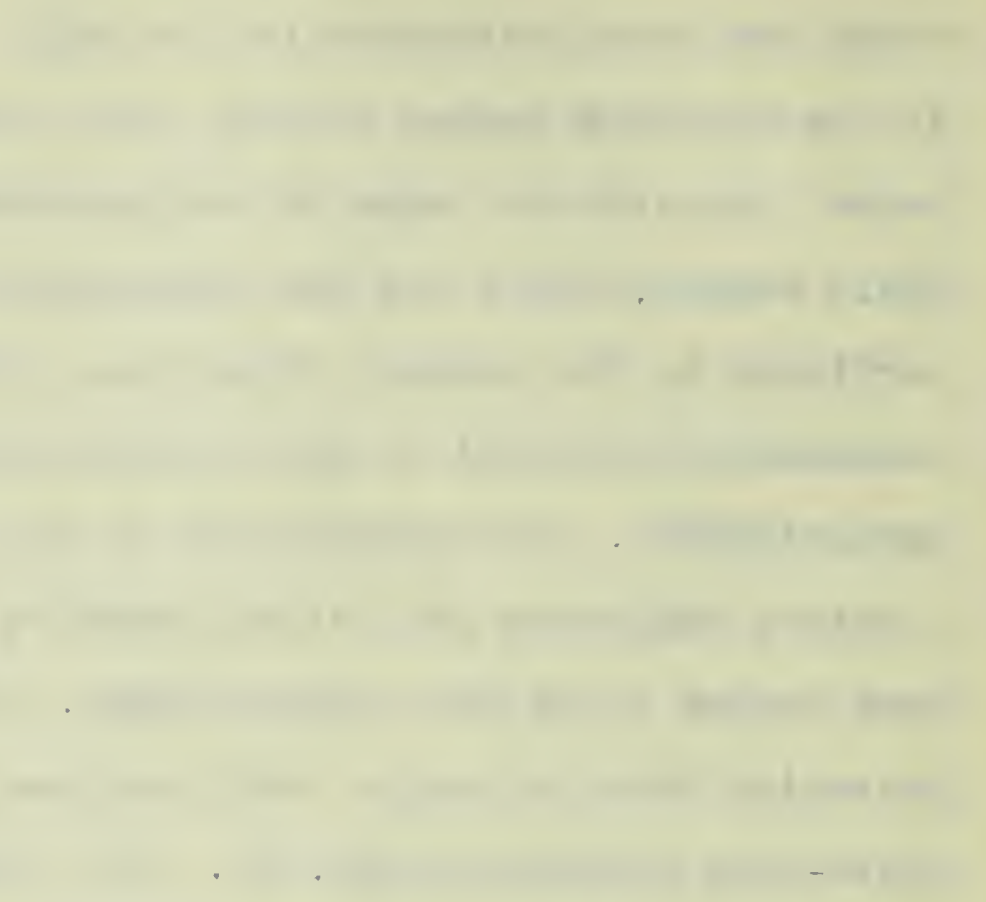

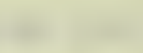
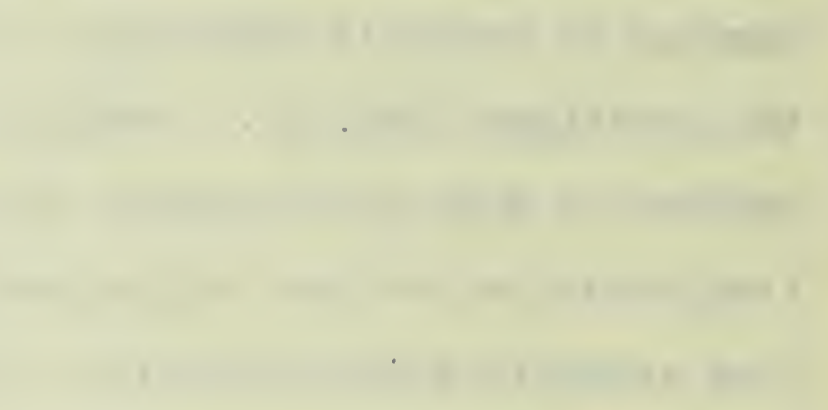

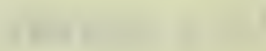

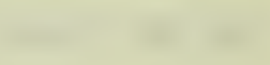

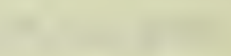


in the ganoids. He says ('82) that this bone is distinct in

Polynterus and Amia and that it is fused with the dentary in Lenidosteous. The dentary is prsent as a dermal bone only, in all of these forms. In Salmo (Schleip '03) the dentary is made up of the same elements that compose it in Amiurus. Helurrich ('84) recognized the elements which make up this bone in Amiurus. The posterior end of Meckel's cartilage is covered by a perichondrial ossification, the anlage of the articulare which furnishes the surface for articulation with the quadrate. There is no independent ossification on the top of the coronoid process corresponding to the autocoronoid of the ganoids (Van Wi,he,'82). The angulare or possibly the goniale is represented by a small dermal ossified sheet ventral to the articulare. The lateral line canal leaves the dentary at its $p$ sterior end and extends ventral to the articulare and thence into the preopercular. In the ganoids the articulare is formed in the same manner as in Amiurus and has been called the autarticulare (Van Wijhe, '82), but has a dermarticulare attached to it as an independent bone. In Salmo (Gaupp, '06) the articulare is developed from two such elements, the latter containing the lateral line canal.

\section{The Adult Skull.}

Licliarrich ('84) has described the cranium of the adult Amiurus catus, but his description and figures are very incomplete and could not be used to supplement the points brought out in the first part of this paper. Other authors have made pasing reference to the cranium of the Siluroids in general, but none of them give a specific description of the osteology of any one 
.

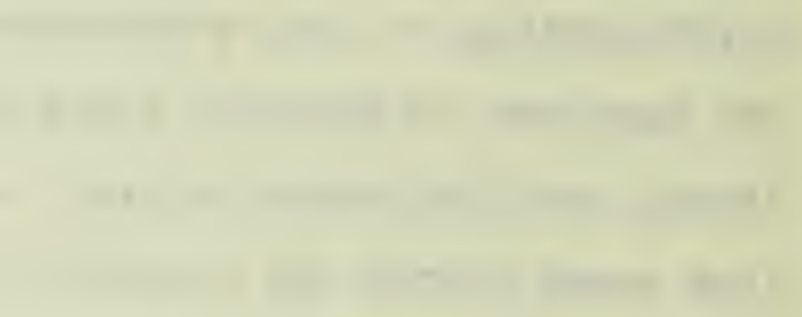

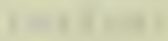
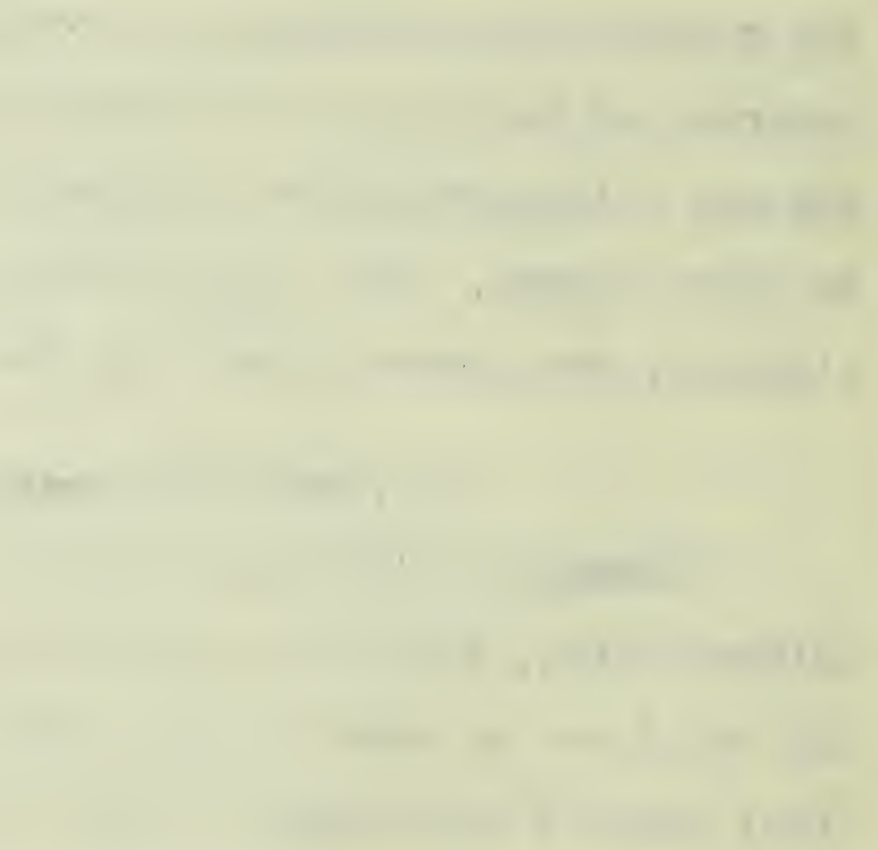
species from the point of view adopted in this paper. Pollard ('95) gives several figures of the chondrocrania of some of the South American forms, with a brief general description of each, but no reference is made to their osteology. Herrick ('OI) remarks the topographical relations of the cranial bones of Amiurus melas in his discussion of the cranial nerves.

The cranium of the adult Amiurus nebulosus (catus) is more depressed and flattened than in the later larval stages. The ossifications laid down in the $32 \mathrm{~mm}$ stage have invaded and replaced the cartilage in many parts. There is however, more cartilage remaining in the adult cranium than Mcifurrich ('84) noted (p.271). "very little cartilage remains in the skull, the anterior portion of the ethmoidal cartilage alone remaining unossfied". I find considerable cartilage present in the floor of the cranium posterior to the ethmoid region, between the otic capsules (fig. 7 ) and in the semicircular canal walls. The posterior instead of the anterior part of the ethmoid region remains unossified as the internasal septum, and will be discussed with the supraethmoia bone.

The fontanelles of the roof are well described by Miliurrich (p.270). Hy description of them will be more complete, as I have traced their formation from the younger stages and have followed the changes which have resulted in their restriction to the median region of the roof. The ossification which divides them into anterior and posterior fontanelles (fig. 10 ), is formed around the epiphysial bar of the larval chondrocranium. Most of the bones of the dorsal surface of the cranium have a delicate sculpturing. 


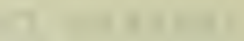

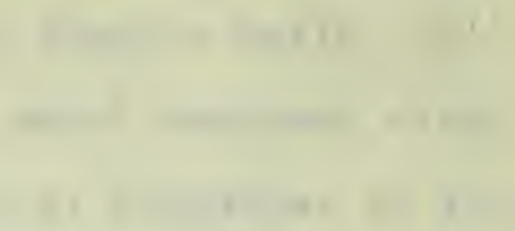

(2)

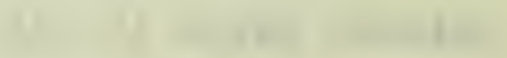

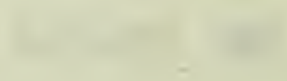
1

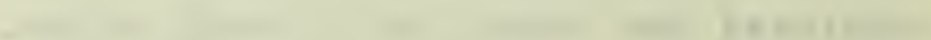

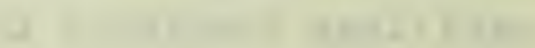

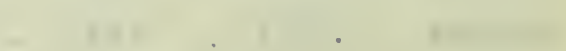
,

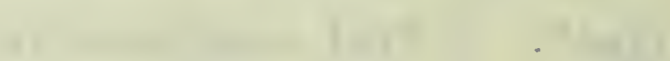
$+$

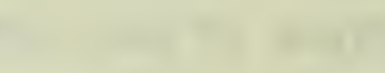

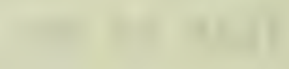

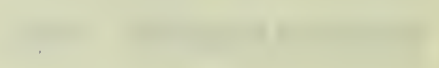

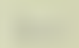

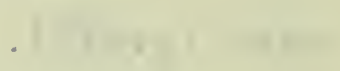

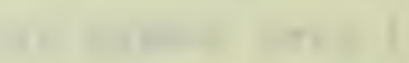

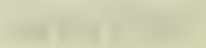

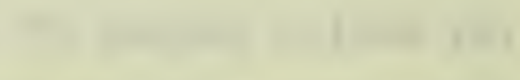

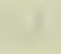


The suprathmoid (figg. 6,7,10). This bone has been described for Amiurus by McMurrich ('84), as the mesethmoid. This name implies that the bone is developer within the ethmoid cartilage and not around it, as has been shown for the larval stages. In development, the bone arises from dermal and perichondrial ossifications. Allis ('10) has described the bone in this region of the mail-cheeked fishes as the supraethmoid; Sagemehl ('84), a dermal bone in this region of Amia as the ethmoid; Parker('73) and Gaupp ('06) as the supraethmoidale, in Salmo; and Gegenbaur (178), as the ethmoidale medium, in Alepocephalus. These various terms have been used to a greater or less extent by other investigators, without regard to the significance of the terminology used. I have used the terminology of Parker and Gaupp as it applies better to the bone in Amiurus, than any of the other terms. Very few of the authors describing the morphological relations of the bone, have studied its development and earlier histological relations. Those whoc have done this agree that, in most teleosts, this bone has two parts, dermal and perichondrial, respectively. In the ganoids, as represented by Amia (Sagemehl,'84), the dernal element alone is present in the same position as that element in the teleosts. A comparison of Amiurus and Amia will be made further along, after this bone in the former animal has been discussed. In some of the teleosts, the sculpturing on the dorsal surface of this bone is very rugose and it is c covered with numerous spines. It is usually an unpaired bone, its diverging posterior edges interdigitating with the frontals. In Amiurus, the supraethmoid is the terminal bone on the dorsal surface of the cranium (fig. 10, se)... Its dorsal 


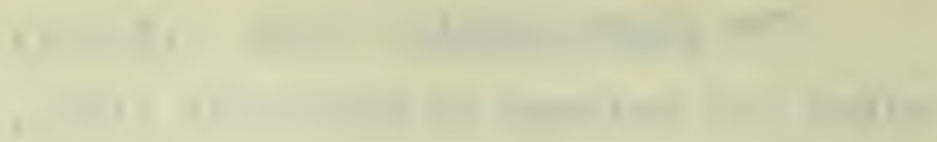

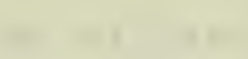

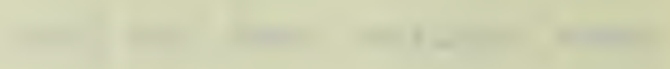

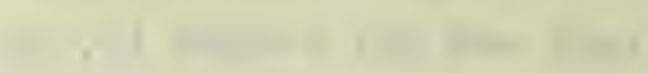

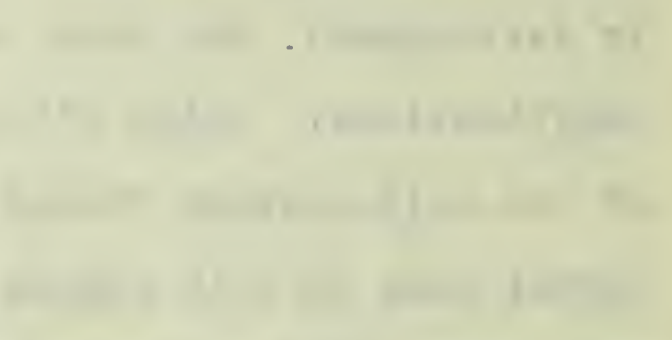

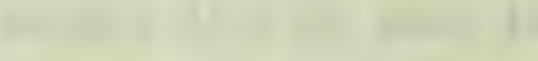
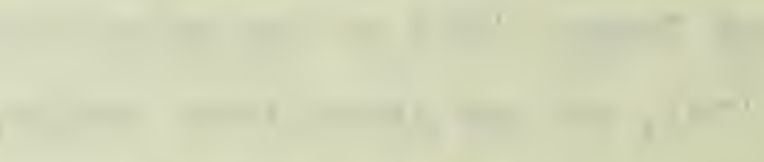

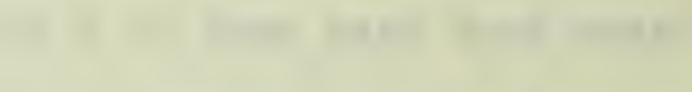

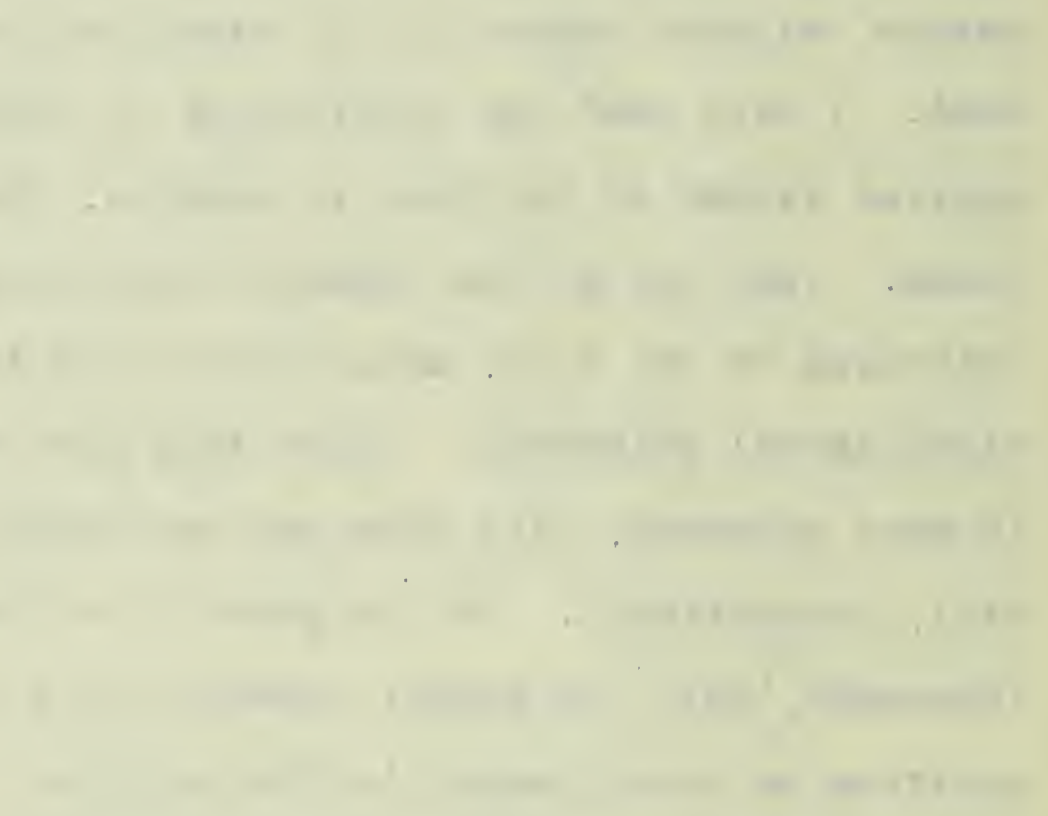


surface is slightly concave toward the posterior margin where it forms the anterior margin of the anterior fontanelle (ant. font.) There are no spines on its dorsal surface, which is covered with fine ridges radiating from the margin of a notch(eth.n.) in the median anterior edge of the bone. Lateral to this notch, which is semicircular in outline, the bone sends out two cornua, which form the antero-lateral edges of the bone, and are the result of growth anteriorly of dorsal and ventral dermal ossifications from the ethmoid cornua of the $32 \mathrm{~mm}$ larva, at which stage, the ossifications are not present, although they begin to develop in the $60 \mathrm{~mm}$ stage. They fuse with each other anteriorly, forming the sharp anterior margin of the cranium and the anterior wall of the nasal fossa (n.f.). They enclose a space which extends toward the middle line as far as the perichondrial part of the bone,(fig.7 ). The ventral sheet extends posteriorly on the ventral surface of the cranium for a very short distance (figs. 6,16). The extent of this ossification can be seen only by removal of the premaxillary bones, which are closely connected to its ventral surface by tough fibrous ligamentous tissue. The anterior margin of the vomer ( Vo.) interdigitates wi th the ventral ossification, and upon removal of it, several spicules from the parasphenid (fig.7 .ps.), are also visible in contact with it.

The parasphenoid lies ventral to a broad surface of cartilage (eth.) . Which forms the posterior ventral floor of the internasal septum. In a longitudinal section through this region (fig. 7 ) the relations of the ossifications to the cartilage are well brought out. The ossification which in the $32 \mathrm{~mm}$ stage forms a perichondrial layer in contact with the superficial dermal 

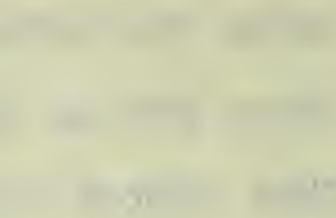

$1=$

I

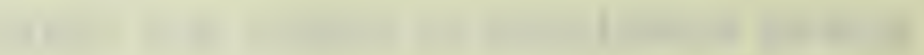


ossification, has now penetrated the cartilage, which in the adult is entirely ossified in the anterior region. A transverse section through this region of the $60 \mathrm{~mm}$ stage shows the beginning of the invasion of the cartilage by the bone, both dorsally and ventrally (fig. ). The posterior margin of the internasal septum persists as cartilage (fig. 7 ). It extends dorsaly on the ventral surface of the dermal ossification as far as the interaigitation of this with the frontals. Ventrally it extends as the floor of the cavum cranii as far posteriorly as the orbitosphenoid (OS.). This disproves McMurrich's statement that the anterior end of the ethmoid plate of the larva remains unossified in the adult.

Anterior to the olfactory foramen, the supraethmoid and the ectethmoids of each side interdigitate in the wall of the nasal fossa. Comparison with the condition of this region in the $32 \mathrm{~mm}$ larva (fig. 3 ), shows that the ossification of the supraethmoid and the ectethmoid is perichondrial, and is developed on the outer wall of the massive internasal septum. The jagged suture between the two bones extends dorso-posteriorly as far as the frontalsuprathmoid suture (fig. 10$)$ and ventrally as far as the vomersupraethmoid suture (fig.6 ). The ertethmoids are in contact with the edges of the ventral surface of the supraethmoid and curve posteriorly from it on the surface of the ethmoid cartilage (fig. 16). MeMurrich ('84) says that, the supraethmoid interaigitates posteriorly with the orbitosphenoid and as my figures show, this is effected by posteriorly extanding spicules of the perichondrial ossification on the ventral surface of the ethmoid cartilage, as the main parts of the two bones under consideration, are widely separate (fig. 16 ). 


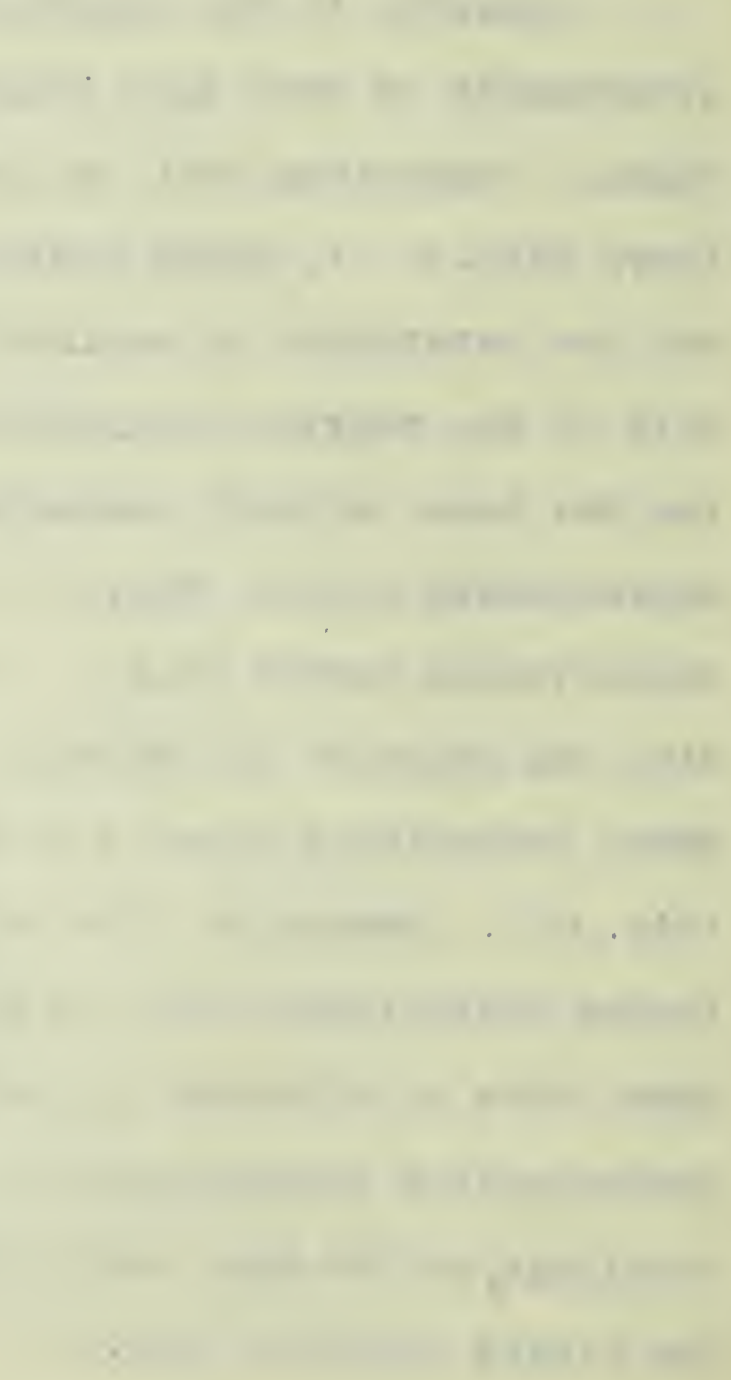


Comparison of the longitudinal section of this region of Amiurus, with that of Amia, as given by Sagemehl ('84), shows several important differences. The solid cartilage characteristic of the ganoid internasal region is present in Amia, and there are no ossifications in it. The ethmoid, is a dermal ossification and lies near the dorsal anterior end of the massive internasal septum. The cartilage beneath this ossification continues posterforly as the solid tegmen cranii, whereas in Amiurus, the posteri ior margin of the internasal cartilage onds dorsally at the anterior end of the frontals. There is no perichondrial ossification present in this region in Amia. The premaxillary bone abuts against the ventral surface of the anterior end of the cartilage, there being no intermediate ossification, such as is found in Amiurus. Nor does the vomer come in contact with the ethmoid, but since the ethmoid of Amia is comparable to the dorsal part of the dermosupraethmoid of Amiurus this condition is not remarkable. The ossifications surrounding the ethmoid plate of Amiurus have invaded the cartilage, while all the ossifications in this region of Amia are dermal. That the cartilage has not entirely ossified in Amiurus is evidence that it has advanced but little farther in its osseous development than has Amia.

In the Characinidae (Sagemehl.'85), another of the lower teleosts families, which in American piscine classification (Gregory. '07), is closely allied to the siluroids as an offshoot from the lower branches of the teleost stack, the ethmoid region is comparable, to a great degree, with the condition of Amiurus. The internasal septum, except in some of the very lowest genera of the family, has the same relations as in Amiurus. The vomer 
.
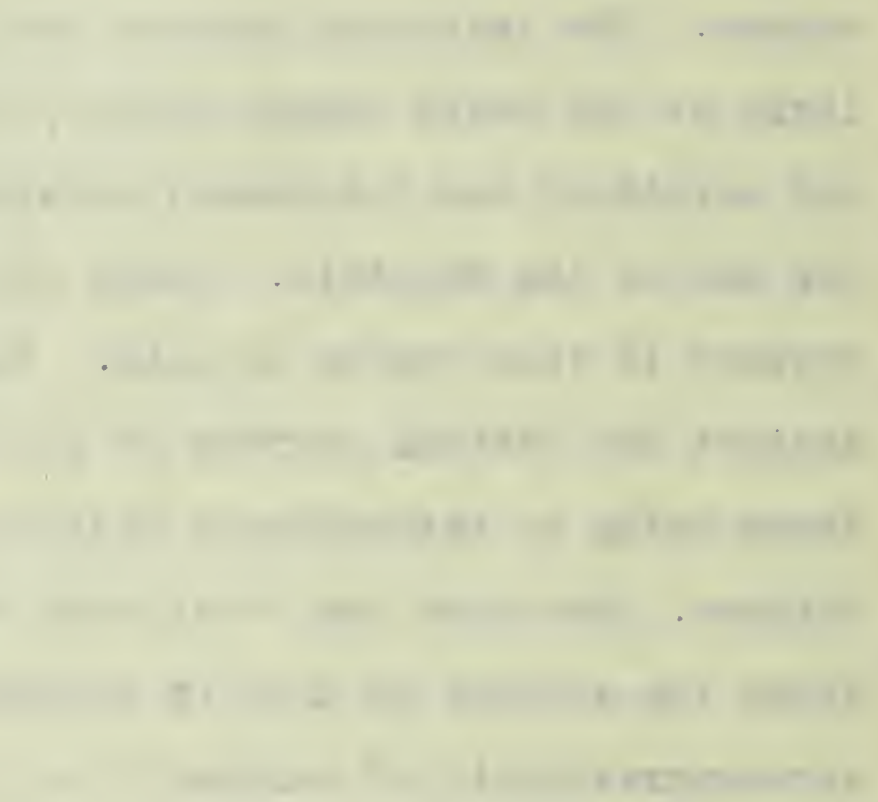

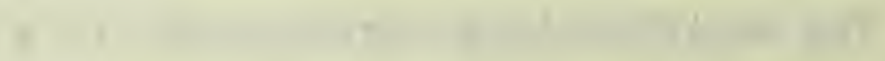

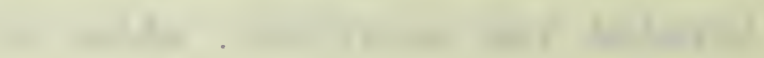

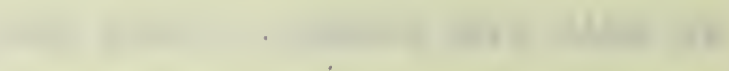

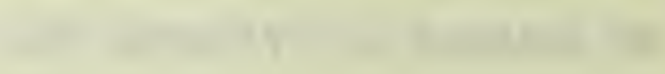

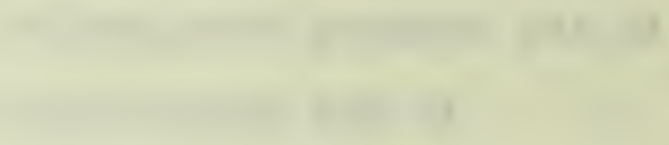

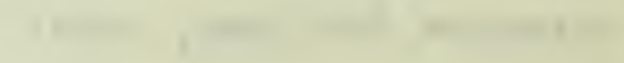

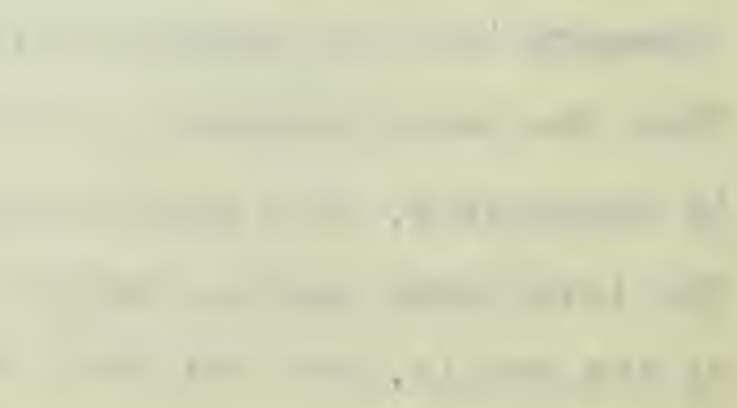


is usually more massive and extends in ventrally between the ethmoid (Sagemehl) and the cartilage. According to Sagemehl, the ethmoid has a double origin, as in fmiurus, the amount of ossification varying from the Amioid condition to complete ossification of the internasal cartilage. In speaking of the ventral extent of the ethmoid in this group, he hoped that further investigations on other groups would justify his conclusion that such a condition did exist in other teleosts.

In the Cyprinoids (Sagemehl.'9l), there is more or less invasion of the cartilage of the internasal septum by bone, but none of the species have proceeeded as far as Amiurus in this respect. In this family the ossification around the ethmoid cartilage has extended on to its ventral surface and is here in contact with the vomer. Concerning this region Sagemehl says:

" In Folge dieses Verhaltens k8nnen wir bei Cyprinoiden an jedem Ethmoid zwei Theile unterschieden: eine dunne Knochenplatte, die annthernd dem ursprtinglichen Decklnochen entspricht und die lateral aie Nasengrube tberdacht, und eine von dieser Platte nach unten abstiegende mehr oder weniger breite, aus spongioser inochensubstanz bestehende, vertikal gestellte inocherne Fand, welche die beiden Nasengruben von einander scheidet, und die durch Knorpelsubstitution entstanden ist."

This condition is also true of Amiurus as we have seen in an earlier part of the discussion. Hence the degree of ossification in the ethmoid region of the Characinidae, Cyprinidae and Siluridae affords another factor for grouping them together. Of the mail-cheeked fishes, (Allis. 'IO). Triglo has a part of the internasal septum invaded by bone, but in none does the dorsal ossification, either dermal or perichondrial, extend over the anterior end of the cranium. In salmo and most of the other teleosts, the ossification is entirely dermal and has no perichondrial element connected with it, repeating the condition 


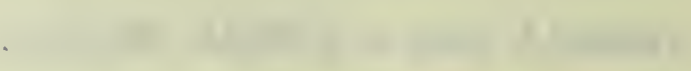

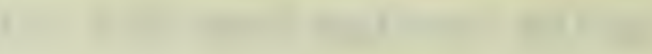
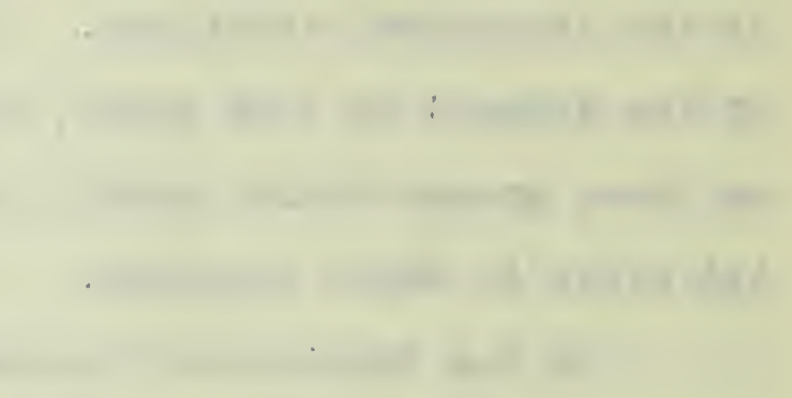

$+1$

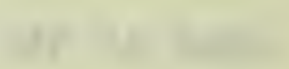
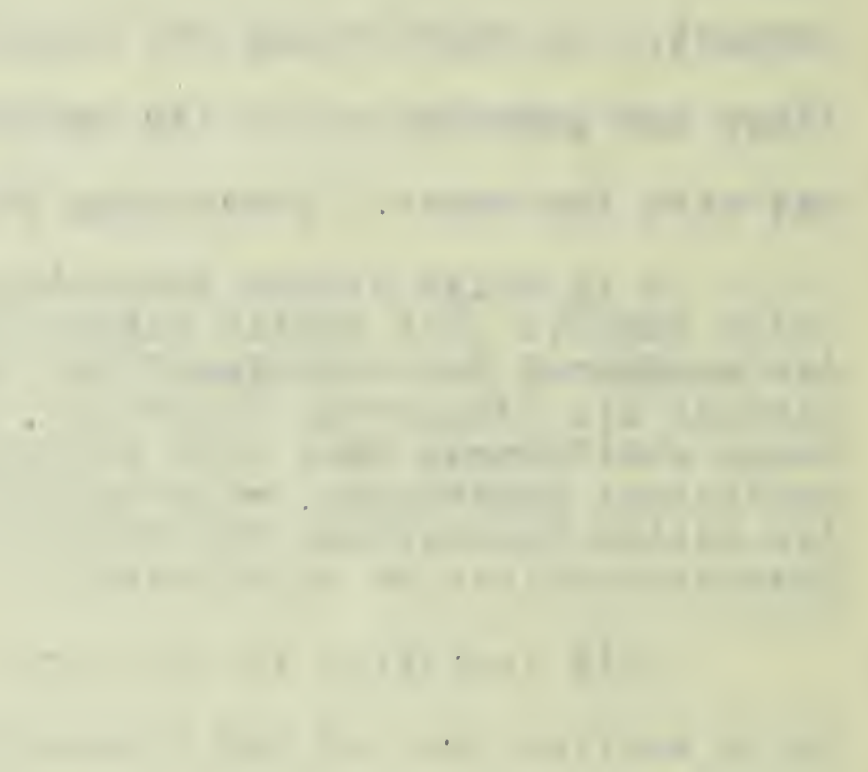

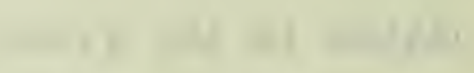

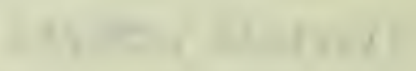

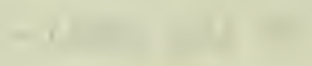

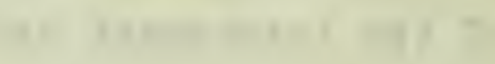

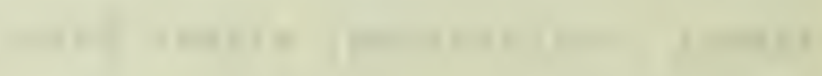

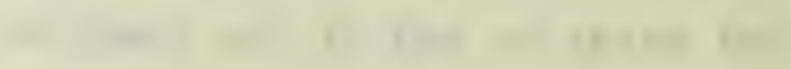

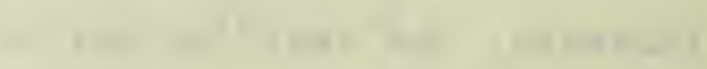


found in Amia. From the above comparisons I think that, of all the lower teleosts, Amiurus has the largest amount of ossification in this region and the steps in the formation of it show that it is both dermal and perichondrial in origin. The former is the first of the two ossifications to appear.

The ectethmoids. Fach of these is developed around the ectethmoid process of either side. In the discussion of this region of the younger forms, the changes which have taken place have been described and the beginning of ossification in the $32 \mathrm{~mm}$ larva has been noted. Perichondrial ossification had just begun at that stage, while the large membranous sheet attached to the lateral edge of the cartilaginous ectethmoid process had already ossified and extended posteriorly above the orbit. In the $60 \mathrm{~mm}$ larva, perichondrial ossifications have appeared on both the dorsal and ventral surfaces of the cartilage which forms the floor of the nasal process and the basal part of the process. The ossification of the dorsal surface unites with a descending perichondrial

wall from the ventral surface of the roof of the internasal septum and forms the olfactory canal.. Thus, in the adult, there is no cartilaginous floor in the nasal fossa. but it is formed by the premaxillary bone and tough connective tissue. In spite of alf the perichondrial ossification which hes taken place in this region. the articular surface for the palatine and a small strip ventral to it remain uncovered ( $\mathrm{fig} .16$ ). This cartilage lies between dorsal and ventral ossifications of the ecethmoid anteriorly, but posterior to the articular surface these parts unite,(fig. 16 ). The ventral ossification interdigitates anteriorly with the vomer and, at the very edge of the cranium with the supraethmoid (fig.6). 
.

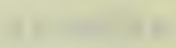
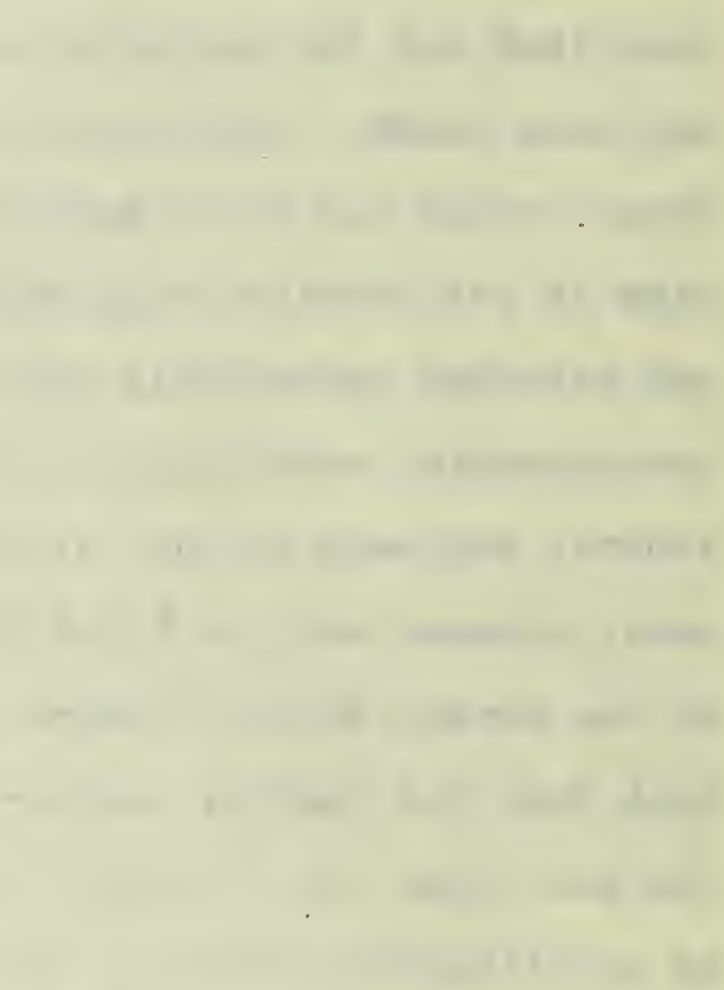

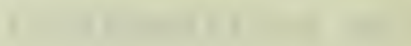

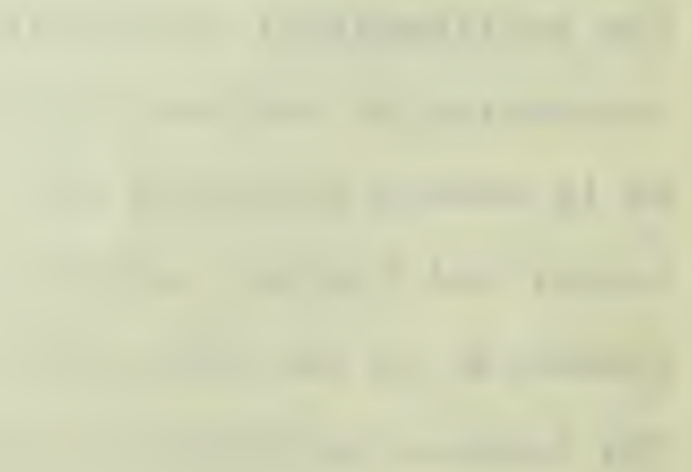

, 
Further contact between the ventral ossification of the ectethmoid and that of the supraethmoid is prevented by a wide expanse of cartilage visible upon removal of the vomer (fig. 16 ). This Iigure alos shows the distance between the ectethmoids of the two sides and the very regular edge that each has. The are also separated from the orbitosphenoid (OS.) by cartilage.

Posteriorly and above, the dermal ossification attached to the margin of the bone, is indistinguishably fused with the perichondrial ossification surrounding the foramen orbito-nasale (fig. 10 ). This dermal ossification is a very pronounced process projecting at right angles from the cranial wall. Its medial end is continuous with that part of the bone which. with the orbitosphenoid, forms the upper and lower margins of the orbital foramen (fig. 20 ). These are the main features that dis tinguish the bone. Its dorsal surface is covered with small ridges which radiate from the center. There are also numerous nerve foramina for twigs of the ophthatmicus superficialis tigemini, but known of these are connected with a lateral line canal as McMurrich ('84) stated, because no such canal is included in the ectethmoid. The posterior margin of the lateral process is continuous with a similar one on the margin of the frontal of the same side. The inner surface of the bone is covered with a thin layer of cartilage (fig. 7 ).

Cuvier ('28) called this bone the frontal anterieur and described it briefly in the perch. In his diagnosis, he said that it enclosed the olfactory nerve, was not entirely ossified, and had an articular surface for the palatine and maxillary bones/ The suborbitals were attached to its lateral surface by ligament- 


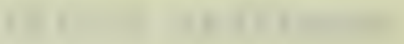

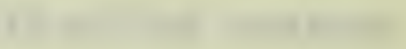

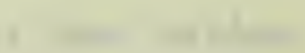

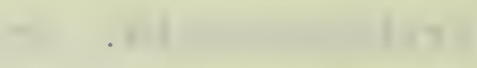

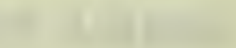

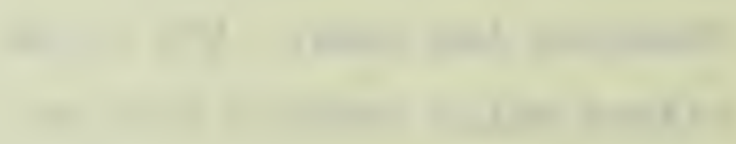

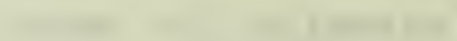
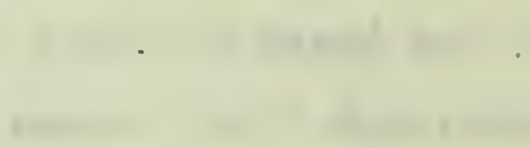

(1)

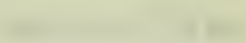

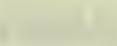

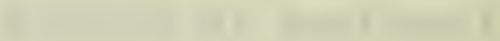


ous tissue. Except for the connexion with the maxillary, this description would apply in a very general way to the ectethmoid as described in this paper. Stannius ('54) used the terminology of Cuvier in describing this bone in the teleosts, and stated that it was one of the marginal bones of the first and second head segements.

Huxley ('64) remarked this bone as a development around the ectethmoid process in Esox, and, though calling the ossification, the prefrontal. he stated that it was comparable to the lateral mass ossification of the ethmoid bone of human anatomy. Vrolik ('73) followed Huxley in using this name. Its synonomy may be found, in common with that of the other cranial bones, in tables given by Owen ('48). Vrolik ('73), and Starks ('01). Vrolik very briefly describes this bone as a "perichondrostiache" ossification, that is, what is here called a dermal ossification. It is figured for the carp. Silurus and other teleosts, but he does not discuss it farther.

In the Cyprinoids (Sagemehl.'91), it encloses the olfactory nerve, the ophthalmic branch of the trigeminus, has an articular facet for the palatine, and is called the prefrontal. It projects very abruptly from the lateral surface of the cranium, separating the nasal fossa and the orbit. Its developmental relations are not discussed. These same relations also hold true for the Characinidae as described by the same author ('85).

Gegenbaur (178) calls this bone the ethmoide laterale or praefrontale. He distinguishes two parts, a lateral and a medial, the latter is developea from the ethmoid cartilage and forms the inner wall of the olfactory canal. He claims that the 

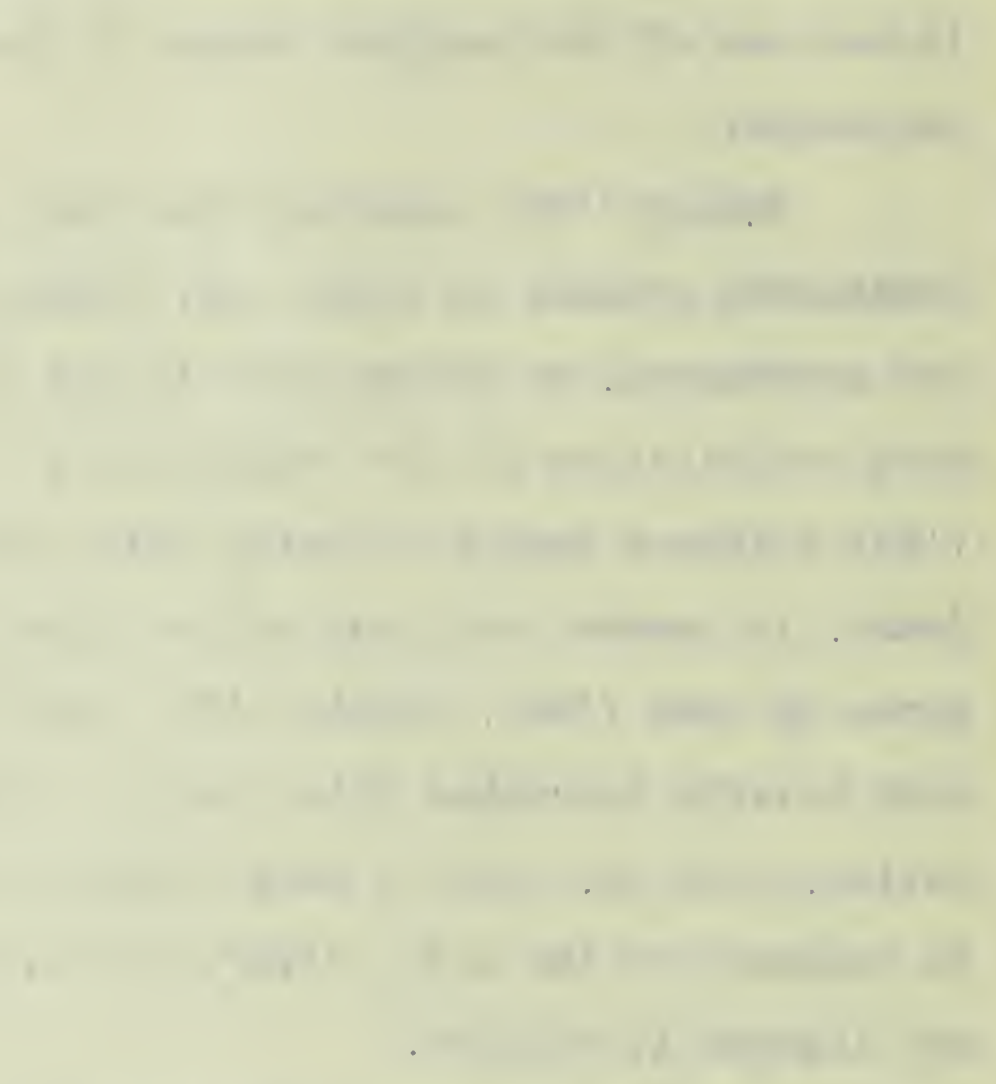

.


sculpturing on the dorsal surface is arranged concentrically and that the ridges represent Iines of growth. The bone does not have the extensive articulation that it has in Amiurus, but is limited to the cap of the ectethmoid process.

McMurrich ('84) made two statements concerning this bone in Amiurus, which contradict each other. In one place $(p .277)$ he says that the upper surface of the bone is very irregular and has numerous foramina connected with the mucous canal system. Farther along in the same paper $(p .280)$, he spys that there is no connexiof between the ectethmoid and the muscous canal lying dorsal to it. If the first statement were qualified to mean nerve foramina, as I think he really means, there would be no confusion in interpreting his statement. Since there are canal foramina in some of the bones of this region, this qualifying statement should be made.

Gaupp ('06) in remarking upon the development of this bone in Salmo, calls it the pleurethmoidale, introducing an entirely unnecessary term. If one standard of nemenclature is to be adopted in comparative osteology, it should be adhered to as far as possible. Anyone reading Gaupp's papers is at once struck by the flood of new and unnecessary terms throughout all of them. Accoraf ing to this investigator, the ectethmoid of the adult salmo is a true perichondrial ossification formed around the planum antorbitale (ectethmoid process). The adult condition is the result of endochontification and resorption, with an added ossification formed by the ligament connecting it to the palatine. The bone includes the ophthalmic branch of the trigeminus, and the anterior ossicle of the infraorbital chain of bones is attached to its lateral surface. 

Allis'('10) description of the development of this bone in the mail-cheeked fishes is given earlier in the paper, but we can compare the adult bones at this time. As was stated previously. both have perichondrial and dermal elements, although Allis claims that the latter is perichondrial rather then dermal. The olfactory nerve issues through this bone in the mail-cheeked fishes and in Amiurus the olfactory tract. Both have a foramen for the passage anteriorly of the ophthalmicus superficialis trigemini and a facet for articulation with the palatine.

From the above discussion we can say briefly, that the criteria for the recognition of the ectethmoid bone of the teleosts are:

1. Perichondrial development around the ectethmoid process.

2. Enclosure of the olfactory tract or nerve in a canal.

3. Enclosure of the anterior end of the ophthalmic branch of the trigeminus nerve.

4. Articular surface for the palatine.

5. May have a large dermal element fused to the perichondrial ossification, forming a lateral process and separating the nasal fossa from the orbit.

7. Attachment by connective tisque to the anterior ossicle of the infraorbital series.

The nasals. In the $32 \mathrm{~mm}$ stage, the only dssifications in the roof of the nasal fossa of each side were those developed around the anterior ends of the supraorbital and suborbital lateral line canals. At that stage they were narrow and tubular, the more medial ossification enclosed the supraorbital and the more lateral the suborbital canal. They were connected to the sur- 


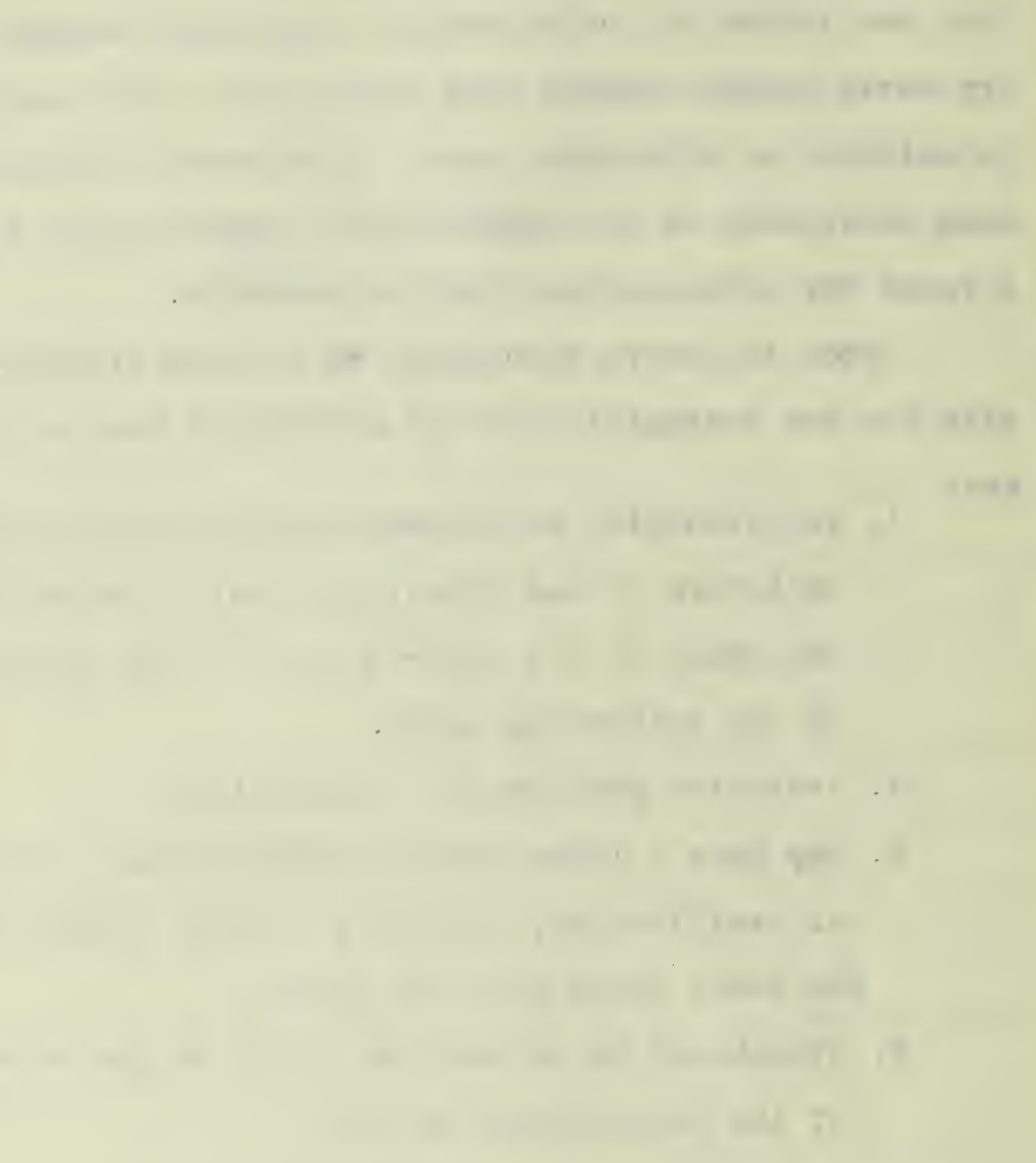


rounding bones by ligamentous tissue, there being no contact of ossifications. In the adilt, the more medial of the two bones is recognized as the nasal and the more lateral as the lacrimal. The nasal (fig. 15 ) is flat and covers most of the fossa roof, its concave antero-lateral margin forming the median margin of the anterior naris. The lateral line canal occupies a very limited space on the longitudinal median dorsal surface of the bone. This canal opens anteriorly by two pores, one at the tip of the bone (fig.11), and the other on the latero-anterior margin, posterior to the anterior naris ( ). Posteriorly, the lateal line canal passes from the narrow posterior tip of the bone and proceed through a mass of connective tissue before entering the anterior end of the frontal ( fr) ). The flat and scale-like appearance of the bone is the result of ossification of part of the fibrous connective tissue belwo the lateral line canal ossification. In outline the bone is suggestive of the nasal of Amia (Sagemehl. '84) but is not nearly as massive nor does it meet its fellow of the opposite side. The enclosed lateral line canal does not connect with that of the other side within the ethmoid as it does in Amia. The nasal of the Characinidae (Sagemehl.'85) is more like that of Amia, and comes in contact with the ethmoid cartilage as in the latter, but not in Amiurus. The cyprinoid nasal is more nearly like that of Amiurus than Amia or the characinids. In Salmo, (Schleip.'03) the nasal develops in contact with the ethmoid cartilage and encloses a lateral line canal. In Gasterosteus (Swinnerton.'02), this bone is very large and intimately connected with the ethmoid cartilage; it extends on to the ventral surface of the cranium after forming the roof of the nasal fossa, but the presence of a lteral line canal within it is not mentioned. 


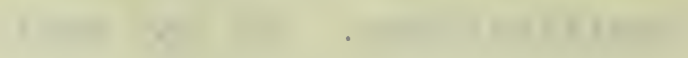

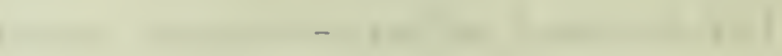

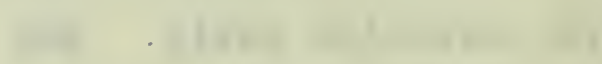
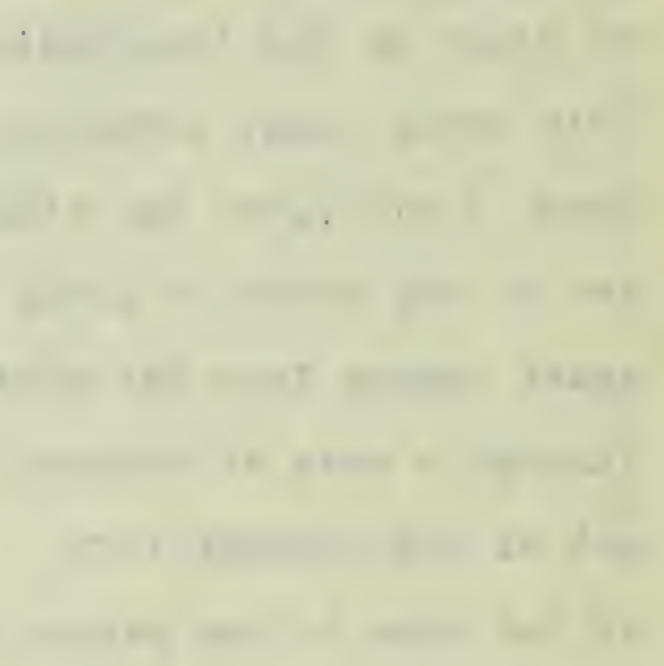

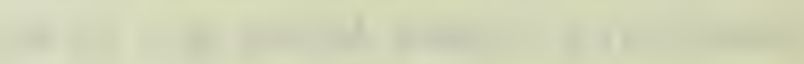
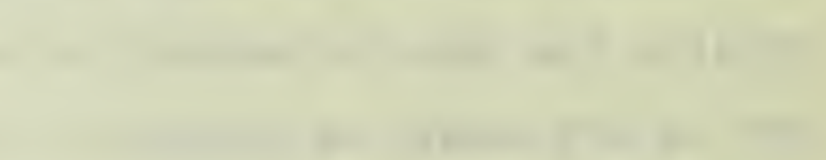

$+$

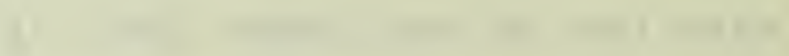

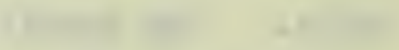
.

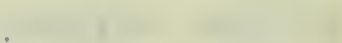

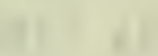
.

C.

$1+2$

14.

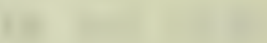


In the Amphibia, Reptilia, Aves, and Mammalia, the nasal bone occurs as a dermal ossification on the roof of the nasal capsule. In some mammals the cartilage of the capsule beneath this bone disappears, and a condition comparable to that of Amiurus results. The teleostean nasal bone is comparable, then, in a certain degree with the nasal of the higher groups. In nearly all of the teleost. however, this bone contains a lateral line canal ossification on its dorsal surface. In Amiurus the bone is isolated, but in most of the other forms it connects to a greater or less degree by suture with the surrounding bones.

The lacrimals. A single lacrimal on each side of the head forms the lateral roof of the nasal fossa. (fig. 15 ). Each is very small and narrow and contains the anterior end of the suborbital lateral line canal of its side. The most anterior dermal tubule of the canal issues from the bone through its dorso-medial edge (fig.ll). From the small central part of the bone four processes radiate, two anterior and two posterior. The antero-lateral process is slender and curves around the extemal margin of the anterior naris. The anterior end of the suborbital canal after leaving the main part of the bone at the proximal end of this process proceeds immediately to the extemal surface of the head. The process is closely connected by ligament to the maxillary, and premaxillary bones, and to the ethmoid cornua of the supraethmoid bone.

The median anterior process of the lacrimal projects toward the middle line of the fossa roof, posterior to the anterior naris. It contains the first dermal tubule of the suborbital lateral line canal, the pore of which lies lateral to the pore 

of the first dermal tubule of the supraorbital canal, posterior to the margin of the anterior naris.

The elongate median posterior process extends posteriorly toward the anterior face of the ectethmoid bone. It lacks a lateral line oanal element. The anterior ossicle of the infraorbital series of lateral line canal bones (fig. 15 ), is connected with its ventral margin by ligament. The lateral posterior process of the lacrimal lies external to the first suborbital bone, so that the suborbital lateral line canal enters the posterior margin of the lacrimal between the posterior processes. After giving off the dermal tubule desribed above, the canal: ends by the passing to the exterior. There is one serserorgan, the most anterior of the suborbital lateral line canal, contained within the lacrimal bone. The nasal bone encloses the most anterior sense organ of the supraorbital canal.

The older writers-, Cuvier, Stannius, Hallman, Wagner, Huxley and others- recognized the lacrimal bone as the anterior element of the suborbital or infraorbital series. In most of the forms studied this bone was the largest and gradually came to have a greater morphological significance than the more posterior bones of the series. It contained a part of the suborbital lateral line canal in most teleosts and Amia, and was usually related to the roof of the nasal organ. Where its development has been studied (Schleip.'03), it has been found to arise primarily as an ossification developed in connexion with a lateral line sense organ, and later has an osseous base formed from surrounding connective tissue. In Amiurus, as noted above, the lateral line element is the first to appear and the dermal part does not $f$ 


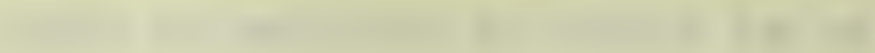

(n)

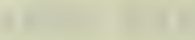

$\sqrt{2}$

政

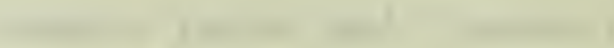

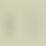

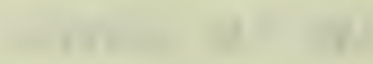

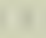

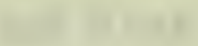

1 1 +
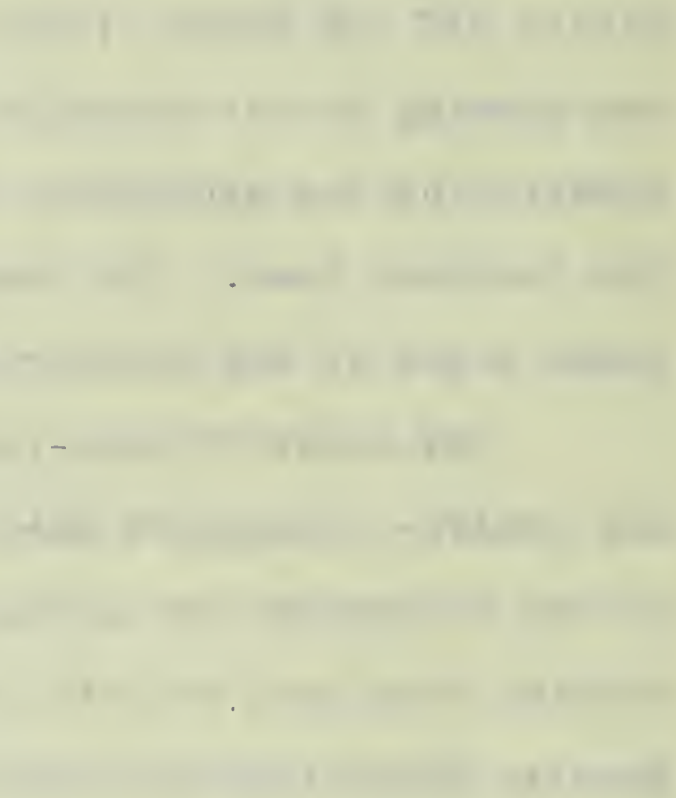

and

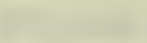

the 
ossify until, much later. I am satisfied that this bone has two parts as Schleip has stated and that, the dermal part may be homologized to the lacrimal bone of the higher groups. As the lateral line canal is associated with those forms which live in the water, so is the lacrimal canal found in those animals which pass most of their lives in the air. In both cases the bone develops lateral to and usually dorsal to the nasal organ and is a dermal ossification. It may have more or less connexion with the surrounding bonos - nasal, maxillary, premaxillary, supraethmoid, and ectethmoid - and in some of the fishes with the vomer. Allis'('98) crterion for the homology of the lacrinal is the inclusion within it of the anterior end of the suborbital canal. In comparing his work on Amia with that of Mciurrich on Amiurus, he concluded that the antorbital of Amia was the homologue of the adnasal. (lacrimal) of Amiurus. Since however, this bone of Amiurus contains the anterior end of the suborbital canal it is the lacrimal and the antorbital of Amia is represented by the long antero-lateral process, which has fused with the lacrimal element as it has in some other teleosts.

The frontals. These bones are the most extensive and conspicuous bones on the dorsal surface of the cranium, forming most of the roof and part of the side walls of the cavum cranii (fig

10 ). The only point of suture between the two is in the region of the original epiphysial bar. Anterior and posterior to this suture they are separated from each other by two longitudinal fontanelies, the remnants of the more extensive ones of the younger stages. Each has a raised margin on the sides of these fontanelles thus bounding a fossa which continues anteriorly as far 


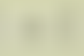

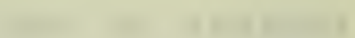
1. -

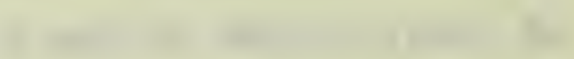

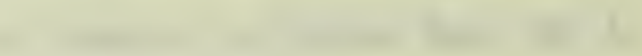
(n) .

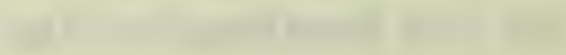

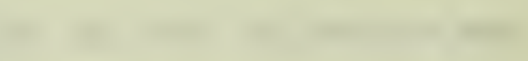

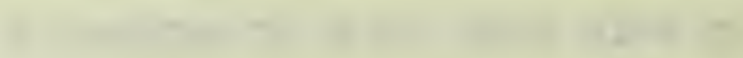
4.
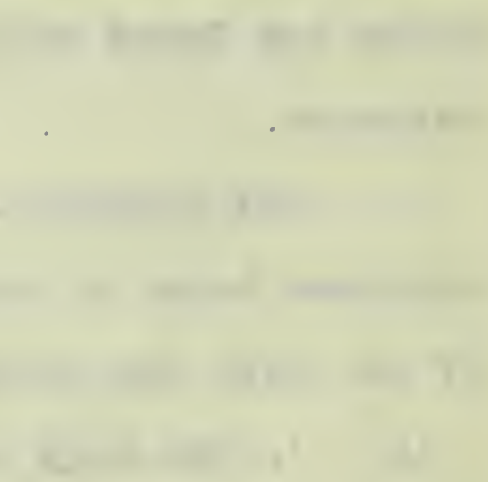
as the supraethmoid and posteriorly on to the dorsal surface of the supraoccipital. This fossa is filled with connective tissue and nerve fibres, and a tough membrane is stretched the entire length of each of the fontanelles. Their restriction is caused by median growth of the frontals, a process noted in its incipience in the $32 \mathrm{~mm}$ stage. Earlier, however, the posterior fontanelle extended between the anterior edges of the occipital arch, but the ossification in this region has grown forward and closed the extreme posterior end of the fontanelle.

Anteriorly, the frontals interdigitate with the median supraethmoid, which forms the anterior margin of the anterior fontanelle. This interdigitation lies above the orbito-nasale foramen and is continuous laterally with that between the ectethmoids and the frontals (fig. 10). An oblique frontal ridge along which the adductor mandibularis muscle has its origin extends posteriorIy across the dorsal surface of the frontal from the lateral posterior margin of the ectethmoid. The frontal ridge does not extend to the posterior end of the bone, but unites with the ridge which forms the margin of the median fossa. Behind the union of the two ridges a wing of bone extends lateraliy to interdigitate with the sphenotic. Anterior to the ridge the surface of the bone is sculptured in longitudinal ridges, which run posteriorly toward the middle line of the cranium, parallel to the dorsal margin of the ridge and extending along its anterior face. Poster ior to the frontal ridge the bone is comparatively smooth.

At the anterior end of the frontal ridge the suborbitul lateral line canal enters the frontal bone from the postfrontal (fig. Il). The two bones are not in contact with each other, so 


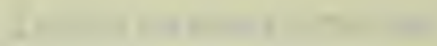
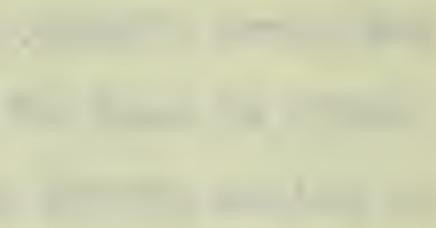

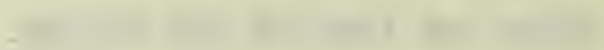

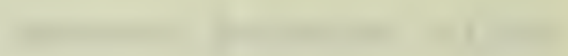

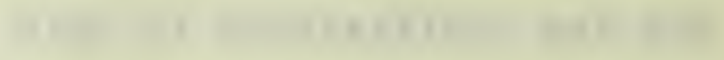

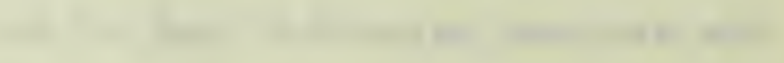

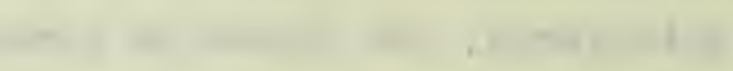

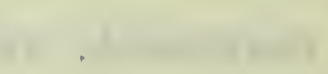

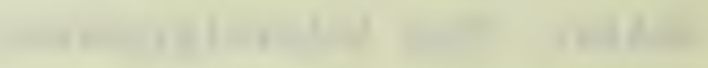

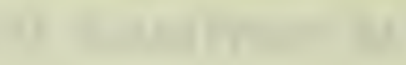

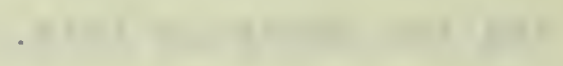

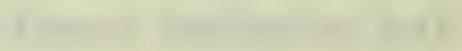

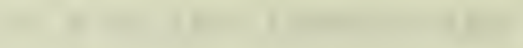

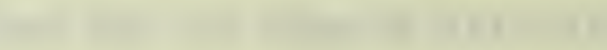

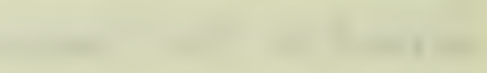
10 $+\frac{10}{20}$

.

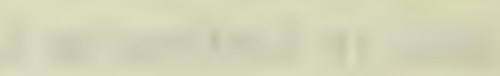

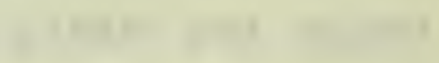

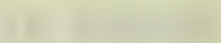

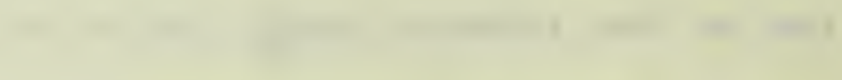

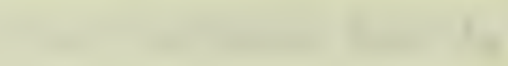

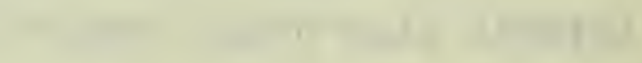
. 
that the canal crosses the dorsal surface of the adductor mandibularis muscle before entering the frontal. A dermal tubule is geven off from this part of the canal as it passes from the postfrontal to the frontal.

The frontal bone extends down into the wall of the orbit externally connecting by suture with the orbito- and alisphenoid ossifications (fig. 20 ). In the anterior part of the orbit it is separated from the ectethmoid bone by a small remnant of the fused alisphenoid-ectethmoid cartilage. Posteriorly it interdigitates with the anterior end of the sohenotic bone, above the alisphenoid. On the inner surface of the carum cranii, the frontal descends in the cranial wall in front of and behind the line of suture between the two frontals, but immediately below the suture this down growth is limited by the dorsal parts of the aliand orbitosphenoids. Anteriorly it overlaps the orbitosphenoid and continues as far forward as the cartilage which lines the cavum within the ectethmoid. Posteriorly it overlaps the alisphenoid, interdgitates with the anterior margin of the sphenotic and proceeds dorsally toward the middle line of the cranium to interdigitate with the supraoccipital.

There are many minute nerve foramina and canals in the frontal bone, but none of them reach the cavum cranii.. The largest canal is that of the ophthalmicus superficialis facialis, which, after issuing from the alisphenoid, sends a branch along the dorsal median wall of the orbit and is enclosed within the frontal: It continues forward within the bone sending small twigs dorsally into the bone to the lateral line organs contained within it and also clear through the bone to the integumental sense 
organs above (fig.10). Anteriorly, the nerve passes to the dorsal surface of the bone through a small foramen, just below the insertion of the connective tissue which connects frontal with nasal.

The supraorbital lateral line canal, which starts in the nasal bone anters the anterior end of the frontal after paasing through the connective tissue between the two bones. The anterior point of ingress of the canal lies just dorsal to the foramen for the passage of the ophthalmic branch of the facialis. From this point its course cannot be followed externally, but must be traced by following it through a series of transverse sections, (a $60 \mathrm{~mm}$ specimen was used for this). There is one dermal tubule and pore anterior to the frontal ridge on the dorsal surface of the bone. As noted above, the suborbital canal enters the frontal at the anterior end of the frontal ridge. It anastomoses with the supraorbital canal beneath the ridge and a dermal tubule extends along the posterior face of the ridge from the supraorbital canal, just before their anastomosis. The canal formed by the anastomosis continues posteriorly from the midale of the frontal ridge and thence into the sphenotic bone (fig.11). There are three sense organs in the canal enclosed in the frontal in points shown in fig. Il. The first and third ones are followed by dermal tubules, but the second is not, and lies just anterior to the union of supraorbital and suborbital canals.

This bone of the adult is the result of the ossification of the membrane above the alisphenoid cartilage of the larva. In sections through the $60 \mathrm{~mm}$ larva the fibrous connective tissue surrounding the ventral surface of this membrane have ossified 

and appear as lamellae capping the perichondrial ossification of the dorsal surface of the alisphenoid cartilage. (fig. 32). The ossifications of the two sides of the head have fused around the opiphysial bar and the cartilage within it has all but disappeared. None of this ossification connecting the frontals of the two sides is perichondrial. In the adult, the cartilage has entirely disappeared from the interior of the ossification (fig.7 ) surround ing the original epiphysial bar. Anterior to this bar the frontal is thin and solid, while behind, although just as solld, the bone is much thicker. The nerve foramina in the bone are later developments and are caused by the growth of osseous trabeculae around the nerve twigs and branches. The ossification around the lateral Iine canal has now become an integral part of the bone.

The older comparative anatomists homologise the frontals of the fishes with those in the higher animals and based their conclusions upon topographical rather than embryological relationships. As far back in the literature as I have gone, these bones have always been known as the frontalla with, perhaps, and added adjective to distinguish them from the anterior and posterior frontalia. In practically every teleost and most of the ganoids the $y$ are the largest bones on the dorsal surface of the cranium and are usually paired. Fontanelles like those of Amiurus were recognized in the teleosts by Cuvier and are again referred to by Stannius ('54). In Amia and most lower teleost families these fontanelles are absent and the frontals are connected by suture along their entire length.

In comparison with the frontals of Amiurus those of Amia show limitations of development ventraly and internally. They 


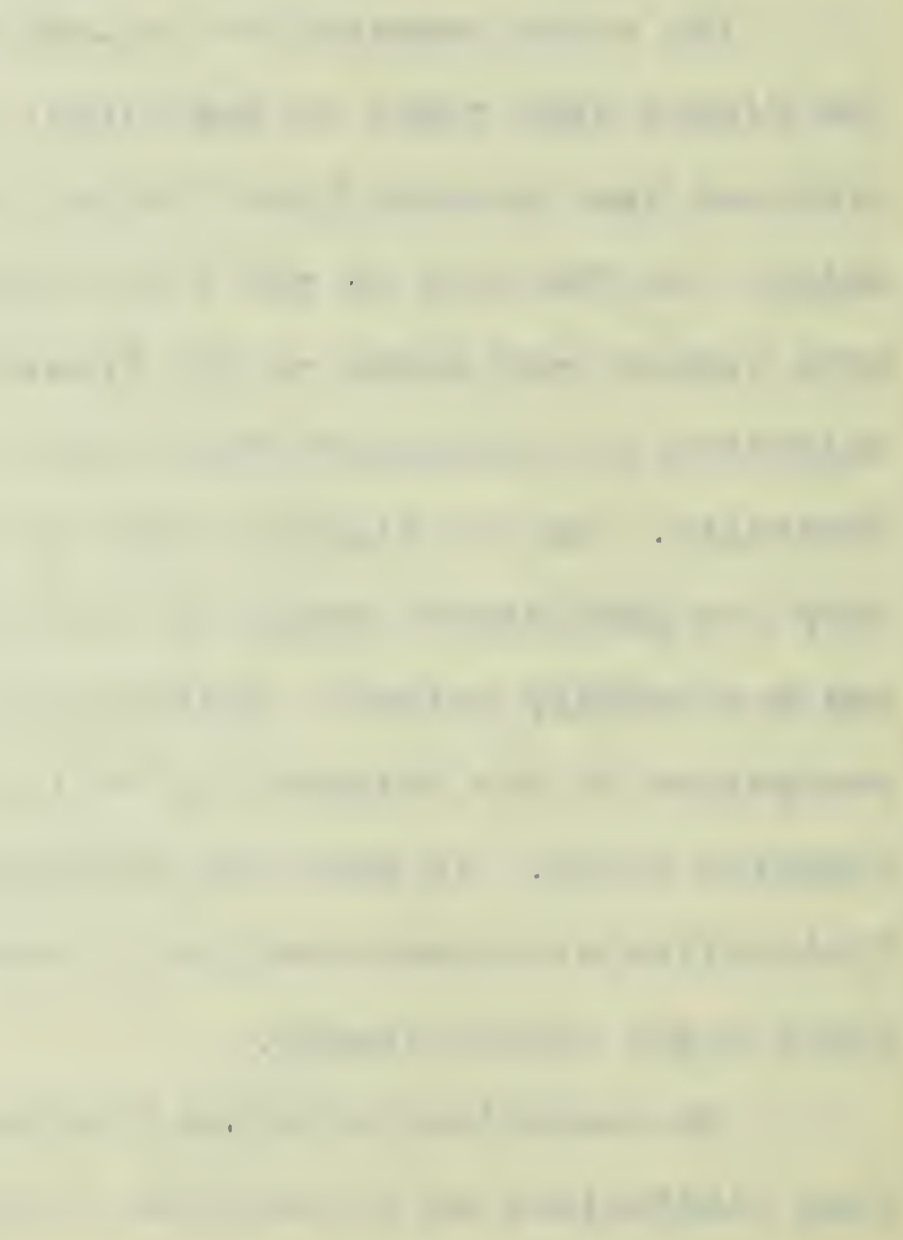


cover more of the dorsal surface of the cranium than those of Amiurus, but they take no part in the wall of the cavum cranii. being separated from it by the solid cartilaginous tegmen cranii (Sagemehl.'84). They do not interdigitate anteriorly with the supraehtmoid because of its limited development, but their relations relations to the nasal bones are comparable to those of Amiurus. In the orbital wall, the frontal of Amia is separated from the orbitosphenoid and alisphenoid ossifications by cartilagel Cartilage does not extend between the frontal and ectethmoid (prefrontal, SagemehI) as in Amiurus.

In the Characinidae there is a mixture of the condition fo found in Amia and that of imiurus. Citharinus (Sagemehl.'85) anproaches the Amirurus type of frontal development externally, but is more like Amia internally, in that more cartilage persists in the side walls and the roof of the cranium than in Amiurus. The epiohysial bar is not enclosed by the frontals, although they meet above it. Sarcodaces lacks the anterior fontanelle found in Citharinus and the nosterior fontanelle lies more between the parietals than the frontals. Internally, ther is less cartilage than in Citharinus, but the epiphysial bar remains unossified. The other families of the lower teleosts - Mormyridae, Osteoglossidae, Clupeidae, Gymnarchidae and others - have the frontals connected by suture as far back as the parietals which are highly developed in these forms. The internal relations of the frontals have not been described for any of these lower teleosts and it would be interesting to find out how much cartilage remains beneath them. In the Cyprinidae (Sagemehl.'91), the frontals have relations which closely approach those of Amiurus, but the anterior 


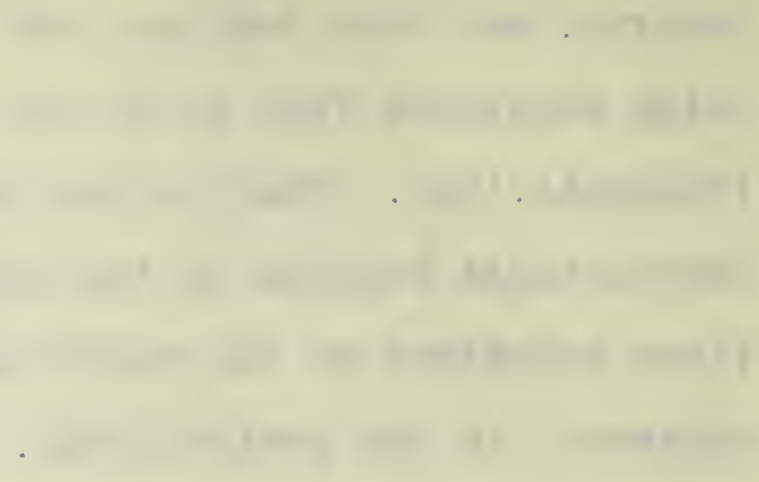

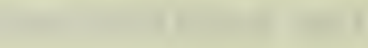

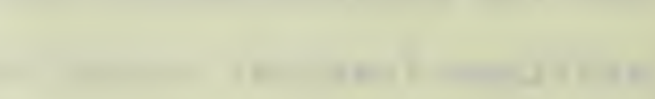

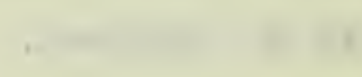

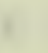
1 $1 n^{-2}$

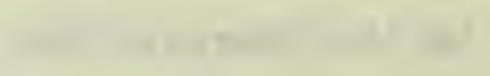

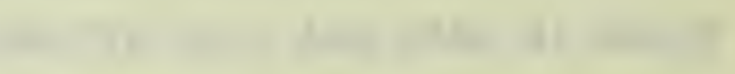

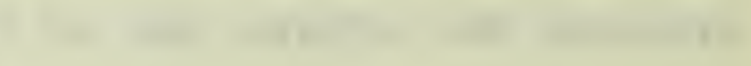
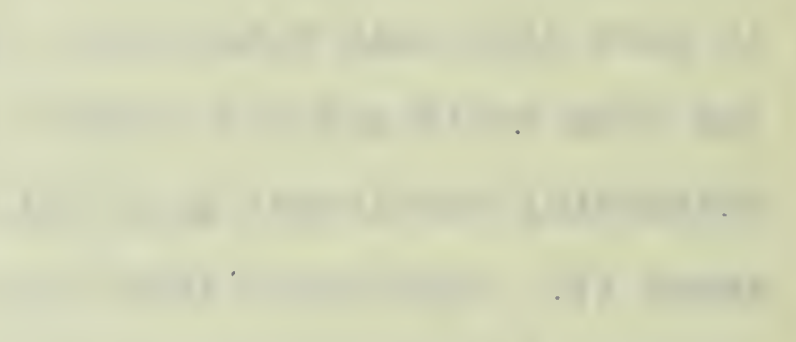

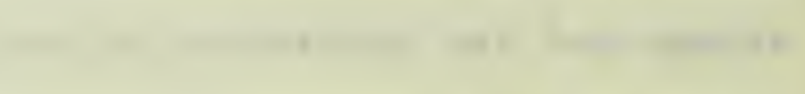
$+2$

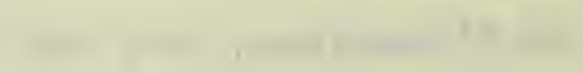

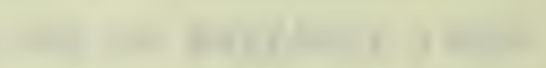
14.

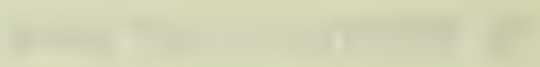

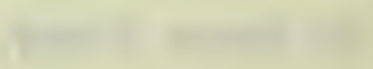

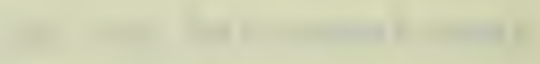
in $+2$ 
fontanelle is always closed in those genera figured by Sagemehl. The epiphysial bar persists as cartilage in the adult and the frontals have not extended beneath it as they have in Amiurus. In none of the forms thus far mentioned have I been able to find a frontal ridge for the adducto mandibularis muscle comparable to that in Amiurus. The postfrontal (sphenotic, Auct.) never has the dorsal extent that it has in Amiurus, but is always overlapped by the posterior margin of the frontal.

In the Salmonidae the frontals lie superficial to the tegmen cranii (Parker.'72), as they do in Esox (Huxley.'64) and take very little part in the formation of the orbital roof, probably because of the persistence of the cartilage in this region. Further discussion of the topographical relations of the frontals is unnecessary because the above shows that there is a general agreement in position throughout the whole group of teleosts.

The relations of the nerves to this bone were neglected by the older anatomists and not until sagemehI's description of Amia were these studied. As in Amiurus twigs from the ophthalmicus superficialis facialis (Sagemehl's fifth) pass into the bone to innervate the sense organs of the lateral line canal. In the Selachians there are a series of foramina in this same region penetrating the supraorbital cartilage (Gegenbaur, '72. Wells, '17). In the Characinidae the ophthalmic branch of the facialis has the same relations as in Amia and Amiurus. In Amia an anterior branch of it extends dorsally through the cartilage and frontal at the anterior end of the orbit. In the Characinidae, Cyprinidae and Amiurus, this branch passes to the dorsal surface of the cranium through the frontal alone. In Amiurus it lies free in the 


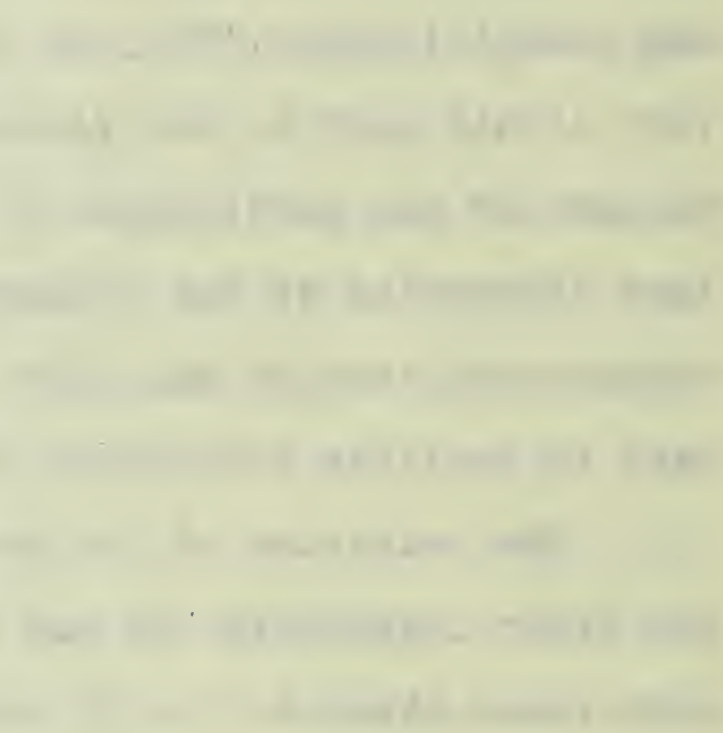

1.

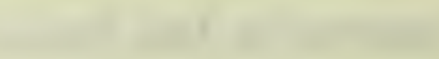


orbit in the younger stages and its enclosure within the frontal is accomplished by growth ventrally from the frontal of osseous spicules which finally enclose the nerve within a canal.

Von K8lliker ('50) was one of the first to work out the histological development of the frontals. Up to his time ther $\wedge^{\text {was a }}$ controversy between those who thought that the bone was developed from membrane and therefore comparable throughout the whole vertebrate series, and those who held that in the Aves and Mammalia it was developed from cartilage. Reichert ('49) was responsible for the latter statement and von KBlliker took it upon himself to settle the controversy by histological and chemical analysis. The chemical analysis of the bone showed that it did not have a trace of the chondrin common to the bones developed from cartilage. As a result of his work he came to the conclusion that the frontal bone throughout all the groups was developed from dermal connective tissue and had nothing to do in development with the underlying cartilage. Subsequent researches on the development of the bone have borne out his statement. Hertwig ('76) and Gegenbaur ('64) both agree that originally the frontal bones were dermal scales which in the course of phylogenetic changes have sunken to theit present position and fused into a solid osseous mass. Acipenser typifies the indifferent stage where the scales have not yet formed bones.

The supraorbital lateral line canal is usually associated with the frontal bone in the ganoids and teleosts and there are many or few pores on the dorsal surface of the bone connected with it. Vrolik ('73), in his general description and in the conclusions of his work on the development of the frontal bones of 


\section{A

$+2$
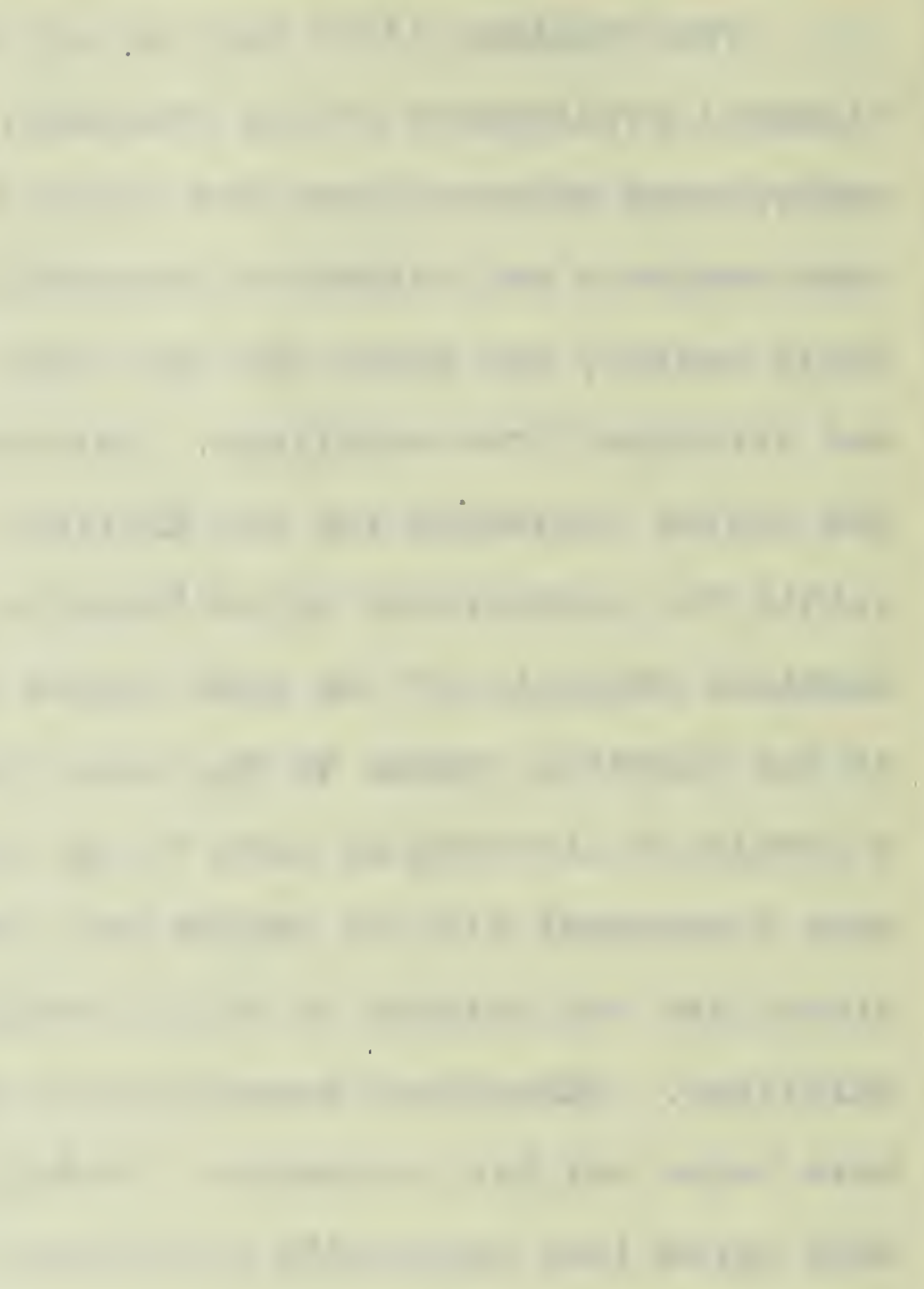

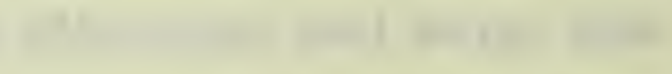

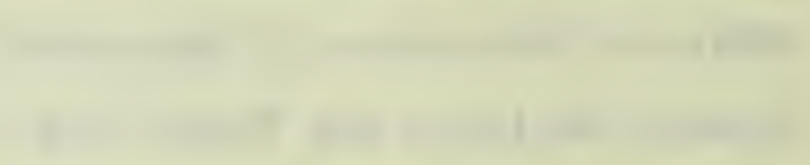

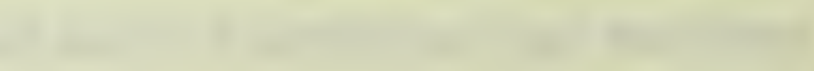
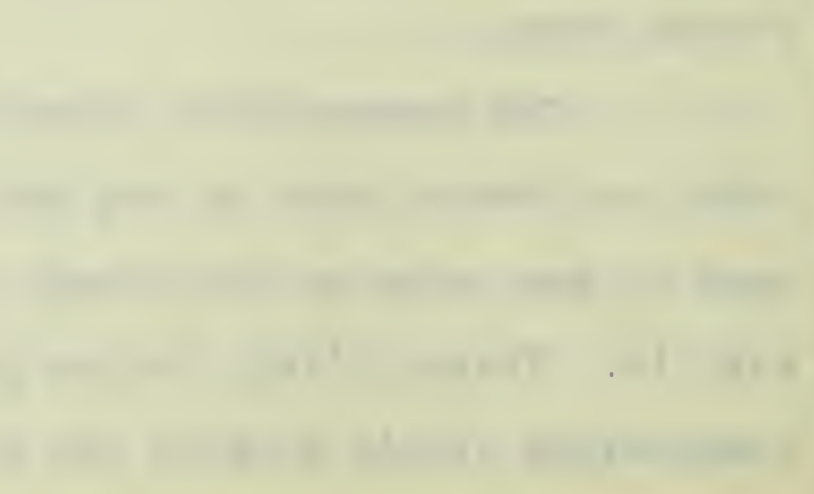
teleosts, states that the frontal bone is developed primarily to protect the canal. This has since been refuted by those who have worked out the developmental relations of the canal and the bone. The ossification around the canal is at first entirely separate $f$ from the anlage of the main part of the frontal- Klaatsch ('95), Schleip ('03), and others. In Amiurus, as remarked earlier in this paper ( $p$.) ), these have been noted as separate ossifications In brief, the frontal bones of the teleosts are paired ossifications arising from fibrous connective tissue. They may lie above a solid cartilaginous roof or they may form an integral part of the cranial roof. Anteriorly they usually interdigitate with the supraethmoids and the ectethmoids, and are separated from the nasal bones by a connective tissue bridge across which each supraorbital canal extends to enter the frontal. Posteriorly they usually interdigitate with the parietals, but in the siluroids the parietals are not present as descrete ossifications so they interdigitate with the supraocipital. There is commonly a fontanelle between the posterior ends of the bones, and in Amiurus and some few of the Characinidae there is an anterior fontanelle as well. The frontals overlap the orbitosphenoid and alisphenoid bones in the wall of the orbit, both internally and externally in those forms where ossification has proceeded very far. They also contain foramina and canals for the passage of the ophthalmic branch of the facialis to the integumental sense organs on the dorsal surface of the head and to the lateral line canal organs within the supraorbital canal.

The infraorbitals. This series includes the lacrimal described above, and another group of bones which extend from the 
$-1$

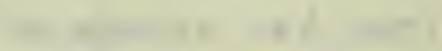

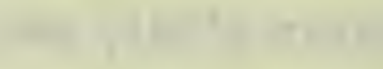

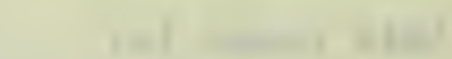

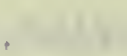

1

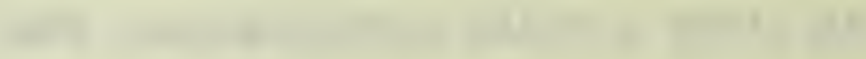

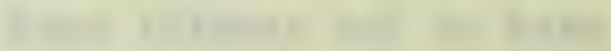

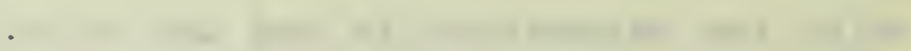
1. it

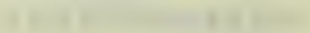

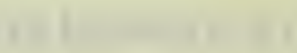
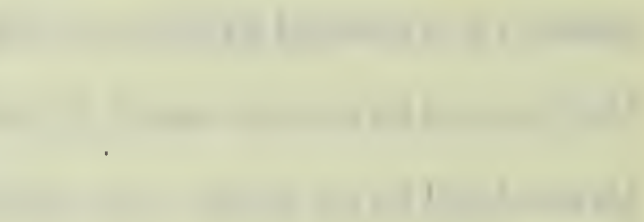

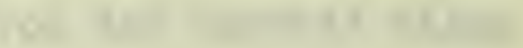

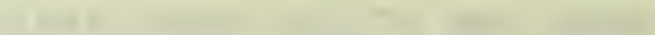

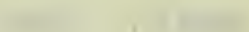

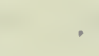

|
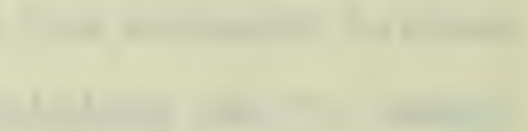

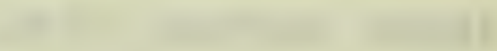

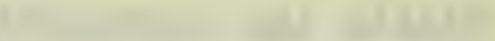
$+2$ 
posterior margin of the lacrimal below the eye, so that the most postero-dorsal bone of the series, the postfrontal, is attached to the frontal ridge, posterior to and above the eje (fig. 15 ). The whole series is maded up of three suborbitals, two postorbitald, and the postfrontal. These bones enclose the infraorbital or suborbital lateral line canal and are developed primarily for its protection. None of the bones unites by suture to its neighbors, but connexion is effected by ligamentous tissue and the fascia enveloping the muscles of this region.

The three suborbitals are the most slender and reed-like of the entire series. They lie deeply embedded in the connective tist sue anterior and posterior to the eatethmoid process, two being anterior to the process and the third just behind it. The first is the smallest of the trio and the second is next in size. Both of these have practically the same diameter as the enclosed lateral line canal. None of the suborbitals are sculptured. The third suborbital lies below the eye and is nearer to the cutis than the other two. It lies above the fascia of the anterior fibres of the adductor mandibularis muscle.

The two postorbitals are broader than any of the suborbitals. The first curves around the posterior margin of the eye and is attached superiorly to the inferior end of the second postorbital. The latter is the largest and longest bone of the series and is slightly curved dorsally toward the anterior part of the orbit. Ridges run on the anterior surface of the bone parallel to the course of the enclosed canal. Both postorbitals are firmly embedded in the fascia of the adductor mandibularis and the dilitator operculi muscles, some of their fibres having their origin along 
the ventral surface of these bones.

The most dorsal and posterior bone, the smallest of the series, is the posterontal. It lies dorsal to the superior end of the second postorbital, and like it, is embedded in the muscle fascia. This bone is not as flat as the others, the posterior margin being grooved, the margin of the groove projecting dorsal1y. The posterior end of the suborbital canal, which passes thr through the other bones of the chain lies within this groove. The anterior face of the bone is sculptured. As remarked above, the postfrontal is connected with the frontal by ligamentous tissue.

The principal morphological feature of this series of bones is their relation to the suborbital lateral line canal. From the lacrimal bone this canal extends through the infraorbital chain into the frontal. As it passes from one bone to the other it lies within the connectiee tissue which joins the two bones, and at these points between the bones, from lacrimal to frontal, a dermal tubule extends from the main canal to the surface of the integument where it opens by a single pore. There are five of these dermal tubules and pores between the posterior end of the lacrimgl and the junction of the suborbital canal with the supraorbital in the frontal bone. There is no tubule between the lacrimal and the first suborbital nor between the postfrontal and the frontal. There is a sense organ in each bone of the series

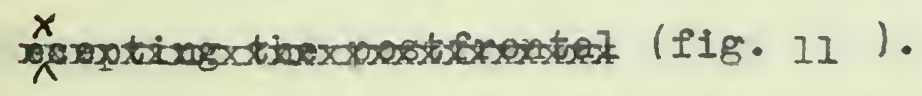

The development of the bones has been studied by Klatich ('95) and Schleip ('03). The former claims that all the bones develop from osteoblasts which proliferate below each sense 

organ of the developing system. He maintains that all the bone connected with a canal arises from these same osteoblasts. Schleip derives the lateral line containing element proper from these osteoblasts, but goes no further. Allis ('98) thinks that true dermal elements are present comparable to those which give rise to such bones as the frontal, supraethmoid, and other dermal bones of the head. In the development of Amiurus the bones begin as Klaatsch and Schleip have stated and in the $32 \mathrm{~mm}$ stage the canals are enclosed in tubular bones, all of which are close to the periphery of the canal wall. The rest of the bone is developed from the ossification of the fascia in the immediate region of these tubular bones, but I have not been able to trace the derivation of the osteoblasts which cause the ossification.

The number and size of these bones vary in the different families of ganoids and teleosts, but their position with regard to the eye and their relation to the suborbital lateral line canal are constant. The older comparative anatomists recognized them as the suborbitalia or frequently as the infraorbitalia, setting off the anterior bone of the series as the lacrimal on account of its size and relation to the nasal capsule. Van wijhe ('B2) remarked in a foot-note, that the developmental relation of these bones to the suborbital canal was a good character for homologizing the bones in the different groups. The nomenclature used in this paper is based upon that used by Allis ('98) in Amia. McMurrich ('84) found six bones in the series in Amiurus, but did not differentiate any of them nor make a detailed study of them. He says there are pores in these bones for the passage of more or fewer mucous canal tubules. In reality, there are no pores for 

the passage of such tubules because these leave the canals between the bones issuing through the connective tissue in this regif ion. Collinge ('95) has given a partial description of the relations of the suborbital lateral line canal to the infraorbital bones in Amiurus catus, and figures no tubules between the lacrimal bone and the junction of this canal with the supraorbital. Gegnbaur ('78) recognized seven elements in the infraorbital chain of Alepocephalus rostratus, the posterior bones being situated in the musole fascia on the dorsal surface of the cheek muscles. a dermal tubule passed to the exterior between each bone and in the first of the series, which is comparable to the main body of the lacrimal of Amiurus there were a number of tubules as in the same bone in Amia.

Allis ('98) called the last bone of the infraorbital series in Amia, the postfrontal, and justifies himself in so doing, by stating that the postfrontal never fuses with the underlying postorbital perichondrial ossification and always contains a part of the suborbital canal. He states that in some members of the in Characidae, and Cyprinidae, and in scomber, in which the dilitator operculi muscle lies on the dorsal surface of the cranium, this postfrontal lies above the muscle. The postfrontal of Amiurus fulfills all of these requirements and hence corresponds to the same bone in the groups mentioned.

According to this view the infraorbital chain of bones is comparable to the orbital ring of the Stegocephalans and Reptiles, in which there is usually a large lacrimal anterior to the eye, a zygomatic below the eye, followed by a postorbital, above which is a postfrontal. The fact that although the zygomatic bone is 

a member of the maxillary series, it never bears teeth lends some support to the assumption that it is a lateral Ine bone rather than a dentary. Iiost older authors homologized this ring of the fishes on purely topographical relationships, to the jugal arch of the Reptiles, and Bojanus (1818) called thom the ossa jugalia. Gaupp ('06) makes no statement concerning this homology. Cuvier first applied the name postfrontal in the fishes to that bone which is today recognized as the sphenotic, because he thought it was the homologue of the postfrontal of the Reptiles.

According to Allis ('98), the lacrimal of Amia is the homol ogue of the first suborbital of Amiurus. He regarded the adnasal of Amiurus as described by McMurrich (Iacrimal, Auct.) as the homologue of the antorbital of Amia, justifying his statement by saying that Collinge says that many authors call the bone by that name. Since this bone in Amiurus contains the anterior end of the suborbital lateral Iine canal. I have called it tho lacrimal, and it is possible that the long anterior lateral process may be the homologue of the antorbital of Amia. Merely because there are six infraorbitals in Amiurus and Amia, counting the lacrimal in the latter, but not in the former, it does not follow that the members of the series are numerically homologous from the anterior to the posterior end. The criterion for homology rests upon the relation of the bone to the nasal cpasule and the part of the lateral Ine that it contains.

The vomer. This bone,broad, flat, and unpaired, lies near the anterior end of the ventral surface of the cranium. It is entirely superficial to the bones which invest the chondrocranium in this region and is covered by the skin of the roof af the 

mouth (fig.6 ). As McMurrich ('84) said, the bone is nail-shaped the head of the nail is represented by the broad anterior portion and the shaft by the posterior spicules. It lacks tha anterior extension common to the vomer of most teleosts, and is limited in front by the supraethmoid. The serrate line of interdigitation between these two bones extends as far laterally on each side as the ventral end of the supraethmoid-ectethmoid interdigitation. The vomer is here separated from the margin of the descending ectethmold by a cartilaginous plate which is continuous with the palatine articular surface. Postero-laterally each side of the vomer interdigitates with the anterior edge of the ventral portion of the ectethmoids. Internal to these edges the several spicules mentioned above, extend posteriorly in a series of grooves on the ventral face of the parasphenoid. The bone does not articulate with the premaxillaries and is firmly united with the parasphenoid The ventral ossification of the supraethmoid extends beneath it, separating the anterior part from the chondrocranium, while the anterior end of the parasphenoid cuts it off behind from the orbit osphenoid (fig. 7 ). The bone itself is very thin and some of the fascia for muscle fibres of the eatopterygoid muscle are attached to the postero-dorsal margins. It has no teeth and none are developed in the roof of the mouth below it. The development of the bone has been described earlier in the paper.

Since Cuvier compared this bone in the fishes to the vomer of man, it has borne this name although there have seen been writ ten many arguments for and against this view which I will not attempt to discuss here. As it is one of the most evident bones on the anterior ventral surface of the skull in all teleosts, 

there has been no confusion in describing its topography. In some of the lower teleosts-Scomber,Salmo, and the mail-cheeked fishes, are among the best known examples - the vomer bears teeth and it was thought by some investigators that these were an integral part of the bone. Schleip ('03) has shown that in Salmo the vomer develop, as in Amiurus, from deep lying connective tissue beneath the chondrocranium and that the teeth arise indopendently In some of the Characinidae and Cyprinidae, the vomer is intimateIf connected with the cartilage of the ethmoid plate. In all adult teleosts it is unpaired, although it may arise from paired parts as in Esox (Walther,'82.). In some it forms a cap on the anterior end of the ethmoid cartilage. In none of the forms described up to this time has a condition wholly similar to that in Amiurus been found. Its limitation to the ventral surface of the cranium is not the common type of development, as there is usually anterior or lateral processes projecting for articulation with the cranial bones of the dorsal surface.

The orbitosphenoid. This is a large unpaired bone forming the floor and side walls of the cranium between the orbital and optic foramina (figs.6,7,16,20 ). It is visible externaly in the wall of the orbit, overlapped dorsally by the frontal and interdigitating anteriorly with the ectethmoid in both the upper and lower margins of the orbital foramen. This part of the bone is only a thin lamella on the cartilage which persists in the side walls of the cranium and unites with a similar lamella on the internal surface of the cartilage in the margins of the foramen. The anterior end of the alisphenoid bone extends down in front of the optic nerve so that the orbitosphenoid is limited 
$-x^{-1}$

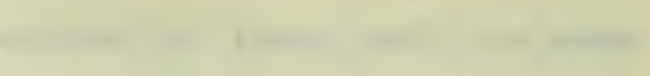

$-$ (1)
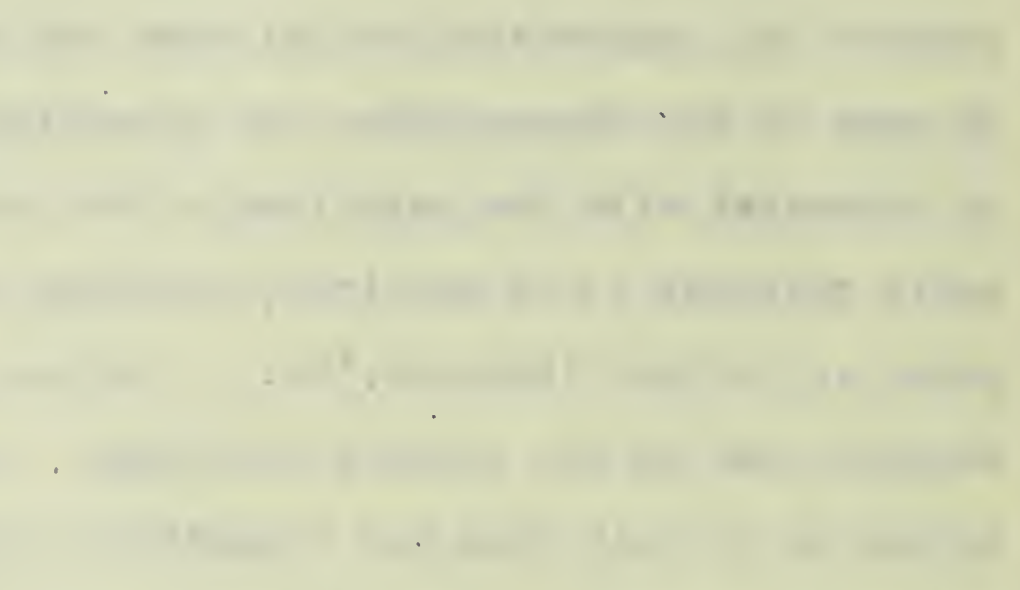
to the ventro-anterior wall of the foramen. In the midventral margin of the foramen it interdigitates extemally with a lateral process of the parasphenoid and the line between them extends across the ventral surface of the cranium to the optic foramen of the other side. The immediate middle part of this interdigitation is visible only upon removal of the vomer and the anterior spicule of the parasphenoid (fig. 16 ). The ventral anterior end of the orbitosphenoid is separated from the laterally lying ectethmoids by cartilage. The median anterior margin lies quite far posterior to the main part of the supraethmoid, but several spicules from the latter bone extend posteriorly to it along the dorsal surface of the parasphenoid (fig. 7,16). The interval between the main parts of the suprathmoid and the orbitosphenoid is occupied by the ethmoid cartilage.

There is a notch on each side of the bone in the orbital wall, just behind the orbital foramen, for the attachment of the pterygoid muscles (fig. 20). The ventral wall of the notch continves posteriorly as far as the optic foramen and forms a shelf supporting the optic nerve. The whole ventral surface of the bone is roughened by fine lines. On the median ventral part of the bone, which is closely applied to the dorsal surface of the parasphenoid, the lines run longitudinally, and on the lateral parts in the orbital walls, radiate from a center on each side (fig. 16 ).

A longitudinal section through the cranium shows the relative extent and thickness of the orbitosphenoid (fig. 7 ). The dorsal posterior surface of the bone is overlapped by the suprasphenoid and the ventral, by the parasphenoid; suprasphenoid and 


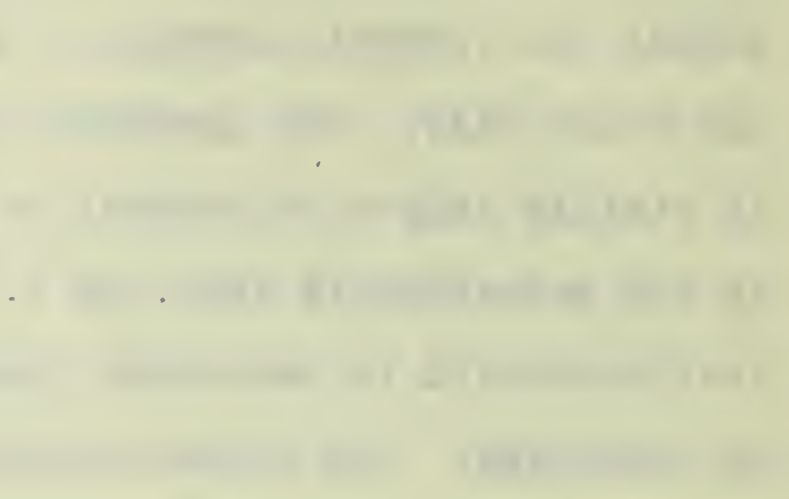

(n)

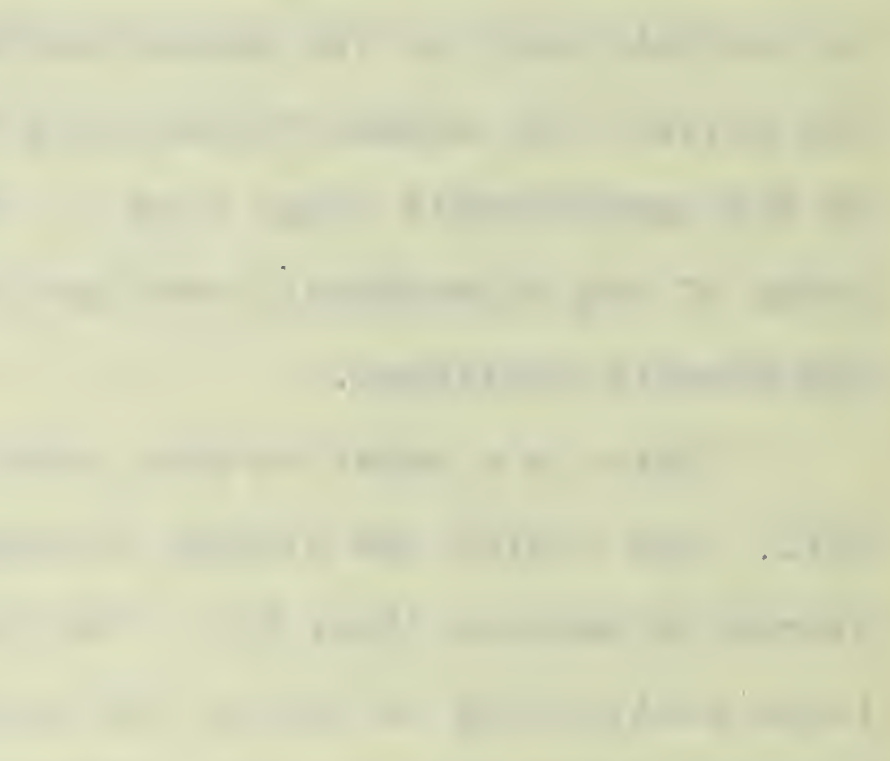


parasphenoid bones fusing at the posterior margin of the bone. Anteriorly the orbltosphenoid thins out and passes gradually into the cartilage of the interhasal septum. The midale part of the bone has entirely ossified, but the persistence of cartilage beneath the external lamellae of the lateral parts of the bone shows that ossification ossification does not extend uniformly through all its parts. The frontal overlaps the dorsal margin of the bone in the carum wall and in line with the epiphysial bar region the alisphenoid and orbitospehnoid meet above the optic formen. Considerable cartilage remains in both of these bones in this region, but between this point and the anterior end, the part of the orbitosphenoid which forms the wall of the cavam is well ossified. Below the optic foramina the orbitosphenoid-suprasphenoid interdigitation continues from one side to the other within the cavum, marking the posterior limit of the orbitosphenoid as a lining bone of the cavum cranii. (fig. 7 ).

The developmental relations of the orbitosphenold have been given in the $32 \mathrm{~mm}$ stage (p.) ). The perichondrial ossifications in the wall of the cranium which now form an integral part of the bone were just beginning at that stage. From the description immediately above, it is evident that there is considerable cartilage yet remaining within these osseous lamellae. The ledge on the external surface of the bone between the orbital and optic foramina is developed from connective tissue surrounding the ventral end of the alisphenoid cartilage and the trabecula cranii, and is intimately connected with the perichondrial ossifications of these cartilages (fig. 3 ). The stout median part of the bone is developed from perichondrial ossifications which have 
$+$

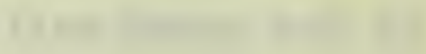

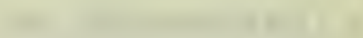

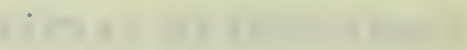

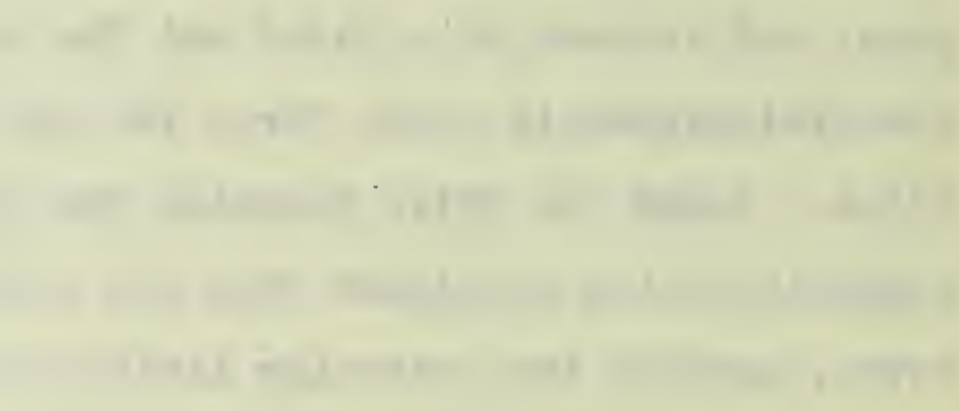
.

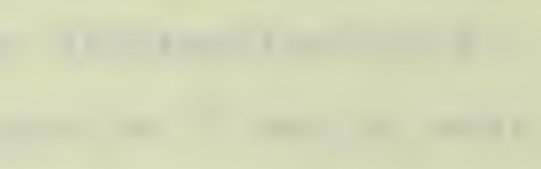

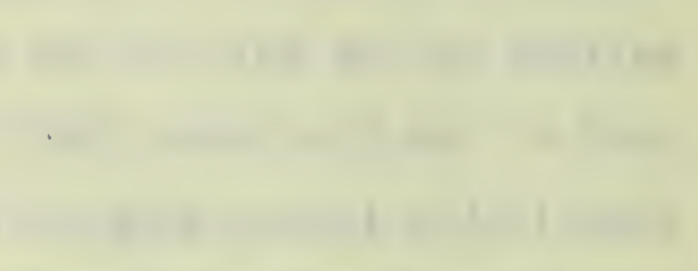

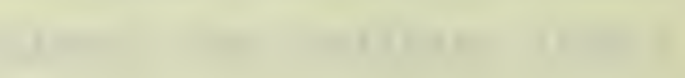

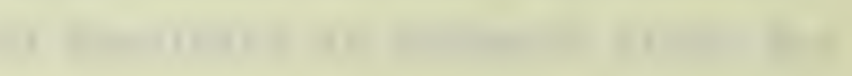

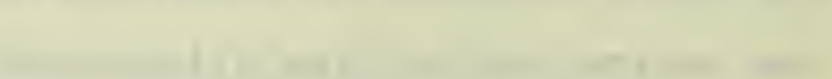

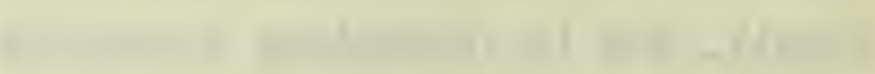

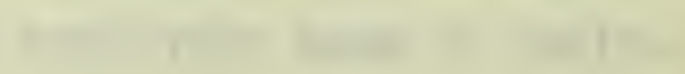


fused with each other across the anterior end of the fenestra hypophyseos (fig. 3 ). In the younger stages the cerebral hemispheres lie immediately dorsal to the orbitosphenoid region, but in the adult they are quite far posterior to it, and the olfactory tract surrounded on each side by a gelatinous mass extends above it. The anterior end of the jugular vein enters the cranium through the orbital foramen and proceeds posteriorly along the dorsal surface of that part of the orbitosphenoid which forms the the wall of the cavum cranii.

The earlier descriptions of this bone were confusing because of its absence in some of the lower teleosts, especially since it is absent in the perch, Cuvier's tyoe of fish cranium. The present identity of the bone with the ala orbitales of mammalian anatomy is derived from the work of Hallmann ('37). He recognized Cuvier's error in naming the petrosal. the ala magna and hence confusing the homologies of the more anterior parts. Since the bone next in front of the petrosal in mammals was the ala magna of the sphenoid, and since this bone in the carp had relations corresponding to it, the name was applied. The bone in front of this was then compared to the ala parva and found to correspond, hence it was named. Agassi? ('42) and stannius ('53) did not recognize this homology, but named the bone the os ethmoideum. The present name, orbitosphenoid, was given to the bone by Owen ('48) and is in general use at the present time.

In many of the lower teleosts where a large interorbital septum is developed the orbitosphenoid is lacking. Among these are Scomber, the mail-cheeked fishes (Allis): Perca (Cuvier,Hallmann); Osteoglossur, Gonorhynchus, Chanos (Ridewood, '04); Gast- 


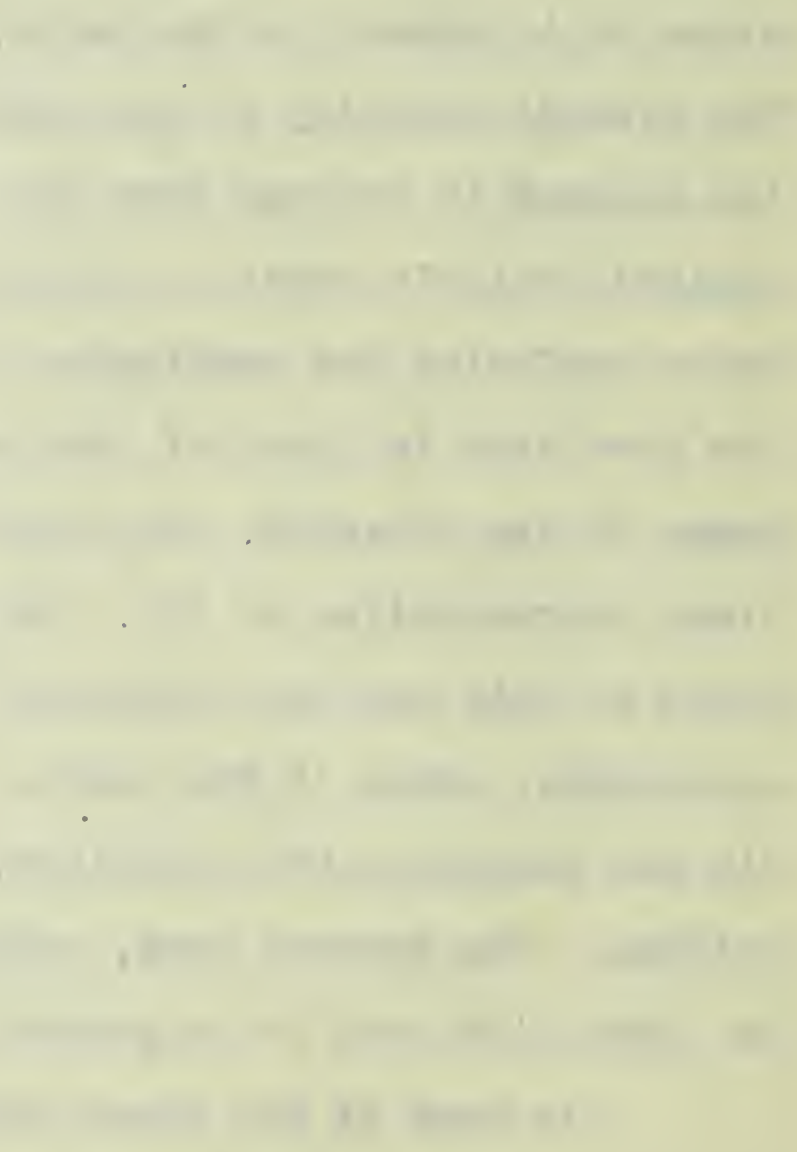


erosteus (Swinnerton, '02); and others not referred to here.

In Amia (Sagemehl, '84) the orbitosphenoid is paired and lies on the cartilage above the anterior margin of the optic foramen, separated from the bones above and in front by cartilage. In Arapiama (Ridewood,'04), it is paired, but unlike Amir, these ossifications extend from the frontals to the parasphenoid. In those species with a medieum sized interorbital septum as Salmo (Parker,'72\%, Alepocephalus (Gegenbaur, '78), and some of the Cyprinidae (\$agemehl,'91), the orbitospehnoid is unpaired and $Y-$ shaped, the arms of the $Y$ extending up in the walls of the cranium and the basal part down into the orbital septum. It always lies above the anterior margin of the optic fenestra and usually the basal piece ossifies as far ventrally as the trabecula communis. In the Characinidae the bone has various gradations in structure from the U-shaped form corresponding to that of Amiurus, to the Y-shaped Salmonoid type. Of all the forms studied I think that the orbitosphenoid as found in Homolopterus of the Gharacinidae is the closest in orbitosphenoid relations to Amiurus. There is the same strongly ossified midventral piece, and the same general relations to the surrounding bones, and the optic nerve. The orbital foramen is also present between the orbitosphenoid and the ectethmoid of each side and considerable cartilage remains within the bone, a strip of it persisting between the frontals and uppor ends of the inner surface of the bone.

Vrolik ('78) maintained that because the orbitosphenoid' is an incohstant bone and because it could be developed from either the membrane of the interorbital septum or cartilage, that it could not be homologized throughout the different groups. The fact of its relation to the nerve foramina, its gradation in 


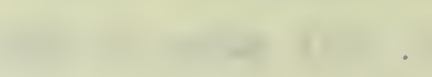

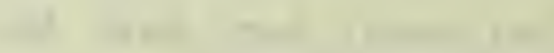
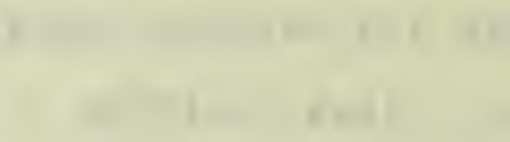

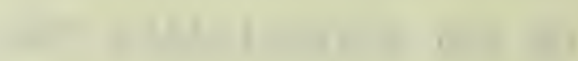

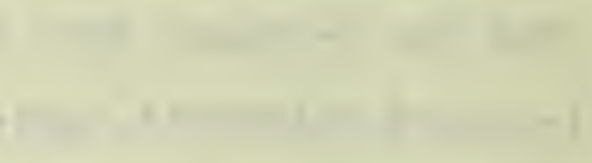

1

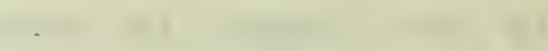

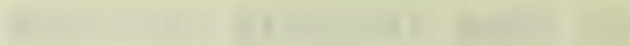

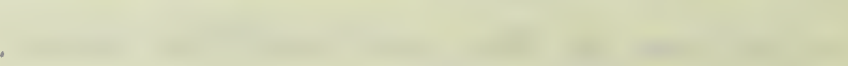

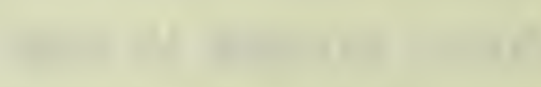

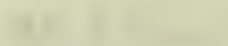

1 n

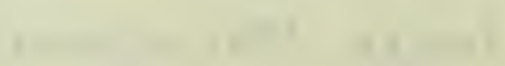

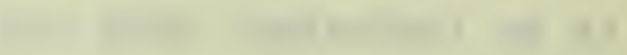

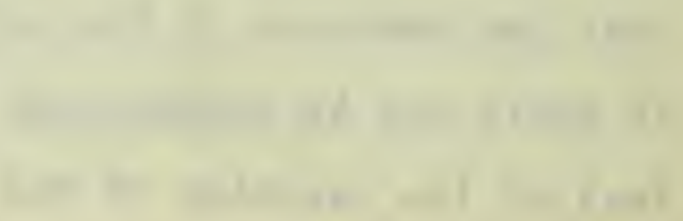


development in the lower forms all help to prove that originally it was a paired bone in the ancestral teleosts, and that it was originally developed from cartilage. Cartilaginous cells are present in the interorbital septum of those forms in which the septum is decidedly primitive, a circumstance which may be taken to indicate that there has been a shortening of the ontogeny of the septum in the higher forms where the septum ossifies directly. The parasohenoid (figs. 6,7). This is a long, flat, unpaired bone extending on the ventral surface of the cranium from the supraethmoid to the anterior end of the basioccipital. Its anterior interdigitation with the supraethmoid is hidden by the vomer. The median anterior end of the parasphenoid is kept from contact with the ethmoid cartilage or internasal septum by the supraethmoid (fig. 7). The posterior spicules of the supraethmoid are inserted in grooves on the ventral surface of the parasphenoid. The anterior lateral margins of the bone, fitting tightly against the cartilage of the ethmoid plate are separated from the ectethmoids by a narrow interval. Posterior to the supraethmoid, the orbitosphenoid is developed between the parasphenoid and the chondrocranium. In this region the parasphenoid is limited to the ventral surface of the orbitosphenoid; the arcus palatini muscles are inserted in a groove on each side of the former. The projection ventral to this groove ends posteriorl $y$ in a little knob ventral to the trigemino-facial foramen ( $f i g$. $6,20)$. At the posterior end of the orbitosphenoid the parasphenoid expans laterally to form the posterior margin of the optic foramen interdigitating dorsally with the alisphenoid. Behind the allsphenoid the parasphenoid interdigitates with the prootic 

and with it forms the ventral posterior margin of the trigeminofacialis foramen. The posterior end of the parasphenoid is inserted in grooves on the ventral surface of the basioccipital.

Behind the orbitosphenoid, the parasphenoid is excluded from the floor of the cavum cranii by the suprasphenoid. In the younger stage the suprasphenoid developed on the cerebral surface of the parasphenoid and is firmly connected with it even in the $32 \mathrm{~mm}$ stage (fig. 32). There are spaces in the floor of the cranium close behind the orbitosphenoid between the para-and suprasphenoid in the adult which show where the cartilage has been resorbed (fig. 7), but traces of cartilage are present also. Sagemehl in his study of the Characinidae and the Cyprinidae did not recognize a suprasphenoid element anchylosed to the cerebral part of the parasphenoid, but described the floor of the cavum as formed by the parasphenoid. It is evident that had he studied the development of this region, he would have identified two elements in the composition of his parasphenoid. In the Cyprinidae, he states that the parasphenoid forms the posterior end of the interorbital septum when such is present. In all of the other teleosts, as Salmo, with a medium sized interorbital septum, the part of the septum posterior to the optic foramina and anterior to the hyopophysis is formed by a $Y$ or $T$-shaped suprasphenoid (basisphenoid of the usual terminology). The parasphenoid always forms the support of the basal part of the Y. In Amiurus there is no basal part to the $Y$, consequently the arms lie directly upon the cerbral surface of the parasphenoid and it is only by the study of the development of this region that the two elements are recognizable. Even in the adult the 

two elements are recognizable to a certain degree in the median section of the cranium (fig. 7), where the posterior end of the orbitosphenoid and the anterior end of the prootic are enclosed by the parasphenoid externally and the suprasphenoid internally. In those fishes which have a well developed eye-muscle canal,-Nalmo, Scomber, and the Loricati,- the parasphenoid is separated from the prootic bones by the lumen of the canal, the floor and part of the side walls of which are formed by the parasphenoid. In Amiurus the parasphenoid is fused to the ventral surface of the prootics (fig. 7). The wings which extend dorsolaterally between the orbitosphenoid and the prootic, are characteristic of the teleostean parasphenoid. In some forms they lie behind the fifth nerve and in others in front of it, which Swinnerton regards as of importance in establishing the morphology of the bone. The ridge for the insertion of the arcus palatini muscles is characteristic of the ventral surface of the parasphenoid. There are usually two of these ridges as in Amiurus, but in Scomber (Allis, '03) they have fused into a single ridge along the middle line of the bone.

Before Huxley, the parasphenoid was regarded as the homologu of the mammalian basisphenoid and was called the 'sphenoide basilare'. Huxley ('64) recognized the peculiar relation of this bone to the ventral surface of the cranium and denied this homology because it extended beneatb the anterior bones of the cranium and posteriorly beneath the basioccipital, and was easily detached from the chondrocranium. He limited the distribution of the parasphenoid to the branchiate vertebrates and this idea was prevalent until Sutton ('84) maintained that the bone was present 

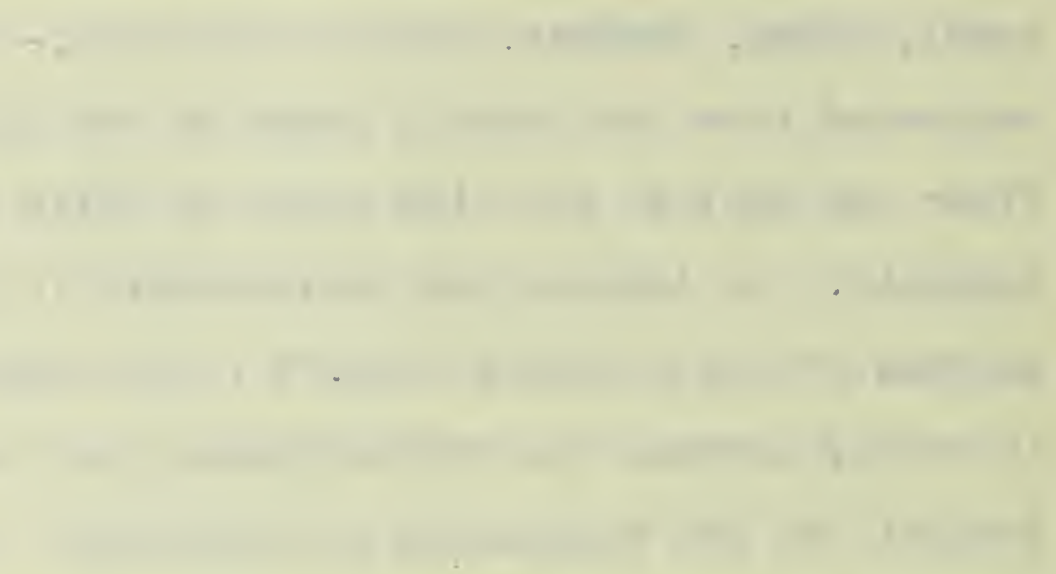

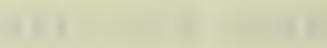
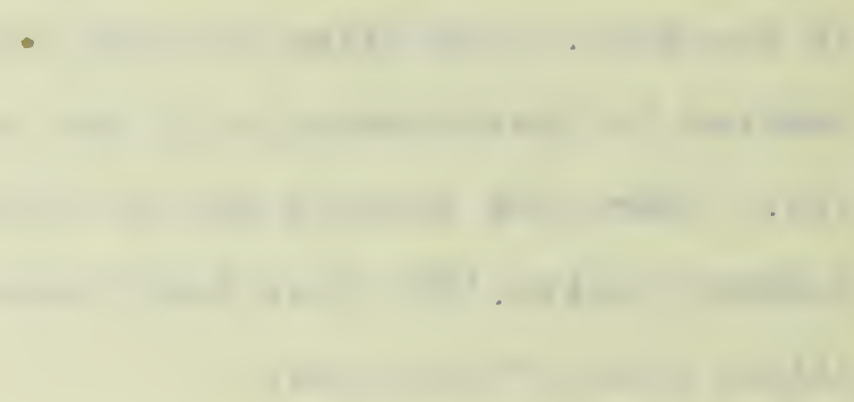

4 
in the higher groups and that it was the representative of the vomer of the mammals. Its great development in the fishes and in the Amphibia is due to the weak base of the chondrocranium. With the highly ossified condition of the sphenoidal cartilages of the mammalia the bone was no longer needed as a support of the cranium and so it became a part of the septum of the nasal passages.

The development of the parasphenoid from membrane belor the anterior basicranial fenestra has been known for a long time in many groups and, as noted above (page 43), the development in Aniurus is typical. In some of the, lower teleosts among which are Osteogiossum (Ridewood, '04), the parasphenoid bears teeth, but it is not known whether they are primarily an integral part of the developing hone or have fused with it later.

The suprasphenoid. This bone in Amiurus is in a very unspecialized condition as compared with those teleosts which have an interorbital septum. It lies cerebral to the parasphenoid and is firmly fused to it (fig. 7). It occupies the floor of the cavum cranil between the optic and trigeminal nerves; anteriorly it overlaps the orbitospkenoid, posteriorly the prootic. LateralIy between the foramina for these nerves it interdigitates with the alisphenoid. As stated on page 44, it is developed from membranous connective tissue between the trabeculae in the fenestra hypophyseos (fig. 32). It has all the characters common to the suprasphenoid bone of the other teleosts, except the eye muscle relations. The homologies of this bone have been discussed earlient in the paper as the terminology used is based principally upon its developmental relations.

The alisphenoids. These are a pair of bones, one on each 

side of the cranium between the optic and trigemino-facial foramina (figs. 7,20). Their ventral ends are separated externalyy from each other by the parasphenoid, and internally by the suprasphenoid. The former is usually sutured to the alisphenoid between the ventro-posterior margin of the optic foramen and the antero-ventral margin of the trigemino-facial foramen. An anterior process of the alisphenoid extends ventrally as the anterior margin of the optic foramen, descending in the orbital wall as far as the orbitosphenoid. This interdigitation between the aliand orbitosphenoids continues dorso-pusteriorly to the anterior end of that part of the frontal which overlaps the dorsal margin of the alisphenoid. The latter extends higher up in the cranial wall than does the more anteriorly situated orbitosphenoid. Above the trigemino-facial foramen the alisphenoid interdigitates with the anterior margin of the ventral part of the sphenotic. the line of interdigitation continuing forward between the sphenotic and the frontal. The sphenotic projects broady above this part of the alisphenoid and a concavity is formed between them by the lateral projection of the alisphenoid. The ligament of the dilitator operculi muscle is inserted on the roughened face of the alisphenoid in this concavity. The very anterior margin of the hyomandibula articulates with the posterior edge of the alisphenoif below the ligament insertion.

The ophthalmic branch of the trigeminus issues from the crainum through a foramen in the wall of the alisphenoid just postero-dorsal to the optic foramen and extends anteriorly along a ledge above the latter. This foramen is the outer end of a short canal which proceeds posteriorly within the alisphenoid 


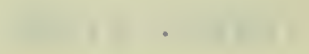

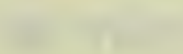
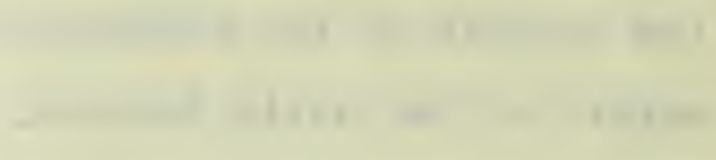

-
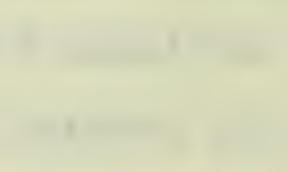

-

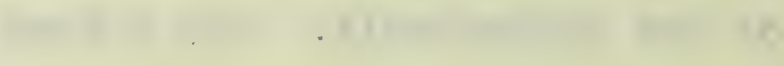

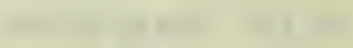

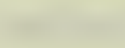

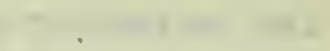

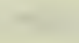

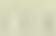


and has its cerebral opening near the posterior ventral margin of the internal surface of the bone (fig. 7). The ophthalmic branch of the facial passes anteriorly through a more dorsally placed canal. Although its cerebral opening is just dorsal to the cerebral opening of the ophthalmic oranch of the trigeminus, the external opening of the canal is farther forward than the external opaning of the latter, and lies just posterior to the point where alisphenoid, frontal and orbitosphenoid meet. The manner in which these nerves are inclued within the bone is first seen in the $32 \mathrm{~mm}$ stage (fig. 4). Up to that time the nerves, after leaving the cartilage, extend unenclosed across the orbit, but with subsequent development they are gradually enclosed by the ossification of the connective tissue around them in connexion with the alisphenoid cartilage, so that eventually the adult condition is reached. The ventral end of the bone is formed by the ossification of the original membranous wall between the optic and trigeminal nerves (fig. 32). This method of development of the alisphenoid from cartilage and membrane has been noted in Salmo (Schleip, '03).

The cerebral surface of the alisphenoid bone is smooth and presents the same relations to the surrounding bones as externally except at its ventral margin, where it is overlapped by the dorsal projection of the suprasphenoid (fig. 7 ). The anterior margin of the alisphenoid where it meets the orbitosphenoid has not entirely renlaced the underlying cartilage, which still shows through the thin surface lamella. There is probably some cartilage yet remaining between the dorsal cap of the bone and the ventral surface of the frontal. The inner ends of the 

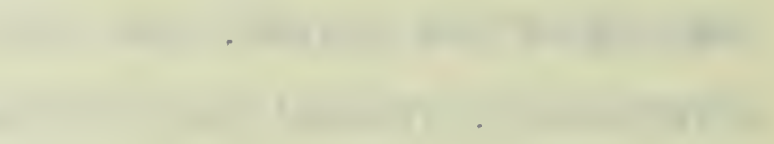

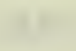
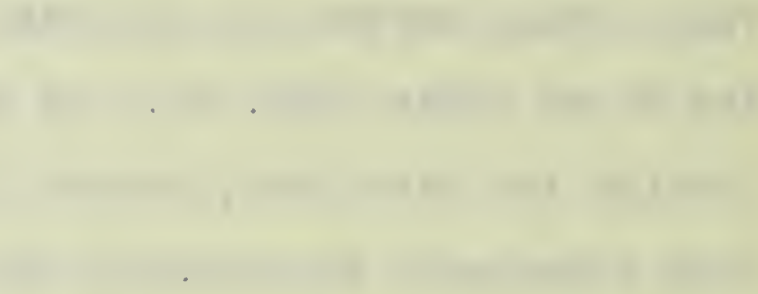

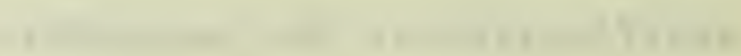
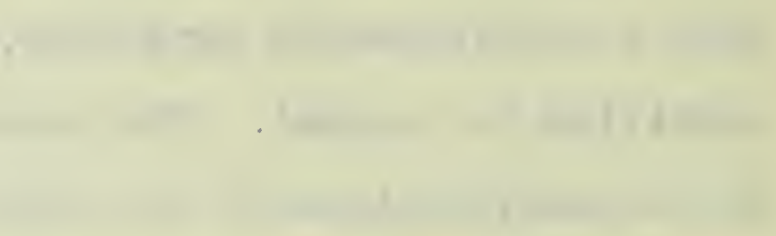

$+2$

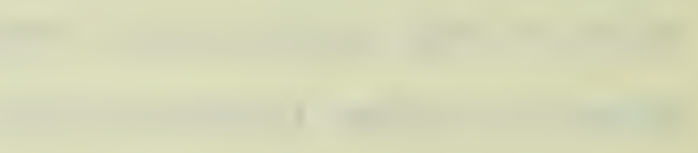

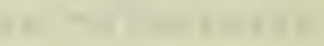

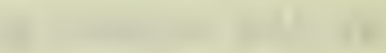

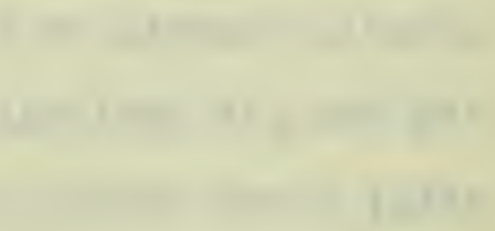


canals for the ophthalmic branches of the fifth and seventh nerves have been discussed above. Heliurrich noted both of these canal openings, but only one nerve. He stated ('84) that the upper opening "opens into the interior of the bone like other similar foramina which perhaps, have a nutritive function." In reality this foramen is the pasterior end of a canal for the passage of the ophthalmicus branch of the facial nerve and not for a blood vessel. He also says that the ventral margin of the alisphenoid bone articulates with the basisphenoid (suprasphenoid, auct.) alone and does not touch the parasphenoid, but from a study of sections through this region, I think that para- and suprasphenoid. are fused along the ventral margin of the bone and that the extern al surface is the parasphenoid and the internal, suprasphenoid. I cannot find any point where alisphenoid meets the prootic as he maintains, but since this is common in most of the teleosts, there is a possibility that such was the condition in the specimens he studied, although it is present in none of mine.

An historical review of the various names which this bone has borne since the earliest descriptions of it by lieckel, irend, Cuvier, and others, is given by owen ('48), Vrolik ('73), and Starks ('OI). Since the orbitosphenoid was lacking in the perch, which, Cuvier used as his type, he caused confusion in the literature by nam ing the alisphenoid as the homologue of the ala orbitalis and the prootic as the ala magna. Hallman ('37), as noted above, recognized the true homology of the bone and called it the ala magna, because of its relation to the first branch of the trigeminus. Huxley's work on the homologies of the basal part of the cranium helped to define the criteria for the identification 


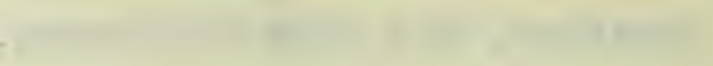

(n)

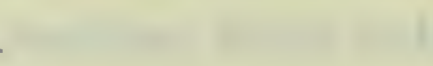

、 
of the bone as it is known today. Orren at the same time, ignored Huxley's conclusions and regarded the bone as the orbitosphenoid because of its relation to the optic nerve. At present all ichthy ologists agree that this bone has aoproximately the same relations to the surrounding bones as has been described for Amiurus and the term alisphenoid is in common use. Yet, as stated above, some do not regard it as the homologue of the greater wing of the mammals (page 46).

In fishes with a well developed interorbital septum, the orbitosphenoid is wanting and the alisphenoid is correspondingly reduced in size. Scomber (Allis,'03). the Loricati (Allis,'10), and Alenocephalus (Gegenbaur,"78), are good examples of this limitation in the development of the bone. In spite of its size in these forms the alisphenoid usually encloses a small foramen for the ophthalmic branch of the fifth nerve, just posterior to the optic. In Negalops (Ridewood, '04) the alisphenoids meet in the roof of the cranium. In Gasterosteous (Swinnerton, '02) the alisphenoids are lacking, their place being taken by dorsal spiculae of the parasphenoid.

The Cynrinidae (Bagemehl, '91) have the nearest approach to the type of alisphenoid found in Amiurus, and in Catostomus there is the same anterior projection of the bone. Stannius ('53) recognized this high development of the alisphenoid as typical of the cyprnids and siluroids, basing his observations on silurus glanis and Cyprinus carpio. Vrolik's figure of Silurus glanis also shows a well developed alisphenoid.

The developmental relations of the bone have been discussed above, but it may be added that the roughened surfaces for the 

attachment of muscles and ligaments of the adult is developed from the muscle fascia and connective tissue surrounding the perichondrial lamella of the alisphenoid cartilage.

The sphenotics. Next to the frontals, these are the most conspicuous paired bones on the dorsal surface of the cranium (fig. 10). Each is subquadrangular in shape and has long: interdigitating margins, projecting into the surrounding bones. Anteriorly, it interdigitates with the posterior margin of the frontal, the line between these two bones being continuous posteriorly with the sphenotic-supraocipital interdigitation. The posterior margin of the dorsal surface of the bone extends in between the squamoso-oterotic and the anterior end of the supraoccipital, almost touching the transverse crest of the latter. The anterior lateral margin of the sphenotic is raised slightly so that a dilitator groove is formed along the latero-dorsal surface, for the insertion of part of the dilitator operculi muscle and ligament. The surface of the bone is without ridges and the lateral line canal ossification has sunken below the surface and is invisible from above. The only foramina on the dorsal surface of the bone are several for the passage of twigs of the ramus oticus of the facial.

The lateral surface of the bone is grooved for articulation with the hyomandibula (fig. 20). This surface is ossified, but the face of the hyomandibula which articulates with it, is still cartilage. The beginning of the ossification in this region has been shown earlier (fig. 19,33). The articular facet is continuous posteriorly with a similar groove on the lateral face of the squamoso-pterotic, and below it the two bones are separated from 


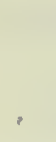


each other by a narrow strip of cartilage, which extends ventrally as far as the prootic bone (fig. 20). The line of interdigitation between sphenotic and prootic extends antero-ventrally from the ventral end of this piece of cartilage and continues as far anteriorly as the dorso-posterior margin of the trigemino-facial foramen. From this point as far forward as the mid-dorsal margin of the foramen the sphenotic alone forms the margin. Hezeit comes in contact with the posterior end of the alisphenoid and the suture between them extends dorso-ventrally as far as the region where the sphenotic meets the frontal. Viewed from above the ventro-external extent of the sphenotic is not very great. The internal surface of the bone forms an almost square area in the cranial wall from the dorsal margin of the trigeminofacial foramen to the supraoccipital (fig.7). Anteriorly it is in contact with the alisphenoid in the margin of the same foramen and above this with the frontal. The interdigitation with the frontal continues posteriorly as the line between sphenotic and supraoccipital. Posteriorly the sphenotic meets the prootic and the continuation of this suture to the supraoceipital is restricted by a small square of cartilage. A shallow recess about in the center of the cerebral surface of the sphenotic contains the cerebral end of a canal through which the ramus oticus facialis passes and which emerges by several foraming. on the dorsal surface as noted. The anterior end of the recess for the anterior semicircular canal lies within the bone, but the canal itself does not extend to the end of the process. The internal surface of the recess, noted above as filled wi th trabeculae (figs. 33,36), has now entirely ossified so that this 

part of the sphenotic bone is solid. Cartilage between the inner and outer lamellae of the bone has not been replaced entirely, traces of it occurring between the pterotic and the sphenotic. The large cartilaginous roof present in the $32 \mathrm{~mm}$ stage between the supraoccipital and the medial dorsal edge of the sphenotic (fig. 3) has been covered by perichondrial ossification continuous with the latter. The lateral line ossification has become an integral part of the bone although restricted to a very small area (fig. 11). There are no sense organs within the lateral line canal in the sphenotic nor are there any tubules leading to the exterior.

From Cuvier('26) to Parker ('72), the sphenotic was regarded as the homologue of the postfrontal of the reptiles, and so named. Parker first called it the sphenotic and described it in Salmo as an ectosteal ossification of the otic capsule above the ampulla of the anterior semicircular canal, thus grouping it with the other otic bones described by Huxley ('64). Up to that time the criterion for the homology of this bone was based upon morphological rather than ontogenetical relations. Vrolik ("72) devotes a short paragraph to the names which this bone has borne in the older literature, but calls it the postfrontf al and describes it in the teleosts as a "perichondrostische ossifikation", the equivalent of a dermal bone of the present paper. In Amia (Bridge,'77; Sagemehl,'84) the bone was called the postfrontal, until Allis ('98) revised the nomenclature of the problematical bones of this animal, and called it the postorbital ossification. The use of this term was unfortunate because he had already applied the name postorbital to a bone of the 
infraorbital series as the homologue of the reptilian postorbital. The name posterontal was given to the superior dorsal bone of the infraorbital chain and from his definition of it, I have followed him in naming its homologue in Amiurus. In Scomber (Allis, '03), he uses the same confusing terms, postorbital bone and postorbital ossification for postorbital and sphenotic respectively. justifying his terminology, on the basis, that they should not convey any relationship to the bones of the higher groups. The term sphenotic as used by Parker is more expressive of the developmental relations of this bone than the terminology of Allis and, as this bone is strictly a piscine and avian ossification no confusion will arise through its use. Allis ('10) evidently has change his views and has called the homologous bone of the loricati, the sphenotic.

Ridewood ('04) maintains that the term postfrontal should be retained because it describes the uppermost surface of the bone, the lateral line element. According to Allis ('98) the postfrontal never fuses with an underlying perichondrial ossification and hence this part of the sphenotic is not comparable to the true postfrontal. He does not attempt to explain to what bone this dermal derivative may be compared. In Amiurus as in many other teleosts, the perichonarial ossification on the chondrocraniurn is fused with a dorsal lying lateral canal ossification (figs. 19,33). McMurrich also noticed this in his work on Amiurus. If the postfrontal of Amiurus is to be regarded as the superior infraorbital bone, then this lateral Iine canal ossification above the sphenotic, must be an element which has no homologue in the higher groups and is developed for the protection of the canal 

alone, eventually sinking in and becoming intimately connected with the perichondrial ossification. That it takes only a minor part in the formation of the broad roof of the bone can be seen by the way in which the major part of the bone is developed medial to it on the surface of the otic capsule.

The homologies of the remaining parts of the bone in the Teleostomes arc easy to trace. The lateral face is usually grooved for articulation with the hyomandibula and is related in Amiurus to the anterior and pasteriorly situated bones. In most of the members of the above group the sphenotic does not have the ventral extent found in Amiurus, nor does it occupy as much of the dorsal surface of the cranium. In Scomber (Allis, '03) and the Ioricati (Allis,'lo), the relations of the ramus oticus facialis are comparable to the condition in Amiurus.

There is a great deal of cartilage within the bone and some times, as in salmo, there is no intemal ossification. The relation of the bone to the recess for the anterior semicircular canal is a constant feature, although in most fishes the canal extends only part way into it.

In some of the Cyprinidae the lateral part of the dorsal surface of the bone is grooved for the insertion of the dilitator operculi ligament and muscles as in Amiurus. In other teleosts this fossa lies more upon the posterior margin of the frontal than upon the sphenotic. It may be said however, that the sphenotic usualy forms a part of the dilitator fossa.

The prootics. These bones form the floor and most of the lateral walls of the cavum cranii, posterior to the suprasphenoid and the formina for the passage of the seventh nerves. As noted 


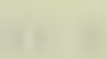

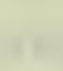
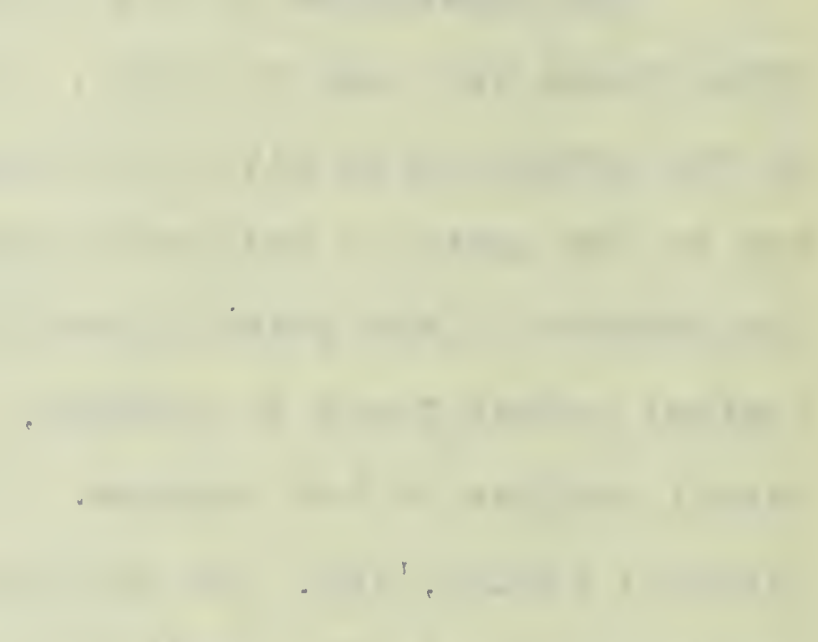

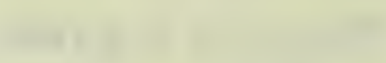


above (fig. 4,26), they develop around the anterior parachordals and the ventral part of the otic capsules. They are fused with each other in the medial line of the cranial floor, below and posterior to the hypophysis. A large amount of the original cartilage remains in both the lateral and ventral parts of the bone, for the most part encased in a perichondrial osseous lamella and continuous with the cartilage of the surrounding bones (fig. 7). That part of the bone which forms the posterior margin of the trigemino-facial foramen is exceedingly thin and transparaent. In tracing the development it was noted that the cartilage which originally formed the posterior margin of the foramen in the 10 $\mathrm{mm}$ stage did not keep pace with the growth of the cartilage of the surrounding parts, so that in the $32 \mathrm{~mm}$ stage, \& thin lamella of bone formed the margin, as if the cartilaginous connexion between the parachordal and otic capsule had been stretched, until only the ossified perichondrium remained between them (fig. 4 ). The other thin part of the bone lies near its posterior margin, just dorso-anteriar to its suture with the basioccipital (fig.20) This part was formed from the outer lamella alone, as is stated in the discussion of the $32 \mathrm{~mm}$ stage, and was solid cartilage in the $10 \mathrm{~mm}$ stage.

The external surface of the bone is smooth except for a shallow depression near the dorsal margin where the adductor hyomandibularis is inserted (fig. 20). The bone is almost square in outline and has anterior,dorsal, and ventral edges serrated, where they overlap the other bones. The posterior margin is traight and separated from the exoccipital by a thin strip of cartilage. Antero-dorsally it interdigitates with the 

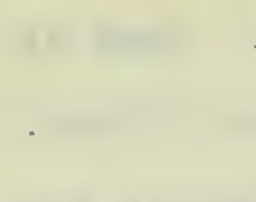
sphenotic below the hyomandibular facet, but takes no part in the formation of the latter. Dorso-posteriorly this line of interdigitation continues between the prootic and the anterior end of the pterotic. Ventro-anteriorly it is overlapped by the parasphenoid and behind by the basioccipital. No foramina are present in the body of the bone for the passage of nerves or blood vessels as these all leave by the trigemino-facial foramen.

The internal surface of the bone is not as regular in outline nor does it present the same smoothness as the outer (fig. 7) As remarked above, the bones of the two sides are fused in the middle line and their anterior edges are overlapped by the posterior margin of the suprasphenoid bone which extends from the ventral margin of one trigemino-facial foramen across the floor of the cranium to the other. There is a shallow depression in the floor of the cranium just behind this contact with the basisphenoid, the sella turcica, for the hypophysis. The floor of the sella is very thin, but immediately posterior to it there is a massive ridge, the dorsum sellae, which is continuous posteriorly with the bulk of the basioccipital bone. This is not completely ossified, but considerable cartilage continuous with that within the basioccipital remains between the inner and outer lameliae.

The median section shows the relations of the prootics to the parasphenoid and basioccipital in this posterior region. The recessus sacculorum project anteriorly into the posterior ends of the prootics and medial to them the transverse suture between the inner lamella of the prootics and the basioccipital is visible In the $32 \mathrm{~mm}$ stage (fig. 27) a thin horizontal lamelia from the median cartilage extends laterally above the anterior end of each 

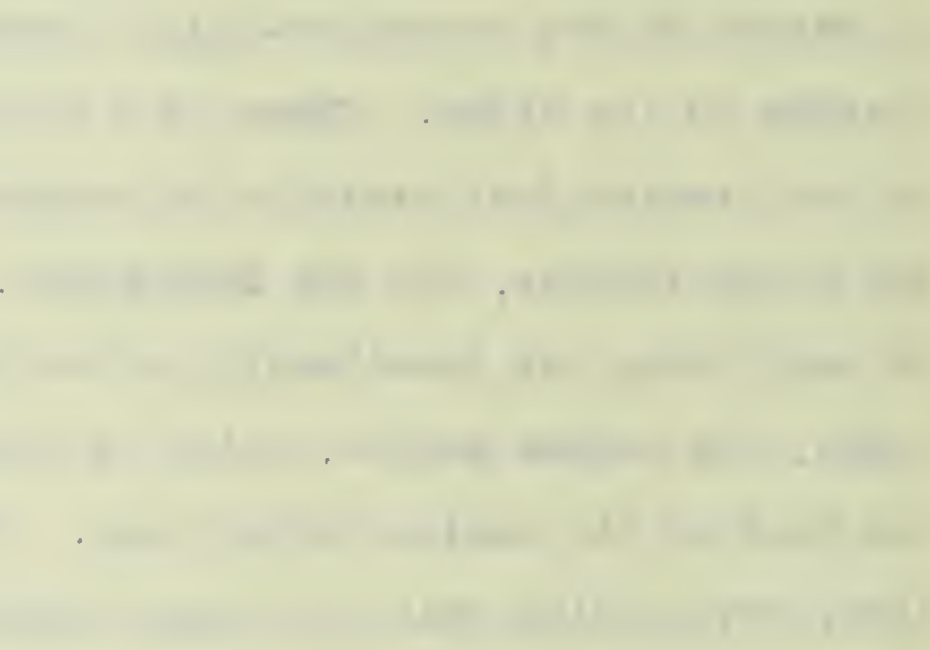

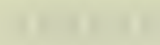

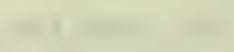


recessus to the ventral edge of the otic capsule, but no lamella. had yet formed on the floar of the reoessus. In the adult, this basal lamella is present and, together with a lamella of the basioccipital, extends ventrally into the recess. The prootic lamella forms both floor and side walls of the recessus and is fused with the ventral face of the horizontal lamella, but the basioccipital lamella meets a descending lamella of the exoccipital half way up in the lateral wall. Thus in the dorsal part of the lateral wall of each recessus sacculi the posterior margin of the prootic is sutured to the exoccipital. This suture continues laterally in the labyrinth recess as far as the base of the lateral septum smicircularis. The bulk of this septum persists as cartilage and separates the fateral margin of the prootic from the exoccipital. A lamella of the prootic extends up on the anterior face of the cartilage and its dorsal end is separated from the posteriof ventral margin of pterotic part of the squamoso-pterotic and the inner lamella of the supraoccipital by cartilage. Anteriorly in the floor of the lateral recess, the prootic meets the pterotic and the line between them extends anteriorly as far as the outer end of the anterior septum (fig. 7). This septum is also partly cartilage, and the prootic lamella embraces its ventral surface and is confluent with the inner surface of the wall of the anterior recess, formed by a vertical projection from the floar of the prootic. In the younger stage this wall was cartilage and showed the beginnings of perichondrial ossification on both its cerebral and labyrinthine surfaces. The cartilage at the cerebral end of t the septum anterius separates the prootic lamella from the supraoccipital. 
I have not benn able to find the eje-muscle canal which lichurich ('84) stated as occurring between the prootic, parasphenoid and basioccipital. These bones are very tightly presed together in this region and there is no space bwteen them.

Cuvier (126) first described this bone in the fishes as the homologue of the human ala magna. About the same time Meckel ('24) recognized it as the homologae of the petrosal because of its relation to the labyrinth and the facial nerve. His ideas were further elaborated by Hallmann ('37), who revised the nomenclature of the bones in this region, but retained this name. Stannius ('53) called it the ala temporalis because of its general similiarity to the temporalis of the mammals. As is well known Huxley ('64) homologized this bone in Esox with one of the three ossification centers of the petrosal part of the temporalis of man and called it the prootic. Some of the modern authors have, nevertheless, retained the term petrosal, although on comparison With the petrosal of mammals it can be compared only to the part defined by Euxley.

The prootic is one of the constant bones of the piscine cranium and usually has the same general relations to the anterior semicircular canal and the facial nerve. In those teleosts which have an eye-muscle canal (Salmo, Scomber, the Loricati,etc. the facialis issues through the bone, separate from the trigeminus. In groups in which the eye-muscle canal is not developed, as in Amiurus, the facialis issues through a notch in the anterior edge of the prootic. In most forms, whether an eye-muscle canal is present or not, the median ventral ends of the bones of the two sides are fused in the floor of the cranium. The eye-muscle 

canal usually lies ventral to the median ends of these bones, which form its roof. The parasphenoid in such cases forms the floor and part of the side walls of the canal. The presence of a large amount of cartilage within the bone has been remarked in Scomber and the Ioricati (Allis), and in some of the Cyprinidae (Sagemehl,'91), and in Salmo (Parker,'72). It is not remarkable to find it where the chondrocranium is persistent to a very great degree in other parts, but in Amiurus, where there is a great deal of os sification, it is significant of the primitiveness of this region.

In some of the Clupeoid fishes(Ridewood, '04), the basicapsular fenestra, which occurs in larval Salmo (Parker, '72; Gaupp. '06), is a constant feature in the adult between the prootic, parasphenoid and basioccipital bones.

In Perca (Cuvier,'26; Hallman,'37), Carpio(Cuvier, Hallman, Stannius, '53; Sagemehl,'91), Pleuronectes (Cole and Johnson, '01), the prootic forms the lower part of the hyomandibular facet. In Salmo, Scomber, the Ioricati, and many other forms, there are separate foramina in the bone for the passage of carotid arteries, jugular vein and the hyomandibularis ramus of the facialis. In Amiurus, some but not all of the bload vessels communicate with the internal parts of the cranium through the large trigeminofacial formen. In scomber, the external surface is grooved as in Amiurus for the insertion of the adductor hyomandibularis: the same thing is possibly true for most fishes, but has not been stated in the descriptions.

The snuamoso-pterotics. In the $32 \mathrm{~mm}$ stage both the scluamosal and the pterotic was in its initial stages and the peri- 

chondrial and dermal elements which make up the adult compound bone were just beginning to suse in the wall of the otic capsule above the lateral semicircular canal (fig. 31). In places, the cartilage had been resorbed and the inner and outer lamellae were connected by osseous trabeculae. The lateral line canal, which in the older stage, is invisible from above, at that time formed a slight ridge on the dorsal surface of the cartilage and was fused to the underlying perichondrial ossification. In the adult, the oater surfaces of the bone, both lateral and dorsal, are made up almost entirely of ossified membrane and muscle fascia (figs. 6, 10,20). This led some of the authors who had not carefully studied the development, to conclude that the whole bone was entirely a dermal ossification, and hence comparable to the squamosal part of the temporalis of man.

The lateral line canal ossification of the adult becomes an integral part of the dorsal surface of the bone and connects posterd-laterally with the superior end of the opercular-mandibular canal and the main lateral canal of the body (fig. 1I). The former passes into the latero-posterior corner of the bone from the dorsal one of two subtemporal lateral line ossicles, the margin of which is fastened to the squamosal part of the bone by ligamentous tissue. Before leaving the squamosal that part of the canal which is to pass into the body, issues to the surface, and runs posteriorly on it for a short distance before pasing into the post-temporal. There are two sense organs in the lateral line canal within the squamoso-pterotic.

The dorsal surface of the squamosal part of the bone is subtriangular in outline and oterlaps the surrounding bones with 

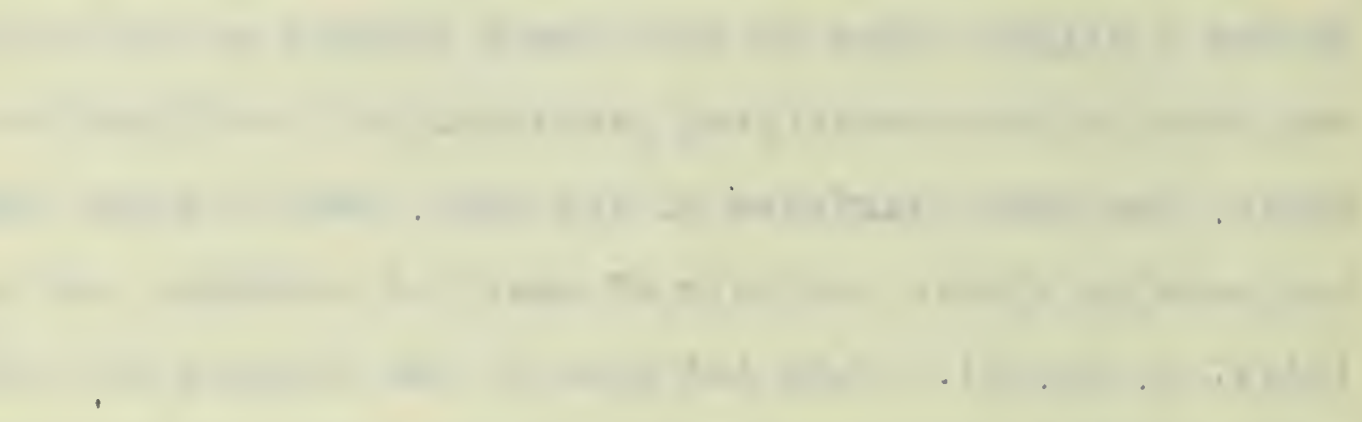

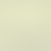

.

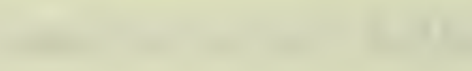


with serrated edges. Anteriorly it articulates with the sphenotic medially with the supraoccipital, and posteriorly with the epiotic (fig. 10).

There is no temporal fossa, but there is a space between the squamosal and pterotic parts, which may be a remnant of it. The latero-posterior end of the bone projects broadly and on its surface is the groove for the lateral line canal before it enters the post-temporal. Connective tissue fibres extend from its margin to the margin of the operculum holding the latter in place. The ventral surface of the bone is grooved and ridged for the insertion of the fibres and ligaments of the adductor operculi muscle (fig. 6). This face of the bone is sculptured more thanis the dorsal; it is formed by the ossification of the fascia and connective tissue extemal to the original perichondrial ossification. The latter ossification shows in two places on this surface -anteriorly on the margin below the hyomandibular articular surface, and posteriorly on the postero-ventral margin of the bone. In both of thes places the bone shows as a very thin lamella separated from the bone nearest it by cartilage; the cartilage is continuous within the lamella of both of the bones. Anteriorly it is separated from the sphenotic and posteriorly from the exoccipital by cartilage. Between these two bones the outer lamella inter digitates with a similar lamella of the prootic and close examination of this part shows that there is considerable cartilage yet remaining beneath these lamellae. Postero-dorsally it interdigitates with the epiotic.

The dorso-lateral margin of the bone is grooved for articulation with the hyomandibular and is entirely ossified in 

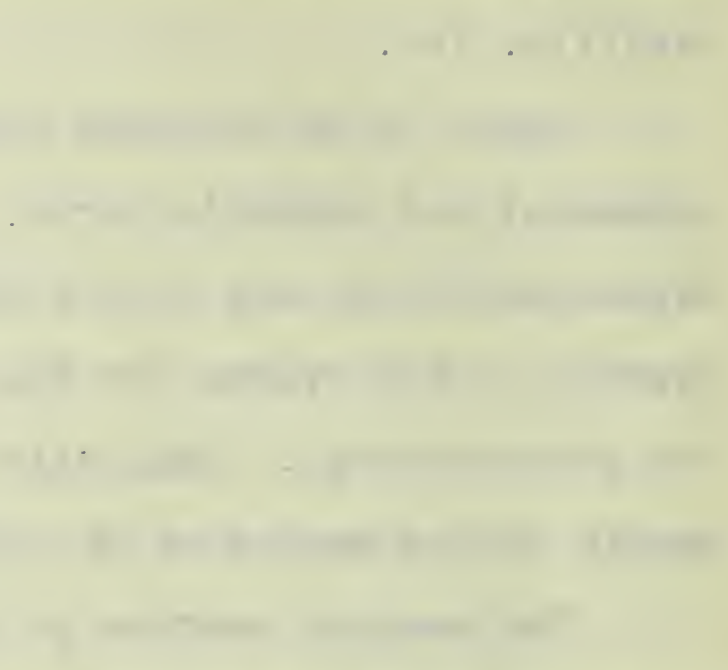

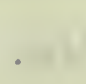


all parts. As noted above, this facet for the hyomandibular continues anteriorly on to the sphenotic. There are several foramina in the ventral surface of the bone which lead into its interior, but do not communicate in any way with the cavum cranii. Several blood vessels and some loose connective tissue fill this space and the region immediately external to it.

Internally the pterotic lamella is limited to the lining: of the recess for the lateral semicircular canal and the anterior wall of the posterior (fig. 7). In the floor of the recess it interdigitates with the prootic lamella, but is separated from the internal lamellae of the other bones - supraocipital and epioticby the cartilage of the lateral septam and the roof of the recess. In the very lateral extremity of the recess, the cartilage has boen resorbed, a process beginning in the $32 \mathrm{~mm}$ stage (fig. 31 ). For the most part however inner and outer perichondrial lamellae are separated by persisting cartilage.

The squamosal part of the bone is the only part found in Amia (Sagemehl, '84), and it it is distinctly separated from the chondrocranium by a space filled with connective tissue and the anterior ends of the body musculature. There is also a lateral line element fusing with the squamosal in Amia just as in Amiurus, and the canal upon leaving the squamosal, pursues the same course. Amiurus repeats the condition which Sagemehl described for most of the Characinidae and Cyprinidae, where a squamosal unites with a pterotic element. This author has stated that in some of the forms with a thick cutis, the lateral line canal ossification never fuses with the squamosal element and hence both are independent ossifications. The internal relations of the pterotic 

lamella are the same as in imiurus and cartilage persists to a great extent within it and the surrounding bones. In those forms where the sphenotic is small (Scomber, Salmo, the Joricati, etc., l and limited to the anterior edge of the otic camsule, the squamosal element of the bone extends anteriorly and articulates with the frontal. The lateral line canal, which in Amiurus passes first through the sphenotic and thence into the squamosal, in these forms passes directly from the frontal into the squamosal. The squamosal element of the bone is usually limited medially by the parietal, but in Amiurus this has fused with the supraoccipital. There is always a ridge or a groove on the ventral surface of the sauamosal part for the support of the shoulder girdle, and another groove on the lateral face, for articulation with the hyomandibula.

Cuvier called this bone the os mastoideum, homolorizing it with the mastoid portion of the ternoral bone of hurnan anatomy. Hallman ('37) recognized it as the homologue of the squamosal element of the temporal, and regarding the bone from adult conditions, this was a logical conclusion, as he did not study the development of the bone. Both of these authors used the cranium of Perca, and Hallman also made a detailed study of the cranium of Cyprinus. Huxley (Esox) called the bone the squamosal and did not recognize its relation to the chondrocranium. Parker ('72) says that he tried to point out to Huxley, the fact, that in Salmo the bone developed in connexion with the wall of the lateral semicircular canal and hence was comparable to another otic ossification center. Huxley would not entirely grant his views, but in his booik remarked that, in the opinion of Parker, the bone under 

consideration was a true otic bone. Thus it remained for Parker ('72) to designate it as the pterotic in Salmo. According to this view it was developed entirely as a chondrocranial bone and did not have the elements which were recognized later by Gaup and Schleip. They called it the dermo and autosquamosal according tothe suggestion of Van Wijhe (182) for the naming of the parts of mixed bones. Sagemehl found both elements in the Characinidae and the Cyprinidae, but called the whole the squamosal. Allis calls this bone by differing names in his papers and in his work on the Ioricati ('I0) designates the bone as the pterotic followed by squamosal in paraenthesis, giving an erroneous significance to the first term.

The epiotics. These are a pair of bones on the lateroposterior dorsal angle of the cranium. Each lies between the squaf moso-pterotic, the supraoccipital and the exoccipital of its side (figs. 9,10). It is pyramindal with the apex on the posterior surface of the cranium and having three faces, the first on the dorsal surface of the cranium, the second on the posterior surface below the apex, and the third on the latero-ventral surface (fig. 6). The dorso-anterior surface of the bone bears a strong vertical crest, along the anterior face of which some opercularmandibular muscle fibres have their insertion. The median prong of the post-temporal bone is firmly fastened by ligament to the posterior surface. A ligament of the trapezius muscle is attachod to the crest below the post-temporal. The crest itself continues medially on the supraoccipital.

At first sight this part of the bone appears as an isolated element, because the squamoso-pterotic bone extends in beneath 

the crest, and apparently separates this part of the bone from the more posterior portion. Closer inspection shows that the crested part of the bone and the more posterior part are a continuum, alth ough the latter is rugose and concave just behind the crest, giving the impression that the crested part of the bone is a separate piece. The posterior part of the bone slopes ventrally to form part of the posterior surface of the cranium (fig. 9). Medially it is separated from the supraoccipital by a strip of cartilage whic continues around the ventral margin of the bone there separating it from the exoccipital. Above this, on the lateral surface of the cranium it interdigitates with the pterotic part of the squamoso-pterotic. This portion of the epiotic is thin and cohcave ventrally for the insertion of fibres of the adductor operculi. It does not develop from the perichondrium of the otic capsule, but by ossification of connective tissue around the ends of the muscle fascia.

The posterior surface of the bone is corrugated for the insertion of the ends of the trapezius muscle fibres. Thus the external surface of the epiotic bone is covered with a superficial ossification developed from muscle fascia, which covers most of the outer perichondrial lamella.

The internal surface of the bone forms the posterior and dorsal walls of the recess for the posterior semicircular canal. liost of the wall is completely ossified and the cartilage has been resorbed except along the margins of the bone. In the earlier stages this part of the otic capsule had an inner lamella which was connected across the wall s of the recess by osseous trabeculae (fig. 38), and which now forms the solid central part of 

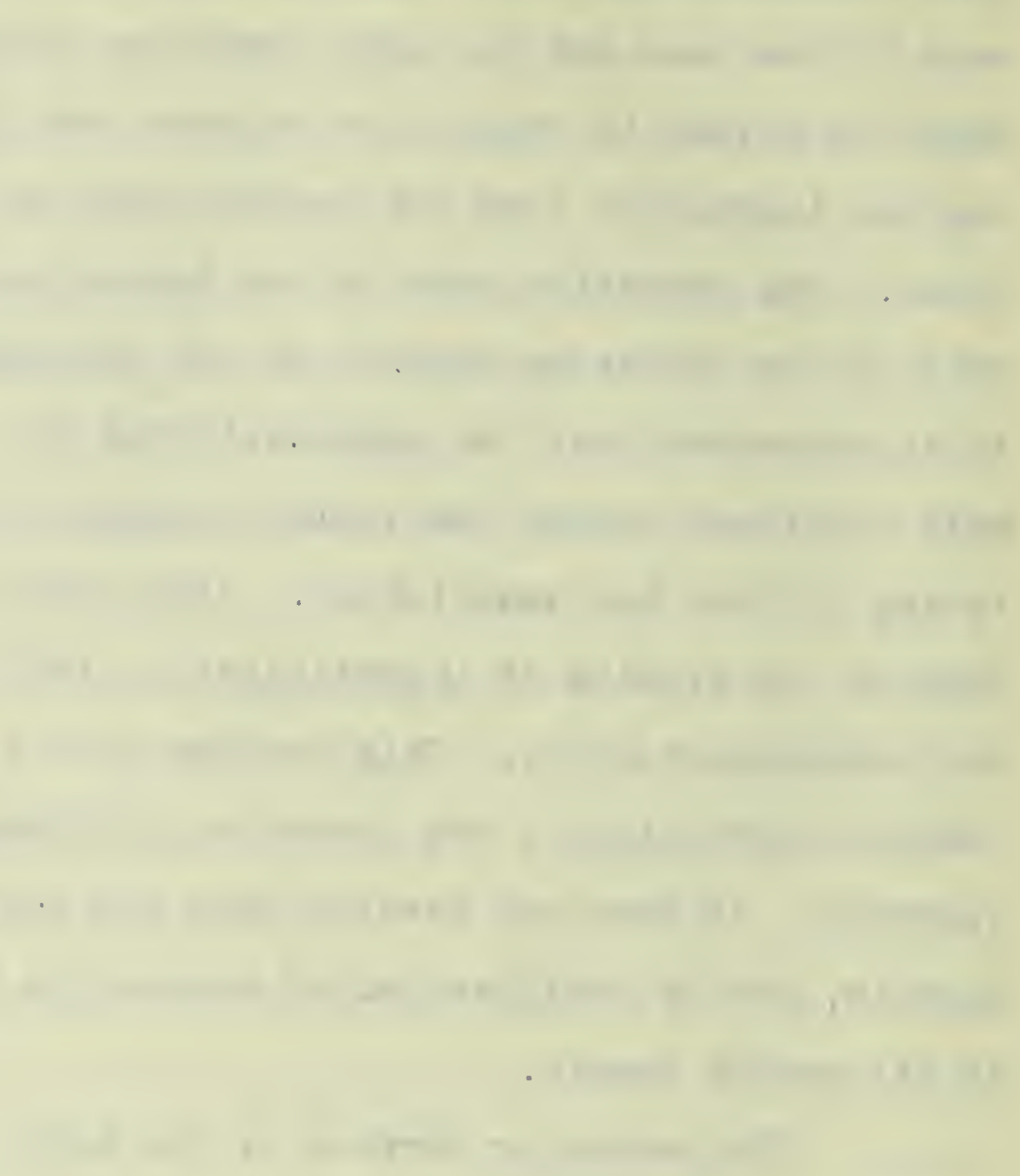

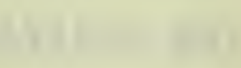

1

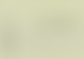

10 $\left(\frac{10}{2}\right.$

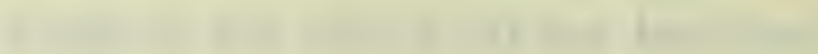

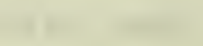

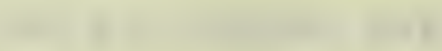
20 + 
the posterior wall of the recess.

Although it has been definitely demonstrated by Huxley, Parker, Schleip, and Gaupp, that the epiotic bone of the teleosts is a distinct otic ossification, developed from the posterior dorsal part of the otic capsule wall, the Cuverian name occipital externum is still prevalent in the Iiterature. Sagemehl('84) modified the term and called it the "exoccipitale" in his work on Amia, the Characinidae and the Cyprnidae. Allis followed him and in all except his most recent papers has named it according to Sagemehl, al though this intproduces confusion with the true exoccipitals.

In all of the teleosts this bone lies at the posterior dorsal corner of the cranium as in Amiurus, and has more or less of a crest for articulation with the post-temporal part of the shoulder girdle. Sometimes it is more linited to the dorsal surface of the posterior region, but usually a part of it extends ventrally as the hinder wall of the posterior semicircular canal. Its homologies are evident throughout the teleosts and even in most ganoids it is a well developed ossification.

The supraoccipital. This is a large unpaired bone which forms the median cranial roof behind the frontals. Its anterior margin is divided into halves by the posterior end of the posterior fontanelle on the margins of which it meets the frontals (fig. 10). The portions of the bone along the fontanlle are raised above the level of the surrounding bones and form a ridge which is continuous anteriorly with a similar ridge on the frontal and posteriorly with the medial surface of the occipital soine. Nuscles of the opercular and mandibular apparatus have their 


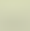

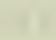

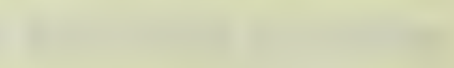


insertion along the sides of these ridges. At the base of the ridge the supraoccipital interdigitates with both the sphenotic and squamoso-pterotic.

Near the posterior margin of the dorsal surface, a crest, continuous with that of the epiotic, meets the longitudinal ridge at right angles and a cavity is formed by their intersection (fig. 10). The crest curves postero-dorsally and forms the lateral margin of the dorsal surface of the spina occipitis, a triangular osseous splint which projects posteriorly from the dorsal surface of the cranium. Between the crests of the two sides, the dorsal surface of the spine has the shape of a trough, the floor of which is irregularly excavate for the insertion of muscle fibres. The ventral edge of the spine is connected to the posterior dorsal surface of the supraoccipital proper by a thin osseous sheet, which as noted above (fig. 29), is developed by the ossification of the connective tissue between the anterior muscles. Behind the crest the main portion of the supraoceipital bone descends on the posterior surface of the cranium as far as the exoccipital bone (fig. 9). Iaterally, there is an interaigita tion between the upper medial nargin of the epiotic and the supraoccipital, which continues anteriorly into the crest. The ventrolateral margin of the supraoccipital is separated from the epiotic by a strip of cartilage, continuous ventrally with that between the epiotic and exoccipital. The ventral margin of the supraoccipital interdigitates with the dorsal margin of the exoccipital in the wall of the foramen magnum, where there is also a strip of cartilage between them. The supraoccipital forms a very small part of the rall of the formen. Just above the foramen 


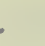


the supraoccipital is embraced by the anterior ventral surface of the anterior spine of the compound vertebra, which, as observed in the development of this region, is the neurapophysis of the third neural arch, the first two neural arches being modified as parts of the Weberian apparatus. The whole external surface of the posterior face of the bone is rugose and ridges for the insertion of muscle fibres.

The internal surface of the bone is very smooth and for the most part is only a superficial lamella on the cartilage around the dorsal ends of the septa semicircularia (fig. 7). Anteriorly on each side it interdigitates with the frontal and laterally with the sphenotic; each side is separated from the posterior end of the sphenotic by a small area of cartilage at the dorsal end of the septum semicircularis anterior. The bone extends over the cartilage between the anterior end lateral septa, but does not meet the pterotic lamella which lines the lateral recess. It forms an osseous sheath on the anterior face of the posterior septum and encloses the fenestra for the passage of the posterior membranous canal. Below this fenestra it meets the exoccipital. The inner end of the canal for the passage of the ranus lateralis accessorius of the facial nerve and the jugular vein, lies in a recess in the bone above the fenestra. In median section this bone shows itself to be well ossified and thick especially in that region which forms the margin of the posterior fontanelle. Laterally, the inner and outer lamellae are separated by cartilage This is one of the best developed bones of the adult teleost cranium and usually has a long posteriorly projecting spine attached to its dorsal surface. Cuvier recognized it in 


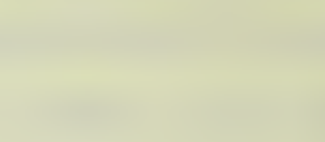

.

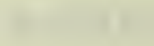

\section{$\left(\frac{10}{2}\right.$}

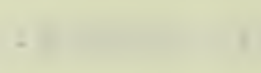

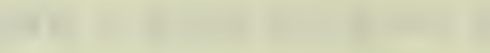
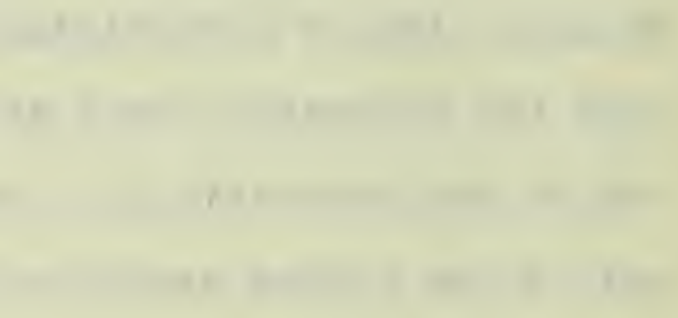

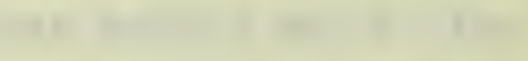

.

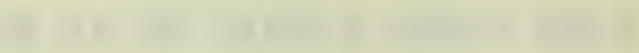


Perce and stated that, while it might possibly be regarded as the interparietal, he preferred to describe it as the homologue of the reptilian supraoccipital. Hallman ('37) figures it in Cyprinus and Perca, but gives no detailed description. Parker ('72) was the first one to describe the development of the bone in detail in the teleosts, as arising from perichondrial lamellae on the occipital arch and synotic tectum, between the parietals, and touching the frontals anteriorly. In salmo the margins of the bone are rounded and there is not the spiculate serrate edge found in Amiurus. SagemehI ('85) described the bone in the Characinidae briefly, and commented upon the extent of the occipital spine, with the remark that from its relations to the muscle, there was evidence that it had been developed from the fascia between them and has secondariIy fused with the main part of the bone developed on the occipital arch. In his discussion of the bone in the Cyprinidae, he states an hypothesis for the development of the bone from the ganoid condition where it is wanting by assuming that the occipital arch in the teloosts upon which the supraocipital bone developed arose from the assimilation of the first vertebrae in a ganoid ancestor of the teleosts and that there is no evidence for regarding the bone as a derivative of the demal plates in this region of Polypterus, Acipenser, Iepidosteous and Amia. Loomis ('00) has shown that in the fossil ganoids of Kansas, that the supraoccipital is absent, although prsent in the fossil teleosts. Zittel('84-93) and Woodward ('98) have described this same condition in the fossil Teleostomes. But in a previous discussion (p. 32), it was concluded that the vertebra at the anterior end of the vertebral column were not 


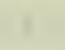


serially homologous in the different groups and that segments can be intercalated and excalated. So instead of regarding the supraoccipital as the homologue of a neural process of the ganoids it must be assumed to be a new part which is intercalated as a new formation in the teleosts, but at what time this intercalation took place there are no fossil records. The homologue of the supr occipital plates of polypterus is the spina occipitis. This has been developed from connective tissue above the occipital arch and is fused to the underlying supraoceipital ossification. In the stegocenhali (Fritsch,'83), there are a pair of supraoccipital plates corresponding to those of polypterus and going yet higher in the vertebrate series we find that two pairs of connective tissue ossifications have been described attached to the dorsoanterior margin of the cartilaginous supraocoipital in man, the interparietals and the preinterparietals (Ficalbi,'90; Ranke, '99). The latter are inconstant, but the former may be the bones which correspond to the spina occipitis of the teleosts and the supraoccipital plates of the Stegocephalans.

Mclfurrich('84) states that in Amiurus the dorsal surface of the spina occipitis is perforated with foramina for the passage of tubules connected with the "mucous" canal system, an error, since the canal system has no branches in the posterior part of the cranium outside of the squamosal part of the squamoso-pterotic Further, he says that the "ascending branch" of the first spinal nerve (my hypoglossus) issues from the cranium through the foramen for the ramus lateralis accessorius facialis. As I have not been able to find a dorsal branch of this nerve in either the younger or the older specimens, I cannot agree with him. 

The exoccipitals. The floor and side walls of the foramen magnum are fomed by the paired exoccipital bones (fig. 9). nearly the whole margin of the bone is smooth except for a few interdigitating spicules on the epiotic and supraoccipital edges. It is separgtod antericrly from tie pterotic part of the squamosopterotic and the posterior margin of the prootic bone by a strip of cartilage which continues ventro-posteriorly between it and the antero-dorsal margin of the basioccipital. On the posterior surface of the cranium it is separated from the epiotic by the cartilage, but interdigitates with the ventral margin of the supraocipital as far as the wall of the foramen magnum, where cartilage is present between the bones.

The anterior ventral surface of the bone is pierced by two foramina, a small anterior one for the glossopharyngeal and A larger one immediately posterior for the vagus (fig. 20). The ossification separating them is a very delicate osseous spicule and was originally cartilage. Just behind the vagus foramen there is a sharp, upwardy curved prong, to which the transcapular bone is attached. This latter bone has developed from the ossification of a ligament between the shoulder girdle and the cranium (fig. 37). Ventral to the articulation of the transcanular with the surface of the exoccipital is rugose for the insertion of the fibres of the shoulder girdle muscles. On the posterior surface of the cranium the bone is concave medial to the base of prong, and at the bottom of this concavity there is a minute foramen for the passage of the hypoglossus nerve. A flange of the bone projects posteriorly behind this foramen at right angles to the posterior surface of the cranium, forming part of the lateral 

wall of the foramen magnum. This part of the bone develops from the ossification of the membranous sheet present in the younger stages posterior to the hypoglossus and fuses with the ventral end of the occipital arch. The posterior ventral margin of the bone is fused with the dorsal surface of the thickened basioceipital.

Within the cranium, the anterior margin of the bone interdigitates with the prootic as far laterelly as the base of the lateral septum semicircularis, and medially as far as the roof of the recessus sacculi (fig. 7). Behind the lateral septum semicircularis, the exoccipital lamella extends laterally over the floor of the recess for the posterior semicircular canal and part way up its posterior wall. It is separated by cartilage from the more lateral and dorsal pterotic and epiotic lamellae. The inner ends of the foramina for the glossopharyngeal and vagus nerves lie in this part of the bone. Medial to the posterior recess, a part of the bone extends out dorsally and, with the supraoccipital. forms a wall between the recess and the cavum cranii. At the base of this wall a horizontal process extends medially above the recessus sacculi and meets a similar process from the other side to form the roof of the sinus impar. The ventral surface of this process meets a splint from the basioccipital, which forms the side wall of the cavum sinus imparis and the roof of the recessus sacculi of that side. The lateral wall of the recessus sacculi is formed by exoccipital and basioccipital lamellae.

The foramen for the hypoglossus nerve lies posterior to and above the lateral end of the horizontal process. The latter forms the ventral margin of the foramen magnum, and between it 

and the dorsal surface of the basioccipital the sinus impar leaves the cranium to divide into the atria sinus imnaris. The posterior ventral end of the exoccipital is fused with the basioccipital.

The exoccipital bone is one of the most constant bones throughout the vertebrate series. It is fairly well developed in all groups of ganoids, although considerable cartilage remains between the inner and outer lamellae. As in Amiurus, it forms the floor and side walls of the foramen magnum and there is usually a gap of cartilage in the dorsal margin of the foramen where in Amiurus the supraocipital lies. In some teleosts - Salmo, Citharinus, and catostomus - the cartilage perists in this region. The anterior margin of the bone usually encloses the ninth and tenth nerves, either in a single foramen or an anterior and a posterior opening, and ossification usually starts in the cartilage around these foramina. The intercalated nerves are enclosed in the posterior part of the bone secondarily, as in simiurus. In the Cyprinidae(Sagemehl,'91), this formen is larger and is divided into two parts, one for the ventral and the other for the dorsal root of the nerve. The dorsal foramen is very large in Catostomas, Cyprinus, and Cobitis, and above the nerve, is filled with lymphatic tissue continuous with the contents of the saccus paravertebralis of the Weberian anparatus. Sagemehl claims that the larger has arisen by the fenestration of a single original foramen such as occurs in Amiurus.

Ostariophysarian teleosts have a median horizontal process on each exoccipital, which, ith its fellow of the opposite side forms the cranial floor above the sinus imoar and the recessus sacculorum. Actual contact of the exoccipital with the surrounding 

bones is not usually the case, because cartilage perists botween them. In this same group of fishes thereiis usually a ligament extending from the basioccipital to the shoulder girale (Sagemehl, '85), which he says is the homologue of the transcapular process of Amiurus.

The synonomy of this bone has been given by owen ('48), Vrolik ('73), and Starks ('01). To their list of synonyms may be added the name given to this bone by Gaupp ('06), pleuroccipitale. Of all the names, exoccipital, suggested by Owen, is the briefest, and most comprehensive of the relations of the bone; pleurocipitale has no excuse.

The basioccioital. This is the most posterior bone on the ventral surface of the cranium and is fused on its ventral face to the anterior centrum of the compound vertebra of the spinal column. The bulk of the bone lies in this immediate region and thins out anteriorly on the ventral and lateral surfaces of the cranium (fig. 6). Its ventro-anterior margin is overlapped by spicules of the parasphenoid and its dorsal anterior surface by the posterior margin of the suprasphenoid and the prootic (fig. 7 ). The dorso-lateral margin of the anterior end of the bone interdigitates externally with the extreme posterior ventral margin of the prootic (fig. 20). Behind this interdigitation the basioccipital is separated from the antero-ventral margin of the exoccipital by cartilage until the two exoccipitals fuse posteriorly. Below this fusion the posterior face of the basiocelpital is circular and aeeply concave (fig. 9). The edges of the concave anterior face of the centrum of the first vertebra is fused with the periphery of this face of the basioccipital and in the space 

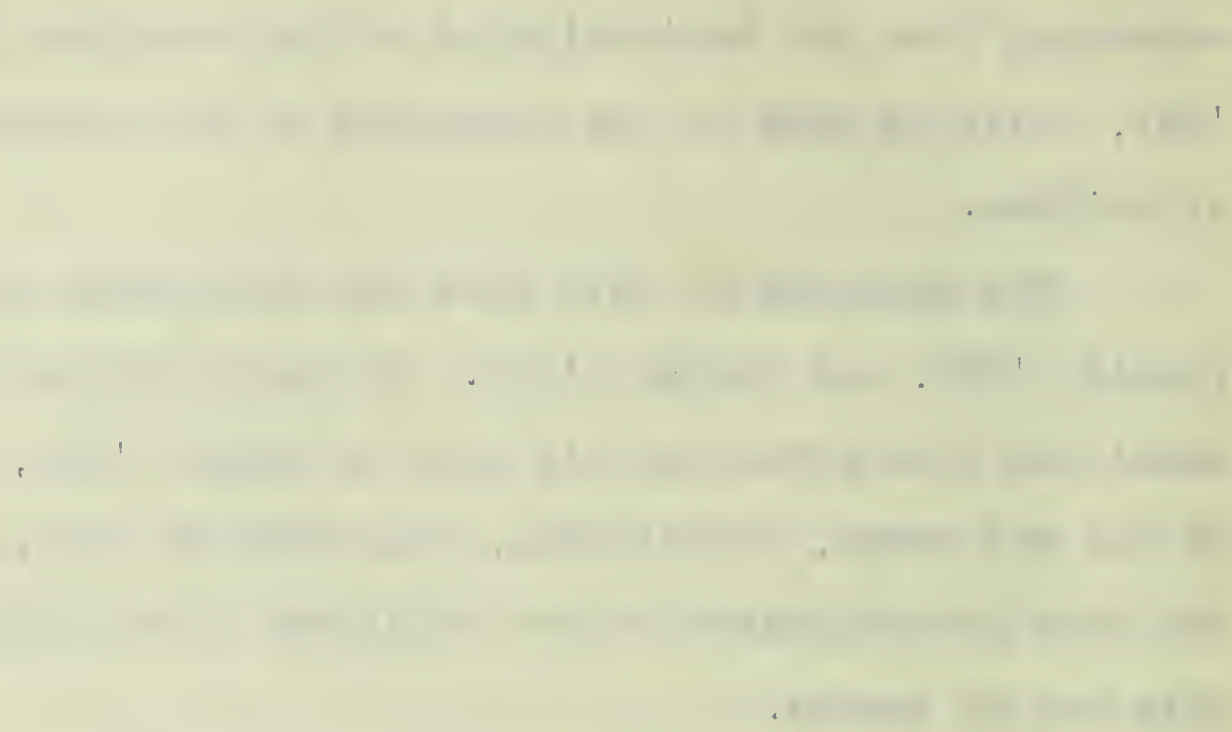

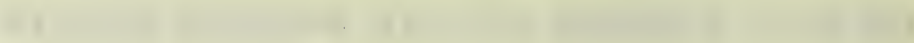
$+2$ 
enclosed between the faces is filled with gelatinous notochordal tissue. A small space in the ventral surface of the basioccipital just anteriar to its fusion with this centrum remains unossified and is filled with cartilage, the remnant of the hypochordal cartilage of the $32 \mathrm{~mm}$ stage (fig. 38 ).

The internal surface of the bone is hollowed out for the reception of the sacculi. It forms the median crest between the recessus sacculorum and part of their floor and side valls. The dorsal surface of the crest is concave forming the floor and walls of the cavum sinus impar. In the side wall of each recessus the internal basioccipital lamella meets the descending lamella of the exoccipital of that side. In the $32 \mathrm{~mm}$ stage this had already completely ossified and so in the adult there is no cartilage left in the walls of the recessus except between the margins of the bones. Considerable cartilage yet remains in the basal blate between the vosterior end of the prootic and the basioccipital (fig. 7). There is no trace of the intercranial notochord so prominent in the younger stages.

The transscapular bone, has part of its attachment to the lateroventral surface of the basioccipital (fig. 9 ).

The basioccipital of the teleosts is very constant in its morphological relations. As in Amiurus its posterior face is concave where attached to the centrum of the first vertebra and the gelatinous mass found between them is nearly always present. In the Ostariophysi the sacculi penetrate more deeoly into the substance of the basioccipital then they do in other teleost groups, but the sacculi always have a relation to the dorsal surface of the bone. The interdigitation of basioccipital with 

parasphenoid, and articulations with prootic and exoccipital, are common characters. The processes on the bone for articulation with the transscapular process are peculiar to the silmridae. The pharyngeal processes of the Characinidae and Cyprinidae, extending from the ventral surface of the basioccipital to the wall of the swim-bladder, are not found in other teleosts. Allis (110) mentions a groove on the dorsal surface of the basiocipital in the Ioricati, which he claims as the homologue of the cavum sinus imparis of the Ostariophysi. The basioccipital throughout the teleosts is usually exclued from participation in the formation of the foramen magnurn by the union of the posterior ends of the exoccipitals above it or by the presence of the sinus impar.

The bułk of the bone is developed from the posterior parachordalia and the ossification of the intercranial notochord. In some of the Cyprinidae considerable cartilage remains in those parts of the bone which form the walls and floor of the recossus sacculorum. In all of the teleosts, the notochord disappears in that part of the basioccipital anterior to the vertebral articular surface. In the forms with an eye-muscle canal, the basioccipital forms its posterior floor.

The premaxillaries. These are a pair of bones forming the anterior end of the uper jaw and are closely fused with each other in the mid-ventral line, of the cranium. They have no ascending process such as occurs in Salmo, Scomber, Alenocephalus, and other teleosts, but are closely fused to the ventral surface of the supraethmoid bone. They curve posteriorly on each side to form the osseous floor of the nasal fossae and are attached by ligament to the palatine and maxillary bones dorso-posteriorly. 

The ventral surface of each bone is covered with teeth, which, as mentioned in the younger stage are only secondarily connected with it. (fig. 15)

The maxillaries. Each maxillary bone (fig. 15) lies lateroposterior to the premaxillary, embedded in the connective tissue forming the lateral margins of the upper lips. Each is untoothed and serves as a support for the elongate, laterally extending, maxillary barbel. This lateral position of the maxillary is common among the teleosts and occurs in Amia also. In Salmo, the bone is continuous posteriorly with the premaxillary and bears a series of teeth on its ventral surface. In scomber it lies partly internal to the premaxillary and has an articular surface for it. In the Ioricati, the bone has a long posterior extent and overlaps the mandible. In none of these forms is it as small as in Amiurus where it has a slender styliform shape and is held, in position partly by connective tissue. It is in actual contact with the palatine bono articulating with it by means of a small ball and socket joint, the latter lying on the palatine. The palatines. These bones retain the same shape and reltions as in the younger stages, although now much larger in size (fig. 15). Ossification has proceeded in all parts and there is only a core of cartilage left. Each palatine is a slender dumbbell shaped ossification lateral to and below the ectethmoid process with which it has articulated from its earlieat stage. The anterior ventral end is grooved for the articulation with the maxillary and the premaxillary is attached to these two bones by tough connective tissue. His earlier, so now, the palatine has no actial contact with the pterygoquadrate ossification. In 
.

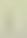

$+2$

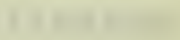

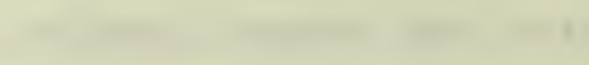

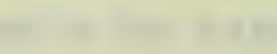

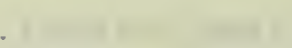


Salmo, the bone is continuous posteriorly with the bones of the pterygoid arch and bears teeth on its ventral surface. In the Characinidae, the palatine bone has varying sizes and shapes, but it is developed on cartilage continuous posteriorly with the cartilage within the pterygoid bones. In Erithrinus, the maxillary articulates with the palatine in the same manner as in Amiurus, but the palatine does not extend as far forward. In scomber (Allis, '03), the palatine is fused with the anterior bone of the pterygoid series and bears teeth.

The ectopterygoid. This bone develops by the ossification of a sheet of connective tissue ventral to the nalatine and connected. with it by connective tissue (fig. 15). The posterior margin interdigitates with the anterior margin of the large metapterygoid. Mcliurrich ('84) described this bone as 'number four' and stated that it could not be homologized with a pterygoid bone because it was developed from membrane. Schleip ('03) found that it developed from membrane in salmo and yet maintains that it is the homologue of the ectopterygoid of other teleosts and that it is separated from the pterygoid cartilage by connective tissue. The bone is very small, quadrate in outline, with delicate sculptured radiating lines. In Salmo it is longer and thinner than in Amiurus and has more of the character of the corresponding bone in Amia (Van Vijhe,'82), the Characinidae and the Cyprinidae. There is no enotpterygoid in Amiurus.

The metapterygoid. This large bone is developed around the pterygoid part of the pterygoquadrate cartilage. It is auadrangular in outline and interdigitates anteriorly with the ectopterygoid, posteriorly with the hyomandibular and ventrally 


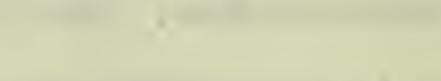

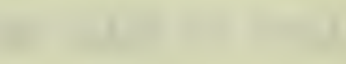

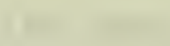

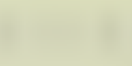

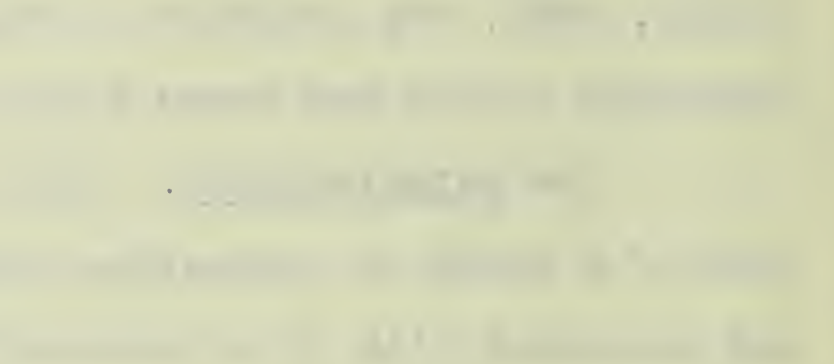

.

$\sqrt{2}$

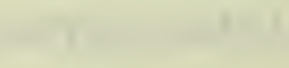


with the quadrate (fig. 15). No cartilage persists in any of the visible parts of the bone. Hedially it is attached to the lateral surface of the cranium by a sheet of muscular and ligementous tissue. A mesopterygoid occurs in most teleosts betreen the meta-and actopterygoids, but here the two interdigitate.

In scomber a small strip of cartilage intervenes between the metrpterygoid and the quadrate and a space and there is a space betweel the former and the elongate hyomandibular bone. In salmo

(Parker,"73), the bone is not nearly as great in extent, occupies a position entirely dorsal to the quadrate and is separated from the latter, as in Scomber, by cartilage. It does not interdigitate with, but overlaps the hyomandibular. In Megalops (Ridewood, '04), a large ectopterygoid hinders its anterior extent and it overlaps the hyomandibular nosteriorly. In Pleuronectes lCole and Johnson, 'OI), it is smaller than in Amiurus and lies posterior and dorsal to the quadrate. The small metapterygoid of the Characinida is separated from the ectopterygoid and cuadrate by cartilage and there is also a large foramen between it and the latter.

The ausdrate. This bone is situated at the ventro-anterio end of the hyomandibular suspensorial apparatus (fig. 15). It is grooved on its inferior face for articulation with the mandible, is rather small, and firnly fused to the surrounding bones, although there is a small area between it and the hyomandibular, where the underlying persisting cartilage shows between the bones. Its posterior face interdigitates with the preopercular bone. lickurrich ('84) states that the cartilage mentioned as occurring between the bones is the symplectic and that in perfectly dried 

skulls there is an interspace between the hyomandibular due to the absence of cartilage.

The hyornandibular. This large bone connects the quadrate with the cranium. It is immovably fused with the latter and if one moves, both must. A process of the bone projects from the anterior edge to the lateral surfaceo of the alisphenoid which is hollowed out for its reception. Posterior and dorsal to this poin of contact the hyomandibular articulates with the side of the cranium in a groove which has been described in connexion with the sphonotic and squamoso-pterotic bones. There are several ridges on the lateral surface of the bone along which the adactor muscles are attached (fig. 15). Just above its interdigitation with the preopercular, is a foramen for the pssage of the ramus hyomandibularis facialis. The knob for the articulation of the operculum has ossified and is overlanped by the ventral surface of this bone, which is hollowed out as a socket for movement on the knob.

In Salmo (Parker, 173), the hyomandibular does not have the anterior and ventral extent that it has in Amiurus and it is isolated from the surrounding bones by cartilage. Parker does not figure the foramen for the hyomandibularis nerve, but from Gaupp's figure ('06) of the formen in the younger stage of Salmo, it is evident that the nerve passes farther forward than in Amiurus. In the Albulidae and Iormyridae, and other lower teleosts, the hyomandibular does not have so great an anterior, posterior, or ventral extent as in Amiurus, and usually a small symolectic element comes between it and the quadrate. The preopercular does not articulate with the hyomandibular as closely as in Amiurus. In 

all of the teleosts the hyomandibular has a knob on its posterior edge for the articulation of the operculum; in some of the characinidae cartilage persists at this point.

The dentary. The teeth which are borne on the lower jaw are attached to the medial dorsal surface of this bone, from the symphysis as far back as the dentary-articulare interdigitation. The bone retains the shape and relations which it had in the younger stages. It tapers anteriorly where it meets the fellow of the ooposite side and is deener posteriorly (fig. 15). The inner surface of the bone is hollow for the reception of the anterior end of Meckel's cartilage. The ventro-anterior surface is perforated by a series of six nores for the passage of tubules of the enclosed mandibular lateral line canal (fig. 11). The canal issues from the mandible through the more posterior pore and enters the connective tissue surrounding the quadrate and thence passes into the preopercular. I agree with Iflifurrich that the dentary is a mixed bone and is the result in part of the ossification of a portion of Meckel's cartilage. The developmental stages show that the bone: at first arises entirely frora the connective tissue membrane around the cartilage fused with a lateral Iine ossification, later part of Neckel's cartilage ossifies and fuses with it (fig. 24 ).

The articulare. This is a triangular bone at the posterior end of the mandible and is grooved on its posterior face for articulation with the quadrate (fig. 15). It does not contain a lateral line element. The internal dorsal surface is fiat and gives attachment to the muscles which move the lower jaw. Considerable cartilage persists between the outer and inner lamellae. 

The bone bears no teeth and interdigitates anteriorly with the dentary, which also extends posteriorly in a groove on its ventral surface.

The preopercular. The manibular-opercular lateral line canal enters this bone from the connective tissue surrounding the posterior ventral end of the quadrate (figs. 11,15). The bone is fused solidly to the quadrate ventrally, and to the hyomandibular dorsally. A small process projects down behind the quadrate and into this bart the opercular canal passes. The posterior edge is ridged and projects above the more posterior lying operculum. The dorsal end of the bone extends for a short distance behind the hyomandibular. There is a small foramen in the middle part of the bone for passage of a branch of the hyomandibularis facialis as it descends after passing through the hyomandibular.

The subtemporals. These are two small bones lying dorsal to the preopercular and above the posterior margin of the hyomandibular (figs. 11,15). They contain the dorsal end of the opercular lateral line canal which passes through them into the squamosal. They are very thin and the canal in passing through them, lies in a groove rather than in a tube, the ventral and lateral walls of which are thicker than the very thin roof. Only one such bone is found in this region of Salmo having the same relations to the lateral Iine canal and the squamosal. Parer ('72) called it the supratemporal, but the supratemporal of the Stegocephalans always lies medial to the squamosal so that this bone could not be its homologue. Ridewood('04) suggests the term adopted here and says that the real supratemporal of salmo between the back of the squamosal and the post-temporal was oter 
$-$ 
looked by Larker, but it is really larger than the subtemporal. SagemehI ('85) states that these bones are present in many of the siluroids.

The opercular anparatus. This consists of three bones; a large dorsal operculum and two smaller ventral bones, the interand suboperculum, (fig. 15). The operculum spreads out posteriorIy in a wide arch and articulates anteriorly with the hyomandibular knob. It is heavily sculptured on its external surface, tapers ventrally and at its inferior apex the short quadrangular interoperculum is attached by ligamentous tissue and interpolated between it and the posterior end of the articulare. The suboperculum is smaller and lies medial to the interoperculum.

\section{Summary.}

1. The chondrocranium of Amiurus is platybasic.

2. In the chondrocranium of the $10 \mathrm{~mm}$ Amiurus there is no intemasal septum; the epiphysial bar is the only part of the chondrocranium dorsal to the brain and divide the opeing in the roof of the primitive skull into an anterior and a posterior fontanelle.

3. The olfactory formen lies in a sagittal plane and is very large in comparison with the olfactory tract. A solum nas 1 is present. The ectethmold process, a short transverse projection between the nasal fossa and the orbit, is perforated by the ophthalmicus superficialis trigomini. An orbital foramen is present posterior to the eatethmoid process.

4. Trabecular and alisphenoid cartilages form the margins 

of a large fenestra in the lateral wall of the cranium for the passage of the optic,oculomotor,trigeminal,abducens, and facialis nerves. The fenstra is closed by membrane at the $10 \mathrm{~mm}$ stage, except where the nerves issue.

5. The alisphenoid cartilage is the homologue of the ala magna of the mammalian chondrocranium.

6. The cavum labyrinthii opens directly into the cavum cranii; there are three septa semicircularia; no basicapsular fenestra is present; the glossopharyngeal and vagus norves issue from the cranium between the otic capsule and the parachordal plate. The otic capsules are fused posteriorly with the occipital arch; a synotic tectum is lacking in the $10 \mathrm{~mm}$ Amiurus. The hyomandibular articular surface lies external lies external to the lateral semicircular canal.

7. The parachordal cartilages lie lateral to the intercranial notochord, are fused anteriorly with the trabeculae, dorso-laterally with the otic capsules, and posteriorly with the occipital axch. The notochord forms the axis of the posterior part of the solid parachordal plate. The sacculi lie in recesses on the dorsal surface of the parachordal plate on each side of the notochord.

8. The ventral ends of the occipital arch are fused with the parachordals posterior to the vagus formen; the posterior end of the arch is inserted into the anterior end of the third neural arch. The hypoglossus nerve has dorsal and ventral roots united within the vertebral canal and a single lateralis ramus issuing between the occipital arch and the anterior process of the scaphium. The nerves posterior to the hypoglossus have the rami 
.

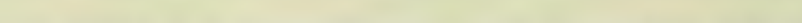

$$
\cdot
$$

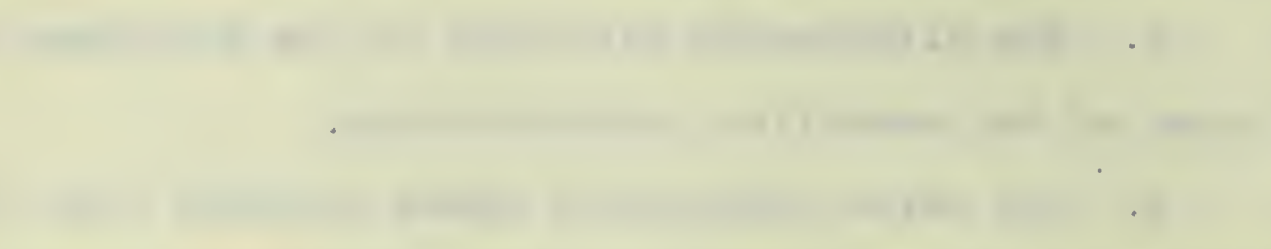

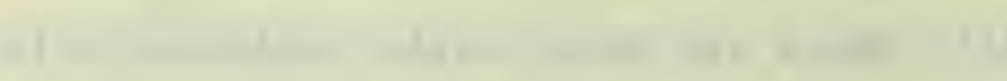


characteristic of true spinal nerves and alternate with the neural arches. Two pairs of myotomes are present lateral to the occipital arch, but their innervation by the nerves in this immediate region could not be clearly made out. The two pairs of myotomes following these are innervated by the second and third pairs of post-vagal nerves.

9. The anlagen of the premaxillarg and maxillary bones are present in the $8 \mathrm{~mm}$ Amiurus.

10. The palatine cartilage is independent of the pterygoquadrate, and the latter is fused to the hyomandibular.

11. Ossification is present in the skull of the $32 \mathrm{~mm}$ Amiurus. The large dorsal fontanelles of the $10 \mathrm{~mm}$ stage are limited to mere slits by the frontal and supraoccipital ossifications; the epiphysial cartilage persists, but lies relatively further posterior; a rudimentary tegmen cranii and synotic tectum are present; a massive cartilaginous internasal septum divides the olfactory tracts; the olfactory foramina lie in a transverse plane.

12. The anlage of the supraethmoid bone has both membrane and perichondrial ossifications entering into its composition. The perichondrial ectethmoid ossification is fused with a connective tissue ossification on the lateral margin of the ectethmoid process. The foramen orbito-nasale lies relatively more posterior than in the $10 \mathrm{~mm}$ stage; perichondrial ossifications appear on the margin of the orbital foramen.

13. The fenestra hypophyseos is closed by the orbitosphenoid, parasphenoid, suprasphenoid, and prootic ossifications. 

14. The intercranial extent of the notochord is apparenty less than in the $10 \mathrm{~mm}$ stage, but this is due to the greater relative growth of the cartilaginous parts surrounding it.

15. The suprasphenoid bone is developed from membrane in the floor of the cranium and is not the homologue of the basisphen oid of the mammalian cranium, but is a bone peculiar to the teleosts.

16. A squamosal ossteication, developed from membrane, fuses with the pterotic ossification, as the latter has no homologue in the mammalian petrosal, the resulting bone of the adult cannot be a temporalis, but must be regarded as a squamoso-pterotid.

17. The spina occipitis of the supraoccipital bone arises from membrane and is the homologue of the supraccinital plates of the Stegocephali and probably of the interparietal element of the mammalian cranium.

18. The skull of the adult imiurus is well ossified, although considerable cartilage persists in the ethmoid and otic regions. The adult cranium resembles, in many points, the crania of some of the Characinidae and Cyprinidae. 


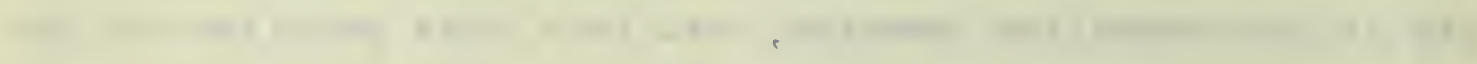
.
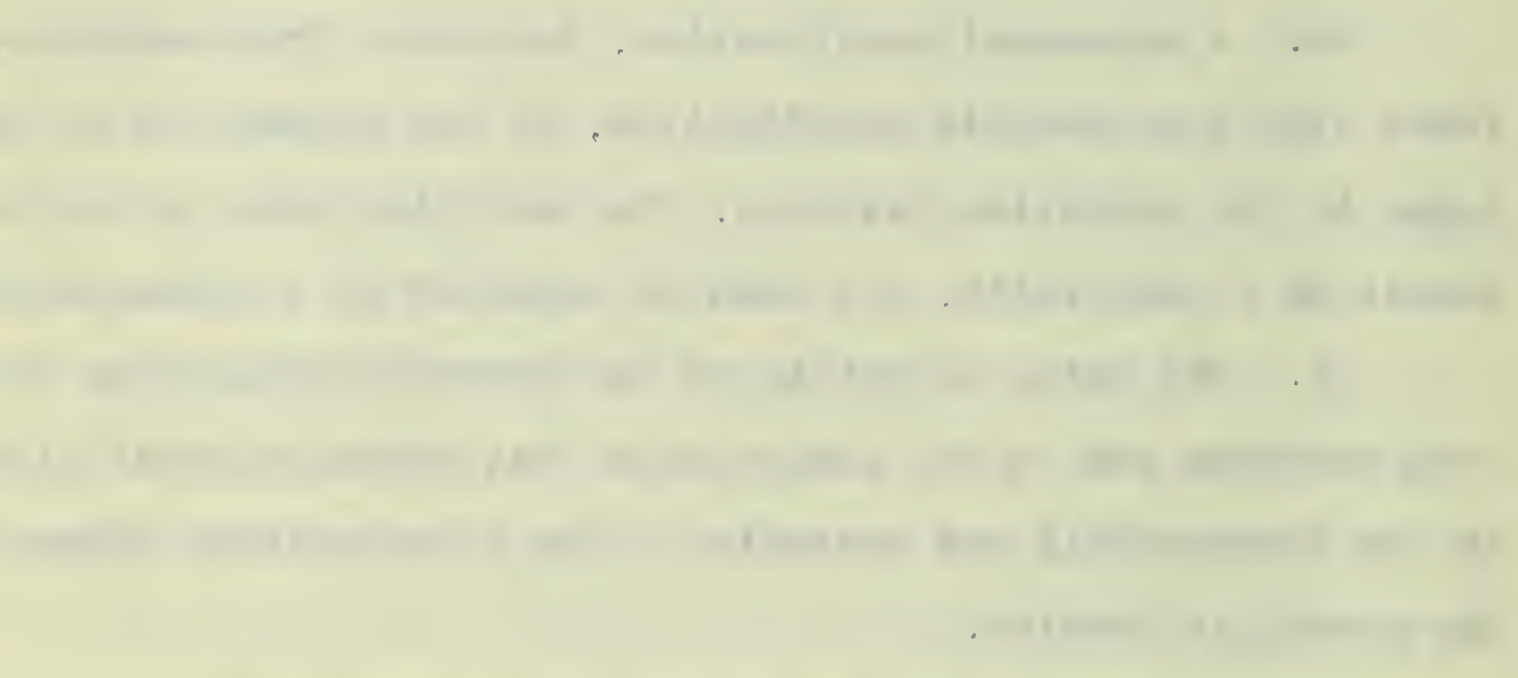

.

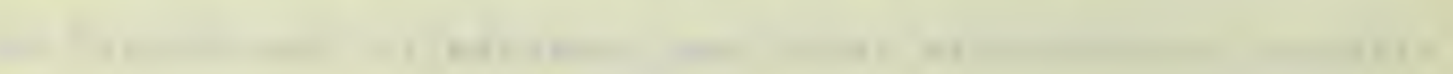




\section{Bibliography}

Agassiz and Vogt. 1842 Developement des Salmones.

Albrecht, P. 1880 Ueber den Proatlas, einen zwischen dem Occipitale und dem Atlas der Amnioten Wirbeltiere gelegen

Wirbel, und den Nervus spinalis I s.proatlanticus. Zool. Anz. , 3.

Allen, Harrison. 1882 on a revision of the ethmoid bone in the liammalia. Bull. lins. Comp. Anat., 10.

Allis, E.P. 1889 Anatomy and Development of the Iateral Iine System in Amia calva. Journ. Morph., 2 .

1897a Cranial muscles and lierves in Amia calva. Journ. liorph., 12.

$1897 \mathrm{~b}$ The liorphology of the petrosal Bone and of the Sphenoidal Region of the Skull of Amir calva. Zool.Bull, I.

1898 Amia and the Teleosts. Zool. Bull., 2.

1899a On Certain Homologies of the squamosal, intercalar, exoccipital and extrascapular bones of Amia calva.

Anat. Anz., 16.

$1899 \mathrm{~b}$ On the morphology of certain of the bones of the cheek and snout of Amia calva. Journ. Morph., 14.

1900a The lateral sensory canals of Polvpterus bicher. Anat. An\%., 17.

1900b The premaxillary and maxillary bones, and the maxillary and the mandibular breatring values of Polypterus bichir. Anat. Anz., 18

1903 Anatomy of Scomber scomber (mackerel). Journ. lioroh., 18 .

1910 The anatomy of the mail-cheeked fishes. Zollogica, Chun., 57.

1913 The homologies of the ethmoid region in Selachii. Anat. Anz., 44.

Baur, G. $1896 \mathrm{Mr}$. Walter J. Collinge's remarks on the preopercular zone and sensory canals of Polybterus. Anat. inz., 12 .

Bojanus. 1818 Versuch einer Deutung der Inochen im Kopfe der Fische. Isis. 

Bridge, T.W. 1878 on the osteology of Polyodon folium. Phil. Trans., 168, part II.

Bridge, T.W. 1887 The cranial osteoldgy of Amia. Journ. of Anat. and Phys., 11.

Bridge, T.T. and Haddon, A.C. 1893 Airbladder and Weberian ossicles in the Siluroid fishes., Phil. Trans. Roy. Soc. London., 184.

Brooks, H. Jt.John. 1884 Osteology and arthrology of the Eaddock (Gadus aeglefinus). Sci. Proc. Roy. Dublin Soc., 4 (N.S.).

Brthl, C.B. 1887 Zur Osteologie der Knochenfische. Iit 150 fig. auf 11 Taf. Berlin, Friedlander and son.

Budgett, J.S. 1907 The work of J. S. Budgett. Edited by J.G. Kerr.

Cole, F.J. and Johnstone, J. 1901 Pleuronectes. Proc, and Trans. of the Iiverpool Biol. Soc. 16.

Collinge, W.E. 1895 On the sensory canal system of fishes. Teleostei. Proc. Zool. Soc. London.,

Collinge, W.E. 1896 The preopercular zone and sensory oanal of Polyoterus. Anat. Anz., 12.

Credner, H. 1893 Die Stegocephalen und Saurier.

Cuvier, G. 1816. Ueber die Zusammensetzung des Oberkiefers der Fische und die imwendung, welche man davon auf die methodische Eintheilung dieser Thire machen kann. Abst. Isis, 1818.

Cuvier, G. et Valeneiennes. 1828 Histoire naturelle des poissons, 1 .

Dean, Bashford. 1895 Fishes; living and fossil.

Dohrn, A. 1901 Studien zur Urgeschichte des Wirbeltierkbpers. 21. Theoretishces über Occipitalsmite und vagus. Mittelh. aus der zoolog. Station zu Ireapel, 15.

Ficalbi, E. 1890 Considerazioni riassuntive sulle ossa accessorie del cranio dei mammiferi e dell'uomo. Ionitore Zoologico Italiano, 1.

Froriep, H. $190{ }^{\circ}$ Minige Bemerkungen z. Yopfrage Anat. Anz., 21. Fritsche, h. 1883 Fauna der Caskohle. 1. 

Furbringer, H. 1897 Ueber die spino-occipitalen Nerven der Selachier und Holocephalen und ihre vergleichende Itornh. Fests. z. 70. Geburtst. v. C. Gegenbaur, 3.

Ganin, 11. 1880 Ueber die Intwickelung des Konfskeletts bei Knockenfischen. Zool. Anz., 3.

Gaupp, E. 1894 Beitrมूge zur Iforphologie des Schädels. Iforph. Arb., 4.

1902 Ueber die Ala temporalis des Säugersch dels und die Regio orbitalis einiger anderer Wirbeltierschädel. Anat. Hefte, 19.

1903 Zur Intwickelung der Schadelknochen bei den Teleostiern. Anat. Anz. Erganz. zum 23; 17.

1906 Die Entrickelung des Kopfskeletts. Handbuch der Verg. u. Exper. Entwick. der Virbeltier, 3; pt 2.

Gegenbaur, C. Ueber die Bilding des Kochengewebes. Jen. Jeits. f. Iied. u. Iraturw., 1 and 3. 1864 .

1872 Das Kopfskelett der Selachier. Unt. z. vergl. Anat. d. Wirbelthiere, 2 .

1878 Uber das Kopfskellet vom Alepocephalus rostratus. Suppl. Morph. Jahrb., 4.

1887 Ueber die Occipitalregion und die ihr benachtbar Wirbel der Fische. Fests. f.

G81di, E.A. 1883 Kopfskelett u. Schultergürtel von Ioricaria catapracta, Balistes capriscus und Acipenser ruthenus. Zool. Anz., 16.

G8Idi, E.A. 1884 Vergleichend-anatomische und entwickelungsgeschichtiche Studien zur Deckknocien Frage. Jen. Jetts. IVat., I\% .

Gouan, A. 1770 Historia Piscium.

Gregory, W.K. 1907 The orders of Teleostomous fishes. Ann. N. Y. Acad. Sci., 17.

Gulliver, G. 1869 On certain nondescrppt bones in the skull of osseous fishes. Ann. and llag. Nat. Hist., 4.

Gunther, H.C.I.G. 1880 Introduction to the study of fishes.

Gutberlet, J.I. $\quad 1915$ On the osteology of some of the Ioricati. Illinois Biological llonographs, 2 .

Hallmann, I. 1837 Die Vergleichende Osteologie des Schlafenbeins. Hannover. 

Harrison, R.G. 1895 Die Intwickelung der unpaaren und paarigen Flossen der Teleostier. Arch. f. mikr. Anat., 46.

1894 Ectodermal or mesodermal origin of the bones in Teleosts. Anat. Anz., 10.

Herrick, C.J. 1901 Irerves of Siluroid fishes. Journ. Comp. Ieurology, 11.

Hertwig, Oscar. 1876 Ueber das Hautskelett der Fischen. llorph. Jahrb., 2 .

Hertwig, Oscar. 1884 Die Intwickelung der Deckknochung am ropfskelett des Hechtes. Jen. Zeits. f. Iaturg., 16.

Hollara, H. 1864 Recherches sur la signification hornologique de quelque pieces faciales des poissons osseour. inn. Sci. Nat., 1.

Hubrecht, A. i. W. 1874 Beitrage zur Kentniss des ropfskeletts der Holocephalen. Nieder I. Arch. f. Zool., 3.

Huxley, I.H. 1858 Theory of the vertebrate skull. Proc. Roy. Soc. London, 9.

1864 Wlements of comparative anatomy.

1874 Colloberation with Harkness, Woodward, etc. Structure and classification of the Labyrinthodonts. Rep.Brit. Asso. Adv. Sci., 1874.

Jordan, D.S. 1905 Guide to the study of fishes.

1893 Temperature and Vertebrae. Wilder uart. Cent. Book.

Zaschkaroff, IN. 1914 Zur Kenntnis des feiner Baues und der Entwickelung des Knochens bei Teleostiern. Anat.Anz., 47.

Kingsley, J.S. 1910 lieristic homologies in vertebrates. Tufts College Studies, 3.

Ilaatsch, H. 1895 Ueber die Bedeutung der Hautsinnesorgane fllr die wschaltung der Skleroblasten aus dem Elktoderm. Ergangungsheft z. Bd. X. Anat. $A n \%$.

Kölliker, A.v. 1850 Die Theorie des Primordialschadels. Zeits. f. Wissens. Zool., 2.

Levi. Giusenpe. 1900 Beitrage zum Studium der Entwickelung des knornelifen Primordialcraniums des Menschens. Arch. $f$. Irikros. Anat. U. Entwicklgsch., 55.

Loomis. F.B. 1900 Die Anatornie und die Verwandtschaft der Ganodd und Inochen-Fische. Inaug. Diss., litunchen. 

Iflimrich. J.P. 1884a on the osteology and development of Sygnathus peckianus. Quart. Journ. Mic. Sci., 23

1884b The osteology of Amilurus catus. Proc. Canad. Inst. 2.

Mittenheimer, C. 1847 Die Membro Piscium Pectorali.

Mtller, J. 1846 Bau und Grenzen der Ganoiden. Abh. a. Berl. Akad. d. Wissensch.

Neumayer, I. 1913 Zur vergleichenden Anatomie des Schydels eochiner und recenter Siluriden. Paleontographica. 59.

Nusbaum, J. 1908 Entwickelungsgeschichte und morphologische Beurteilung der Occipitalregion des Schldels und s. Anat. Anz., 32.

Oken, I. 1819 Philosophie der Bein umgerissen von 0. Isis, 9. Owen, R. 1846 Lectures on Comparative Anatomy.

1848 Homologies of the vertebrate skeleton.

1866 Anatomy of vertebrates, 1.

Pappenheim, 1907 Ein Beitrag zur Osteologie des Fischschadels Zool. Anz., 32.

Parker, W.K. 1873 On the structure and development of the skull of the salmon. Phil. Trans. Roy. Soc. Iondon, 163.

1882 On the structure and development of the skull in the Sturgeon. Phil. Trans. Roy. Soc. Iondon, 173,pt. I.

1882 On the development of the skull in Ienidosteous osseous. Phil. Trans. Roy. Soc. London, 173, pt. II. and Bettany, G.T., 1877 The morphology of the skull.

Platt, J.B. 1893 Ectodermic origin of the cartilages of the head. Anat. Anz., 8.

Pollard, H.B. 1892 on the Anatomy and phylogenetic position of Polypterus. Zool. Jahrb., 5.

1892b The lateral line system of the Siluroids. Zool. Jahrb., 5 .

1894 Suspension of jaws in fishes. Anat. Anz., 10.

1895 Oral cirri of the Siluroids and the origin of the head in vertebrates. Zool. Jahrb., 8. 

Quain, 1915 Elements of anatomy. 11th edit.

Ranke, J. Ueber die tberzahligen Knochen der menschlichen Sch dddeldecke. Setzungsberichte der mathematische-physikalischen Klasse der K. bayr. Akkad. d. Wissens. zu Ittuchen, 29.

Retzius, G. 1881 Das Gehörorgan der Wirbeltiere, 1.

Ridewood, W.G. 1904a On the cranial osteology in the lower Teleosts. Proc. Zool. Soc. London, 2.

1904b Cranial osteology of the Clupeoid fishes. Idem, 2.

1904c Cranial osteology of the families lormyridae, Notopteridae and Hyodontidae. Journ. Iinn. Soc. London,29

Ryder, J. H. 1886 The development of osseous fishes. Annual Rept. of Comm. of Fish and Fisheries.

Sagemehl, M. 1884 Beitrlge zur vergleichende Anatomie der Fische. I. Das Cranium von Amia calva. Norph. Jahrb., 9.

1885 Beitrd̈gezur vergleichende Anatomie der Fische. III. Das Cranium der Characiniden. Idem, 10.

1891 Beitræ̈ge zur vergleichende Anatomie der Fische. IV. Mornh. Jahrb., 17.

Schleip, W. 1903 Die Entwickelung der Kopfknochen bei dem Lachs und der Forelle. Anat. Hefte, 23.

Schreiner, K.E. Einige Ergebnisse uber den Bau und die Entwickelung der Occipitalregion von Amia und Lepidosteas. Zeits.

f. wiss. Zoologie, 72.1902.

Schauinsland, H. Die Entwickelung der Wirbelsdule nebst Rinpen und Brusthein. Handb. d. vergl. u. exper. Entwickls. d. Wirbeltiere, 3. 1906.

Sewertzoff, A. 1897 Beitrag zur Entwickelungsgeschichte des Wirbeltierschldel. Anat. Anz.,13.

1899 Die Entwickelung des Selachierschaddels. Festschrift etc, fẗr Karl von Iupffer, Jena.

1902 Zur Entwickelungsgeschichte des Cermtodus forsteri. Anat. Anz., 21.

Shufeldt, R.W. 1883 Osteology of Amir calva. Including eertain special references to the skeleton of the Teleosteans. Report U.S. Comm. of Fisheries.

Stannius, H. 1854 Handbuch der Anatomie der Wirbeltiere. Starks, E.C. 1901 Synonomy of the fish skeleton. Proc. Wash.
Acad, Sci., 3. 

Starks, E.C. 1902 Relationship and osteology of the Caproid fishes or Antigonidae. Proc. U. S. Nat. lius., 25.

1904 Theoosteology of some Berycoid fishes. Idem, 27.

1908 On the orbitosphenoid in some fishes. Science, N.S., 28.

Sunino, F. 1904 loorpfologia del cranio dei Teleostei. Rome.

Sutton, J.B. 1884 Observations on the parasphenoid, vomer, and the palatopterygoid arcade. Proc. Zool. Soc. Iondon.

Swinnerton, H.H. 1902 A contribrtion to the mornhology of the Teleostean head skeleton. Quart. Journ. llicros. Sci., 45.

Terry, R.J. 1917 The primordial cranium of the cat. Journ. liorph., 29.

Thyng, F.W. 1904 The squamosal bone in tetrapodous Vertebrata. Proc. Boston Soc. Nat. Hist., 32.

Tischomiroff, A. 1885 Zur Entwickelung des Schddels bei den Teleostiern. Zool. Anz., 8.

Traquair, R.H. 1879 ; On the structure and affinities of the Platysomidae. Trans. Roy. Soc. Edinb., 29.

\#1871 Cranial osteology of Polypterus. Journ of Anat. and Bhysiology, 5.

Veit, Otto. 1907 Ueber einige Besonderheiten am Primordialcranium von Lepidosteus osseous. Anat. Hefte., 33.

Vrolik, A. 1873 Studien uber die Verkn\&cherung und die Knochen des Schaddels der Teleostei. Niederl. Arch. Zool., I.

Wagner, R. 1843 Lehrbuch der Anatomie der Wirbelthiere.

Walther, J. 1882 Die Entwickelung der Deckknochen am Kopfskelett des Hechtes, (Esox lucius). Jena. Zeits. f. Naturwiss., 16.

Wijhe, J.W.van. 1882 Visceralskelett und die Nerven des Kopfes der Ganoiden und von Ceratodus. Niederl. Arch. f. Zool.,5.

Willcox, I.A. 1899 Iotes on the occipital region of the trout, Trutta fario. Zool. Bull, 2.

Winslow, G.M. 1897 The chondrocranium in the Ichthyopsida. Tufts College Studies, 1.

Woodward, A.S. 1893 Osteology of Lepidotus and Dapedinus. Quart. Journ. Ificros. S̈ci., 20.

* INot procurable. 

1898 Vertebrate paleontology. Cambridge.

Workman, I.S. Ophthalmic and eye-muscle nerves of the catfish (Amiurus). Journ. Comp. Neur.,10.

Wright, R.R. 1884 The nervous system and sense organs of Amiurus. Proc. Canad. Inst., 2.

1885 On the skull and auditory organ of the Siluroid, Hynothalmus. Trans. Roy. Soc. Canada, 4.

Zittel, K. 1880-93 Hanabuch der PalHontologie. Mthehen.

( $\dot{A}$ translation and adaptation by C.R.Eastman. London.). 

Explanation of Fioures.

\section{Plate I.}

Fig. 1. Nodel of chondrocraniun, $10 \mathrm{~mm}$ Amiurus: lateral view, $\mathrm{x} 2 / 3$.

Fig. 2. The same; dorsal view, $x 2 / 3$.

Plate II.

Fig. 3. liodel of chondrocranium, $32 \mathrm{~mm}$ Amiurus: cartilaginous parts only are represented on the left side; cartilage on right side stippled to contrast with ossifications. Dorsal $\nabla i e w, X 1 / 3$.

Fig. 4. The same; ventral view, X $1 / 3$.

Fig. 5. Model of mandibluar and suspensorial apparatus, 32 mm Amiurus; cartilage stippled. Iateral view, X I/3.

\section{Plate III.}

Fig. 6. Adult cranium; ventral view, X 1.5.

Fig. 7. The same; median section and internal surface, cartilage stippled, X 1.5 .

Fig. 8. Transverse section through middle part of the otic capsule and parachordal plate, $32 \mathrm{~mm}$ Amiurus. Camera lucida X 30. Fig. 9. Adult oranium, posterior surface, X 1.5. Plate IV.

Fig. 10. Adult cranium, dorsal view, X 1.5.

Fig. 11. The same, diagram of the course of the lateral line canals, position of pores and sense organs in relation to bones.

Fig. 12. Transverse section through the posterior end of the occipital arch, $8 \mathrm{~mm}$ Amiurus. Camera lucida X 50.

Fig. 13. Transverse section through the scaphia, $8 \mathrm{~mm}$ Amiurus. Camera Iucida X 50 . 

Fig. 14. Transverse section through the posterior end of the orbital region, $8 \mathrm{~mm}$ Amiurus. Camera Iucida X 50 .

F Plate $V$.

Fig. 15. Adult cranium; lateral $\nabla$ iew, X 1.5 .

Fig. I6. The same; ventral view of anterior end with vomer and parasphenoid removed, $X 1.5$.

Fig. 17. Transverse section through occipital region, $8 \mathrm{~mm}$ Amiurus. Camera Iucida, X 50.

Fig. 18. Transverse section through the ethmoid region, $8 \mathrm{~mm}$ Amiurus. Camera Iucida, X 50.

Fig. 19. Transverse section through the roof of the anterior semicircular canal, $32 \mathrm{~mm}$ Amiurus. Camera lucida X 50.

Fig. 20. Adult cranium; lateral view, X I.5.

Fig. 21. Transverse section through occipital arch-parachordal fusion, $8 \mathrm{~mm}$ Amiurus. Camera lucida X 50 .

$$
\text { Plate VI. }
$$

Fig. 22. Transverse section through the anterior end of the ethmoid region, $32 \mathrm{~mm}$ Amiurus. Camers Iucida X 30.

Fig. 23. Transverse section through the hypoglossus formen, $32 \mathrm{~mm}$ Amiurus. Camera Iucida, X 30.

Fig. 24. Transverse section through the lower jaw, half way between the symphysis and the articulation with the quadrate, $60 \mathrm{~mm}$ amiurus. Camera lucida X 50.

Fig 25. Transverse section through the same region, $32 \mathrm{~mm}$ Amiurus. Camera Iucida X 50.

Fig. 26. Transverse section through the parachordal plate ventral to the vagus foramen, $32 \mathrm{~mm}$ Amiurus. Camera lucida X 30 . 

Fig. 27. Transverse section through the anterior end of the parachordal plate, $32 \mathrm{~mm}$ Amiurus. Camera Iucida X 30.

Fig. 28. Transverse section through the parachordal plate posterior to fig. 27, $32 \mathrm{~mm}$ Amiurus. Camera lucida X 30.

Fig. 29. Transverse section through the posterior end of the occipital arch, $32 \mathrm{~mm}$ Amiurus. Camera lucida X 30.

Fig. 30. Transverse section through the ethmoid region, 8 mm Amiurus. Camera lucida X 50 .

Fig. 32. Transverse section through the posterior end of the orbital region, $32 \mathrm{~mm}$ Amiurus. Camera Iucida X 50.

\section{Plate VII.}

Fig. 33. Transverse section through the roof of the anterior end of the otic cansule, $60 \mathrm{~mm}$ Amiurus. Camera lucida X 50 .

Fig. 34. Transverse section through the synotic tectum, 32 mm larva. Camera Iucida X 50.

Fig. 35. Diagram of nerve, neural arch and myotome relations of a larval Amiurus.

Fig. 36. Transverse section through the anterior end of the anterior semicircular canal, $32 \mathrm{~mm}$ Amiurus. Camera lucida X 50.

Fig. 37. Transverse section through the posterior end of the basal plate, $32 \mathrm{~mm}$ larva. Camera lucida X 30.

Fig. 38. Transverse sectionsthrough the posterior end of the otic capsule, $32 \mathrm{~mm}$ Amiurus. Camera lucida X 50.

Fig. 39. Transverse section through the posterior part of the ethmoid region, $32 \mathrm{~mm}$ Amiurus. Camera lucida X 30. 

Abbreviations.

alis., alisphenoid bone

alis.c., alisphenoid cartilage

a.m., adductor mandibularis

ant.font., anterior fontanelle

ant.pro., anterior process of the scaphium

art., articulare

bo., basioccipital

br., brain

ca., foramen for internal carotid artery

ca.si., canal sinus imparis

csa., anterior semicircular canal

csi., cavum sinus imparis

csl., lateral semicircular canal

csp., posterior semicircular canal

dent., dentary

e., eye

ept., ectopterygoid

ect., ectethmoid

ect.pro., ectethmoid process

end., endorhachis

ep.b., epiphysial bar

epo., epiotic

eth., ethmoid plate

eth.cr. ethmoid cornu

ex., exoccipital

f.bcr., fenestra basicranii anteriorius

f.h., fenestra hypophyseos 

f.mg., foramen magnum

f.o.n., foramen orbito-nasale

fr., frontal

hma., hyomandibula

hma.gr., hyomandibular groove

hmds.VII., hyomandibularis branch of VII

hy., hyoid arch

hyp., hypochordal cartilage

hypg., foramen for hypoglossus nerve

hypg.n., hypoglossus nerve

inth., interhyal

int.s., internasal septum

iop., interoperculum

1., lagena

1a., lacrimal

1.1.c., lateral line canal

1.0., levator operculi

1. os., lateral line assification

m., Ireckel's cartilage

mpt., metapterygoid

$\mathrm{mx}$., maxillary

my.1-5., myotomes $1-5$

n.1-4., post-vagal nerves $1-4$

na., nasal

na.al., nasal alar cartilage

na.o., nasal organ

nch., notochord

ne.1-3., neural arches $1-3$ 

occ., occipital arch

olf., olfactory foramen

olf.I., olfactory lobe

op., operculum

oph.V., foramen for ophthalmicus superficialis trigemini oph.VII., foramen for ophthalmicus superficialis facialis or.f., orbital foramen

os., orbitosphenoid

ot.c., otic capsule

pal., palatine

pch., parachordal

pf., postfrontal

pmx., premarillary

po., postorbital

post.,

post.font., posterior fontanelle

pa., pterygoauadrate cartilage

pre., preopercular

pro., prootic

ps., parasphenoid

pt., post-temporal

ptr., pterotic

a., quadrate

r.lat.acc., ramus lateralis accessorius facialis foramen rc.m. rectus eye muscle

r.m., rete mirabile of the internal carotid artery

r.ot.VII., ramus oticus facialis foramen

r.s., recessus sacculi 

sя., septum semicircularis anterius

sac. sacculus

sbo., suborbitals

sca., scaphium

se., supraethmoid

sl., septum semicircularis laterale

s.n., solum nasi

sn.1. first true spinal nerve or second post-vagal nerve sp., septum semic ícular is posterius

sph., sohenotic

spoc., spina occipitis

s.pv., saccus paravertebralis

sq., squamosal

sq.ptr., squamoso-pterotic

st., subtemporals

t.p., tubule pore of lateral line canal

tr., trabecula cranii

ut., utriculus

vg., vagus nerve

vis., visceral arches

vo., vomer

II., optic foramen

V-VII., trigemino-facial formen

IX., glossopharyngeal foramen

X. vagus foramen 


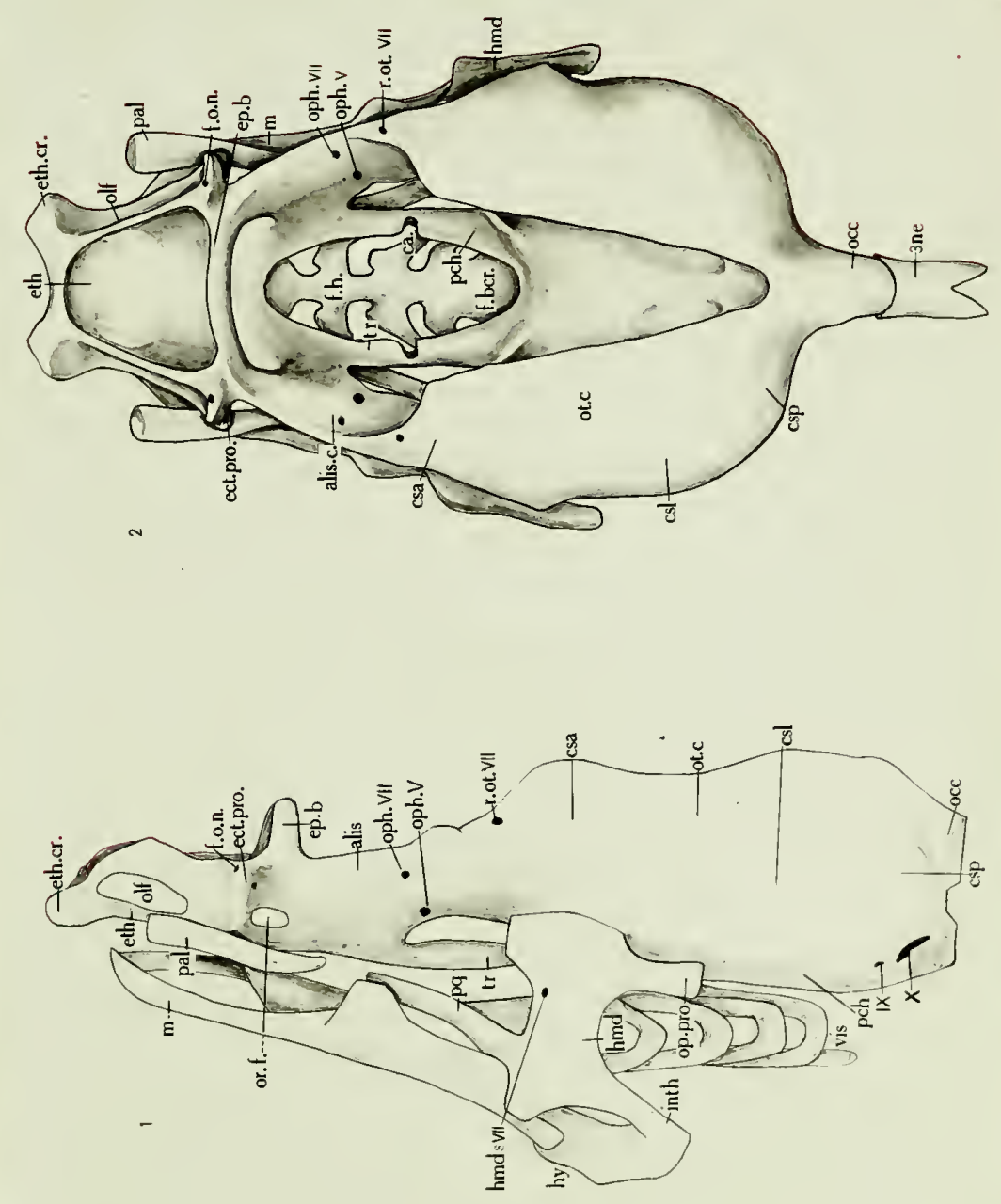



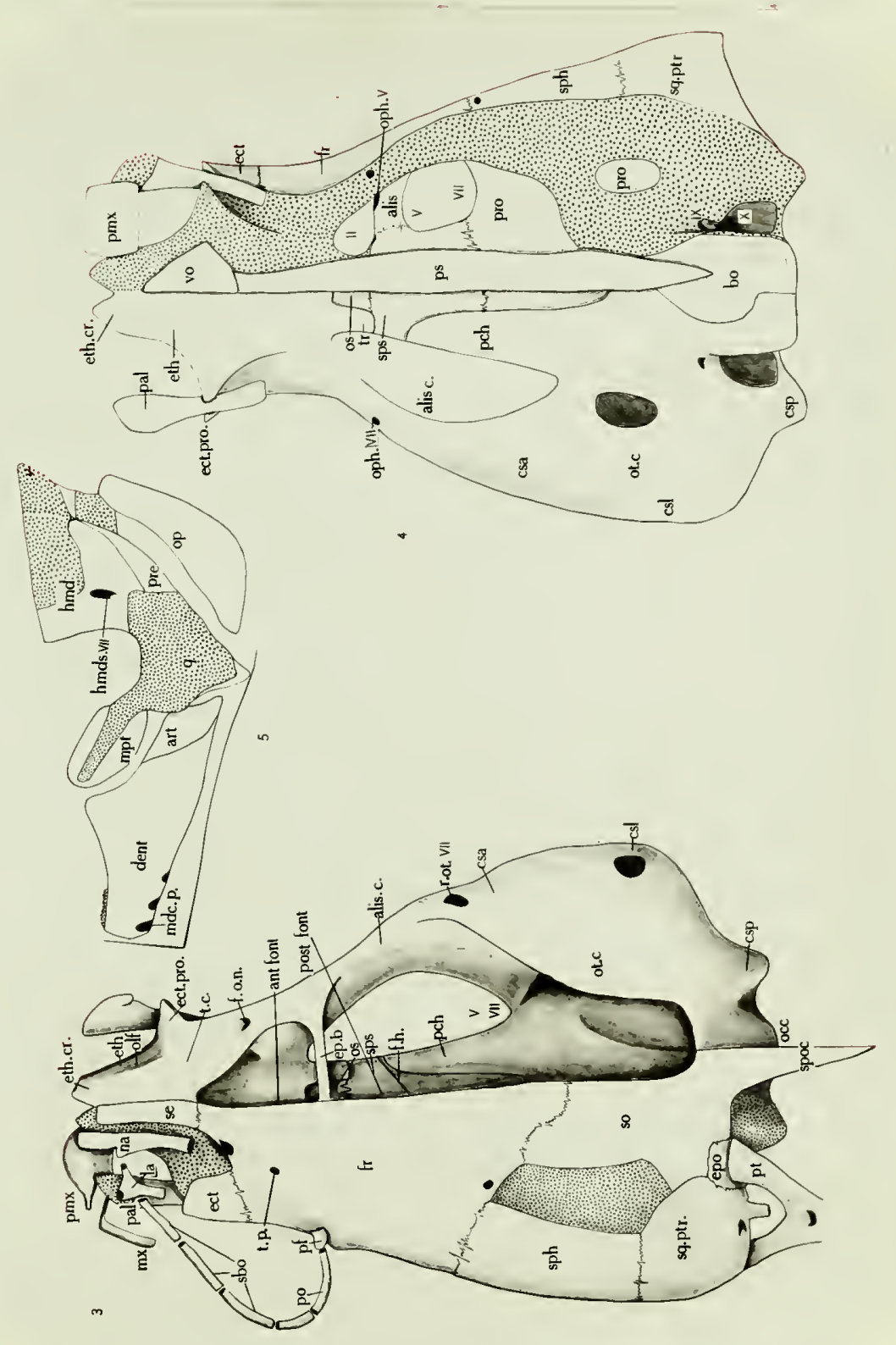





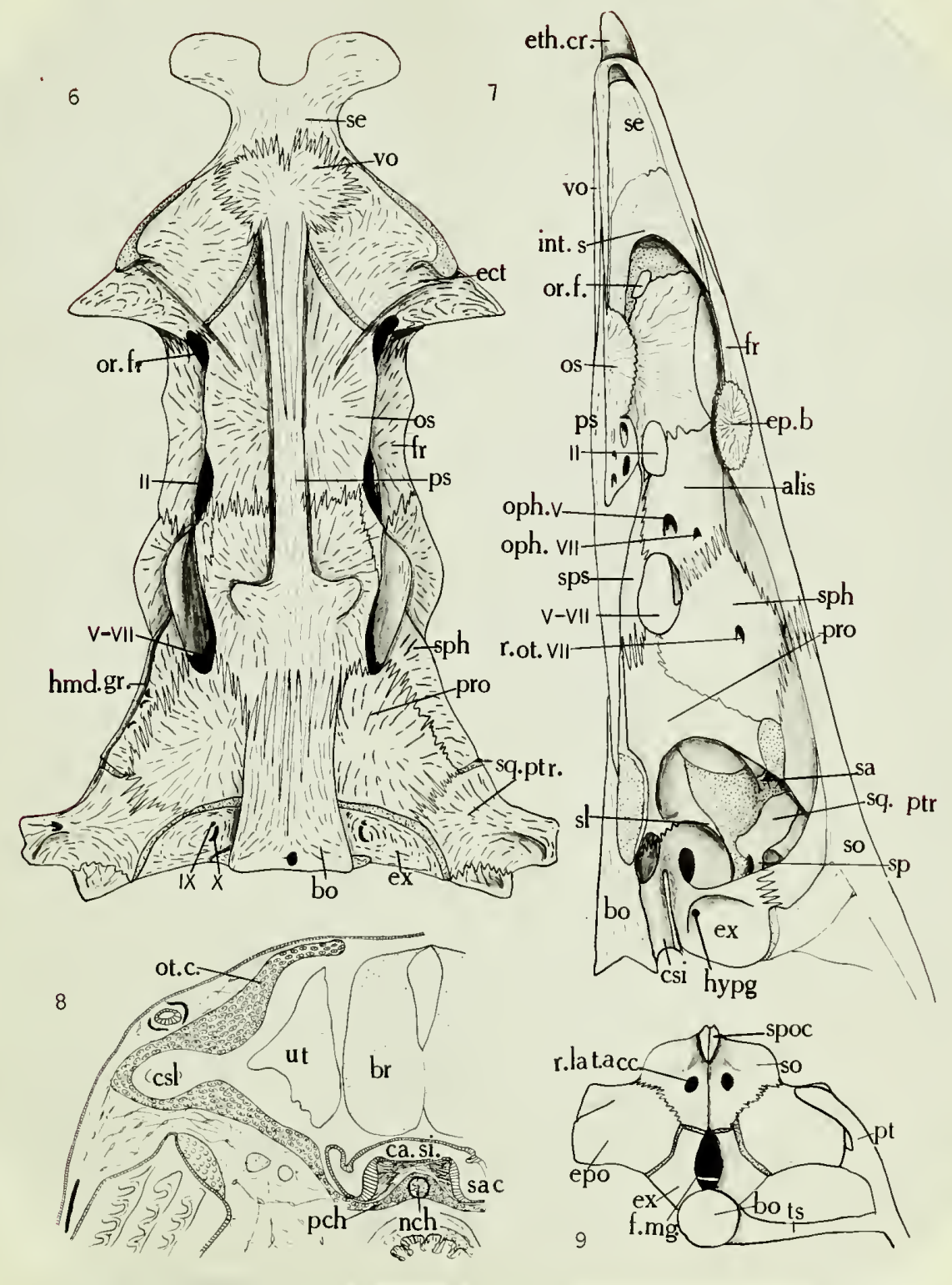



Plate IV
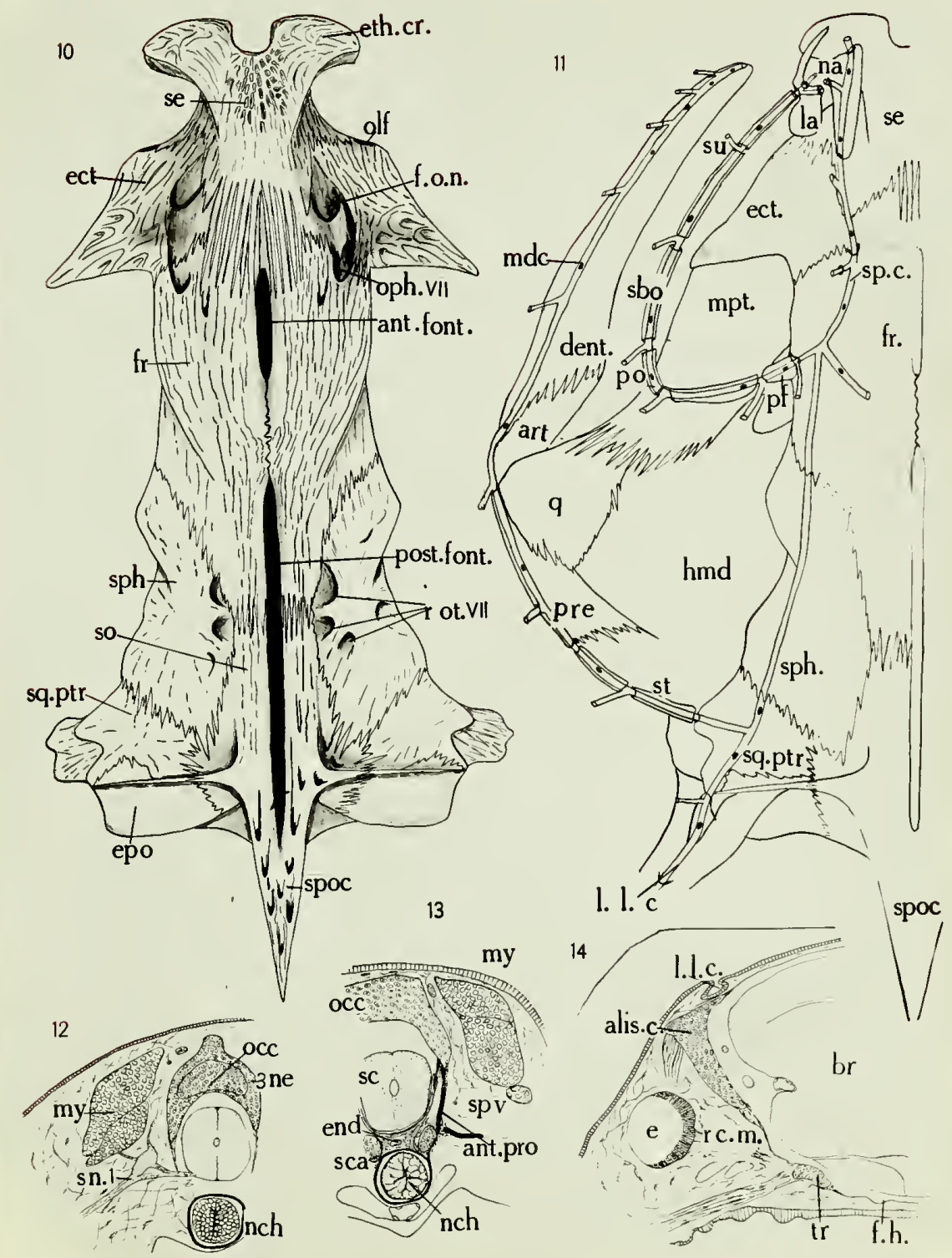

Plate V

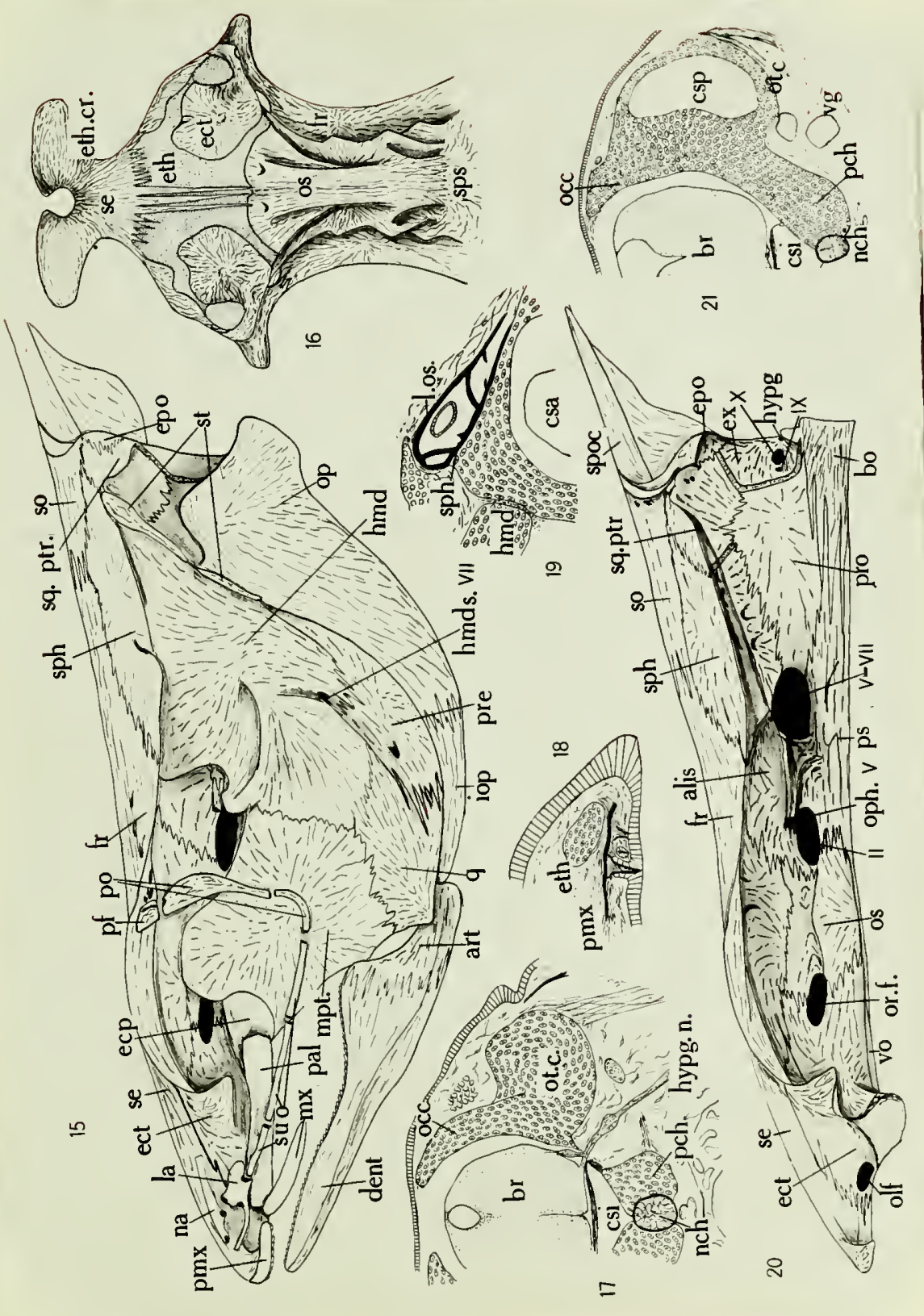



Plate VI

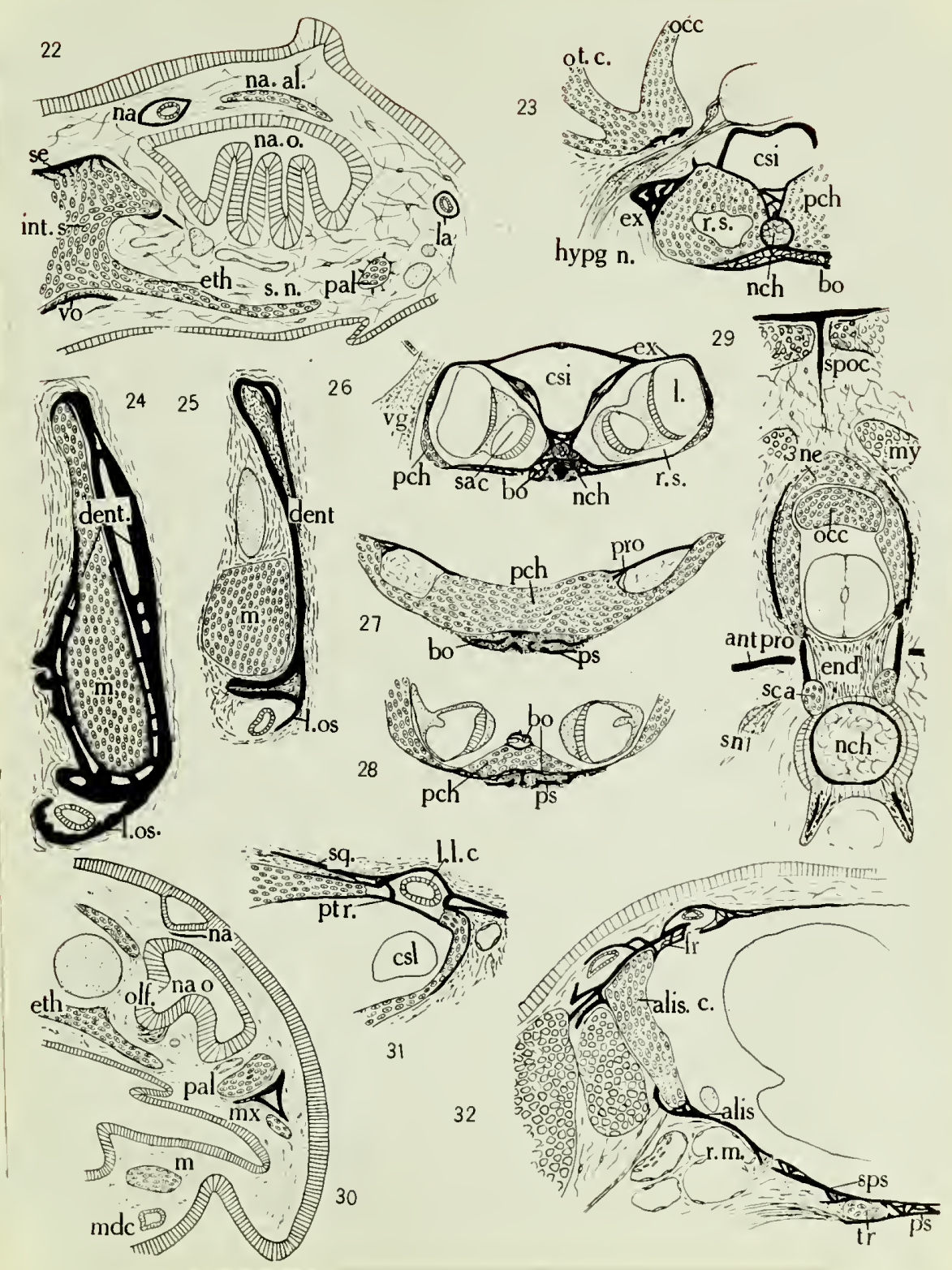



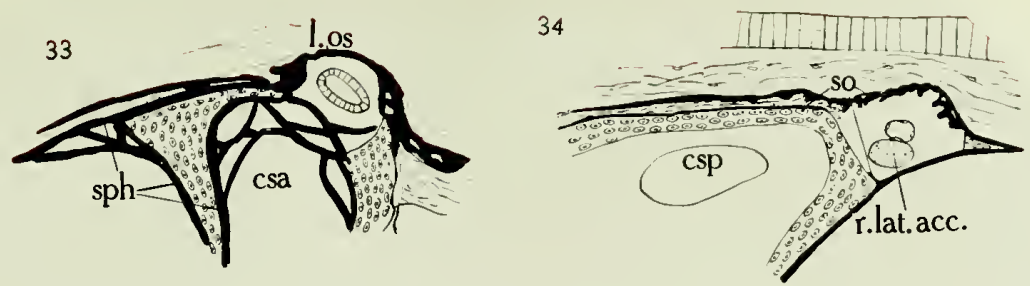

35

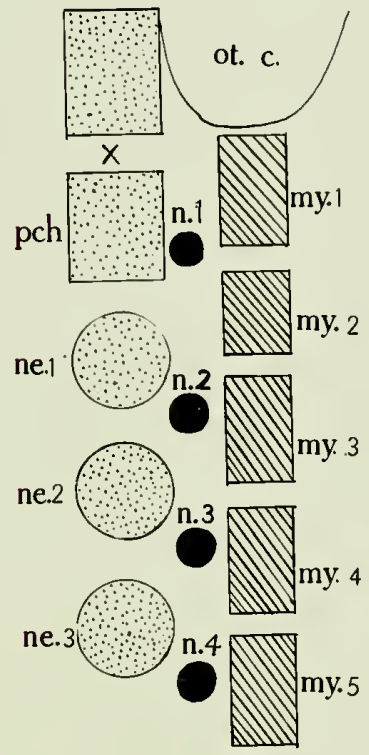

36
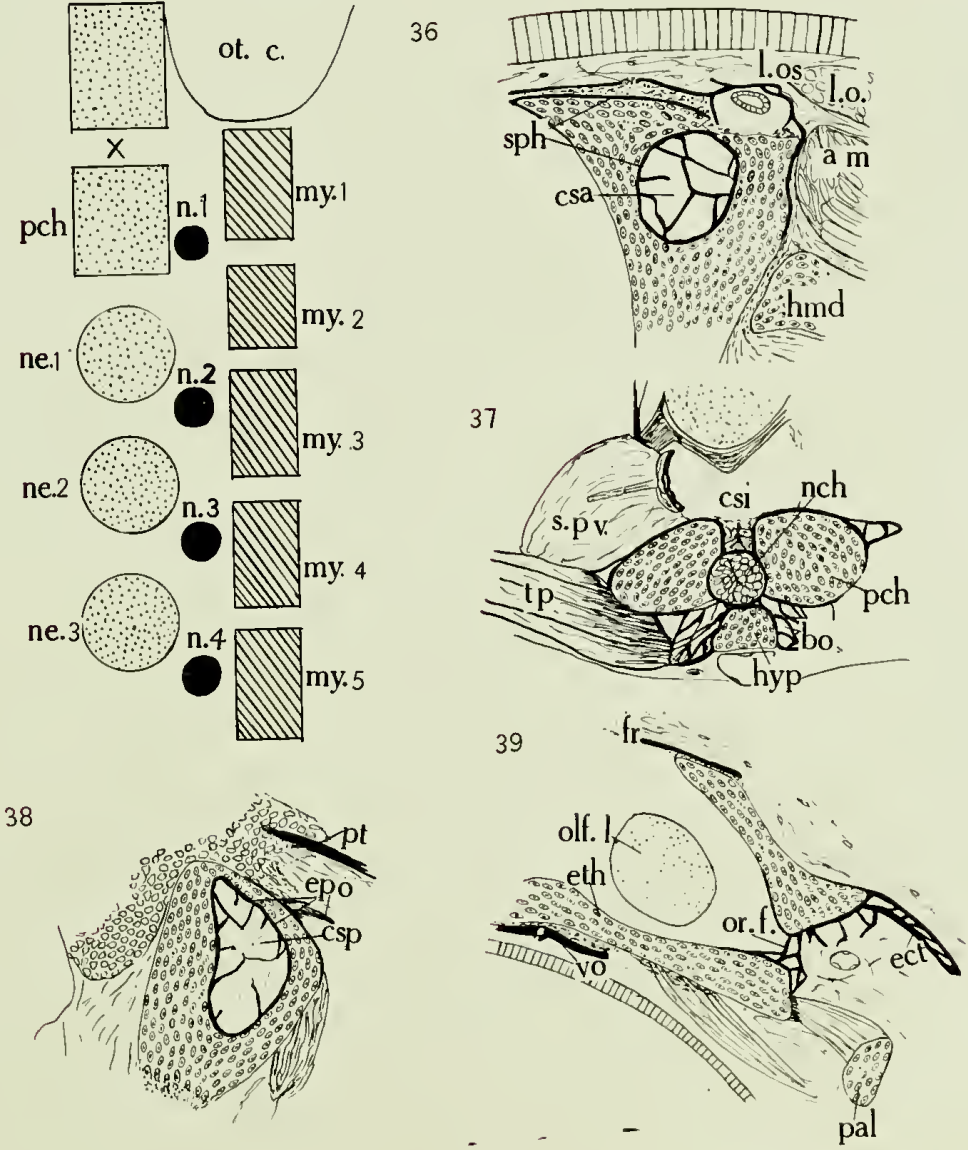
Vita.

1893 Born, October 2Oth, Boston, Mass.

1898-1910 Attended the Boston Public Schools.

1910 Graduated from South Boston High School, Boston, liass. 1910-14 Attended the College of Iiberal Arts, Tufts College, Iledford, Hass.

1914 A.B. degree, Tufts College.

1914-15 Scholar, University of Illinois, Urbana, Illinois. 1915 A. I. degree, University of Illinois in Zoology.

1915-17 issistant in 20ology, University of Illinois. 1916 ilected to membership in Illinois chapter of Sigmn Xi. 1917 Student, Puget Sound Biological Station, Friday Harbor, Wagh., summer session.

1917-18 Fellow in Zoology, University of Illinois. 

